Sylvia Liebler

Der Einfluß der

Unabhängigkeit von

Notenbanken auf die

Stabilität des Geldwertes 
Sylvia Liebler

\section{Der Einfluß der Unabhängigkeit von Notenbanken auf die Stabilität des Geldwertes}

Das Ziel der Arbeit ist die Überprüfung der aufgestellten These: Der Grad der Unabhängigkeit einer Notenbank hat keinen wesentlichen Einfluß auf die Entwicklung des Geldwertes. Dies erfordert zunächst die Operationalisierung des Begriffs Unabhängigkeit. Hierzu wird aus den vier Dimensionen institutionelle, vermögensrechtliche, personelle und funktionelle Unabhängigkeit ein umfassender Kriterienkatalog erarbeitet. Damit werden dann die Zentralbanken der Länder Deutschland, Schweiz, USA, Italien, Großbritannien, Frankreich, Japan und Niederlande untersucht und die Interdependenzen zwischen dem Unabhängigkeitsgrad der Notenbanken und der Inflationsentwicklung in diesen Ländern analysiert. Das Fazit dieser Untersuchung lautet, daß der Grad der Unabhängigkeit einer Notenbank offensichtlich keinen signifikanten Einfluß auf die Inflationsentwicklung eines Landes hat.

Sylvia Liebler wurde 1966 in Husum geboren. Sie studierte in Freiburg i. Br. und Mannheim Volkswirtschaftslehre und promovierte 1996 bei Prof. Dr. Dr. h. c. Bert Rürup. Daneben war sie 1988 als freie Mitarbeiterin bei der Werbeagentur Amos et Friends in Mannheim sowie 1991 bis 1993 bei Andersen Consulting Unternehmensberatung GmbH in Sulzbach Ts. tätig. Seit 1996 baut sie den Bereich Marktforschung bei der VR-LEASING GmbH auf. 
Der Einfluß der Unabhängigkeit von Notenbanken auf die Stabilität des Geldwertes 


\section{Sozialökonomische Schriften}

Herausgegeben von Bert Rürup

Band 11

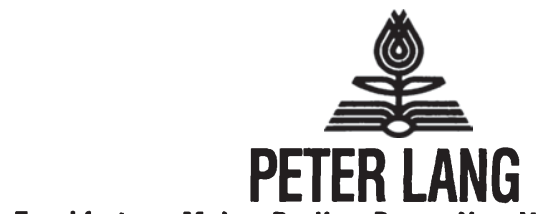

Frankturt am Main - Berlin - Bern - New York · Paris - Wien 


\section{Sylvia Liebler}

\section{Der Einfluß der Unabhängigkeit von Notenbanken auf die Stabilität des Geldwertes}

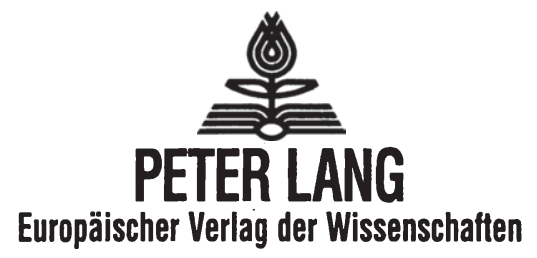

Sylvia Liebler - 978-3-631-75025-4 
Die Deutsche Bibliothek - CIP-Einheitsaufnahme

Liebler, Sylvia:

Der Einfluß der Unabhängigkeit von Notenbanken auf die Stabilität des Geldwertes / Sylvia Liebler. - Frankfurt am Main ; Berlin ; Bern ; New York ; Paris ; Wien : Lang, 1996

(Sozialökonomische Schriften ; Bd. 11)

Zugl.: Darmstadt, Techn. Hochsch., Diss., 1996

ISBN 3-631-30315-7

Open Access: The online version of this publication is published on www.peterlang.com and www.econstor.eu under the international Creative Commons License CC-BY 4.0. Learn more on how you can use and share this work: http://creativecommons. org/licenses/by/4.0.

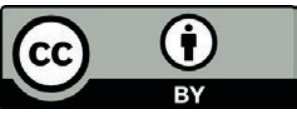

This book is available Open Access thanks to the kind support of ZBW - Leibniz-Informationszentrum Wirtschaft.

NE: GT

\author{
D 17 \\ ISSN 0172-1747 \\ ISBN 3-631-30315-7 \\ ISBN 978-3-631-75025-4(eBook) \\ (C) Peter Lang GmbH \\ Europäischer Verlag der Wissenschaften \\ Frankfurt am Main 1996 \\ Alle Rechte vorbehalten.
}

Das Werk einschließlich aller seiner Teile ist urheberrechtlich geschützt. Jede Verwertung außerhalb der engen Grenzen des

Urheberrechtsgesetzes ist ohne Zustimmung des Verlages unzulässig und strafbar. Das gilt insbesondere für Vervielfältigungen, Übersetzungen, Mikroverfilmungen und die Einspeicherung und Verarbeitung in elektronischen Systemen.

Printed in Germany $1234 \quad 67$ 


\section{Geleitwort}

Nicht erst, aber besonders aufgrund der Diskussion um die Maastrichter Verträge bzw. über die Stabilität der angestrebten gemeinsamen europäischen Währung wird die „Unabhängigkeit der Notenbanken“, konkret die Unabhängigkeit der neu zu schaffenden europäischen Zentralbank, als Garant für die Stabilität des Geldwertes angesehen bzw. propagiert.

Bemerkenswert an diesem Argument ist, daß es in aller Regel ohne eine Konditionierung bzw. eine Operationalisierung des Begriffs „Unabhängigkeit“" vorgetragen wird.

Vor diesem Hintergrund setzt nun diese Arbeit an, denn die aufgestellte und zu überprüfende These lautet:

Der Grad der Unabhängigkeit der Notenbank hat keinen wesentlichen Einfluß auf die Entwicklung des Geldwertes.

Zur Überprüfung der Hypothese ist es erforderlich, den Begriff der Unabhängigkeit zu operationalisieren. Hierzu arbeitet die Verfasserin die

- institutionelle

- vermögensrechtliche

- personelle und

- funktionelle

Unabhängigkeit als unterschiedliche Dimensionen heraus.

Anhand eines umfassenden daraus abgeleiteten Kriterienkatalogs überprüft Frau Liebler dann die Zentralbanken Deutschlands, der Schweiz, der USA, Italiens, Großbritanniens, Frankreichs, Japans und der Niederlande, nimmt eine Reihung vor und amalgamiert ihre Befunde zu einem „Unabhängigkeitsindex“, um dann die Interdependenzen zwischen dem Unabhängigkeitsgrad der jeweils untersuchten Notenbanken und der Inflationsentwicklung in diesem Lande zu analysieren.

Das Fazit dieser Untersuchung lautet, daß der „Grad der Unabhängigkeit einer Notenbank offensichtlich keinen signifikanten Einfluß auf die Inflationsentwicklung eines Landes hat". Es ist der Arbeit und ihrer Verfasserin eine intensive Diskussion von Design und Ergebnis ihrer Analyse zu wünschen.

Prof. Dr. Dr. h.c. Bert Rürup 
Sylvia Liebler - 978-3-631-75025-4

Downloaded from PubFactory at 01/11/2019 09:08:34AM

via free access 


\section{Vorwort}

Die Intention zur Bearbeitung dieser Thematik enstand aus der Erkenntnis, da $\beta$ zwar die Notwendigkeit einer unabhängigen Zentralbank viel diskutiert wird, aber die Frage, wann eine Notenbank unabhängig ist, bisher kaum systematisch untersucht wurde.

Herm Prof. Dr. Dr. h.c. B. Rürup danke ich herzlich für die wissenschaftliche Betreuung dieser Arbeit, seine wertvollen Anregungen sowie die Übernahme des Hauptgutachtens.

Herrn Prof. Dr. Dr. A. Podlech danke ich für die Übernahme des Korreferats.

Ferner danke ich Herm Prof. Dr. T. Lenk bzw. Dr. W. Sesselmeier und Dr. J. Dornbach für ihre zahlreichen Hinweise und Anregungen.

Mein Dank richtet sich ganz besonders an meinen Mann für die wichtigen Diskussionen und seine Unterstützung während des gesamten Bearbeitungszeitraumes.

Sylvia Liebler 
Sylvia Liebler - 978-3-631-75025-4

Downloaded from PubFactory at 01/11/2019 09:08:34AM

via free access 


\section{Inhaltsverzeichnis}

$\begin{array}{ll}\text { Abbildungsverzeichnis } & \text { XVII }\end{array}$

$\begin{array}{ll}\text { Abkürzungsverzeichnis } & \text { XIX }\end{array}$

1 PROBLEMSTELLUNG 1

2 GANG DER UNTERSUCHUNG 5

\section{BEGRIFF UND PROBLEMATIK DER}

UNABHÄNGIGKEIT VON NOTENBANKEN 6

3.1 Gegenstand der Unabhängigkeitsuntersuchung 7

3.1.1 Unabhängigkeit von staatlichen Akteuren

3.1.1.1 Unabhängigkeit von der Jurisdiktion $\quad 8$

3.1.1.2 Unabhängigkeit von der Exekutive $\quad 8$

3.1.1.3 Unabhängigkeit von der Legislative 9

3.1.2 Unabhängigkeit von nicht-staatlichen Akteuren 9

3.2 Formen und Abstufungen der Unabhängigkeit 11

3.2.1 Institutionelle Unabhängigkeit 11

3.2.2 Vermögensrechtliche Unabhängigkeit 11

3.2.3 Personelle Unabhängigkeit $\quad 12$

3.2.4 Funktionelle Unabhängigkeit $\quad 12$

3.2.5 Juristische und faktische Unabhängigkeit 12

3.2.5.1 Anwendung der Normen 13

3.2.5.2 Einfluß der Persönlichkeit 13

3.2.5.3 Öffentliche Meinung 14

3.2.5.4 Bewertung der faktischen Unabhängigkeit $\quad 14$

3.2.6 Abstufungen der Unabhängigkeit $\quad 16$

3.3 Begriff und Definition von Unabhängigkeit 17

3.4 Beeinträchtigung der Unabhängigkeit durch verschiedene EinfluBinstanzen

4 ENTWICKLUNG EINES BEWERTUNGSSCHEMAS ZUR BEURTEILUNG DER UNABHÄNGIGKEIT VON NOTENBANKEN

4.1 Anforderungen und Vorgehensweise 21

4.2 Institutionelle Unabhängigkeit $\quad 22$

4.2.1 Rechtsform $\quad 22$

4.2.2 Anderung der Normen $\quad 22$ 
4.2.3 Aufbau der Notenbank $\quad 25$

4.2.4 Zusammenfassung 25

4.3 Vermögensrechtliche Unabhängigkeit 26

4.3.1 Eigentumsverhältnisse $\quad 26$

4.3.2 Haushaltsmäßige Selbständigkeit $\quad 27$

4.3.3 Zusammenfassung $\quad 28$

4.4 Personelle Unabhängigkeit 28

4.4.1 Art und Zusammensetzung der Gremien 28

4.4.2 Ernennungsinstanzen $\quad 29$

4.4.3 Kreis der Ernennungsfähigen 31

$\begin{array}{ll}\text { 4.4.3.1 Fachliche Eignung } & 32\end{array}$

4.4.3.2 Sektorale und regionale Vertretung 33

4.4.3.3 Ausschluß bestimmter Personenkreise 33

4.4.3.4 Zusammenfassung $\quad 34$

4.4.4 Besoldung $\quad 34$

4.4.5 Amtsdauer $\quad 37$

$\begin{array}{ll}\text { 4.4.5.1 Amtszeit } & 37\end{array}$

$\begin{array}{ll}\text { 4.4.5.2 Berufungszeitpunkte } & 38\end{array}$

4.4.5.3 Möglichkeit der Wiederernennung 39

4.4.5.4 Abberufung $\quad 40$

4.4.5.4.1 Fehlen von Abberufungsvorschriften 41

4.4.5.4.2 Ausschluß einer Abberufungsmöglichkeit $\quad 42$

4.4.5.4.3 Abberufung unter Angabe von Gründen 43

4.4.5.4.4 Jederzeitige Abberufungsmöglichkeit ohne Begründung 46

4.4.5.4.5 Zusammenfassung 46

4.4.6 Entwicklung eines Schemas zur Beurteilung der personellen

4.5 Funktionelle Unabhängigkeit $\quad 55$

4.5.1 Globale Ziele einer Notenbank $\quad 55$

4.5.2 Temporäre Ziele einer Notenbank $\quad 59$

4.5.3 Geldpolitisches Instrumentarium $\quad 61$

4.5.3.1 Prinzipieller Umfang des geldpolitischen Instrumentariums 61

4.5.3.1.1 Gesamtheit des Instrumentariums $\quad 63$

4.5.3.1.2 Juristisches und faktisches Instrumentarium 63

4.5.3.1.3 Durchsetzungsverfahren geldpolitischer Instrumente 64

4.5.3.1.4 Wirkungsgrad der Instrumente 65

4.5.3.2 Anwendungsbeschränkungen des Instrumentariums 67

4.5.3.2.1 Technisch-institutionelle Einschränkungen 68

4.5.3.2.1.1 Regelungen zur Ausgestaltung geldpolitischer Instrumente $\quad 68$

$\begin{array}{ll}\text { 4.5.3.2.1.2 Mangelnde Infrastruktur } & 69\end{array}$

4.5.3.2.2 Einschränkungen durch notenbankfremde Instanzen 69

$\begin{array}{ll}\text { 4.5.3.2.2.1 Moralischer Druck } & 69\end{array}$

$\begin{array}{ll}\text { 4.5.3.2.2.2 Auskunfts- und Mitteilungspflichten } & 71\end{array}$ 
$\begin{array}{ll}\text { 4.5.3.2.2.3 Anhörungsrecht } & 71\end{array}$

4.5.3.2.2.4 Veto- und Genehmigungsrecht $\quad 72$

4.5.3.2. 2.5 Rechtliche Anfechtbarkeit geldpolitischer Beschlüsse 73

$\begin{array}{ll}\text { 4.5.3.2.2.6 Stimmrecht } & 73\end{array}$

$\begin{array}{ll}\text { 4.5.3.2.2.7 Weisungsrecht } & 73\end{array}$

4.5.3.3 Einordnung ausgewählter Einschränkungsbeispiele in die Systematik $\quad 74$

4.5.3.3.1 Staatsfinanzierung durch die Notenbank $\quad 74$

4.5.3.3.2 Verpflichtung zur Unterstützung der allgemeinen Wirtschaftspolitik

$\begin{array}{ll}\text { 4.5.3.3.3 Internationale Einflüsse und Verpflichtungen } & 80\end{array}$

4.5.4 Zusammenfassung der Einflußfaktoren auf die funktionelle $\begin{array}{ll}\text { Unabhängigkeit } & \mathbf{8 3}\end{array}$

4.5.5 Beurteilung der funktionellen Unabhängigkeit $\quad 84$

4.5.5.1 Untersuchungsrelevantes geldpolitisches Instrumentarium $\quad 84$

4.5.5.2 Ausgabe von Zentralbankgeld durch die Notenbank 89

$\begin{array}{ll}\text { 4.5.5.2.1 Art der Kreditnehmer } & 89\end{array}$

$\begin{array}{ll}\text { 4.5.5.2.2 Umfang } & 90\end{array}$

$\begin{array}{ll}\text { 4.5.5.2.3 Zinssatz } & 90\end{array}$

$\begin{array}{ll}\text { 4.5.5.2.4 Bedingungen } & 91\end{array}$

4.5.5.3 Direkte Einflußnahme auf die Kreditvergabe der Banken 91

4.5.5.3.1 Art der Kreditnehmer 91

4.5.5.3.2 Umfang $\quad 92$

$\begin{array}{ll}\text { 4.5.5.3.3 Zinssatz } & 92\end{array}$

$\begin{array}{ll}\text { 4.5.5.3.4 Bedingungen } & 93\end{array}$

4.5.5.4 Offenmarktpolitik $\quad 93$

4.5.5.4.1 Art und Gegenstand des Geschäfts 93

$\begin{array}{ll}\text { 4.5.5.4.2 Preis } & 94\end{array}$

$\begin{array}{ll}\text { 4.5.5.4.3 Umfang } & 94\end{array}$

$\begin{array}{ll}\text { 4.5.5.4.4 Handelspartner } & 95\end{array}$

4.5.5.5 Mindestreservepolitik 95

4.5.5.5.1 Reservepflichtige Institute 95

$\begin{array}{ll}\text { 4.5.5.5.2 Bemessungsgrundlage } & 96\end{array}$

4.5.5.5.3 Mindestreservesatz 96

4.5.5.5.4 Materielle Beschaffenheit der Mindestreserve 96

4.5.5.6 Bewertungsschema zur Beurteilung geldpolitischer Instrumente 97

4.5.5.7 Auswertung des Bewertungsschemas für die funktionelle
Unabhängigkeit

4.6 Zusammenfassende Bewertung der Unabhängigkeit von

$\begin{array}{ll}\text { Notenbanken } & 104\end{array}$

4.7 Ermittlung des Zusammenhangs zwischen dem Unabhängigkeitsgrad von Notenbanken und der Inflationsentwicklung 


\section{ERMITTLUNG DES UNABHÄNGIGKEITSGRADS DER NOTENBANKEN AUSGEWÄHLTER LÄNDER}

\subsection{Deutschland}

5.1.1 Personelle Unabhängigkeit

5.1.1.1 Ernennungsinstanzen (Ebene 1)

5.1.1.2 Abberufungsinstanzen (Ebene 2) 110

5.1.1.3 Kreis der Ernennungsfähigen (Ebene 6) 111

5.1.1.4 Beurteilung der personellen Unabhängigkeit 111

$\begin{array}{ll}\text { 5.1.2 Funktionelle Unabhängigkeit } & 112\end{array}$

5.1.2.1 Instrumentenübergreifende Regelungen 112

5.1.2.2 Ausgabe von Zentralbankgeld durch die Notenbank $\quad 114$

5.1.2.2.1 Art der Kreditnehmer $\quad 114$

$\begin{array}{ll}\text { 5.1.2.2.2 Umfang } & 114\end{array}$

5.1.2.2.3 Zinssatz 116

5.1.2.2.4 Bedingungen 116

5.1.2.3 Direkte Einflußnahme auf die Kreditvergabe der Banken 117

$\begin{array}{ll}\text { 5.1.2.3.1 Art der Kreditnehmer } & 117\end{array}$

$\begin{array}{ll}\text { 5.1.2.3.2 Umfang } & 117\end{array}$

$\begin{array}{ll}\text { 5.1.2.3.3 Zinssatz } & 118\end{array}$

$\begin{array}{ll}\text { 5.1.2.3.4 Bedingungen } & 119\end{array}$

$\begin{array}{ll}\text { 5.1.2.4 Offenmarktpolitik } & 120\end{array}$

5.1.2.4.1 Art und Gegenstand des Geschäfts $\quad 120$

$\begin{array}{ll}\text { 5.1.2.4.2 Umfang } & 121\end{array}$

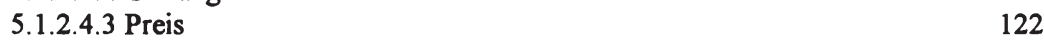

$\begin{array}{ll}\text { 5.1.2.4.4 Handelspartner } & 123\end{array}$

5.1.2.5 Mindestreservepolitik $\quad 123$

$\begin{array}{ll}\text { 5.1.2.5.1 Reservepflichtige Institute } & 123\end{array}$

$\begin{array}{ll}\text { 5.1.2.5.2 Bemessungsgrundlagen } & 123\end{array}$

$\begin{array}{ll}\text { 5.1.2.5.3 Mindestreservesatz } & 124\end{array}$

5.1.2.5.4 Materielle Beschaffenheit der Mindestreserven 124

5.1.2.6 Zusammenfassende Beurteilung der funktionellen Unabhängigkeit
der Deutschen Bundesbank

$\begin{array}{ll}\text { 5.2 Schweiz } & 125\end{array}$

5.2.1 Personelle Unabhängigkeit $\quad 126$

5.2.1.1 Ernennungsinstanzen (Ebene 1) 126

$\begin{array}{ll}\text { 5.2.1.2 Abberufungsinstanzen (Ebene 2) } & 127\end{array}$

$\begin{array}{ll}\text { 5.2.1.3 Kreis der Ernennungsfähigen (Ebene 6) } & 127\end{array}$

5.2.1.4 Beurteilung der personellen Unabhängigkeit $\quad 128$

5.2.2 Funktionelle Unabhängigkeit $\quad 128$

5.2.2.1 Instrumentenübergreifende Regelungen 128

5.2.2.2 Ausgabe von Zentralbankgeld durch die Notenbank 129

5.2.2.2.1 Art der Kreditnehmer 129

$\begin{array}{ll}\text { 5.2.2.2.2 Umfang } & 129\end{array}$

5.2.2.2.3 Zinssatz 130

5.2.2.2.4 Bedingungen 131 
5.2.2.3 Direkte Einflußnahme auf die Kreditvergabe der Banken 132

5.2.2.3.1 Art der Kreditnehmer $\quad 132$

5.2.2.3.2 Umfang 132

$\begin{array}{ll}\text { 5.2.2.3.3 Zinssatz } & 133\end{array}$

$\begin{array}{ll}\text { 5.2.2.3.4 Bedingungen } & 134\end{array}$

5.2.2.4 Offenmarktpolitik $\quad 134$

5.2.2.4.1 Art und Gegenstand des Geschäfts 134

$\begin{array}{ll}\text { 5.2.2.4.2 Umfang } & 136\end{array}$

5.2.2.4.3 Preis 136

$\begin{array}{ll}\text { 5.2.2.4.4 Handelspartner } & 137\end{array}$

$\begin{array}{ll}\text { 5.2.2.5 Mindestreservepolitik } & 137\end{array}$

$\begin{array}{ll}\text { 5.2.2.5.1 Reservepflichtige Institute } & 137\end{array}$

$\begin{array}{ll}\text { 5.2.2.5.2 Bemessungsgrundlagen } & 138\end{array}$

$\begin{array}{ll}\text { 5.2.2.5.3 Mindestreservesatz } & 139\end{array}$

5.2.2.5.4 Materielle Beschaffenheit der Mindestreserven $\quad 140$

5.2.2.6 Zusammenfassende Beurteilung der funktionellen Unabhängigkeit
der Schweizerischen Nationalbank

$\begin{array}{ll}\text { 5.3 USA } & 140\end{array}$

5.3.1 Personelle Unabhängigkeit $\quad 141$

5.3.1.1 Ernennungsinstanzen (Ebene 1) 141

5.3.1.2 Abberufungsinstanzen (Ebene 2) 141

5.3.1.3 Kreis der Ernennungsfähigen (Ebene 6) 142

5.3.1.4 Beurteilung der personellen Unabhängigkeit 142

5.3.2 Funktionelle Unabhängigkeit 142

5.3.2.1 Instrumentenübergreifende Regelungen $\quad 142$

5.3.2.2 Ausgabe von Zentralbankgeld durch die Notenbank $\quad 144$

$\begin{array}{ll}\text { 5.3.2.2.1 Art der Kreditnehmer } & 144\end{array}$

$\begin{array}{ll}\text { 5.3.2.2.2 Umfang } & 145\end{array}$

$\begin{array}{ll}\text { 5.3.2.2.3 Zinssatz } & 146\end{array}$

$\begin{array}{ll}\text { 5.3.2.2.4 Bedingungen } & 146\end{array}$

5.3.2.3 Direkte Einflußnahme auf die Kreditvergabe der Banken $\quad 146$

5.3.2.3.1 Art der Kreditnehmer $\quad 146$

$\begin{array}{ll}\text { 5.3.2.3.2 Umfang } & 147\end{array}$

$\begin{array}{ll}\text { 5.3.2.3.3 Zinssatz } & 147\end{array}$

$\begin{array}{ll}\text { 5.3.2.3.4 Bedingungen } & 148\end{array}$

$\begin{array}{ll}\text { 5.3.2.4 Offenmarktpolitik } & 148\end{array}$

5.3.2.4.1 Art und Gegenstand des Geschäfts $\quad 148$

$\begin{array}{ll}5.3 .2 .4 .2 \text { Umfang } & 149\end{array}$

$\begin{array}{ll}\text { 5.3.2.4.3 Preis } & 150\end{array}$

5.3.2.4.4 Handelspartner $\quad 150$

5.3.2.5 Mindestreservepolitik 151

5.3.2.5.1 Reservepflichtige Institute 151

$\begin{array}{lr}\text { 5.3.2.5.2 Bemessungsgrundlagen } & 151\end{array}$

$\begin{array}{ll}\text { 5.3.2.5.3 Mindestreservesatz } & 152\end{array}$

5.3.2.5.4 Materielle Beschaffenheit der Mindestreserven $\quad 152$

5.3.2.6 Zusammenfassende Beurteilung der funktionellen Unabhängigkeit
des Federal Reserve Systems 
5.4.1 Personelle Unabhängigkeit

5.4.1.1 Ernennungsinstanzen (Ebene 1)

5.4.1.2 Abberufungsinstanzen (Ebene 2) 154

5.4.1.3 Ernennungs- und Abberufungsmodalitäten (Ebene 3) 155

5.4.1.4 Wiederernennungsvorschriften (Ebene 5) 155

5.4.1.5 Kreis der Ernennungsfähigen (Ebene 6) 155

5.4.1.6 Beurteilung der personellen Unabhängigkeit $\quad 155$

5.4.2 Funktionelle Unabhängigkeit $\quad 156$

5.4.2.1 Instrumentenübergreifende Regelungen 156

5.4.2.2 Ausgabe von Zentralbankgeld durch die Notenbank 157

5.4.2.2.1 Art der Kreditnehmer 157

$\begin{array}{ll}\text { 5.4.2.2.2 Umfang } & 158\end{array}$

$\begin{array}{ll}\text { 5.4.2.2.3 Zinssatz } & 160\end{array}$

$\begin{array}{ll}\text { 5.4.2.2.4 Bedingungen } & 160\end{array}$

5.4.2.3 Direkte Einflußnahme auf die Kreditvergabe der Banken 161

5.4.2.3.1 Art der Kreditnehmer 161

$\begin{array}{ll}\text { 5.4.2.3.2 Umfang } & 162\end{array}$

5.4.2.3.3 Zinssatz 163

5.4.2.3.4 Bedingungen 163

5.4.2.4 Offenmarktpolitik $\quad 163$

5.4.2.4.1 Art und Gegenstand des Geschäfts 164

5.4.2.4.2 Umfang 165

$\begin{array}{ll}\text { 5.4.2.4.3 Preis } & 165\end{array}$

5.4.2.4.4 Handelspartner $\quad 165$

5.4.2.5 Mindestreservepolitik 166

5.4.2.5.1 Reservepflichtige Institute 166

$\begin{array}{ll}\text { 5.4.2.5.2 Bemessungsgrundlagen } & 166\end{array}$

5.4.2.5.3 Mindestreservesatz 166

5.4.2.5.4 Materielle Beschaffenheit der Mindestreserven $\quad 167$

5.4.2.6 Zusammenfassende Beurteilung der funktionellen Unabhängigkeit
der Banca d'Italia

$\begin{array}{ll}\text { 5.5 Großbritannien } & 167\end{array}$

5.5.1 Personelle Unabhängigkeit 168

5.5.1.1 Ernennungsinstanzen (Ebene 1) 168

5.5.1.2 Abberufungsinstanzen (Ebene 2) 168

5.5.1.3 Kreis der Ernennungsfähigen (Ebene 6) 169

5.5.1.4 Beurteilung der personellen Unabhängigkeit $\quad 169$

5.5.2 Funktionelle Unabhängigkeit $\quad 169$

5.5.2.1 Instrumentenübergreifende Regelungen 169

5.5.2.2 Ausgabe von Zentralbankgeld durch die Notenbank 170

5.5.2.3 Direkte Einflußnahme auf die Kreditvergabe der Banken 172

$\begin{array}{ll}\text { 5.5.2.4 Offenmarktpolitik } & 172\end{array}$

5.5.2.5 Mindestreservepolitik 173

5.5.2.6 Zusammenfassende Beurteilung der funktionellen Unabhängigkeit
der Bank von England 


\section{XV}

5.6 Frankreich 174

5.6.1 Personelle Unabhängigkeit 174

5.6.1.1 Ernennungsinstanzen (Ebene 1) 174

5.6.1.2 Abberufungsinstanzen (Ebene 2) 175

5.6.1.3 Kreis der Ernennungsfähigen (Ebene 6) 175

5.6.1.4 Beurteilung der personellen Unabhängigkeit $\quad 175$

5.6.2 Funktionelle Unabhängigkeit 176

5.6.2.1 Instrumentenübergreifende Regelungen 176

5.6.2.2 Ausgabe von Zentralbankgeld durch die Notenbank 180

5.6.2.3 Direkte Einflußnahme auf die Kreditvergabe der Banken 182

$\begin{array}{ll}\text { 5.6.2.4 Offenmarktpolitik } & 184\end{array}$

5.6.2.5 Mindestreservepolitik 185

5.6.2.6 Zusammenfassende Beurteilung der funktionellen Unabhängigkeit

5.7 Japan 186

5.7.1 Personelle Unabhängigkeit 187

5.7.1.1 Ernennungsinstanzen (Ebene 1) 187

5.7.1.2 Abberufungsinstanzen (Ebene 2) 188

5.7.1.3 Kreis der Ernennungsfähigen (Ebene 6) 188

5.7.1.4 Beurteilung der personellen Unabhängigkeit $\quad 188$

$\begin{array}{ll}\text { 5.7.2 Funktionelle Unabhängigkeit } & 189\end{array}$

5.7.2.1 Instrumentenübergreifende Regelungen $\quad 189$

5.7.2.2 Ausgabe von Zentralbankgeld durch die Notenbank $\quad 189$

5.7.2.3 Direkte Einflußnahme auf die Kreditvergabe der Banken 191

5.7.2.4 Offenmarktpolitik 192

5.7.2.5 Mindestreservepolitik $\quad 192$

5.7.2.6 Zusammenfassende Beurteilung der funktionellen Unabhängigkeit
der Bank of Japan

5.8 Niederlande 193

5.8.1 Personelle Unabhängigkeit 193

5.8.1.1 Ernennungsinstanzen (Ebene 1) 193

5.8.1.2 Abberufungsinstanzen (Ebene 2) 194

5.8.1.3 Ernennungs- und Abberufungsmodalitäten 195

5.8.1.4 Kreis der Ernennungsfähigen (Ebene 6) 195

5.8.1.5 Beurteilung der personellen Unabhängigkeit 195

5.8.2 Funktionelle Unabhängigkeit 196

5.8.2.1 Instrumentenübergreifende Regelungen 196

5.8.2.2 Ausgabe von Zentralbankgeld durch die Notenbank 196

5.8.2.3 Direkte Einflußnahme auf die Kreditvergabe der Banken $\quad 197$

$\begin{array}{ll}\text { 5.8.2.4 Offenmarktpolitik } & 198\end{array}$

5.8.2.5 Mindestreservepolitik 198

5.8.2.6 Zusammenfassende Beurteilung der funktionellen Unabhängigkeit der Nederlandschen Bank 199

\subsection{Vergleichende Gegenüberstellung des Unabhängigkeitsgrades} ausgewählter Notenbanken 


\section{EINFLUß DER UNABHÄNGIGKEIT VON NOTENBANKEN AUF DIE ENTWICKLUNG DES GELDWERTES}

6.1 Inflationsentwicklungen in den untersuchten Ländern

6.2 Korrelationsanalyse zwischen dem Unabhängigkeitsgrad der untersuchten Notenbanken und der Inflationsentwicklung

6.3 Interpretation der Ergebnisse

6.3.1 Abhängige Notenbanken und inflationsbekämpfende Geldpolitik 207

6.3.1.1 Differenz zwischen juristischer und faktischer Unabhängigkeit 207

6.3.1.2 Öffentliche Präferenz für Geldwertstabilität 208

6.3.1.3 Disziplinierungszwang durch internationale Abkommen 209

6.3.1.4 Technisch-institutionelle Einschränkungen 209

6.3.2 Unabhängige Notenbanken und inflationsfördernde Geldpolitik $\quad 209$

6.3.2.1 Fehlentscheidungen der Notenbankleitung 209

$\begin{array}{ll}\text { 6.3.2.2 Zielsetzung der Geldpolitik } & 210\end{array}$

$\begin{array}{ll}\text { 6.3.2.3 Anreizstruktur } & 210\end{array}$

6.3.3 Exogene Einflüsse auf die Geldwertstabilität $\quad 211$

6.3.3.1 Lohnpolitik der Tarifpartner 211

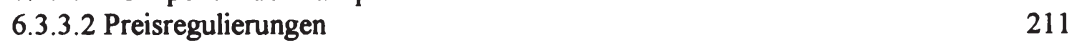

6.3.3.3 Ausrichtung der allgemeinen Wirtschaftspolitik des Staates 212

$\begin{array}{ll}\text { 6.3.3.4 Internationale Einflüsse } & 212\end{array}$

7 ZUSAMMENFASSUNG UND

SCHLUBBETRACHTUNG 213

8 LITERATURVERZEICHNIS 216 


\section{Abbildungsverzeichnis}

Abb. 1: Schema zur Beurteilung der personellen Unabhängigkeit

Abb. 2: Auswirkung der verschiedenen Formen der Kreditfinanzierung des Staates durch die Notenbank auf die Unabhängigkeit einer Notenbank

Abb. 3: Geldpolitische Instrumente zur Beurteilung der funktionellen Unabhängigkeit

Abb. 4: Einflußmöglichkeiten auf den Einsatz geldpolitischer Instrumente

Abb. 5: Bewertung der möglichen Einschränkungen der funktionellen Unabhängigkeit

Abb. 6: Abstufungen funktioneller Unabhängigkeit

Abb. 7: Portfolio der funktionellen und personellen Unabhängigkeit

Abb. 8: Funktionelle und personelle Unabhängigkeit ausgewählter Länder

Abb. 9: Portfolio der funktionellen und personellen Unabhängigkeit ausgewählter Länder

Abb. 10:Inflationsentwicklung der untersuchten Länder 1975 - 1990

Abb. 11:Kumulierte Inflationsraten der untersuchten Länder 1975 - 1990

Abb. 12:Daten und Berechnung des Rangkorrelationskoeffizienten $r_{s}$ 
Sylvia Liebler - 978-3-631-75025-4

Downloaded from PubFactory at 01/11/2019 09:08:34AM

via free access 


\section{Abkürzungsverzeichnis}

a. a. O. am angegebenen Ort

Abb. Abbildung

Art. Artikel

Aufl. Auflage

BBankG Bundesbankgesetz

Bd. Band

bzgl. bezüglich

bzw. beziehungsweise

CICR Comitato Interministriale per il Credito ed il Risparmio

Diss. Dissertation

et al. et alii

etc. et cetera

EWS Europäisches Währungssystem

f. (ff.) folgende Seite (folgende Seiten)

FAZ Frankfurter Allgemeine Zeitung

FOMC Federal Open Market Committee

Hrsg. Herausgeber

i. e. S. in engerem Sinne

i. w. S. in weiterem Sinne

Jg. Jahrgang

KWG Gesetz über das Kreditwesen

mind. mindestens

o. O. ohne Ortsangabe

o. V. ohne Verfasserangabe

S. Seite

u. a. unter anderem

v. a. vor allem

vgl. vergleiche

Vol. Volume

z. B. zum Beispiel 
Sylvia Liebler - 978-3-631-75025-4

Downloaded from PubFactory at 01/11/2019 09:08:34AM

via free access 


\section{Problemstellung}

Die Frage der Unabhängigkeit von Notenbanken spielt insbesondere seit dem Fortfall des Goldautomatismus eine große Rolle in der wirtschaftspolitischen und wissenschaftlichen Diskussion. "Die Währung, ehemals unantastbar durch ihre Verankerung in der natürlichen Knappheit des Goldes, in dem internationalen Automatismus der Wechselkurse und in den unbestrittenen Spielregeln der Zentralbankpolitik, ist dadurch in unserer Zeit in weitem Umfange 'politisiert' und dem Zugriff der um die Behauptung und Verbesserung der Lebensansprüche kämpfenden Gruppen und Bevölkerungsschichten preisgegeben worden"1. Die Aufgabe der Notenbanken hat sich von einem bloßen Reagieren auf Goldbewegungen hin zu einer aktiven Geldpolitik verschoben ${ }^{2}$. Sie üben damit Funktionen aus, die in Zielrichtung und Auswirkung von den wirtschaftspolitischen Aktivitäten der Regierung kaum zu trennen sind ${ }^{3}$. Das ihr daraus entstehende große Einflußpotential auf wesentliche Bereiche des Wirtschaftslebens ${ }^{4}$ macht die Entscheidung, wer über die Politik der Notenbank entscheiden darf, also den Grad der Unabhängigkeit des Währungsinstitutes von Staat und anderen Gruppierungen, so diffizil. Vornehmlich in Deutschland, das von zwei Hyperinflationen geprägt ist, überwiegt die Meinung, daß "es in einem demokratischen Rechtsstaat zum Schutz der Währung einer neutralen Instanz" bedarf, "die das Anliegen der Währungsstabilität verkörpert und wirksam vertritt"5.

Gegen einen staatlichen Einfluß auf die Notenbankpolitik wird v. a. das Argument der Doppelrolle des Staates als Kreditinteressent sowie als Verantwortlicher für die Stabilität des Geldwertes ${ }^{6}$ angeführt oder anders ausgedrückt, des nicht auf Geldwertstabilität bedachten Politikers, der den Notenbankkredit als billige und bequeme Staatsfinanzierungsquelle zu nutzen sucht 7 . Hettlage formulierte dies einmal mit dem Satz: "Die gefährlichsten, wenn vielleicht auch ahnungslosen

1 Schmölders, Günter: Die Politiker und die Währung, in: Zeitschrift für das gesamte Kreditwesen 1/1957, S. 28.

2 Vgl. Veit, Otto: Grundriß der Währungspolitik, Frankfurt/Main 1961, S. 182.

3 Vgl. Poullain, Ludwig: Für eine „demokratische“ Autonomie - Der Entscheidungsspielraum der Bundesbank, in: Duwendag, Dieter (Hrsg.): Macht und Ohnmacht der Bundesbank, Frankfurt/M 1973, S. 39.

4 Vgl. Szagunn, Volkhard: Notenbank und Staat, in: Versicherungswirtschaft 12. Jg. 1957, S. 19

5 Schmölders, Günter: Geldpolitik, 2. Aufl., Tübingen Zürich 1968, S. 194.

6 Vgl. Schuppler, Edith: Die Unabhängigkeit der Notenbank, Schriftenreihe der österreichischen Bankwissenschaftlichen Gesellschaft, hrsg. v. Krasensky, H. XIX, Wien 1962, S. 48.

7 Vgl. Caesar, Rolf: Die Unabhängigkeit der Notenbank im demokratischen Staat. Argumente und Gegenargumente, in: Zeitschrift für Politik, H.1/80, S. 351. 
Feinde der Sparer und der Währung sitzen heute auf den Bänken des Parlaments."8 So werden durch Zentralbankgeldschöpfung abhängiger Notenbanken geschlossene Deckungslücken öffentlicher Haushalte häufig als die Hauptinflationsursache der Geschichte angeführt ${ }^{9}$. Eine unabhängige Notenbank könne dagegen in einer langfristigen Sichtweise ${ }^{10}$ eine von Wahlgesichtspunkten und parteipolitischen Aspekten freie Geldpolitik betreiben 11 und sei eher dazu in der Lage, im Interesse der Stabilität des Geldwertes auch unpopuläre Entscheidungen zu treffen 12 . Gegner unabhängiger Notenbanken kritisieren v. a. die mangelnde demokratische Legitimation eines solchen Währungsinstituts ${ }^{13}$ und die Gefahr einer unzureichenden Koordination mit den übrigen Teilbereichen der Politik ${ }^{14}$. Daneben existieren noch eine Vielzahl weiterer Argumente für oder wider die Unabhängigkeit einer Notenbank, von denen jedes für sich eine gewisse Berechtigung besitzt und die im Rahmen dieser Arbeit nicht weiter diskutiert werden sollen ${ }^{15}$. Festzuhalten bleibt, daß auf diesem Wege keine eindeutige Lösung der

8 Hettlage, Über Sparsamkeit und Wirtschaftlichkeit in der Verwaltung, in: Wirtschaftliche öffentliche Verwaltung, hsrg. von Badenhoop, Reinhard K., Stuttgart 1961, S.46.

Vgl. Muthesius, Volkmar: Wer oder was bedroht den Geldwert, in: Junge Wirtschaft 6. Jg. 1958, S. 494; Rittershausen, Heinrich: Die Zentralnotenbank, Frankfurt am Main 1962, S. 326; Vocke, Wilhelm: Gesundes Geld, Bd. I, 2. Aufl., Frankfurt am Main 1956, S. 127; Preuße, Heinz Gert: Zur Autonomie der Notenbank unter veränderten internationalen Rahmenbedingungen, Göttingen 1991, S. 16f.

Vgl. Castello-Branco, Marta; Swinburne, Mark: Die Unabhängigkeit der Zentralbank, in: Finanzierung \& Entwicklung 3/92, S. 19.

11 Vgl. Christians, F. W.: Deutsche Bundesbank: Autonomie für Sachverstand, in: Die Bank 5/77, S. 4.

12 Vgl. Vocke, Wilhelm: a.a.O., S. 127; Kleinhans, Joachim: Die Unabhängigkeit der Bundesbank muß Tabu bleiben, in: Raiffeisen-Rundschau 23. Jg. 1971, S.192; Muthesius, Volkmar: Die Notenbank im Bundesstaat, in: Zeitschrift für das gesamte Kreditwesen 23/1949, S. 536; Bernauer, Engelbert: Staat und Notenbank - Autonomie und Koordination, Diss. Freiburg i. Br. 1960, S. 54 und 59.

13 Vgl. Arnim, Hans Herbert von: Die Deutsche Bundesbank - Pfeiler der Demokratie, in: Zeitschrift für Wirtschaftspolitik 37. Jg. 1988, S. 51ff; Caesar, Rolf (1980): a.a.O., S. 362; Hahn, Oswald: Die Währungsbanken der Welt, Bd. II; Stuttgart 1968, S. 20; Issing, Otmar: Die Unabhängigkeit der Bundesbank, in: Ehrlicher, Werner; Simmert, Diethart B (Hrsg.): Geld- und Währungspolitik in der Bundesrepublik Deutschland, Berlin 1982, S. 54; Mairose, Ralf: Soll die Bundesbank den Kurs bestimmen?, in: Wirtschaftsdienst 1970/V, S. 287.

14 Vgl. Caesar, Rolf (1980): a.a.O., S. 364; Schmitz, Wolfgang: Der Beitrag der Währungspolitik zum Binnenmarkt, in: Aus Politik und Zeitgeschichte 39. Jg. 1989, S. 18.

15 Umfassende Diskussion des für und wider von Unabhängigkeit z.B. bei Caesar, Rolf (1980): a.a.O., S. 53ff; Cargill, Thomas F.: Solomon Brothers Center for the Study of Financial Institutions: Central Bank Independence and regulatory responsibilities: The Bank of Japan and the Federal Reserve, New York 1989, S. 5f; Bernauer, Engelbert: a.a.O., S. 54-68. 
Unabhängigkeitsfrage zu erwarten ist. Die Diskussion muß an einem viel früheren Punkt angesetzen, und zwar an der Frage, was eine unabhängige Notenbank eigentlich ist. Solange es nicht möglich ist, die Unabhängigkeit einer Notenbank zu operationalisieren, laufen "Mahnungen vor einem Verlust an Notenbankautonomie bzw. Warnungen vor einer zu mächtigen, die Regierungspolitik gefährdenden Notenbank ... ins Leere"16. Vorher kann nicht beurteilt werden, ob die Unabhängigkeit einer Notenbank tatsächlich den Stellenwert verdient, der ihr häufig beigemessen wird. Erst nach einer klaren Definition und Bewertung der Unabhängigkeit einer Notenbank, kann man untersuchen, ob eine unabhängige Notenbank die Stabilität einer Währung besser gewährleisten kann als eine, die den Weisungen anderer Institutionen unterliegt. Ist dies nicht der Fall, verlöre die Diskussion um Un- oder Abhängigkeit von Währungsinstituten ihre Brisanz.

Eine Vielzahl von Autoren hält die Unabhängigkeit einer Notenbank für eine wesentliche Voraussetzung für die Erlangung bzw. Erhaltung von Geldwertstabilität ${ }^{17}$. So schreibt z. B. Goodman ${ }^{18}$, daß Länder mit unabhängigen Notenbanken gewöhnlich geringere Inflationsraten aufweisen als Länder mit abhängigen Notenbanken, weil Notenbanken in der Regel eine strengere Geldpolitik anstreben als Regierungen. Ähnlich ist auch Blessing der Auffassung, daß sich "die Abstufungen in der Stellung der Notenbanken in der freien Welt... meist recht deutlich an der Güte der Währungen ablesen"19 lassen. Man könne im allgemeinen von der Härte einer Währung auf die Stellung der Zentralbank schließen ${ }^{20}$. Die Ergebnisse bisheriger Untersuchungen zu diesem Thema weisen mit wenigen Ausnahmen ${ }^{21}$ in die gleiche Richtung ${ }^{22}$. Der allgemein zu beobachtende Trend, den

16 Dickertmann, Dietrich; Hansmeyer, Karl-Heinrich: Die Bundesbank im Streit der politischen Interessen, in: Wirtschaftsdienst 1973/XI, S. 580.

17 Z.B. Lusser, Markus: Die unabhängige Notenbank - vierte Gewalt im Staate?, Vortrag vor der Generalversammlung des Kantonalbernischen Handels- und Industrievereins, Sektion Biel-Seeland, Biel, am 25.4.88, abgedruckt in: Deutsche Bundesbank/ Auszüge aus Presseartikeln Nr.30, 2.5.88, S. 4; Szagunn, Volkhard: a.a.O., S. 20; Vocke, Wilhelm: a.a.O., S. 128; Pfleiderer, Otto: Die Notenbank im System der wirtschaftspolitischen Steuerung, in: Planung III, hrsg. v. Joseph. H. Kaiser, Baden-Baden 1968, S. 425.

Vgl. Goodman, John B.: The Politics of Central Bank Independence, in: Comparative Politics, Vol. 23 3/1991, S. 329.

19 Blessing, Karl:, Die Einflußmöglichkeiten der Notenbank, in: Junge Wirtschaft 6. Jg. 1958, S. 490.

20 Vgl. Blessing, Karl, a.a.O., S. 490

21 So fand Barro, Robert J. in einem Vergleich zwischen Inflationsraten und dem Unabhängigkeitsindex von 67 Ländern keine Korrelation zwischen beiden Variablen: Vgl.

Barro, Robert J.: Inflation and economic growth, in: Bank of England Quarterly Bulletin, May 1995, S. 166 - 175.

22 So z. B Bade, Robin; Parkin, Michael: Central Bank Laws and Monetary Policy; Dept. of Economics, University of Western Ontario, London, Ontario, Canada N6A 5C2, June 1987; Grilli, V.; Masciandaro, D.; Tabellini, G.: Political and monetary institutions and 
Notenbanken mehr Autonomie zu gewähren ${ }^{23}$, scheint dies ebenfalls zu bestätigen. So reformierten etwa Neuseeland und Chile 1989 ihre Zentralbanken zu einem unabhängigen Institut ${ }^{24}$. Frankreich und Belgien folgten jüngst ${ }^{25}$ und bei der Ausgestaltung der künftigen europäischen Notenbank orientiert man sich an der Autonomie der Deutschen Bundesbank. Liefert eine unabhängige Zentralbank nun tatsächlich eine höhere Geldwertstabilität als eine abhängige? Angesichts der niedrigen Inflationsraten, die beispielsweise Frankreich mit seiner bis kürzlich noch stark weisungsabhängigen Notenbank seit einigen Jahren aufweist, im Gegensatz zu den - nicht nur durch die Wiedervereinigung - hohen deutschen Inflationsergebnissen, scheinen Zweifel darüber angebracht. Das Ziel dieser Arbeit ist es, zu ergründen, ob die Unabhängigkeit einer Notenbank tatsächlich ein wesentlicher Einflußfaktor für die Entwicklung des Geldwertes ist. Entgegen der überwiegenden Meinung in der Literatur wird dazu folgende Hypothese aufgestellt, die es in der vorliegenden Arbeit zu bestätigen bzw. zu widerlegen gilt: Der Grad der Unabhängigkeit einer Notenbank hat keinen wesentlichen Einfluß auf die Entwicklung des Geldwertes.

public finance policies in the industrial countries, Economic Policy 1991, S.341-392; Preuße, Heinz Gert: a.a.O., S. 17f; Alensia, Alberto; Summers, Lawrence: Central bank Independence and Macroeconomic Performance: Some Comparative Evidence, Discussion paper Number 1496 Harvard University, July 1990.

23 Vgl. Issing, Otmar: Unabhängigkeit der Notenbank und Geldwertstabilität, Mainz, Stuttgart 1993, S. 14.

24 Vgl. Massey, Patrick: The changing role of New Zealand's Reserve Bank, in: The Irish Banking Review, Autumn 1990, S. 15 - 27; Castello-Branco, Marta; Swinburne, Mark: a.a.O., S. 19.

25 Vgl. o. V.: Auch Belgiens Zentralbank unabhängig, in: FAZ vom 22.4.1993; o. V.: Paris bestellt unabhängigen Zentralbankrat, in: FAZ vom 6.1.1994. 


\section{Gang der Untersuchung}

Bevor der Zusammenhang zwischen Unabhängigkeit einer Notenbank und Geldwertstabilität untersucht werden kann, muß zunächst geklärt werden, wodurch sich eine unabhängige Notenbank auszeichnet. Wie kann Unabhängigkeit definiert werden? Welche Formen und Abstufungen gibt es und wie läßt sich der Unabhängigkeitsgrad einer Notenbank bestimmen. Inhalt des ersten und gleichzeitig wesentlichen Teils dieser Arbeit wird also die Erarbeitung einer Unabhängigkeitsdefinition und anhand dieser die Entwicklung eines allgemeinen Bewertungsschemas sein, anhand dessen der Unabhängigkeitsgrad einer Zentralbank bestimmt werden kann. Im zweiten Teil folgt die Anwendung dieses Schemas auf ausgewählte Notenbanken und damit die Ermittlung des Unabhängigkeitsgrades dieser Institute. Abschließend werden diese Ergebnisse der Geldwertentwicklung in den betrachteten Ländern gegenübergestellt, um auf diese Weise Aufschlüsse über die Zusammenhänge zwischen dem Unabhängigkeitsgrad von Notenbanken und der Geldwertstabilität zu erhalten. 
Sylvia Liebler - 978-3-631-75025-4

Downloaded from PubFactory at 01/11/2019 09:08:34AM

via free access 


\section{Begriff und Problematik der Unabhängigkeit von Notenban- ken}

Bei der Suche nach einer Definition für Unabhängigkeit stellt sich zunächst die Frage nach dem Subjekt, demgegenüber die Unbhängigkeit einer Notenbank betrachtet werden soll. Dies wird im folgenden erörtert. Im Anschluß daran werden die in der Literatur gebräuchlichen Formen und Abstufungen sowie Definitionen von Unabhängigkeit von Notenbanken dargelegt. Auf der Basis dieser Grundlagen kann schließlich die im Rahmen dieser Arbeit verwendete charakterisierende Definition einer unabhängigen Zentralbank erarbeitet werden.

\subsection{Gegenstand der Unabhängigkeitsuntersuchung}

Grundsätzlich versteht man unter Abhängigkeit im juristischen Sinne bestimmte Beziehungen zweier Rechtssubjekte zueinander ${ }^{26}$. Im Rahmen dieser Untersuchung geht es um das Verhältnis zwischen Notenbank und verschiedenen Rechtssubjekten. Im allgemeinen spricht man von der Unabhängigkeit der Notenbank vom Staat 27 und hier v. a. vom Finanzministerium ${ }^{28}$ bzw. der Staatsführung 29 . Aber auch nicht-staatliche Akteure wie Interessengruppen ${ }^{30}$ oder Personen aus Wirtschaft und anderen Bereichen können Einflußträger sein.

\subsubsection{Unabhängigkeit von staatlichen Akteuren}

Der Unabhängigkeitsgrad einer Notenbank läßt sich nicht einfach mit dem Ausmaß staatlicher Einflußmöglichkeiten bestimmen. Die besondere Problematik liegt darin, daß eine absolute Unabhängigkeit vom Staat schlicht unmöglich ist ${ }^{31}$. Keine Institution innerhalb des Staatsverbandes kann außerhalb von Rechtsprechung und Gesetzgebung stehen ${ }^{32}$. Fair ${ }^{33}$ unterscheidet daher zwischen Unab-

26 Vgl. Hahn, Oswald (1968) Bd. II: a.a.O., S. 2, Schmid, Beat: Die Unabhängigkeit der Schweizerischen Notenbank, Diss. Bern 1979, S. 30.

27 Vgl. Hahn, Oswald (1968) Bd. II: a.a.O, S. 2; Rittershausen, Heinrich: a.a.O., S. 319; Bernauer, Engelbert: a.a.O., S. 46; Eynern, Gert v.: Die Unabhängigkeit der Notenbank. Vortrag anläßlich der Jahresfeier der Deutschen Hochschule für Politik Berlin am 15. Januar 1957, Berlin 1957, S. 10.

28 Vgl. Rittershausen, Heinrich: a.a.O., S. $318 \mathrm{ff}$.

29 Vgl. Uhlenbruck, Dirk: Die verfassungsmäßige Unabhängigkeit der Deutschen Bundesbank und ihre Grenzen, Diss. Köln 1967 a, S. 38.

30 Vgl. Uhlenbruck, Dirk (1967 a): a.a.O., S. 51; Vocke, Wilhelm: a.a.O., S. 127.

31 Vgl. Uhlenbruck, Dirk (1967 a): a.a.O., S. 38.

32 Vgl. Uhlenbruck, Dirk (1967 a): a.a.O., S. 38. 
hängigkeit innerhalb der Regierung und Unabhängigkeit von der Regierung. Ähnlich differenzieren Swinburne und Castello-Branco ${ }^{34}$ zwischen Unabhängigkeit der Notenbank bei den geldpolitischen Entscheidungen und Unabhängigkeit der Geldpolitik.

Zur näheren Untersuchung ist es sinnvoll, die drei Staatsgewalten getrennt zu betrachten.

\subsubsection{Unabhängigkeit von der Jurisdiktion}

Unabhängigkeit von der Rechtsprechung würde bedeuten, daß die Notenbank keinerlei Vorschriften unterliegt. Für eine Institution innerhalb des Staatsverbandes kann dies grundsätzlich nicht in Frage kommen ${ }^{35}$. Eine Notenbank unterliegt zumindest den allgemeinen Rechtsgrundsätzen des jeweiligen Staates. So ist beispielsweise die Deutsche Bundesbank $u$. a. an die allgemeinen verfassungsrechtlichen Grundsätze behördlichen Handelns ${ }^{36}$ gebunden und fällt diesbezüglich in den Zuständigkeitsbereich des Bundesverfassungsgerichtes ${ }^{37}$. Wird sie normsetzend tätig, erfordert dies eine verfassungsrechtlich zulässige gesetzliche Ermächtigung 38. Im Falle von Verwaltungakten in Gestalt von Verfügungen muß die Bundesbank beispielsweise die gesetzlichen Anforderungen bezüglich Form und Übermittlung von Verfügungen beachten ${ }^{39}$. Im Rahmen dieser Arbeit ist dies v. a. insofern interessant, als durch eine Möglichkeit der Anfechtung geldpolitischer Beschlüsse auf dem Rechtsweg eine vorliegende funktionelle Unabhängigkeit der Notenbank unterlaufen werden könnte.

\subsubsection{Unabhängigkeit von der Exekutive}

Völlige Unabhängigkeit gegenüber der Exekutive scheint gegeben, wenn die Notenbank agieren kann, ohne durch Weisungsbefugnisse, Veto-, Informations- oder

33 Vgl. Fair, Don: The independence of central banks, in: The Banker 10/79, S. 31.

34 Vgl. Swinburne, Mark; Castello-Branco, Marta: Central Bank Independence: Issues and Experience, IMF Working Paper 91/58, June 1991, S. 5.

Vgl. Bernauer, Engelbert: a.a.O., S. 46f.

36 Nämlich die Grundsätze der Erforderlichkeit, der Verhältnismäßigkeit und des geringstmöglichen Eingriffs; Vgl. Maunz, Theodor; Dürig, Günter: Grundgesetz, Bd. II, Art. 88, Rdnr. 28, S. 13.

37 Vgl. Braun, Karlpeter: Die Stellung der Notenbank als währungspolitische Instanz - Das Verhältnis zwischen Regierung und Notenbank in der Bundesrepublik Deutschland und in den Vereinigten Staaten von Amerika, Diss. Tübingen 1969, S. 50f.

Vgl. Fögen, Hermann: Geld- und Währungsrecht, München 1969, S. 105.

Vgl. Fögen, Hermann (1969): a.a.O., S. 106. 
sonstige Rechte der Regierung behindert zu werden 40 . Für die Beurteilung der Unabhängigkeit ist es wichtig, auf welche Bereiche der Notenbanktätigkeit sich die Befugnisse der Regierung beziehen. Ein Mitspracherecht der Regierung bei personalpolitischen Entscheidungen der Notenbank hat andere Auswirkungen auf die Unabhängigkeit als direkte Eingriffsmöglichkeiten in die Geldpolitik.

\subsubsection{Unabhängigkeit von der Legislative}

Bei der gesetzgebenden Gewalt muß zwischen dem Parlament als Gesetzgeber und dem Parlament als Kontrollorgan unterschieden werden ${ }^{41}$. Durch seine Eigenschaft als Gesetzgeber besteht theoretisch unbeschränkte Abhängigkeit der Notenbank vom Parlament ${ }^{42}$, da Aufgabenkreis, Organisation und währungspolitische Befugnisse des Währungsinstitutes per Gesetz oder aufgrund eines Gesetzes festgelegt werden 43 . Auch eine unabhängige Notenbank besitzt keine so weitreichende Organisationsgewalt, daß sie diese Regelungen selbst beschließen könnte 44 .

Eine Abhängigkeit der Notenbank vom Parlament als Kontrollorgan liegt vor, wenn das Parlament über Kontrollbefugnisse verfügt, wie etwa dem Mißtrauensvotum, die beispielsweise zur Abberufung der Notenbankleitung führen ${ }^{45}$ oder die einen direkten Eingriff in die Geldpolitik der Notenbank zur Folge haben.

\subsubsection{Unabhångigkeit von nicht-staatlichen Akteuren}

$\mathrm{Zu}$ den nicht-staatlichen Akteuren, die potentiell Einfluß auf die Notenbank ausüben können, gehören im wesentlichen Wirtschaftsgruppen, die vertreten durch Gewerkschaften, Verbände etc. ihre Interessen bei der Notenbank durchzusetzen versuchen ${ }^{46}$. Viele Autoren halten Einflüsse der Wirtschaft auf die Unabhängigkeit einer Notenbank für mindestens ebenso bedeutsam wie die staatlicher Stel-

40 Vgl. Lampe, Ortrun: Die Unabhängigkeit der Deutschen Bundesbank, München 1971, S. 22.

41 Vgl. Samm, Theodor: Die Stellung der Deutschen Bundesbank im Verfassungsgefüge, Schriften zum öffentlichen Recht, Bd. 63, Berlin 1967, S. 35.

42 Vgl. Caesar, Rolf: Der Handlungsspielraum von Notenbanken, Baden-Baden 1981, S. 150.

43 Vgl. Forsthoff, Ernst: Lehrbuch des Verwaltungsrechts, Bd. I, 9. Aufl., München, Berlin 1966, S. 465.

44 Lampe, Ortrun: a.a.O., S. 21.

45 Vgl. Lampe, Ortrun: a.a.O., S. 22.

46 Vgl. Hahn, Oswald (1968) Bd. II: a.a.O., S. $10 f$. 
len 47 . Gronau 48 weist darauf hin, daß auch politisch autonome Zentralbanken nicht unabhängig von solchen Interessengruppen sind.

Nicht-staatliche Akteure können direkt oder indirekt auf die Notenbank einwirken. Indirekt können sie die die Notenbank betreffende Gesetzgebung beeinflussen, sei es durch Lobbying oder ihr Einrücken in die Parlamente ${ }^{49}$. Bezeichnenderweise hat sich im angelsächsischen Sprachraum für Verbände der Begriff "invisible government" eingebürgert ${ }^{50}$. Besonders extrem sind die Einflußmöglichkeiten von Interessengruppen im Falle einer von Weisungen der Regierung abhängigen Notenbank, da sie hier über die Regierung auf die konkrete Geldpolitik Zugriff haben. Eine direkte Einflußnahme ist über MitbestimmungsWeisungs-, Kontrollrechte etc. möglich, über die private Akteure in Bezug auf die Geldpolitik der Notenbank verfügen. Dies kann beispielsweise durch eine Vertretung von Wirtschaftsgruppen in einem Beirat der Notenbank oder direkt in den Leitungsgremien des Instituts erfolgen. Einflußnahme ist ebenso über private Anteilseigner der Notenbank möglich. Nicht in allen Fällen ist die Notenbank vollständig im Staatsbesitz. Einige Währungsinstitute sind noch ganz oder teilweise in privater Hand. Vorwiegend in den Anfängen des Zentralbankwesens beherrschten Anteilseigner aufgrund ihrer gesellschaftsrechtlichen Befugnisse die Geschäftspolitik der Zentralbanken ${ }^{51}$. So wurde beispielsweise die Diskontpolitik der englischen Zentralbank weitgehend von privaten Kapitalbesitzern bestimmt ${ }^{52}$. Als weiteres bedeutendes Beispiel für das Einwirken Privater auf die Notenbank sei hier auf den Einfluß der berühmten "200 Aktionäre" 53 auf die Banque de France verwiesen, die mehrfach aufgrund ihrer Machtposition Druck auf die Regierung ausübten 54 .

47 Vgl. Vocke, Wilhelm: a.a.O., S. 127; Eynern, Gert v.: a.a.O., S. 16ff; Beck, Heinz: Gesetz über die Deutsche Bundesbank. Kommentar, Mainz-Gonsenheim, Düsseldorf 1959, S. $114 \mathrm{f}$.

Vgl. Gronau, Klaus D.: Bedenkliche Sonderstellung der Bundesbank, in: Wirtschaftsdienst 1970/V, S. 298.

Vgl. Bernauer, Engelbert : a.a.O., S. 57.

50 Vgl. Bernauer, Engelbert : a.a.O., S. 57.

51 Vgl. Schuppler, Edith: a.a.O., S. 76f.

52 Vgl. Hultman, Ivar: Die Centralnotenbanken Europas, Berlin 1912, S. 21.

53 Vgl. Moreau, E.: Souvenirs d'un Gouverneur de la Banque de France. Histoire de la Stabilisation du Franc (1926-1928), Paris 1954, S. 212.

54 Vgl. Myers, Margaret G.: Paris as a Financial Centre, London 1936, S. 43ff und S.89ff; Bopp, K. R. 1941: The Government and the Bank of France, in: Public Policy. A Yearbook of the Graduate School of Public Administration, Havard University, ed. by C. F. Friedrich, E. S. Mason, Vol.II, Cambridge Mass., S. 4ff; Bing, Walter B.: Wirtschaft und Währung Frankreichs - Im Spiegel der Jahresberichte der Banque de France, Frankfurt am Main 1956, S. 9; Eynern, Gert v. (1957): a.a.O., S. 16f; Eynern, Gert v.: Grundriß der politischen Wirtschaftslehre, Köln Opladen 1968, S. 222. 
Die Einschränkung der Unabhängigkeit durch private Akteure läßt sich theoretisch noch weiter fassen. So sieht Caesar ${ }^{55}$ die notenbankpolitische Entscheidungsfreiheit bereits dadurch eingeschränkt, daß eine Notenbank - selbst eine juristisch stark unabhängige - "die Vorstellungen privater Gruppen in ihr Kalkül miteinbezieht" 56 und dies um so mehr, je intensiver die Kommunikation zwischen ihr und den privaten Gruppen ist. Zusätzlich beschränke das Ausmaß von Ausweich- und Umgehungsmöglichkeiten für private Wirtschaftssubjekte, deren Verhalten durch notenbankpolitische Maßnahmen beeinflußt werden soll, den ökonomischen Handlungsspielraum einer Notenbank ${ }^{57}$.

\subsection{Formen und Abstufungen der Unabhängigkeit}

Es existieren verschiedene Ansätze einer Systematisierung der verschiedenen Formen von Unabhängigkeit. In der Regel wird der allgemeine Begriff der Unabhängigkeit in einen institutionellen, vermögensrechtlichen, personellen und funktionellen Aspekt gegliedert ${ }^{58}$. Daneben läßt sich nach faktischer und juristischer Unabhängigkeit unterscheiden 59 .

\subsubsection{Institutionelle Unabhängigkeit}

Die institutionellen Unabhängigkeit zielt auf die Rechtsstellung und Rechtsform der Notenbank ab. Hier geht es in erster Linie um die Frage der Ausgestaltung einer Notenbank als Verfassungsorgan bzw. als "vierte Gewalt" im Staat 60 .

\subsubsection{Vermögensrechtliche Unabhängigkeit}

Die vermögensrechtliche Unabhängigkeit wird zuweilen als institutionelle Unabhängigkeit im engeren Sinne aufgefaßt 61 . Sie baut auf den Kriterien der Grundkapital- und Gewinnbeteiligung auf62. Im wesentlichen geht es hier um die Eigentumsverhältnisse der Zentralbank, die Gewinnverteilungsvorschriften und die haushaltsmäßige Selbständigkeit63. Unter haushaltsmäßiger Selbständigkeit

\footnotetext{
55 Vgl. Caesar, Rolf (1981): a.a.O., S. 146.

56 Caesar, Rolf (1981): a.a.O., S. 155.

57 Vgl. Caesar, Rolf (1981): a.a.O., S. 153.

58 Vgl. Uhlenbruck, Dirk (1967 a): a.a.O., S. 39.

59 Vgl. Caesar, Rolf (1981): a.a.O., S. 59.

60 Vgl. Caesar, Rolf (1981): a.a.O., S. 60.

61 Vgl. Caesar, Rolf (1981): a.a.O., S. 125.

62 Vgl. Caesar, Rolf (1981): a.a.O., S. 60.

63 Vgl. Caesar, Rolf (1981): a.a.O., S. 125.
} 
versteht man die Möglichkeit der Notenbank, über ihre Ausgaben selber bestimmen und sie auch finanzieren zu können 64 .

\subsubsection{Personelle Unabhängigkeit}

Personelle Unabhängigkeit einer Notenbank setzt voraus, "daß deren Willensbildungsorgane nicht schon durch die Auswahl der den Willen bildenden Mitglieder auf eine bestimmte Notenbankpolitik festgelegt sind"65. Sie soll beispielsweise verhindern, da $\beta$ die Regierung die Notenbankleitung mit Personen besetzen kann, die die Übereinstimmung mit der allgemeinen Wirtschaftspolitik der Regierung von vornherein sicherstellen. Sie soll eine Aushöhlung der funktionellen Unabhängigkeit verhindern 66 . Für personelle Unabhängigkeit ist deshalb im wesentlichen ausschlaggebend, welche Instanzen für die Ernennung und gegebenenfalls auch Abberufung der Mitglieder der Notenbankleitung zuständig sind 67.

\subsubsection{Funktionelle Unabhängigkeit}

Man spricht hier auch von materieller oder sachlicher Unabhängigkeit 68 . Darunter wird verstanden, da $B$ die Notenbank ihre geldpolitischen Entscheidungen frei von Einflußrechten notenbankfremder Instanzen treffen kann und nur dem Gesetz verantwortlich ist.

\subsubsection{Juristische und faktische Unabhängigkeit}

Die Beziehungen zwischen der Notenbank und ihren Abhängigkeitsträgern sind theoretisch äußerst schwer zu fassen, weil sie sehr vielschichtig sind. Die naheliegendste Methode ist die Untersuchung der gesetzlichen Bestimmungen. Aber die durch Gesetze verankerte Unabhängigkeit ist nicht unbedingt gleich der tatsächlichen Unabhängigkeit. Notenbanken, die formal über einen beträchtlichen Unabhängigkeitsgrad verfügen, können faktisch abhängiger sein als Notenbanken mit verhältnismäßig geringer juristischer Unabhängigkeit und umgekehrt69. Diese Differenz kann verschiedene Ursachen haben, von denen einige im folgenden beispielhaft erläutert werden sollen.

64 Vgl. Swinburne, Mark; Castello-Branco, Marta: a.a.O., S. 35.

65 Lampe, Ortrun: a.a.O., S. 18.

66 Vgl. Uhlenbruck, Dirk (1967 a): a.a.O., S. 52.

67 Vgl. Caesar, Rolf: Notenbanken im Spannungsfeld der Politik, in: Wirtschaftsdienst 1982/XI, S. 570.

68 Vgl. Schmid, Beat: a.a.O., S. 33.

69 Vgl. Cargill, Thomas F.(1989): a.a.O., S. 5. 


\subsubsection{Anwendung der Normen}

Unterschiede zwischen der geschriebenen und der praktizierten Verfassung ergeben sich zum einen durch unterschiedliche Auslegung von Verfassungs- und Gesetzesbestimmungen ${ }^{70}$. Sie treten ebenfalls auf, wenn notenbankfremde Akteure die ihnen per Gesetz zustehenden Einflußrechte nicht wahrnehmen. Als Beispiel sei hier das aufschiebende Vetorecht der deutschen Regierung bezüglich geldpolitischer Entscheidungen der Bundesbank angeführt, das bisher noch nie angewandt wurde ${ }^{71}$. Eine weitere Ursache kann eine Weiterentwicklung des geldpolitischen Instrumentariums sein. Notenbanken können faktisch über einen größeren instrumentellen Spielraum verfügen als das Gesetz vorgibt. Dies liegt im wesentlichen daran, da $\beta$ die Instrumente der Marktentwicklung angepaßt werden. Die Entwicklung von Finanzinnovationen erfordert tendenziell auch eine Weiterentwicklung des geldpolitischen Instrumentariums, um den Wirkungsgrad der Geldpolitik zu erhalten und Ausweichreaktionen der Akteure zu vermeiden. Zudem ist es sinnvoll, neue Mittel vor ihrer gesetzlichen Legitimierung zu erproben ${ }^{72}$. Denkbar ist auch die Möglichkeit, daß Instrumente, die den Notenbanken vom Gesetz vorenthalten werden, auf dem Wege freiwilliger Vereinbarungen angewandt werden, auch wenn sie in diesem Fall rechtlich nicht erzwingbar sind.

\subsubsection{Einfluß der Persönlichkeit}

In der Literatur wird regelmäßig auf die Wichtigkeit der handelnden Persönlichkeiten für die tatsächliche Stellung der Notenbank hingewiesen ${ }^{73}$. Einige Autoren gehen sogar soweit und sagen, eine instrumentell gut ausgestattete Notenbank sei so unabhängig wie ihr Präsident ist ${ }^{74}$. Schwache Persönlichkeiten in der Notenbankleitung können möglicherweise eine de jure unabhängige Notenbank de facto abhängig werden lassen, weil sie eine ständige Herausforderung an Politiker und

Vgl. Schmid, Beat: a.a.O., S. 34.

71 Vgl. Caesar, Rolf (1982): a.a.O., S. 571.

72 Vgl. Schuppler, Edith: a.a.O., S. 32f.

73 Vgl. Caesar, Rolf (1981): a.a.O., S. 159f; Schuppler, Edith: a.a.O., S. 89; Veit, Otto: Der Wert unseres Geldes, Frankfurt am Main 1958, S. 99-101; Hankel, Wilhelm: Brauchen wir eine unabhängige Notenbank?, in: Wirtschaftsdienst 1970/V, S. 291; Spindler, Joachim v.; Becker, Willy; Starke, O.-Ernst: Die Deutsche Bundesbank, Stuttgart Berlin Köln Mainz 1973, S. 260f; Lampe, Ortrun: a.a.O., S. 33; o. V.: Bundesbank ohne Illusionen, in: Zeitschrift für das gesamte Kreditwesen 21/1952, S. 552; Schmölders, Günter (1968): a.a.O., S. 224; Könneker, Wilhelm: Vom Zentralbanksystem zur Deutschen Bundesbank, in: Zeitschrift für das gesamte Kreditwesen 20/1957, S. 798; Sylla, Richard: The Autonomy of Monetary Authorities: The Case of the U.S. Federal Reserve System, in: Toniolo, Gianni: Central bank's independence in historical perspective, Berlin, New York 1988, S. 37.

74 Vgl. Poullain, Ludwig: a.a.O., S. 51. 
Wirtschaftsvertreter darstellen, das Vakuum, das sie erzeugen, mit ihren Interessen zu füllen ${ }^{75}$. Umgekehrt läßt sich eine mit Weisungsrechten ausgestattete Regierung evtl. von starken Persönlichkeiten in der Notenbankspitze beeinflussen 76 . Caesar ${ }^{77}$ spricht in diesem Zusammenhang von einer "charismatischen Persönlichkeit".

Die Persönlichkeit der entscheidenden Notenbankmitglieder scheint ein nicht zu unterschätzendes Kriterium für die tatsächliche Unabhängigkeit eines Währungsinstituts zu sein. Doch läßt sich weder die Stärke der Persönlichkeit selbst noch ihr Einfluß auf die Unabhängigkeit objektiv bestimmen. Letzteres hängt beispielsweise auch von der Persönlichkeit des Gegenübers ab, in den meisten Fällen des Wirtschafts- oder Finanzministers.

\subsubsection{Offentliche Meinung}

Das Ansehen einer Notenbank und ihrer Politik in der Öffentlichkeit kann die faktische Unabhängigkeit des Währungsinstituts ebenfalls beeinflussen. Je höher die Notenbank in der öffentlichen Meinung steht, desto größer dürfte ihre faktische Unabhängigkeit sein. Dies kommt v. a. in Konfliktsituationen zwischen Regierung und Notenbank zum Tragen, deren Ausgang auch davon abhängen kann, auf wessen Seite die Öffentlichkeit steht ${ }^{78}$. Seit den siebziger Jahren ist eine verstärkte Öffentlichkeitsarbeit der Notenbanken zu beobachten ${ }^{79}$, die diese These bestätigen mag.

Die Wichtigkeit der öffentlichen Meinung bedeutet aber auch, daß keine - auch noch so unabhängige - Notenbank auf Dauer Entscheidungen treffen kann, die nicht mit den vorherrschenden Zielen und Prioritäten in der Gesellschaft vereinbar sind. Dem Druck der öffentlichen Meinung kann sie sich langfristig nicht entziehen. Dies zwingt sie, sich für das "Gesamtwohl der Wirtschaft"80 einzusetzen, will sie ihren Status beibehalten oder ihn gar in Richtung einer stärkeren Unabhängigkeit verändern.

\subsubsection{Bewertung der faktischen Unabhängigkeit}

Wie kann der Unterschied zwischen juristischer und faktischer Unabhängigkeit bei der Analyse der Autonomie einer Notenbank berücksichtigt werden? Sinnvol-

75 Vgl. Poullain, Ludwig: a.a.O., S. 41.

76 Vgl. Hahn, Oswald (1968) Bd. II: a.a.O., S. 85; ähnlich auch Lampe, Ortrun: a.a.O., S.

33; o. V.: Bundesbank ohne Illusionen: a.a.O., S. 552.

77 Vgl. Caesar, Rolf (1981): a.a.O., S. 160f.

78 Vgl. Caesar, Rolf (1981): a.a.O., S. 157.

79 Vgl. Caesar, Rolf (1981): a.a.O., S. 140

80 Schmitz, Wolfgang (1989): a.a.O., S. 19. 
le Kriterien zur Beurteilung der faktischen Unabhängigkeit sind schwer zu identifizieren, ebenso wie die Erfassung ihrer relativen Bedeutung81. Einige Autoren ziehen zur Messung der faktischen Unabhängigkeit Hilfsindikatoren heran, wie z. B. die Häufigkeit ernsthafter Konfliktsituationen zwischen Notenbank und Regierung ${ }^{82}$, der Ausgangspunkt dieser Konflikte, ein Vergleich der jeweiligen Zielprioritäten von Notenbankpolitik und allgemeiner Regierungspolitik, die effektive Einschaltung der Notenbank in die Staatsfinanzierung, die Rolle der Notenbank im Rahmen der äußeren Währungspolitik, der Grad an Koordinierungsverflechtung zwischen Notenbank und staatlichen sowie privaten Akteuren sowie die Einschätzung der Position der Notenbank in der öffentlichen Meinung83. Wooley ${ }^{84}$ versucht, den Unabhängigkeitsgrad einer Notenbank verhaltensmäßig zu bestimmen, indem er autonomes Verhalten als Zeichen von Unabhängigkeit wertet. Nach seiner Definition ist eine Notenbank dann unabhängig, wenn sie ihre Instrumente ohne vorherige Billigung durch andere Aktoren anwenden kann und wenn sich ihr Instrumenteneinsatz innerhalb eines kurzen Zeitraums (etwa ein Viertel Jahr) klar von dem unterscheidet, was andere Akteure bevorzugen. Hier ist allerdings zu bezweifeln, daß sich eindeutig bestimmen läßt, was andere Akteure bevorzugen. Auch bei den anderen Hilfsindikatoren ist eine objektive Bewertung der Kriterien im Einzelfall oft nicht möglich und einer Gewichtung der Kriterien ist eine gewisse Willkür nicht abzusprechen 85 .

Neben dem Mangel an operationalisierbaren Indikatoren gibt es weitere Schwierigkeiten bei der Messung der faktischen Unabhängigkeit. Der Grad an faktischer Unabhängigkeit dürfte im Zeitablauf schwanken. Jeder Wechsel des Notenbankpräsidenten, eine veränderte Haltung der Öffentlichkeit gegenüber der Zentralbankpolitik aufgrund aktueller wirtschaftlicher Gegebenheiten oder auch nur die Inanspruchnahme von Einflußrechten durch die Regierung, die diese bisher nicht wahrgenommen hat, führt unweigerlich zu einer Änderung der faktischen Unabhängigkeit. Das bedeutet, daß der faktische Unabhängigkeitsgrad für jede marginale Zeitperiode neu bestimmt werden müßte. Aus diesen Gründen wird sich das zu erstellende Bewertungsschema auf die Ermittlung der juristischen Unabhängigkeit beschränken.

81 Vgl. Caesar, Rolf(1981): a.a.O., S. 143.

82 Vgl. Issing, Otmar (1982): a.a.O., S. 50 deutet die Häufigkeit von Konflikten als Bewährung der Unabhängigkeit, da die Notenbank in einem solchen Fall ihre Politik unbeirrt verfolgt.

83 Vgl. Caesar, Rolf: Central Banks in the Political Area, in: Intereconomics, Jan./Feb. 1983, S. 6f.

84 Vgl. Woolley, John T.: Monetary Politics: The Federal Reserve and the Politics of Monetary Policy, Cambridge: Cambridge University Press 1984, S. 69 - 87.

Vgl. Caesar, Rolf (1983): a.a.O., S. 7. 


\subsubsection{Abstufungen der Unabhängigkeit}

Die Literatur bietet verschiedene Ansätze, Unabhängigkeit nach Intensitätsgraden abzustufen, die einander jedoch relativ ähnlich sind. Sie beschränken sich weitgehend auf die Beschreibung der Beziehung zwischen Regierung und Notenbank. Viele einschlägige Arbeiten bauen auf dem Schema von Starke 86 auf87. Er unterscheidet die drei theoretisch reinen Abstufungen der Subordination, Koordination und Integration der Notenbank, wobei sich Subordination durch Weisungsgebundenheit der Bank auszeichnet, Koordination durch unabhängige Gleichberechtigung von Notenbank und Regierung und Integration als Zwischenstufe, bei der die Bank ein Teil der Regierung ist und als solcher innerhalb der Regierung überstimmt werden kann ${ }^{88}$. Dazwischen sind jeweils Übergangs- und Mischformen denkbar ${ }^{89}$. Einige Autoren ergänzen diese Dreiteilung um das Verhältnis einer Überordnung der Notenbank ${ }^{90}$. Es ist offensichtlich, daß solche Schematisierungen der Wirklichkeit kaum gerecht werden können. Hier ist zudem anzumerken, daß Koordination keine Grundbeziehung zwischen Staat und Notenbank darstellt, sondern ein Mittel ist zur Gewährleistung der Einheit der Wirtschaftspolitik ${ }^{91}$. Eine Koordination von Notenbankpolitik und allgemeiner Wirtschaftspolitik der Regierung findet auch bei einer Subordination der Notenbank statt. Die von Rittershausen ${ }^{92}$ entwickelten Abstufungen sind präziser. Er unterscheidet unter dem Aspekt der Abhängigkeit oder Unabhängigkeit vom Finanzministerium konkrete Möglichkeiten einer Einflußnahme auf die Geldpolitik der Notenbank, nämlich:

"a) Die Notenbank als abhängige Abteilung des Finanzministeriums

b) Die Notenbank als Aktiengesellschaft oder Körperschaft des öffentlichen Rechts, also selbständige juristische Rechtspersönlichkeit und damit nach auBen hin unabhängig, sachlich trotzdem abhängig wie eine Abteilung des Finanzministeriums, den Anweisungen des Finanzministers unterstehend

c) Die Notenbank als Aktiengesellschaft oder andere juristische Person mit einem höheren Grad der Unabhängigkeit besonders vom Finanzministerium

86 Vgl. Starke, Otto-Ernst: Die Stellung der Notenbank im Staatsgefüge, in: WertpapierMitteilungen, 11. Jg., Teil IV B, Nr. 3 vom 19.1.1957 b, S. 81.

87 Vgl. Bernauer, Engelbert : a.a.O., S. 2; Veit, Otto (1961), a.a.O., S. 182f; Schuster, Leo: Zentralbankpolitik und Bankenaufsicht in den EWG-Staaten, Köln, Opladen 1967, S. 23f; Hahn, Oswald (1968) Bd. II: a.a.O., S. 2.

Vgl. Starke, Otto-Ernst (1957 b): a.a.O., S. 81.

Vgl. Starke, Otto-Ernst (1957 b): a.a.O., S. 81.

So z.B. Hahn, Oswald (1968) Bd. II: a.a.O., S. 2; Schmid, Beat: a.a.O., S. 31.

Vgl. Bernauer, Engelbert : a.a.O., S. 2.

Vgl. Rittershausen, Heinrich: a.a.O., S. $319 \mathrm{f}$. 
d) Unabhängigkeit vom Finanzministerium und von finanziellen Weisungen des Regierungschefs, aber verpflichtet, ihre Politik mit der Wirtschaftspolitik der Regierung zu koordinieren

e) Völlige Unabhängigkeit“ ${ }^{\circ}$.

\subsection{Begriff und Definition von Unabhängigkeit}

Die Definition von Unabhängigkeit ist die Basis für eine Bewertung des Unabhängigkeitsgrades einer Notenbank. Das Spektrum der in der Literatur verwendeten Definitionen ist sehr weitreichend, wobei Begriffe wie Autonomie oder Handlungsspielraum meist synonym verwendet werden ${ }^{94}$. Verschiedene Definitionen führen zwangsläufig zu unterschiedlichen Ergebnissen in ihrer Bewertung. Daher ist eine sorgfältige Auswahl der Arbeitsdefinition erforderlich. Man könnte beispielsweise eine Notenbank bereits als abhängig bezeichnen, weil sie aufgrund der Komplexität ihrer Beziehungen nie völlig autonom innerhalb der Gesamtgesellschaft agieren kann ${ }^{95}$. So muß eine Notenbank unter Umständen ihre Politik aufgrund von Tarifabschlüssen ändern, die sie allenfalls indirekt beeinflussen kann96. In eine ähnliche Richtung weist eine Definition, die häufig mit Handlungsspielraum umschrieben wird. Der Begriff des Handlungsspielraums wurde im Zusammenhang mit Notenbanken von Hansmeyer ${ }^{97}$ eingeführt. Er enthält eine ökonomische, rechtliche und politische Komponente 98 . Die ökonomische Komponente umfaßt Wirkungshemmnisse geldpolitischer Instrumente; der rechtliche Rahmen ist durch die Notenbankgesetzgebung gezogen und die politische Komponente beinhaltet das Ausmaß, "in dem relativ konfliktfreies Handeln möglich ist"99. Caesar ${ }^{100}$ greift dies auf und definiert den Handlungsspielraum als die Ge-

93 Rittershausen, Heinrich: a.a.O., S. 319 f.

94 U.a. Uhlenbruck, Dirk (1967 a): a.a.O., S. 22ff; Englert, Michael: Der Handlungsspielraum der amerikanischen Bundesbank im Regierungssystem der Vereinigten Staaten, Rheinfelden 1988, S. 77; Issing, Otmar: Die Unabhängigkeit der Bundesbank. Bemerkungen zur geplanten Novellierung des Bundesbankgesetzes, in: Klatt, Sigurd; Willms, Manfred (Hrsg.): Strukturwandel und makroökonomische Steuerung, Berlin 1975, S. 365ff; ausführlich zur Terminologie bei Caesar, Rolf (1981): a.a.O., S. 56ff.

95 Vgl. Kaiser, Rolf, H.: Bundesbankautonomie - Möglichkeiten und Grenzen einer unabhängigen Politik, Frankfurt/Main 1980, S. If.

96 Vgl. Kaiser, Rolf, H.: a.a.O., S. 2 F.1

97 Vgl. Hansmeyer, Karl Heinrich: Wandlungen im Handlungsspielraum der Notenbank?, in: Andreae, C. A.; Hansmeyer, K. H.; Scherhorn, G. (Hrsg.): Geldtheorie und Geldpolitik, Günter Schmölders zum 65. Geburtstag, Berlin 1968, S. $155 f$.

98 Vgl. Hansmeyer, Karl Heinrich: a.a.O., S. 155.

99 Hansmeyer, Karl Heinrich: a.a.O., S. 155f.

100 Vgl. Caesar, Rolf (1981): a.a.O., S. 69. 
samtheit der Möglichkeiten einer Notenbank, ihre Aufgaben nach allgemeinem Verständnis zu erfüllen ohne Behinderung durch juristische Bestimmungen, ökonomische Wirkungshemmnisse oder politische Widerstände, wobei sich der Umfang dieser Möglichkeiten durch die Entscheidungsalternativen der Notenbank bzw. das Ausmaß der Durchsetzbarkeit des Gewollten bestimmt. Diese Definition ist sehr weit gefaßt. Unabhängigkeit wird hier quasi gleich gesetzt mit den Möglichkeiten, über die eine Notenbank verfügt, bestimmte Ziele zu erreichen. Time-Lags beim Einsatz geldpolitischer Instrumente schränken die Unabhängigkeit nach dieser Definition ebenso ein, wie beispielsweise die Tarifautonomie. Es gibt fast nichts, was hier nicht irgendeinen Einfluß auf die Unabhängigkeit hätte. Auch aus einem weiteren Grund ist diese Definition im Rahmen dieser Arbeit nicht verwendbar. Eine der wesentlichen Aufgaben, die einer Notenbank nach allgemeinem Verständnis zukommen, ist zweifellos die Sicherung des Geldwertes. Will man - wie es hier der Fall ist - den Einfluß der Unabhängigkeit einer Notenbank auf die Geldwertstabilität untersuchen, kann man nicht bereits Unabhängigkeit definieren als die Möglichkeiten, über die eine Notenbank verfügt, Geldwertstabilität zu erreichen. Es ist daher wichtig, streng zwischen Unabhängigkeit auf der einen Seite und den Möglichkeiten, die eine Notenbank hat, Geldwertstabilität zu erreichen, zu differenzieren.

Arndt 101 vertritt eine ganz andere Auffassung von Autonomie. Er bezeichnet eine Notenbank dann als autonom, wenn sie Unternehmenscharakter hat, selbst wenn sie formaljuristisch direkt dem Regienungschef unterstellt ist. Dies war unter dem Goldautomatismus möglich, als die Notenbanken legitim als Unternehmen, nämlich als Banken im Weltmarkt, agierten, dabei wie jedes andere Unternehmen auf ihre Liquidität achten mußten und unter dem Zwang standen, "ihnen präsentierte Forderungen... in einem Geld einlösen zu müssen, das sie selbst nicht beliebig produzieren konnten: in Gold..."102. Ihr kommerzieller Charakter lag in der Möglichkeit, mit dem Notenausgabegeschäft Gewinne zu erzielen. Für heutige Notenbanken ist eine derartige Autonomie nur insofern möglich, als der Staat eine Außenwährungspolitik betreibt, die faktisch auf einen stabilen Wechselkurs zur Leitwährung hinausläuft, wobei an die Stelle des Goldes das Kreditgeld der Leitwährung und die Geldpolitik der Leitwährungsbank an die Stelle der Goldproduktion tritt 103 .

101 Vgl. Arndt, Hans-Joachim: Politik und Sachverstand im Kreditwährungswesen, Berlin 1963, S. 340f.

102 Arndt, Hans-Joachim (1963): a.a.O., S. 340.

103 Vgl. Arndt, Hans-Joachim (1963): a.a.O., S. 341. 
Deutschsprachige Literatur stützt sich weitgehend auf die Unabhängigkeitsdefinition des sog. Scharnbergberichts ${ }^{104}$ aus den Gesetzesmaterialien zum Deutschen Bundesbankgesetz: "Unter Unabhängigkeit wird verstanden, daß die Bank bei ihren währungspolitischen Entscheidungen nicht der parlamentarischen Kontrolle unterliegt, nicht an Weisungen der Bundesregierung gebunden ist und nicht dem Einfluß potentieller Interessenten an einer für die Sicherheit unserer manipulierten Währung gefährlichen Ausdehnung des Geldvolumens gerät"105. Die Weisungsfreiheit taucht auch bei Bernauer auf, der ein Währungsinstitut dann als autonom bezeichnet, wenn weder Regierung (bzw. ein Regierungsmitglied) noch Parlament ihr gegenüber weisungsbefugt ist ${ }^{106}$.

Einige Autoren definieren Unabhängigkeit als die "alleinige Zuständigkeit der Notenbank für die Anwendung des ihr vom Gesetzgeber zur Verfügung gestellten Instrumentariums" 107 Problematisch ist hier die Tatsache, daß das der Notenbank zur Verfügung stehende Instrumentarium als gegeben angenommen wird ohne Berücksichtigung der Instrumente, die ihr das Gesetz vorenthält. Das führt dazu, $\mathrm{da} ß$ womöglich eine mit wenig Instrumenten, aber ohne Weisungsbefugnissen notenbankexterner Instanzen ausgestattete Zentralbank unabhängiger bewertet wird, als eine, der ein umfangreiches Instrumentarium zur Verfügung steht, deren Anwendung aber teilweise an Auflagen oder Weisungen gebunden ist. Geeigneter scheint daher folgende Definition:

Eine Notenbank ist unabhängig, wenn sie ihre geldpolitischen Entscheidungen selbständig treffen kann.

Damit ist sowohl die Unabhängigkeit vom Staat als auch von anderen Einflußträgern abgedeckt. Das der Notenbank zur Verfügung stehende Instrumentarium wird nicht als gegeben angenommen, da es ein wesentliches Kriterium ihrer Entscheidungsfreiheit ist.

104 Vgl. Scharnberg: Schriftlicher Bericht des Ausschusses furr Geld und Kredit (= Scharnbergbericht), BT-Drucksache zu Drucksache Nr. 3603, 2. Wahlperiode 1953, S.5, abgedruckt in Beck, Heinz: a.a.O., S. 597 - 610.

105 Scharnbergbericht: a.a.O., S. 5.

106 Vgl. Bernauer, Engelbert : a.a.O., S. 4.

107 Vgl. Pfleiderer, Otto: a.a.O., S. 425, ähnlich auch bei Hahn, Hugo J.; Siebelt, Johannes:

Zur Autonomie einer küntigen Europäischen Zentralbank, in: Die öffentliche Verwal-

tung 1989 H.6, S. 234. 


\subsection{Beeinträchtigung der Unabhängigkeit durch verschiedene Einflußinstanzen}

Spielt es für den Unabhängigkeitsgrad einer Notenbank eine Rolle, ob die Autonomie durch eine oder mehrere Instanzen eingeschränkt wird? Auf den ersten Blick scheint es, als sei die Unabhängigkeit einer Zentralbank weniger gemindert, wenn die Einschränkungen von verschiedenen Instanzen herrühren, also quasi ein Pluralismus der Einflußinstanzen. Dies wäre z. B. der Fall, wenn die Regierung über Rechte verfügt, direkt auf die geldpolitischen Entscheidungen der Bank einzuwirken, während die personelle Besetzung der Notenbankorgane privaten Gruppen vorenthalten ist. Je mehr Befugnisse bei einer Instanz konzentriert sind, desto größer sind deren Möglichkeiten, ihre Ziele durchzusetzen, weil sie die Notenbankpolitik stark prägen kann. Eine Verteilung der Einwirkungsmöglichkeiten auf verschiedene Instanzen kann dagegen einen einseitigen Einfluß einer Instanz verhindern und damit vielleicht einen positiven Beitrag zur Geldwertsicherung leisten. Die Notenbank erhält dadurch aber keine größere Entscheidungsfreiheit über ihre Politik. Für den Unabhängigkeitsgrad ist es daher irrelevant, von wem eine Einschränkung der Autonomie herrührt, sei es vom Staat oder von verschiedenen privaten Gruppen. Genausowenig spielt es eine Rolle, ob die einzelnen Einschränkungen ausnahmslos von einem Akteur ausgehen oder ob sie gleichmäßig auf alle in Frage kommenden verteilt sind 108 . Fntscheidend für eine Minderung der Autonomie ist die Tatsache, $d a \beta$ eine Einschränkung der Entscheidungsfreiheit der Bank vorliegt.

108 Entgegen der Ansicht von Hahn, Oswald (1968) Bd. II: a.a.O., S. 11. 


\section{Entwicklung eines Bewertungsschemas zur Beurteilung der Unabhängigkeit von Notenbanken}

\subsection{Anforderungen und Vorgehensweise}

Es gibt wenig Literatur, die über eine bloße Aufzählung der Unabhängigkeitskriterien hinausgeht und sich um die theoretische Klärung der Beziehungen zwischen Notenbank und ihren Einflußträgern bemüht. Der Grund liegt nicht etwa darin, da $B$ das Problem im wesentlichen gelöst wäre ${ }^{109}$, sondern da $\beta$ diese $\mathrm{Be}$ ziehungen theoretisch äußerst schwer zu fassen sind 110 . Erschwerend tritt hinzu, da $B$ Unabhängigkeit nicht exakt meßbar ist. In der Regel hält man allenfalls die Richtung ihres Ausmaßes für bestimmbar ${ }^{111}$.

Die Aufgabe des zu entwickelnden Bewertungsschemas liegt darin, alle Einflußfaktoren, die die Unabhängigkeit einer Notenbank beeinflussen, zu identifizieren, sie entsprechend ihrem relativen Gewicht zu berücksichtigen, um dann zu einem objektiven Gesamturteil über den Unabhängigkeitsgrad eines Noteninstituts zu gelangen. Dies setzt zunächst die Operationalität der Kriterien voraus. Zudem muß der Möglichkeit von Zusammenhängen zwischen einzelnen Kriterien Rechnung getragen werden. Verschiedene Einflußfaktoren können sich gegebenenfalls gegenseitig wirkungslos machen. So sind beispielsweise die personellen Regelungen einer Zentralbank relativ bedeutungslos, wenn die Regierung in großem Umfang weisungsberechtigt ist ${ }^{112}$. Umgekehrt könnte eine funktionelle Unabhängigkeit durch personelle Abhängigkeiten unterlaufen werden ${ }^{113}$.

Ausgangspunkt der Untersuchung bildet die Unterteilung der Unabhängigkeit in die vier Bereiche der institutionellen, vermögensrechtlichen, personellen und funktionellen Unabhängigkeit. Jeder dieser Bereiche wird durch eine Reihe von Einflußkriterien bestimmt. Bei der Identifizierung dieser Kriterien werden vorzugsweise die in der einschlägigen Literatur verwendeten Kriterien aufgegriffen und auf ihren tatsächlichen Einfluß auf den Unabhängigkeitgrad einer Notenbank untersucht. Die so ermittelten, die Unabhängigkeit einer Notenbank bestimmenden Kriterien werden anschließend zu einem Bewertungsschema zusammengefaßt.

109 Vgl. Braun, Karlpeter: a.a.O., S. 54.

110 Vgl. Veit, Otto (1961), a.a.O., S. 182.

111 Vgl. Kaiser, Rolf, H.: a.a.O., S. 1.

112 Vgl. Caesar, Rolf (1981): a.a.O., S. 60.

113 Vgl. Clifford, Jerome A.: The Independence of the Federal Reserve System, Pennsylvania 1968, S. 52. 


\subsection{Institutionelle Unabhängigkeit}

In der Regel wird die institutionelle Unabhängigkeit als unbedeutend angesehen und daher nicht näher untersucht ${ }^{114}$. Dem ist schon deshalb nicht ohne weiteres zuzustimmen, weil die institutionellen Regelungen die grundlegende Beziehung der Notenbank zu Staat und anderen Einflußträgern festlegt. Ersten Aufschluß darüber gibt die Rechtsform der Zentralbank. Daneben ist von Interesse, in welcher Form die Regelungen, die die Un- bzw. Abhängigkeit einer Notenbank festschreiben, gesetzlich verankert sind. Schließlich könnte auch die Organisationsform der Zentralbank für deren Autonomie von Bedeutung sein.

\subsubsection{Rechtsform}

Aufgrund der bloßen Beschreibung der Rechtsform sind die sich daraus ergebenden Folgen für die Zentralbankpolitik nicht ersichtlich ${ }^{15}$. Entscheidend ist, ob aufgrund der Rechtsform staatliche oder nicht-staatliche Stellen befugt sind, auf personal- oder geldpolitische Entscheidungen der Notenbank Einfluß zu nehmen. Nicht-staatliche Stellen dürften im wesentlichen in ihrer Funktion als mögliche Anteilseigner über Einflußrechte verfügen. Dieser Punkt wird im folgenden Abschnitt ausführlicher behandelt. Von größerer Bedeutung sind hier Art und Umfang staatlicher Aufsicht ${ }^{116}$. Es muß geklärt werden, inwieweit durch Kontrollund Aufsichtsrechte direkt Einfluß auf die Zentralbankpolitik (z. B. über nationale Rechnungshöfe) ausgeübt werden kann. Für die Unabhängigkeit der Notenbank spielt also letztlich keine Rolle, ob eine privatrechtliche oder öffentlich-rechtliche Konstruktion vorliegt. Entscheidend ist die Frage, ob sich daraus konkrete Einflußrechte externer Instanzen ergeben, die die Entscheidungsfreiheit der Bank, das geldpolitische Instrumentarium nach ihrem Ermessen einzusetzen, beeinträchtigen.

\subsection{2 Änderung der Normen}

Alle Normen, die die Unabhängigkeit einer Zentralbank gewährleisten, lassen sich ändern ${ }^{117}$. Besteht die Möglichkeit, durch Gesetzesänderungen juristische Restriktionen für das geldpolitische Handeln der Notenbank zu setzen oder aufzuheben, verfügt der Gesetzgeber damit über ein Druckmittel, das die Notenbank

114 Vgl. Spindler, Joachim v.; Becker, Willy; Starke, O.-Ernst (1973): a.a.O., S. 265f; Veit, Otto (1961), a.a.O., S. 27, Caesar, Rolf (1981): a.a.O., S. 125; anderer Ansicht ist: 0. V.: Festina Lente!, in: Zeitschrift für das gesamte Kreditwesen 19/1956, S. 724f.

Vgl. Kaiser, Rolf H.: a.a.O., S. 21.

Vgl. Kaiser, Rolf H.: a.a.O., S. 21.

Vgl. Hahn, Oswald (1968) Bd. II: a.a.O., S. 85. 
zu erhöhter Rücksichtnahme auf deren geldpolitische Vorstellungen veranlassen könnte118. Die Notenbank wird sich möglicherweise kompromißbereiter bzw. konfliktvermeidender verhalten. Dazu ist eine explizite Drohung der Regierung gar nicht unbedingt erforderlich. Die bloße Möglichkeit mag ausreichend sein, die Bank dazu zu bewegen, eine andere Geldpolitik zu betreiben, als mit ihren Vorstellungen vereinbar wäre ${ }^{119}$. Dies gilt um so mehr, je leichter die Unabhängigkeit der Zentralbank abgeschafft werden kann. In vielen Ländern ist dies durch eine einfache Mehrheit im Parlament möglich, sodaß eine Regierung mit einer nur knappen Mehrheit in der Lage wäre, die Statuten radikal zu ändern ${ }^{120}$. In autoritär regierten Staaten bzw. Diktaturen dürfte eine Änderung der Normen noch problemloser möglich sein. Dagegen ist Gefahr einer Änderung des Status der Zentralbank verhältnismäßig gering, wenn dieser entweder in der Landesverfassung verankert ist oder beide Statuten (Verfassung und Notenbankgesetzgebung) einen vergleichbaren Rang genießen ${ }^{121}$. In diesem Fall wird eine Gesetzesänderung einmal durch die erforderliche größere Mehrheit, zum anderen durch die Tatsache erschwert, daß "Vorschläge, Verfassungsbestimmungen zu ändern, eine von jedermann bemerkte, sehr ernst zu nehmende Angelegenheit sind"122. Die öffentliche Meinung bietet einen gewissen Schutz vor Pressionen seitens des Gesetzgebers ${ }^{123}$, sofern sie sich mit derjenigen der Notenbank deckt. So dürfte beispielsweise in Deutschland eine Änderung der gesetzlich garantierten Unabhängigkeit der Bundesbank, die eine glaubwürdige Autorität genießt ${ }^{124}$, nur schwerlich durchsetzbar sein, da sich die "Vorteile einer weisungsungebundenen Notenbank so stark in das öffentliche Bewußtsein eingeprägt haben"125.

Die Geschichte zeigt, daß die Gefahr von Gesetzesänderungen zu Lasten der Unabhängigkeit nicht ganz unbegründet ist ${ }^{126}$. Eine Regierung, die zu inflationärer Finanzierung von Staatsausgaben bereit ist, wird die juristische Unabhängigkeit

118 Vgl. Caesar, Rolf (1981): a.a.O., S. 139.

119 Vgl. Neumann, Manfred J. M.: Precommitment by Central Bank Independence, in: Open economies review 2/1991, S. 105.

120 Vgl. Neumann, Manfred J. M.: a.a.O., S. 105.

121 Vgl. Neumann, Manfred J. M.: a.a.O., S. 105.

122 Möller, Alex: Bundesbank - Hüterin der Währung, in: Versicherungswirtschaft 18/1956, S. 480.

123 Vgl. Hahn, Oswald (1968) Bd. II: a.a.O., S. 85.

124 Vgl. Christians, F. W.: a.a.O., S. 4.

125 Kloten, Norbert: Die Verantwortung des Zentralbankensystems für die deutsche Wirtschaft, in: Bankinformation 11/76, S. 8.

1261937 wurde beispielsweise die Autonomie der Deutschen Reichsbank formell aufgehoben, Vgl. Deutsche Bundesbank (Hrsg.): Sonderdruck der Deutschen Bundesbank Nr.7: Die Deutsche Bundesbank, 1987, S. 3 
der Zentralbank gewöhnlich nicht als nachhaltiges Hindernis betrachten ${ }^{127}$. Dies gilt v. a. im Falle ernsthafter Konflikte oder Kriege ${ }^{128}$. Dann nämlich herrscht bei den Parlamenten eine große Bereitschaft zur Verabschiedung von Ausnahmegesetzen, gepaart mit ihrer physischen Überforderung aufgrund einer Flut von zu bearbeitenden Regelungen und Gesetzen ${ }^{129}$. Aber auch in Friedenszeiten ist die Gefahr nicht gänzlich von der Hand zu weisen. Sowohl in Europa als auch in Amerika mehren sich die Stimmen, die eine stärkere Anbindung der Notenbanken an die Regierung fordern ${ }^{130}$. Das mag zum einen an den Erfolgen liegen, die die Notenbanken in den letzten Jahren bei der Inflationsbekämpfung vorweisen konnten und die den Regierenden den Anreiz gibt, Geldpolitik für andere Zwekke, etwa zur Bekämpfung der Arbeitslosigkeit oder zur Stimulierung des Wirtschaftswachstums einzusetzen ${ }^{131}$. Zusätzliches Konfliktpotential zwischen Notenbank und Regierung entsteht durch die zunehmende wirtschaftliche $\mathrm{Zu}$ sammenarbeit der Industrieländer, bei der immer öfter auch die Geldpolitik zum Verhandlungsgegenstand wird 132 . So ist etwa die Diskussion um die Unabhängigkeit der Deutschen Bundesbank an der Bildung des deutsch-französischen Wirtschaftsrates, der die Wirtschaftspolitik beider Länder aufeinander abstimmen soll, neu entflammt ${ }^{133}$.

Es stellt sich nun die Frage, welchen Einfluß die Möglichkeit einer Änderung der Statuten auf den Unabhängigkeitsgrad einer Zentralbank hat? Oben wurde bereits darauf hingewiesen, daß eine vom Staat errichtete Notenbank vom Gesetzgeber vollkommen abhängig ist, weil dieser die Normen für das Währungsinstitut festlegt. Lampe ${ }^{134}$ bezeichnet daher eine Notenbank dann als unabhängig vom Gesetzgeber, wenn das Parlament das Notenbankgesetz nach dessen Erlaß nicht mehr ändern und damit Einfluß auf die Währungspolitik der Bank nehmen kann. Ist die Unabhängigkeit der Bank aber tatsächlich eingeschränkt, wenn die Möglichkeit einer Normenänderung besteht? Selbst, wenn die Regierung in diesem Fall Druck auf die Notenbank ausübt, läßt sich nicht nachweisen, daß die Notenbank ohne diesen Druck eine andere Politik betreiben würde. Die Bank ist zudem nicht gezwungen, entgegen ihren Überzeugungen zu handeln. Sie kann frei über ihre Politik entscheiden, zumindest solange, wie ihre Statuten unverändert blei-

127 Vgl. Schmölders, Günter (1968): a.a.O., S. 346; Andreae, W.: Geld- und Geldschöpfung, Stuttgart/Wien 1953, S. 435.

128 Vgl. Kamitz, Reinhard: Goldwährung und Finanzpolitik, in: Zeitschrift für das gesamte Kreditwesen 1/1955, S. 17.

129 Vgl. Hahn, Oswald (1968) Bd. II: a.a.O., S. 85.

130 Vgl. Lusser, Markus (1988): a.a.O., S. 3.

131 Vgl. Lusser, Markus (1988): a.a.O., S. 3.

132 Vgl. Lusser, Markus (1988): a.a.O., S. 3.

133 Vgl. Lusser, Markus (1988): a.a.O., S. 3.

134 Vgl. Lampe, Ortrun: a.a.O., S. 21. 
ben. Insofern ist ihre Unabhängigkeit nicht eingeschränkt. Kommt es tatsächlich zu einer Reform der Gesetzgebung, muß der Unabhängigkeitsuntersuchung die neue Gesetzgebung zugrunde gelegt werden.

\subsubsection{Aufbau der Notenbank}

Ein mehrstufiger Aufbau der Zentralbank, wie ihn beispielsweise die Bank Deutscher Länder hatte, wird zuweilen als Garant für größere Unabhängigkeit betrachtet ${ }^{135}$. Ein Verzicht auf eine "einheitliche Leitung fernab von der Frontlinie der Wirtschaftsorgane“136 mag die Gefahr einseitiger Einflüsse auf die Notenbankpolitik mindern. Doch gerade im Fall der Bank Deutscher Länder ist anzumerken, da $B$ die Steuerung des Zentralbanksystems tatsächlich viel einheitlicher und zentraler von statten ging, als die Organisationsform erwarten lie ${ }^{137}$. Juristisch gesehen war das System rein föderalistisch aufgebaut; doch die formal selbständigen Landeszentralbanken waren geschäftlich nie wirklich selbständig138. Keine von ihnen wäre für sich alleine lebensfähig gewesen.

$\mathrm{Ob}$ das Währungsinstitut nun ein- oder mehrstufig aufgebaut ist, hat als solches keinerlei Auswirkungen auf die Entscheidungsfreiheit der Notenbank und ist für die Unabhängigkeit des Instituts somit irrelevant. Dezentralisierung mag zwar eine bessere Informationsgrundlage für geldpolitische Entscheidungen schaffen aufgrund der Marktnähe. Dies wirkt sich aber allenfalls auf die Qualität der Geldpolitik aus. Zum anderen ist eine Gefahr einseitiger Einflüsse für die Unabhängigkeit einer Zentralbank unbedeutend, sofern diese einseitigen Einflüsse in der Bank selber liegen und nicht von außen (z. B. durch Weisungs- oder Vetorechte notenbankfremder Instanzen) induziert sind. Im letzteren Fall würde die Einschränkung der Unabhängigkeit nicht durch den Aufbau der Bank, sondern durch die Einflußrechte anderer Instanzen verursacht.

\subsubsection{Zusammenfassung}

Kontroll-, Aufsichts- und sonstige Rechte, die bankfremden Instanzen aufgrund der Rechtsform der Bank enstehen, haben nur dann einen Einfluß auf die Unabhänggkeit einer Zentralbank, wenn dadurch ein direkter Eingriff in die geld- oder personalpolitischen Entscheidungen der Bank möglich ist. Daher läßt sich dieser Bereich der institutionellen Unabhängigkeit in die Ausführungen zu der personellen bzw. funktionellen Unabhängigkeit einordnen. Die Art und Weise, wie die Regelungen, die die Un- bzw. Abhängigkeit einer Notenbank festschreiben, ge-

135 Vgl. o. V.: Bundesbank ohne Illusionen: a.a.O., S. 551.

136 Walther Wolfslast: in: o. V.: Bundesbank ohne Illusionen: a.a.O., S. 551

137 Vgl. Könneker, Wilhelm (1957): a.a.O., S. 796.

138 Vgl. Könneker, Wilhelm (1957): a.a.O., S. 796. 
setzlich verankert sind, ist für die Unabhängigkeit eines Noteninstituts ebensowenig von Bedeutung wie die organisatorischen Strukturen der Bank.

\subsection{Vermögensrechtliche Unabhängigkeit}

\subsubsection{Eigentumsverhältnisse}

Viele Autoren halten die Eigentumsfrage für die Unabhängigkeit einer Notenbank für unbedeutend ${ }^{139}$. Swinburn und Castello-Branco ${ }^{140}$ verweisen dabei auf die Deutsche Bundesbank, die - vollständig im Staatsbesitz - als eine der unabhängigsten Notenbanken überhaupt gilt. Andere sprechen sich dagegen explizit gegen Privateigentum von Notenbanken aus ${ }^{141}$. Schließlich findet sich auch die Auffassung, daß sich das Grundkapital einer unabhängigen Notenbank nicht restlos in staatlicher Hand befinden darf ${ }^{142}$. Es wird argumentiert, private Eigentümer hätten ein Interesse an guter kaufmännischer Leitung und wären selbständiger gegenüber der Finanzverwaltung, während Staatsbanken leicht in die Abhängigkeit parlamentarischer Majoritäten geraten könnten ${ }^{143}$. Dagegen wird gegen private Notenbanken angeführt, da $ß$ auch hier der Staat meist großen Einfluß auf die Besetzung der Notenbankleitung hat. Eine Staatsbank könne zudem das Gemeininteresse besser wahren und schließlich dürfe der Gewinn aus der Notenausgabe nicht dem privaten Kapital zufallen ${ }^{144}$.

Wie anfangs festgestellt, darf sich die Unabhängigkeitsfrage nicht auf die Unabhängigkeit vom Staat beschränken, sondern sie umfaßt die Unabhängigkeit von allen notenbankfremden Instanzen. Insofern ist es für den Einfluß auf die Unabhängigkeit gleichbedeutend, ob sich die Bank in staatlichem oder privatem Besitz befindet. Entscheidend sind vielmehr die aus dem Eigentum entstehenden Rechte. Die Unabhängigkeit der Notenbank ist insofern eingeschränkt, als Anteilseigner

139 So z.B. Beck, Heinz: a.a.O, S. 119; Tamagna, Frank M.: Processes and instruments of monetary policy: A comparative analysis, in: Monetary Management, A series of research studies prepared for the Commission on Monetary credit, Englewood Cliffs, N. J., 1963, S. 7ff; Spindler, Joachim v.; Becker, Willy; Starke, O.-Ernst (1973): a.a.O., S. 265f; Veit, Otto (1961), a.a.O., S. 27f; Schuster, Leo (1967): a.a.O., S. 22; de Kock, M. H.: Central Banking, 4. Ed. London 1974, S. 307ff; Caesar, Rolf(1981): a.a.O., S. 125f; Kritz, M. A.: Central Banks and the State today, in: AER, Vol. XXXVIII, 1948, S. 580.

Vgl. Swinburne, Mark; Castello-Branco, Marta: a.a.O., S. 31 F.1.

wie z.B. Eynern, Gert v. (1957): a.a.O., S. 32.

Vgl. o. V.: Festina Lente!: a.a.O., S. 724f.

Vgl. Bernauer, Engelbert : a.a.O., S. 51.

Vgl. Bernauer, Engelbert : a.a.O., S. 50. 
befugt sind, auf die Besetzung der Bankleitung oder direkt auf geldpolitische Entscheidungen Einfluß zu nehmen.

\subsubsection{Haushaltsmäßige Selbständigkeit}

Mit haushaltsmäßiger Selbständigkeit bzw. budgetärer Unabhängigkeit bezeichnet man die Möglichkeit einer Notenbank, ihre eigenen Ausgabenbudgets festsetzen und diese auch finanzieren zu können, d.h. finanziell von der Regierung und anderen Institutionen unabhängig zu sein. In der Regel existieren Vorschriften über die Art der Gewinnverwendung; in einigen Fällen wird darüber mit der Regierung verhandelt ${ }^{145}$. Darf die Notenbank ihre Gewinne dazu verwenden, ihre Ausgaben zu decken, ist sie budgetär unabhängig. Das gleiche wäre der Fall, wenn sie ihr gewünschtes Budget vom Staat oder anderen Institutionen erhielte. Ist sie dagegen darauf angewiesen, da $\beta$ ihr Budget von staatlichen oder nichtstaatlichen Stellen bewilligt wird, ist sie diesbezüglich abhängig.

Nun stellt sich die Frage, ob sich eine eingeschränkte haushaltsmäßige Selbständigkeit negativ auf die Unabhängigkeit einer Notenbank auswirkt. Dies wäre dann der Fall, wenn das Noteninstitut dadurch in ihren geldpolitischen Entscheidungen behindert ist. Theoretisch könnte eine budgetbewilligende Instanz auf eine Notenbank indirekt Einfluß ausüben, indem sie ihren Zugang zu Finanzmitteln beschränkt ${ }^{146}$. Dies hat aber für die geldpolitischen Entscheidungen keinerlei direkte Bedeutung 147 .

Bei eventuellen Gewinnansprüchen von Anteilseignern stellt sich die Situation etwas anders dar. Verfügen Eigentümer über Einflußrechte (z. B. Weisungsrechte), die die Bank gegen ihren Willen zu einer gewinnmaximierenden Politik zwingen könnten, bedeutet dies eine Einschränkung der Unabhängigkeit, die jedoch nicht in den Gewinnansprüchen der Anteilseigner selber begründet ist. Aber auch die Art der Gewinnverwendung selbst kann einen Einfluß auf die Unabhängigkeit haben, nämlich dann, wenn die Notenbank nicht selbst über Art und Umfang ihrer Gewinnverwendung entscheiden kann und man berücksichtigt, daß eine Gewinnausschüttung eine Ausgabe von Zentralbankgeld durch die Notenbank ist. Dieser Punkt wird bei der Bewertung der funktionellen Unabhängigkeit noch einmal aufgegriffen.

145 Vgl. Swinburne, Mark; Castello-Branco, Marta: a.a.O., S. 35.

146 Vgl. Swinburne, Mark; Castello-Branco, Marta: a.a.O., S. 35f; Castello-Branco, Marta; Swinburne, Mark: a.a.O., S. 21.

147 Es gibt aber auch die Auffassung, Budgetbewilligungsverfahren seien durch Kürzungen oder Streichungen einzelner Etatposten durchaus geeignet, die Maßnahmen einer Notenbank in eine bestimmte Richtung zu leiten, z.B. Englert, Michael: a.a.O., S. 123. 


\subsubsection{Zusammenfassung}

Die Eigentumsverhältnisse einer Notenbank sind als solche für die Unabhängigkeit der Bank unbedeutend. Eine Auswirkung auf den Unabhängigkeitsgrad liegt nur dann vor, wenn bankfremde Instanzen aufgrund ihres Eigentums befugt sind, auf die Besetzung der Bankleitung oder direkt auf die geldpolitischen Entscheidungen Einfluß zu nehmen. In diesem Fall müssen diese Rechte bei der Beurteilung der personellen und funktionellen Unabhängigkeit berücksichtigt werden. Haushaltsmäßige Selbstständigkeit ist ebenfalls kein Kriterium für Unabhängigkeit, da sie die geldpolitischen Entscheidungen nicht direkt beeinflußt.

Sowohl die institutionellen als auch die vermögensrechtlichen Regelungen können auf die personelle und die funktionelle Unabhängigkeit einer Notenbank zurückgeführt werden. Daher müssen sie in dem zu entwickelnden Bewertungsschema nicht gesondert Berücksichtigung finden.

\subsection{Personelle Unabhängigkeit}

Die personelle Besetzung der Notenbankorgane wirkt sich nur indirekt auf die geldpolitischen Entscheidungen eines Währungsinstituts aus. Daher ist bei der Beurteilung der personellen Unabhängigkeit die zuvor festgelegte Unabhängigkeitdefinition nicht anwendbar. Die zentrale Frage für die Beurteilung der personellen Unabhängigkeit einer Notenbank ist vielmehr, wieviel Entscheidungsfreiheit die Notenbank bei der personellen Besetzung ihrer Organe hat.

Im folgenden werden Faktoren, die in der Literatur als Kriterien für die personelle Autonomie einer Notenbank gelten, aufgegriffen und auf ihre Auswirkungen auf die personelle Unabhängigkeit untersucht.

\subsubsection{Art und Zusammensetzung der Gremien}

Zunächst muß geklärt werden, welche Organe einer Notenbank in die Unabhängigkeitsuntersuchung einbezogen werden sollen. Da sich die hier verwendete Unabhängigkeitsdefinition auf die Freiheit bei geldpolitischen Entscheidungen bezieht, ist es sinnvoll, die Untersuchung auf die für die geldpolitischen Entscheidungen zuständigen Gremien zu beschränken, also die Leitungsgremien der Bank. Notenbankleitungen bestehen gewöhnlich aus zwei bis drei Gremien ${ }^{148}$. Eines ist üblicherweise aufsichtführend, eines entscheidungstreffend (Exekutive). Existiert ein drittes Gremium, ist dies häufig eine Art Subkommittee zum Aufsichtsgremi-

148 Vgl. Swinburne, Mark; Castello-Branco, Marta: a.a.O., S. 30. 
um $^{149}$. Die Art und Zusammensetzung der Notenbankorgane spielt eine Rolle bei der Gewichtung des Einflusses von Ernennungsinstanzen auf die personelle Unabhängigkeit. Je stärker das Gewicht eines Gremiums bei der Entscheidungsfindung einer Notenbank ist, desto größer ist auch der Einfluß der jeweiligen Ernennungsinstanz. Schwieriger ist die Frage der Einbeziehung von Organen, die nur indirekt an der Entscheidungsfindung der Bank beteiligt sind, wie z. B. Beratungsgremien. In einigen Notenbanken gibt es solche institutionalisierten Interessenvertretungen aus Politik und Wirtschaft, die im wesentlichen beratende Funktionen ausüben. Diese Gremien können entweder ehrenamtlich oder hauptamtlich agieren und unterscheiden sich in ihrer Zusammensetzung sowie der Art ihrer Bestellung. Eine Trennung zwischen neutralen Sachverständigen und Interessenvertretern dürfte hier nur schwer möglich sein. Es ist davon auszugehen, daß sie tendenziell im Interesse derer handeln, die sie delegiert haben, wenn sie nicht sogar offiziell damit beauftragt sind. Dennoch bieten solche Beratungsgremien ein "institutionalisiertes Gegengewicht zu unkontrollierbaren Einflußnahmen"150. Auch wenn diese Beiräte gewöhnlich kein Stimmrecht bei geldpolitischen Entscheidungen haben, verfügen sie mitunter über großen Einfluß auf die Geldpolitik ${ }^{151}$. Hahn ${ }^{152}$ vertritt sogar die Auffassung, daß dieser Einfluß je nach Art der rechtlichen Ausgestaltung und Stärke der Interessenvertreter im Extremfall einer Weisungsgebundenheit der Notenbank nahekommen kann.

Wie beeinflußt die Existenz solcher Beratungsgremien die Unabhängigkeit einer Notenbank? Muß die Bank Forderungen oder Wünsche der Beiräte lediglich zur Kenntnis nehmen, kann von einer Einschränkung der Unabhängigkeit keine Rede sein. Ein Einfluß liegt nur dann vor, wenn die Notenbankleitung in ihrer Entscheidungsfreiheit eingeschränkt werden kann, beispielsweise durch Veto-, Stimmoder Weisungsrechte seitens der Beratungsgremien. Ist das der Fall, ist von Bedeutung, welche Instanz für die Bestellung der Beiratsmitglieder zuständig ist. Kann die Notenbankleitung ihre Beratungsgremien selber zusammenstellen, liegt auch dann keine Einschränkung der Unabhängigkeit vor.

\subsubsection{Ernennungsinstanzen}

In der Regel beschränkt sich die Literatur bei der Untersuchung der Ernennungsinstanzen auf die Ernennungsfunktionen staatlicher Stellen ${ }^{153}$. Auch wenn Regierungen in der Praxis meist eine wesentliche Rolle bei der personellen Besetzung der Notenbankorgane spielen, dürfen Ernennungen von Notenbankmitgliedern

149 Wie z.B. in der Schweiz; Vgl. Swinburne, Mark; Castello-Branco, Marta: a.a.O., S. 30.

150 Kaiser, Rolf, H.: a.a.O., S. 49.

151 Vgl. Hahn, Oswald: Die Währungsbanken der Welt, Bd. I; Stuttgart 1968, S. 168.

152 Vgl. Hahn, Oswald (1968) Bd. II: a.a.O., S. 43.

153 Vgl. Goodman, John B.: a.a.O., S. 332. 
durch Wirtschaftsgruppen, Gewerkschaften etc. nicht außer acht gelassen werden. Prinzipiell könnte man sagen, daß die Ernennung von Notenbankmitgliedern durch jegliche bankfremde Instanz die personelle Unabhängigkeit einer Zentralbank einschränkt. Dabei ist zu unterscheiden, ob die Notenbankleitung ausschließlich von einer Instanz ernannt wird oder ob verschiedene Instanzen daran mitwirken. Letzteres ist mit dem Ausdruck Pluralismus der Ernennungsinstanzen in die Literatur eingegangen ${ }^{154}$. Hier gibt es wiederum zwei Formen. Die eine versteht unter Pluralismus das Zusammenwirken einer vorschlagenden, anhörenden und ernennenden Instanz. Bei der anderen sind verschiedene Institutionen oder Personen für die Ernennung jeweils eines Teils der Notenbankleitung zuständig. Einige Autoren vertreten die Ansicht, ein Pluralismus der Ernennungsinstanzen trage zur personellen Unabhängigkeit einer Notenbank bei155. Im Falle einer vorschlagenden, anhörenden und ernennenden Instanz wird das damit begründet, daß keine dieser Instanzen einen überragenden Einfluß auf die Ernennung von Notenbankmitgliedern hat ${ }^{156}$. Es heißt, das Unabhängigkeitspostulat sei dann erfüllt, wenn jede Instanz dabei ihre "eigenen, verfassungsrechtlich garantierten Interessen"157 verfolgt, ohne daß eine der anderen weisungsbefugt ist. Doch ist nicht anzunehmen, daß die drei Instanzen auch nur annähernd über die gleichen Einflußmöglichkeiten auf die personelle Besetzung verfügen. Der Einfluß eines Anhörungsrechts dürfte verhältnismäßig gering sein, da es sich um eine rein beratende Funktion handelt. Auch, wenn die ernennende bzw. vorschlagende Instanz dazu verpflichtet wäre, die Meinung der anhörenden zur Kenntnis zu nehmen, braucht sie diese in ihrer Entscheidung nicht zu berücksichtigen. Im Extremfall ist sie völlig bedeutungslos. Der Einfluß von ernennender und vorschlagender Instanz hängt von der rechtlichen Ausgestaltung im Einzelfall ab. Es ist jedoch davon auszugehen, daß die vorschlagende Instanz die wesentliche Funktion bei der Besetzung der Notenbankspitze innehat. Sie kann ihre Vorschläge auf

154 Vgl. Lampe, Ortrun: a.a.O., S. 26; Scharnbergbericht: a.a.O., S. 5; Samm, Theodor: a.a.O., S. 51f; Uhlenbruck, Dirk (1967 a): a.a.O., S. 84; Kloten, Norbert: a.a.O., S. 8.; Schmidt, Reiner: Grundlagen und Grenzen der Unabhängigkeit der Deutschen Bundesbank, in: Caemmerer, E. von u.a. (Hrsg.): Xenion, Festschrift für Pan. J. Zepos,. II. Bd., Athen, Freiburg/Br., Köln, Katrikalis 1973, S.665.

155 Vgl. Eckert, Lucia: Verfassungsrecht und Autonomie der Deutschen Bundesbank, in: Bank-Archiv Bd. 38, 6/1990, S. 419; Scharnbergbericht: a.a.O., S. 5; Samm, Theodor: a.a.O., S. 51f; Uhlenbruck, Dirk (1967 a): a.a.O., S. 84; Kloten, Norbert: a.a.O., S. 8; Wilbert, Rudolf: Ein Vorschlag zum Bundesbankgesetz, in: Zeitschrift für das gesamte Kreditwesen 5/1955, S. 146; Geisler, Rudolf Paul: Notenbankverfassung und Notenbankentwicklung in USA und Westdeutschland. Eine vergleichende Untersuchung über das Problem der Zentralisation und Dezentralisation und des Verhältnisses von Staat und Notenbank, Volkswirtschaftliche Schriften Heft 9, Berlin 1953, S. 159; Koester, HansGeorg von: Das Gesetz über die Deutsche Bundesbank, in: Sparkasse 18/1957, S. 281. Vgl. Lampe, Ortrun: a.a.O., S. 26.

157 Lampe, Ortrun: a.a.O., S. 26. 
solche Personen beschränken, von denen eine Unterstützung ihrer eigenen Politik zu erwarten ist ${ }^{158}$. Die Ernennungsinstanz kann (je nach Regelung) allenfalls die Ernennung der vorgeschlagenen Person verweigern, wenn nicht gar ein Vorschlag zwangsläufig die Ernennung einer Person nach sich zieht. Im letzteren Fall wäre die Ernennung eine reine Formsache und die ernennende Instanz ohne Einfluß. Daraus läßt sich schließen, daß ein Pluralismus von vorschlagender, beratender und ernennender Instanz kein ausreichendes Mittel zur Abschwächung einseitiger externer Einflüsse ist ${ }^{159}$. Die Aufteilung der Ernennungsrechte auf verschiedene Instanzen scheint hingegen eher geeignet, eine einseitige Besetzung der Leitungsorgane zu verhindern. Hier kommt es quasi zu einer Neutralisierung der verschiedenen politischen Interessen 160 . Wie wirkt sich das nun auf die Unabhängigkeit einer Notenbank aus? Ist die Unabhängigkeit weniger beeinträchtigt, wenn verschiedene Instanzen an der Besetzung der Leitungsorgane mitwirken, sei es nun durch Zusammenwirken von vorschlagender, beratender und ernennender Instanz oder durch eine Aufteilung der Ernennungsbefugnisse für die einzelnen Leitungsgremien auf mehrere Instanzen? Je vielschichtiger die Zusammensetzung der beteiligten Ernennungsinstanzen sind, desto geringer ist die Gefahr einer einseitigen Beeinflussung durch einen Aktor ${ }^{161}$. Ausschlaggebend für die Unabhängigkeit einer Notenbank ist jedoch nicht die Dominanz eines oder mehrerer externe Aktoren, sondern das Ausmaß, in dem bankfremde Instanzen die Besetzung der Leitungsgremien beeinflussen können. Jede Ernennung, die nicht durch die Notenbank selber erfolgt, schränkt diese in ihrer Entscheidungsfreiheit ein. Unabhängigkeit bezüglich des Kriteriums der Ernennungsinstanzen besteht daher nur, wenn die Organe der Notenbank selbstständig über die personelle Besetzung ihrer Leitungsgremien entscheiden können.

\subsubsection{Kreis der Ernennungsfähigen}

Hier geht es um Vorschriften über den Personenkreis, der für eine Ernennung in die Notenbankleitung grundsätzlich in Frage kommt. Diese Vorschriften können beispielsweise eine bestimmte fachliche Eignung verlangen, die Ernennung von Angehörigen bestimmter Berufsgruppen ausschließen bzw. fordern sowie für eine regional oder sektoral ausgewogene Zusammensetzung der Gremien sorgen.

158 Vgl. Lampe, Ortrun: a.a.O., S. 26.

159 im Gegensatz zu Caesar, Rolf (1981): a.a.O., S. 127; Scharnbergbericht: a.a.O., S. 5; Schmidt, Reiner: a.a.O., S.665.

160 Vgl. Braun, Karlpeter: a.a.O., S. 111; Geisler, Rudolf Paul: a.a.O., S. 159; Schmidt, Willi: Das Bundesnotenbankgesetz, in: Zeitschrift für das gesamte Kreditwesen 18/1956, S. 698.

161 Vgl. Caesar, Rolf(1981): a.a.O., S. 127. 


\subsubsection{Fachliche Eignung}

Die Voraussetzung einer bestimmten fachlichen Eignung von Mitgliedern einer Notenbank soll die Ernennung von Personen verhindern, "denen mangels genügender Kenntnisse ein hinreichender Überblick über das Fachgebiet abgeht"162. Neumann begründet die Notwendigkeit dieser Bedingung für die Unabhängigkeit der Bank damit, daß ein Mangel an eigener Urteilsfähigkeit ein Notenbankmitglied von dem Urteil anderer Personen oder Instanzen abhängig machen könnte ${ }^{163}$. Andererseits trifft die Notenbankleitung auch in solchen Fällen ihre geldpolitischen Entscheidungen letztlich selbständig. Sie ist nicht gezwungen, Empfehlungen oder Forderungen bankfremder Instanzen in ihren Entscheidungen zu berücksichtigen. Insofern trägt die Voraussetzung einer fachlichen Eignung der Führungspersönlichkeiten nicht zu einer stärkeren Unabhängigkeit der Bank bei. Die Forderung nach fachlicher Eignung der Notenbankleitung soll zudem zur Relativierung des Machtpotentials der Vorschlagsinstanzen beitragen ${ }^{164}$. Die Gefahr sinkt, daß externe Ernennungsinstanzen politisch genehme, aber fachlich unqualifizierte Personen in Notenbankpositionen erheben ${ }^{165}$. Dieses Argument ist durchaus einleuchtend, hat aber nichts mit Unabhängigkeit im hier verstandenen Sinne zu tun. Für die personelle Unabhängigkeit ausschlaggebend ist ausschließlich der Umfang, in dem die Bank personalpolitische Entscheidungen frei treffen kann. Dieser wird z. B. dadurch beeinflußt, daß die Auswahl der Kandidaten für neu zu besetzende Notenbankämter nur aus einem begrenzten Personenkreis getroffen werden kann. Das bedeutet eine geminderte personelle Unabhängigkeit der Notenbank, wenn sie, kann sie ihre Mitglieder selbst rekrutieren, die Auswahl nur aus einem festgelegten Kreis treffen kann. Die Unabhängigkeit ist hier nur dann unberührt, wenn die Notenbank selbst das Anforderungsprofil ihrer Mitarbeiter bestimmen kann. Sind externe Instanzen für die Ernennungen zuständig, sind auch sie durch eine Forderung nach besonderer fachlicher Eignung der Kandidaten in ihrer Entscheidungsfreiheit eingeschränkt. Dadurch erhält die Notenbank aber nur dann mehr Freiraum, wenn sie die Bedingung der fachlichen Eignung gestellt hat. Andernfalls ist diese Vorgabe hier für die personelle Autonomie der Bank bedeutungslos.

162 Spindler, Joachim v.; Becker, Willy; Starke, O.-Ernst (1973): a.a.O., S. 229.

Vgl. Neumann, Manfred J. M.: a.a.O., S. 102.

Vgl. Kaiser, Rolf H.: a.a.O., S. 31.

Vgl. Kloten, Norbert: a.a.O., S. 8. 


\subsubsection{Sektorale und regionale Vertretung}

In einigen Staaten verlangt die Notenbankgesetzgebung eine gewisse sektorale oder regionale Vertretung in den Organen der Bank ${ }^{166}$. Eine in dieser Weise ausgewogene Zusammensetzung der Gremien verhindert einerseits die Dominanz einzelner Gruppierungen. Andererseits besteht die Gefahr, daß regionale Wirtschaftsbelange oder spezifische Interessen der Sektoren zu sehr in den Vordergrund rücken, zu Lasten einer dem Wohl des gesamten Staates dienenden einheitlichen Geldpolitik. Diese Regelungen beeinflussen demnach die Qualität der Geldpolitik. Für den Einfluß solcher Vorgaben auf die personelle Unabhängigkeit der Notenbank gilt dagegen das gleiche wie im Falle der fachlichen Eignung. Die Forderung nach Besetzung der Organe anhand sektoraler oder regionaler Kriterien bewirkt eine Einschränkung des in Frage kommenden Personenkreises und damit eine Einschränkung der Wahlfreiheit der Ernennungsinstanzen. Im Falle von Selbstrekrutierung der Notenbank ist dies mit einer Minderung der personellen Unabhängigkeit verbunden. Bei externen Emennungsinstanzen ist die personelle Autonomie nicht berührt.

\subsubsection{Ausschluß bestimmter Personenkreise}

$\mathrm{Ob}$ ein Mitglied der Notenbankleitung unabhängig von den Wünschen der Regierung handeln wird, hängt in hohem Maße von seinem persönlichen Charakter $\mathrm{ab}$, aber auch von seiner bisherigen Beteiligung an aktueller Politik ${ }^{167}$. Aus diesem Grund tendieren Interessengruppen und Regierungen dazu, in die Leitungsebenen der Notenbanken Personen ihrer eigenen politischen Zugehörigkeit einzubringen ${ }^{168}$, sofern sie die Möglichkeit dazu haben. In vielen Ländern ist daher die Ernennung bestimmter Personenkreise (in der Regel Regierungsmitglieder oder Angehörige bestimmter Berufsgruppen) in Leitungsfunktionen der Notenbank untersagt ${ }^{169}$. Besteht dagegen diese Möglichkeit, ist zu vermuten, daß sich diese Personen bei ihren geldpolitischen Entscheidungen von den Interessen der Gruppierungen, denen sie angehörten oder noch angehören, leiten lassen und insofern nicht unabhängig entscheiden. Dies gilt besonders, wenn sie im Anschluß an die Notenbanktätigkeit eventuell eine weitere Karriere in ihrem früheren Tätigkeitsfeld planen. Doch sollte die Gefahr derartiger Abhängigkeiten nicht überbewertet werden. Es ist nicht vorauszusehen, wie sich die neuernannten Notenbankmitglieder in konkreten Situationen verhalten werden. Möglicherweise sind sie bereit, sich gänzlich den Zielen der Notenbank zu unterwerfen. Public Choice-

\footnotetext{
166 Z. B. in Frankreich, Japan, Großbritannien, Schweiz, USA, Niederlande.

167 Vgl. Neumann, Manfred J. M.: a.a.O., S. 102.

168 Vgl. Neumann, Manfred J. M.: a.a.O., S. 102.

169 Vgl. Aufricht, Hans: Comparative Survey of Central Bank Law, London 1965, S. 103. 
Untersuchungen belegen, daß dies sogar sehr wahrscheinlich ist, sofern ausreichende Anreize (Gehalt, Ansehen der Position) dafür bestehen, sich von allen früheren politischen Bindungen oder Abhängigkeiten zu befreien und die Ziele der Notenbank als berufliches Leitmotiv zu akzeptieren 170 .

Wie wirken sich Vorschriften, Angehörige bestimmter Gruppen nicht zur Ernennung in Leitungsgremien der Notenbank zuzulassen, auf die Unabhängigkeit der Bank aus? Hier ist wieder zu unterscheiden, ob die Notenbank selbst über die Ernennungsrechte verfügt, oder ob bankexterne Instanzen über die Besetzung der Leitungsgremien entscheiden. Kann die Notenbank ihre Mitglieder selbst rekrutieren, schränken derartige Vorschriften ihren Entscheidungsspielraum, Personen ihrer Wahl zu ernennen, ein und damit ihre personelle Unabhängigkeit. Im Falle externer Ernennungsinstanzen gilt das gleiche wie in den obigen beiden Abschnitten. Vorschriften, die die Ernennung von Regierungsmitgliedern oder Mitgliedern bestimmter Interessengruppen verhindern, könnten zu einer erfolgreicheren Geldpolitik im Sinne einer Stabilisierung des Geldwerts beitragen. Eine höhere Unabhängigkeit bescheren sie der Notenbank dagegen nicht.

\subsubsection{Zusammenfassung}

Festzuhalten bleibt, daß jegliche gesetzliche Einschränkung des für Leitungsfunktionen der Notenbank in Frage kommenden Personenkreises die Entscheidungsfreiheit der Ernennungsinstanzen beschränkt. Im Falle der Selbstrekrutierung der Notenbankmitglieder durch die Bank bewirkt dies eine Minderung der personellen Unabhängigkeit, weil sie ihre Personalauswahl nicht frei treffen kann. Es liegt nur dann keine Minderung der personellen Unabhängigkeit vor, wenn die Bank selbst den Anforderungskatalog an potentielle Mitarbeiter festlegen kann. Sind bankexterne Instanzen für die Ernennung zuständig, sind Beschränkungen des Kreises der Ernennungsfähigen für die Unabhängigkeit des Noteninstituts unbedeutend. Die Ernennungsinstanzen sind zwar auch hier in ihrer Entscheidungsfreiheit beschränkt. Damit ist aber kein Zuwachs an Freiheit für die Notenbank verbunden, es sei denn die Bank legt diese Vorgaben fest.

\subsubsection{Besoldung}

Eine hohe Besoldung der Notenbankfunktionäre wird gelegentlich als Kriterium für eine unabhängige Geldpolitik angeführt ${ }^{171}$. Eine angemessene Vergütung ist zunächst Voraussetzung, um hochqualifiziertes Personal gewinnen zu können. Nicht selten ist die Annahme einer leitenden Stellung in der Notenbank für die

170 Vgl. Neumann, Manfred J. M.: a.a.O., S. 103

171 Vgl. Neumann, Manfred J. M.: a.a.O., S. 103, Uhlenbruck, Dirk (1967 a): a.a.O., S. 86f, anderer Auffassung ist Lampe, Ortrun: a.a.O., S. 32. 
Kandidaten mit dem Verzicht auf hochdotierte Stellungen in der freien Wirtschaft verbunden 172. Daraus resultiert zumindest das Risiko einer Abwanderung dieser Persönlichkeiten in die Privatwirtschaft ${ }^{173}$. Die Gefahr, daß Zentralbankfunktionäre die Notenbanktätigkeit nur als eine Art Karrieresprungbrett betrachten, liegt darin, daß sie womöglich bei geldpolitischen Entscheidungen tendenziell auf potentielle Anschlußkarriere-Sektoren Rücksicht nehmen könnten. Schlechte Vergütung erhöht zudem die Gefahr der Zugänglichkeit der Notenbankleitung für Forderungen von Interessengruppen (Bestechlichkeit u.ä.). Gegen eine hohe Besoldung ließe sich allerdings anführen, da $B$ die Ernennungsinstanzen versucht sein könnten, verdiente Personen ihres Einflußbereichs mit der Mitgliedschaft in der Notenbankleitung auszuzeichnen und dabei mehr die großzügige Vergütung als die fachlichen Qualitäten der Kandidaten im Auge zu haben ${ }^{174}$. So wird die Besetzung der Stellen von Landeszentralbankpräsidenten bei der Deutschen Bundesbank häufig als Geschenk an verdiente Parteifunktionäre kritisiert ${ }^{175}$.

Welchen Einfluß hat die Besoldung tatsächlich auf die personelle Unabhängigkeit einer Notenbank? Die Höhe der Vergütungen wirkt sich im wesentlichen auf die Anreizstruktur aus, die Ziele der Notenbank zu verfolgen oder zu vernachlässigen, nicht aber auf die Entscheidungsfreiheit der Notenbankmitglieder. Die Versuchung von Ernennungsinstanzen, verdienten Parteifreunden einen prestigeträchtigen und finanziell lohnenden Posten zu verschaffen, ist zwar nicht von der Hand zu weisen. Eine Einschränkung der Unabhängigkeit liegt dann aber nicht in der Besoldungshöhe, sondern in der Existenz bankfremder Ernennungsinstanzen begründet. $\mathrm{Zu}$ der Gefahr einer möglichen Zugänglichkeit von Notenbankmitgliedern für Forderungen von Interessengruppen aufgrund geringer Besoldung oder der Erwartung einer Anschlußkarriere ist zudem anzumerken, daß sie in gleichem $\mathrm{Maße}$ auch dann vorläge, wenn die Notenbank ihre Mitarbeiter selbst rekrutieren würde. Aber auch hier ist daraus keine Einschränkung der Entscheidungsfreiheit der Notenbankmitglieder abzuleiten und somit auch keine Minderung der personellen Unabhängigkeit.

Dennoch ist die Besoldung nicht bedeutungslos für die personelle Unabhängigkeit. Ist die Vergütung sehr niedrig angesetzt, sind viele potentielle Notenbankmitglieder nicht bereit, ein Amt in der Bankleitung zu übernehmen. Je höher die Besoldung steigt, desto größer wird somit der Kreis der Ernennungsfähigen. Eine

172 Vgl. Hahn, Oswald (1968) Bd. II: a.a.O., S. 44.

173 Vgl. Uhlenbruck, Dirk (1967 a): a.a.O., S. 87; Neumann, Manfred J. M.: a.a.O., S. 103.

174 Vgl. Kaiser, Rolf H.: a.a.O., S. 33; Lampe, Ortrun: a.a.O., S. 32.

175 Vgl. Woll, Artur: Zur Unabhängigkeit der Deutschen Bundesbank - Unzeitgemäße Betrachtungen zu einem aktuellen Problem, in: Nienhaus, Volker; Suntum, Ulrich van (Hrsg.): Grundlagen und Erneuerung der Marktwirtschaft, Baden-Baden 1988, S. 194ff; Kaiser, Rolf H.: a.a.O., S. 33ff; Muthesius, Volkmar: Das wilde Tier, in: Zeitschrift für das gesamte Kreditwesen 16/1976, S. 756. 
Ernennungsinstanz ist also in ihrer Entscheidungsfreiheit eingeschränkt, Persönlichkeiten ihrer Wahl mit einem Amt zu bekleiden, wenn die Gehälter extern - z. B. durch Anbindung an die Beamtentarife - festgesetzt sind und hier um so mehr, je geringer die Besoldungshöhe liegt. Die größtmögliche Entscheidungsfreiheit besteht dann, wenn die Ernennungsinstanz selbst über die Besoldungshöhe entscheiden kann. Um den Einfluß der Besoldung auf die personelle Unabhängigkeit zu beurteilen, muß wiederum zwischen externen Ernennungsinstanzen und der Notenbank als Emennungsinstanz unterschieden werden. Im Falle externer Ernennungsinstanzen spielt die Besoldungshöhe für die personelle Autonomie keine Rolle, weil die Minderung der Entscheidungsfreiheit der externen Ernennungsinstanz keine größere Entscheidungsfreiheit für die Notenbank bedeutet, vorausgesetzt die Notenbank ist nicht selbst befugt, die Besoldungshöhe festzulegen. Aber auch, wenn die Bank die Vergütung bestimmt, ist dadurch ihr Einfluß auf die personelle Besetzung verschwindend gering im Vergleich zu derjenigen der Emennungsinstanz.

Schließlich ist noch auf zwei Aspekte hinzuweisen. Einige Autoren fordern u. a. angemessene Abfindungen und Pensionen beim Auslaufen der Amtszeit von Notenbankmitgliedern, um die Gefahr für die Unabhängigkeit durch das Interesse an einer Wiederernennung zu mindern ${ }^{176}$. Es wird angenommen, daß sich Notenbankfunktionäre bei geldpolitischen Entscheidungen eher den Wünschen der Ernennungsinstanzen fügen, wenn sie eine Wiederernennung anstreben. Hierzu ist auch anzumerken, daß eine solche Regelung zwar einer stabilitätsorientierten Geldpolitik förderlich sein kann. Dieses Argument ist aber für die Unabhängigkeit einer Notenbank bedeutungslos, weil es die Entscheidungsfreiheit der Notenbankmitglieder nicht berührt.

Der zweite Punkt, der gelegentlich im Zusammenhang mit der Unabhängigkeit von Notenbanken angesprochen wird, ist eine Kopplung der Notenbankgehälter an die Inflationsentwicklung bzw. eine erfolgsabhängige Vergütung. Wären die Gehälter voll indexiert, d.h. stiegen sie mit der Inflationsentwicklung, hätten die Notenbankmitglieder keinen finanziellen Anreiz, mit ihrer Geldpolitik für eine niedrige Inflationsrate $\mathrm{zu}$ sorgen ${ }^{177}$. Stiegen ihre Bezüge dagegen mit ihrem geldpolitischen Erfolg, hätten sie einen Anreiz, Stabilitätspolitik zu betreiben. Doch auch dies hat keine Auswirkungen auf die Unabhängigkeit einer Notenbank, weil nur die Anreizstruktur, nicht aber die Entscheidungsfreiheit der Notenbankmitglieder beeinflußt wird.

Zusammenfassend läßt sich folgendes festhalten. Ist die Notenbank die ernennende Instanz, schränkt die externe Festsetzung der Gehälter ihre personelle Unab-

176 Z. B. Hahn, Oswald (1968) Bd. II: a.a.O., S. 44, dies natürlich unter der Voraussetzung, $\mathrm{da} ß$ Wiederernennungen nicht gesetzlich ausgeschlossen sind.

177 Vgl. Neumann, Manfred J. M.: a.a.O., S. 103. 
hängigkeit ein, weil sich der Kreis der Ernennungsfähigen auf die Persönlichkeiten beschränkt, die bereit sind, zu dem festgesetzten Gehalt ein Notenbankamt zu übernehmen. Hat die Zentralbank keinen Einfluß auf die Ernennungen, ist ihre personelle Unabhängigkeit bereits stark beschränkt, sodaß sie, sofern sie die Gehälter ihrer Mitglieder nach eigenem Ermessen festsetzen kann, nur einen geringfügigen Einfluß auf den Kreis der Ernennungsfähigen und damit auf die personelle Besetzung ihrer Organe erhält. Eine inflationsabhängige Indexierung der Gehälter ist für die Unabhängigkeit einer Notenbank ebenso bedeutungslos wie angemessene Abfindungen und Pensionen nach Ablauf der Amtszeit.

\subsubsection{Amtsdauer}

Die Amtsdauer von Mitgliedern der Notenbankleitung hängt von verschiedenen Faktoren ab. Die Basis bildet die gesetzlich vorgeschriebene Amtszeit, die durch eventuell vorhandene Abberufungsmöglichkeiten verkürzt und durch Wiederernennung verlängert werden kann. Neben der Amtsdauer der Notenbankfunktionäre könnten auch die Berufungszeitpunkte für die personelle Unabhängigkeit einer Notenbank von Bedeutung sein.

\subsubsection{Amtszeit}

Eine lange Amtszeit gilt gemeinhin als ein Kriterium für die personelle Unabhängigkeit einer Notenbank, vorausgesetzt, bankexterne Instanzen sind für die Ernennung der Notenbankmitglieder zuständig178. Da in den meisten Fällen die Regierung als Haupteinflußträger auf die personelle Besetzung und damit wesentliche Gefahr für die Unabhängigkeit gilt, orientiert sich die als unabhängigkeitssichernd geforderte Amtszeit in der Regel an der Länge der Politikerwahlperioden. Neumann befürwortet beispielsweise eine Amtszeit von mindestens einer Legislaturperiode, bzw. besser noch länger als zwei Legislaturperioden, berücksichtigt man, da $B$ viele Regierungen über zwei oder mehrere Wahlperioden im Amt sind 179 . Dies verringert die Möglichkeiten der Regierung, Notenbankmitglieder in ihrem Sinne auszutauschen ${ }^{180}$. Insbesondere soll eine lange Amtsdauer verhindern, daß eine neue Regierung die Möglichkeit hat, durch Neubesetzung von Stellen solcher Notenbankmitglieder, deren Amtszeit abgelaufen ist, eine Mehrheit in den Leitungsgremien der Bank zu gewinnen ${ }^{181}$. Hahn182

178 Vgl. Schuppler, Edith: a.a.O., S. 91; Caesar, Rolf (1981): a.a.O., S. 127f; Robert, Rüdiger: Die Unabhängigkeit der Bundesbank, Kronberg/Ts 1978, S. 6; Schmid, Beat: a.a.O., S. 45; mit Einschränkung Swinburne, Mark; Castello-Branco, Marta: a.a.O., S. 31; Scharnbergbericht: a.a.O., S. 5.

Vgl. Neumann, Manfred J. M.: a.a.O., S. $103 f$.

Vgl. Lampe, Ortrun: a.a.O., S. 31; Uhlenbruck, Dirk (1967 a): a.a.O., S. 86.

Vgl. Neumann, Manfred J. M.: a.a.O., S. 103. 
sieht die personelle Unabhängigkeit der Notenbankleitung immer dann eingeschränkt, wenn diese nicht auf Lebenszeit ernannt wird. Eine Ernennung auf Lebenszeit birgt aber auch die Gefahr, daß sich als unfähig erwiesene Notenbankmitglieder nur schwer von ihren Ämtern entfernt werden können.

Spielt die Länge der Amtszeit tatsächlich eine Rolle für die Unabhängigkeit einer Notenbank? Eine lange Amtszeit trägt tendenziell zur Vermeidung einseitiger Einflüsse auf die Emennungen der Notenbankleitung bei und ist insofern von Vorteil für die Qualität der Geldpolitik. Im Falle bankexterner Ernennungsinstanzen kann dies bedeuten, daß die Ernennungen eher im Sinne der Notenbank getätigt werden als bei kurzen Amtszeiten. Die Bank selbst gewinnt dadurch allerdings keinen größeren Einfluß auf die personelle Besetzung ihrer Organe. Daher ist die Amtszeit von Notenbankmitgliedern für die personelle Unabhängigkeit hier nicht von Bedeutung. Das gilt nicht, wenn die Notenbank ihre Mitarbeiter selbst rekrutiert. Hier wirkt sich eine festgelegte Amtszeit nur dann nicht negativ auf die personelle Unabhängigkeit der Bank aus, wenn die Amtsinhaber unbegrenzt wiederernannt werden können und die Bank sie nach Wunsch abberufen kann. Andernfalls kann die Bank nicht frei über den Zeitraum der Beschäftigung ihrer Mitarbeiter entscheiden und ist insofern in ihrer personellen Unabhängigkeit eingeschränkt. $\mathrm{Ob}$ eine lange oder kurze Amtszeit eine geringere Einschränkung der personellen Unabhängigkeit bedeutet, hängt von der Konstellation anderer Faktoren $\mathrm{ab}$ und ist daher nicht ceteris paribus zu klären. Ist beispielsweise eine Wiederernennung von Notenbankmitgliedern ausgeschlossen, ist die größtmögliche personelle Unabhängigkeit der Bank dann gegeben, wenn die Amtszeit auf Lebenszeit besteht und die Bank ihre Mitarbeiter jederzeit abberufen kann. Je kürzer die Amtszeit ist, desto geringer ist die Entscheidungsfreiheit des Noteninstituts, die personelle Besetzung der Leitungsorgane nach ihren Vorstellungen zu gestalten. Ist dagegen eine Wiederernennung möglich, die Abberufungsmöglichkeiten durch die Notenbank aber stark beschränkt, ist die größtmögliche personelle Unabhängigkeit der Bank bei einer sehr kurzen Amtszeit gegeben. Bei Selbstrekrutierung der Notenbankleitung durch die Bank läßt sich über die Auswirkung der Amtszeit auf die personelle Unabhängigkeit also keine allgemeine Aussage treffen.

\subsubsection{Berufungszeitpunkte}

Eine Staffelung der Berufungszeitpunkte bedeutet ein zeitliches sich Überschneiden der Amtszeiten der Notenbankmitglieder bei grundsätzlich gleicher Amtszeit ${ }^{183}$. Sie bewirkt, da $\beta$ nie die gesamten Führungsgremien einer Notenbank gleichzeitig ausgetauscht werden können. Dies hat zum einen den Vorteil, daß

182 Vgl. Hahn, Oswald (1968) Bd. II: a.a.O., S. 44.

183 Vgl. Braun, Karlpeter: a.a.O., S. 112. 
immer ein gewisser Anteil erfahrener Notenbankmitglieder vorhanden ist, um eine dauerhaft reibungslose Erfüllung der Aufgaben der Zentralbank zu gewährleisten. Zum anderen verhindert es den Austausch wesentlicher Teile der Führungsriege innerhalb kurzer Zeit durch externe Ernennungsinstanzen 184 . Gibt es eine solche Regelung nicht, könnte ein Regierungswechsel - vorausgesetzt, der Regierung obliegt die Emennungsbefugnis - wesentliche personelle Veränderungen in der Notenbankleitung nach sich ziehen ${ }^{185}$. Daher leistet eine Staffelung der Berufungszeitpunkte nach dargestellter Ansicht einen positiven Beitrag zur Unabhängigkeit einer Notenbank. Derartige Regelungen sind allerdings nur wirkungsvoll, wenn durch variable Handhabung gewährleistet ist, daß die Staffelung nicht durch die Wiederbestellung oder das Ausscheiden von Notenbankmitgliedern wegen Erreichen der Altersgrenze oder Tod außer Kraft gesetzt werden kann.

Um den Einfluß der Staffelung von Berufungszeitpunkten auf die Unabhängigkeit einer Notenbank zu beurteilen, muß wieder zwischen notenbankfremden Ernennungsinstanzen und der Selbstrekrutierung durch die Notenbank unterschieden werden. Im Falle bankexterner Ernennungen kann die Staffelung der Berufungszeitpunkte wiederum dazu beitragen, einseitige Ernennungen zu verhindern und ist daher durchaus positiv zu werten. Die Notenbank selbst gewinnt dadurch allerdings keine größere Entscheidungsbefugnis auf die personelle Besetzung ihrer Organe, auch wenn auf diese Weise mehr Ernennungen in ihrem Sinne zu erwarten sind. Insofern ist diese Regelung für die personelle Unabhängigkeit der Bank bedeutungslos. Nur, wenn das Institut selbst die Regelungen der Berufungszeitpunkte treffen kann, hat es - wenn auch sehr geringen - Einfluß auf die personelle Besetzung der Notenbankleitung. Kann die Notenbank ihre Mitglieder selbst rekrutieren, stellt sich das Problem einseitiger Ernennungen nicht. Auch hier ist die personelle Unabhängigkeit durch eine vorgeschriebene Staffelung der Berufungszeitpunkte leicht beeinträchtigt, weil diese Regelung die Notenbank in ihrer Entscheidungsfreiheit einschränkt, zu jedem gewünschten Zeitpunkt personelle Veränderungen vorzunehmen. Umfangreiche Wiederernennungs- und Abberufungsmöglichkeiten seitens der Notenbank können die negativen Auswirkungen einer Festlegung von Berufungszeitpunkten auf die personelle Unabhängigkeit der Bank neutralisieren. Kann die Bank selbst Regelungen zur Staffelung der Berufungszeitpunkte treffen, liegt keine Einschränkung ihrer Unabhängigkeit vor.

\subsubsection{Möglichkeit der Wiederernennung}

Die Literatur ist sich über die Auswirkungen von Wiederernennungsvorschriften auf die Unabhängigkeit einer Notenbank nicht einig. Ein Ausschluß von Wiederernennungen gilt als unabhängigkeitsfördernd, weil er die Möglichkeiten von

184 Vgl. Poullain, Ludwig: a.a.O., S. 40; Caesar, Rolf(1981): a.a.O., S. 128.

185 Vgl. Braun, Karlpeter: a.a.O., S. 112. 
Pressionen auf die Notenbankleitung reduziert ${ }^{186}$. An einer weiteren Amtszeit interessierte Notenbankmitglieder könnten versucht sein, durch Wohlverhalten gegenüber den Ernennungsinstanzen die Wahrscheinlichkeit ihrer Wiederernennung zu erhöhen ${ }^{187}$. Umgekehrt könnte der Ausschluß von Wiederernennungen unabhängiges Verhalten der Amtsinhaber gefährden, da sie durch einen "Wink mit einer Anschlußkarriere leicht $\mathrm{zu}$ Wohlverhalten ermuntert werden"188 könnten.

Die Beurteilung des Einflusses von Wiederwahlbestimmungen hängt wie in den vorigen Abschnitten von der Art der Ernennungsinstanz ab. Im Falle externer Ernennungen der Notenbankleitung ist die Gefahr des Wohlverhaltens von Amtsinhabern gegenüber den über ihre Wiederemennung befindenden Instanzen nicht von der Hand zu weisen. Dennoch sind die betroffenen Notenbankmitglieder frei, möglichen Pressionen nachzugeben oder sich ihnen zu widersetzen. Ihre Entscheidungsfreiheit ist insofern nicht beeinträchtigt. Gleiches gilt für Wohlverhalten im Hinblick auf eine Anschlußkarriere. Es liegt also weder im Falle eines Verbotes noch bei Zulässigkeit einer Wiederernennung eine Einschränkung der personellen Unabhängigkeit aufgrund der obigen Argumente vor. Kann die Notenbank ihre Mitglieder selbst ernennen, bedeutet ein Verbot von Wiederernennung möglicherweise den Verzicht auf gute Mitarbeiter ${ }^{189}$, vorausgesetzt die Amtsdauer ist nicht auf Lebenszeit ausgelegt. Die damit verbundene Einschränkung des Kreises der Ernennungsfähigen mindert die Entscheidungsfreiheit der Notenbank, Kandidaten ihrer Wahl zu bestellen. Hier wirkt sich ein Verbot von Wiederernennungen negativ auf die personelle Unabhängigkeit aus. Die gleiche Einschränkung der Entscheidungsfreiheit durch ein Wiederernennungsverbot besteht zwar auch für externe Ernennungsinstanzen; diese ist aber nur dann mit einer Erhöhung der personellen Unabhängigkeit der Notenbank verbunden, wenn die Bank über Abberufungsrechte verfügt. Darauf wird im folgenden Kapitel näher eingegangen.

\subsubsection{Abberufung}

Die Regelungen bezüglich der Abberufung von Notenbankmitgliedern sind in der Praxis sehr vielfältig. Sie reichen von einem Fehlen von Abberufungsvorschriften über den Ausschluß jeglicher Amtsenthebungen, der Möglichkeit einer Abberufung aus verhältnismäßig technischen Gründen wie kriminelle Vergehen, Kon-

186 Vgl. Caesar, Rolf (1981): a.a.O., S. 127; Woll, Artur: Die Unabhängigkeit der Deutschen Bundesbank muß gesichert werden!, in: Wirtschaftsdienst 1988/III, S. 124.

187 Vgl. Hahn, Oswald (1968) Bd. II: a.a.O., S. 40f; Neumann, Manfred J. M.: a.a.O., S. 104.

188 Otmar (1993): a.a.O., S. 16.

189 Vgl. Hahn, Oswald (1968) Bd. II: a.a.O., S. 44.

Sylvia Liebler - 978-3-631-75025-4 
kurs, Krankheit der Personen o.ä. bis zu einer Abberufung ohne Angabe von Gründen. Abberufungsvorschriften gelten insbesondere dann als die Unabhängigkeit der Notenbank beeinträchtigend, wenn sie bankfremden Instanzen erlauben, solche Notenbankmitglieder abzuberufen, die sich ihren Forderungen oder Wünschen widersetzen. Dies scheint bei Regelungen, die Abberufungen nur aus relativ technischen Gründen gestatten, nur bedingt möglich. Ist eine Abberufung dagegen aus politischen Gründen oder gar ohne Angabe von Gründen erlaubt, kann die Abberufungsinstanz erheblichen Einfluß auf die Währungspolitik gewinnen, weil die Notenbankmitglieder den möglichen Verlust ihres Amtes bei ihren geldpolitischen Entscheidungen berücksichtigen müssen ${ }^{190}$. Es gibt Staaten, in denen externe Instanzen über umfangreiche Abberufungsrechte verfügen, diese aber selten oder nie anwenden 191 . Das könnte als Zeichen einer besonderen Effektivität dieser potentiellen Drohung gewertet werden 192 . Es ist aber ebenso denkbar, daß die Regierungen vor dieser Waffe zurückschrecken 193 oder einfach bisher keine Notwendigkeit zu ihrer Anwendung sahen.

Im folgenden werden mögliche Abberufungsreglungen diskutiert und auf ihren Einfluß auf die personelle Unabhängigkeit untersucht.

\subsection{Fehlen von Abberufungsvorschriften}

Fehlen Abberufungsregelungen völlig, läßt sich nicht ohne weiteres eine Aussage über den Einfluß auf die personelle Unabhängigkeit treffen, obgleich einige Autoren darin eine besondere Sicherung der Unabhängigkeit sehen 194 . Aus dem Fehlen solcher Regelungen darf auch nicht zwangsläufig geschlossen werden, daß Mitglieder der Notenbankleitung nicht abberufbar sind ${ }^{195}$. Spindler/Becker/Star-

190 Vgl. Szagunn, Volkhard: a.a.O., S. 20

191 Vgl. Caesar, Rolf (1982): a.a.O., S. 572.

192 Vgl. Issing, Otmar (1993): a.a.O., S. 16.

193 Vgl. Issing, Otmar (1993): a.a.O., S. 16.

194 Vgl. Spindler, Joachim v.; Becker, Willy; Starke, O.-Emst (1973): a.a.O., S. 230; Beck, Heinz: a.a.O, S. 198; Uhlenbruck, Dirk (1967 a): a.a.O., S. 87; Starke, Otto-Ernst: Das Gesetz über die Deutsche Bundesbank und seine wichtigsten öffentlich-rechtlichen Probleme, in: Die öffentliche Verwaltung H.22 1957 a, S. 612; Kaiser, Rolf H.: a.a.O., S. 38; Gaugenrieder, C. A.: Die rechtliche Stellung der deutschen Zentralnotenbank in Geschichte und Gegenwart, Diss. Würzburg 1961, S. 129.

195 Vgl. Hahn, Oswald (1968) Bd. II: a.a.O., S. 153 Im Falle der Deutschen Bundesbank, deren Statuten keine Abberufungsvorschriften enthalten, bejaht die Literatur einhellig die theoretische Abberufungsmöglichkeit von Notenbankmitgliedern, so z.B. Siebelt, Johannes: Der juristische Verhaltensspielraum der Zentralbank, Baden-Baden 1988, S. 175; Starke, Otto-Ernst (1957 a): a.a.O., S. 612; Spindler, Joachim v.; Becker, Willy; Starke, O.-Ernst (1973): a.a.O., S. 231; Beck, Heinz: a.a.O, S. 199. 
ke196 weisen in diesem Zusammenhang darauf hin, daß Abberufungsregelungen ausdrücklich in den Statuten verankert sein müssen, andernfalls gelten die allgemeinen Rechtsnormen des Staates. Hahn ${ }^{197}$ schlägt daher zur Klärung eine Analyse des Staatssystems vor, weist aber darauf hin, daß eine Einordnung dieses Falls in eine Rangfolge verschiedener Abhängigkeitsgrade von Abberufungsregelungen auf diese Weise nicht möglich ist. Auch könnten, abhängig vom Status der Notenbankmitglieder, z. B. Beamtenrecht, allgemeine Kündigungsvorschriften oder die Anstellungsverträge der leitenden Mitarbeiter Aufschluß über die Abberufungsmöglichkeiten geben, wobei man je nach Auswahl der Gesetze und eventuell deren unterschiedlichen Auslegungsmöglichkeiten durchaus $\mathrm{zu}$ divergierenden Ergebnissen gelangen kann ${ }^{198}$. Eine empirische Untersuchung der vorgenommenen Abberufungen und deren Begründungen in Ländern, in denen solche Regelungen fehlen, könnte in diesem Fall zusätzliche Anhaltspunkte über die Deutung des Fehlens von Abberufungsvorschriften in den Statuten einer Notenbank bieten. In der Regel dürfte ein Fehlen solcher Vorschriften weder ein Verbot jeglicher Abberufungen noch einen Freibrief für jederzeitige Abberufung ohne Angabe von Gründen bedeuten. Wahrscheinlicher ist, daß Abberufungen nur beim Vorliegen triftiger Gründe, über die eventuell die allgemeinen Rechtsnormen des Staates oder andere Gesetze Auskunft geben können, möglich sind. Eine allgemeine Aussage über die Auswirkung des Fehlens von Abberufungsvorschriften auf die personelle Unabhängigkeit ist hier nicht möglich.

\subsection{AusschluB einer Abberufungsmöglichkeit}

Ein expliziter Verzicht auf Regelungen, die eine Abberufung von Mitgliedern der Notenbankleitung vor Ende ihrer Amtszeit ermöglichen, wird zuweilen als Mittel zur Wahrung von Unabhängigkeit betrachtet ${ }^{199}$. Solche Regelungen sind natürlich nicht unproblematisch. Sich als unfähig oder aus anderen Gründen untragbar erweisende Notenbankmitglieder könnten ein Land beispielsweise durch Fehlentscheidungen im Extremfall in eine schwere Krise stürzen, ohne daß ein Eingreifen des Staates oder anderer Instanzen möglich wäre.

Für die personelle Unabhängigkeit ist dabei von Bedeutung, daß die Entscheidungsfreiheit der für die personelle Besetzung der Leitungsorgane zuständigen Instanz durch das Verbot Notenbankmitglieder auszutauschen, gemindert wird. Das bedeutet, daß die personelle Unabhängigkeit der Notenbank als Ernennungsinstanz bei einem Ausschluß jeglicher Abberufungsmöglichkeiten eingeschränkt ist. Die Entscheidungsfreiheit der Zentralbank ist hier bzgl. des Kriteriums der

196 Vgl. Spindler, Joachim v.; Becker, Willy; Starke, O.-Ernst (1973): a.a.O., S. 231.

197 Vgl. Hahn, Oswald (1968) Bd. II: a.a.O., S. 47.

198 Siebelt, Johannes: a.a.O., S. 174.

199 Vgl. Hahn, Oswald (1968) Bd. II: a.a.O., S. 45. 
Abberufungsregelungen genauso stark beeinträchtigt, als wenn eine externe Instanz das Abberufungsrecht innehätte. Sie könnte in keinem Fall selbst Abberufungen vornehmen. Im Zusammenhang mit den Ernennungsvorschriften betrachtet stellt sich die Lage etwas anders dar. Ist die Notenbank alleinige Ernennungsinstanz, hat die Notenbank bei einem generellen Abberufungsverbot letztlich den alleinigen Einfluß auf die Besetzung der Notenbankleitung. Sind dagegen andere Instanzen mit einem Abberufungsrecht ausgestattet, können diese durch Amtsenthebungen erheblichen Einfluß auf die personelle Besetzung der Notenbankleitung gewinnen. Daher dürfte hier die Einschränkung der personellen Unabhängigkeit durch das Verbot jeglicher Abberufungen doch erheblich geringer ausfallen als bei externen Abberufungsinstanzen.

Im Falle externer Ernennungsinstanzen hat die Notenbank weder auf Ernennungen, noch auf Abberufungen einen Einfluß und ist somit in ihrer Entscheidungsfreiheit stark behindert. Das bedeutet eine völlige Abhängigkeit der Notenbank bezüglich dieses Kriteriums. Die Tatsache, daß hier auch externe Instanzen keine Abberufungen vornehmen können, ändert daran nichts, weil daraus keine Erhöhung der Entscheidungsfreiheit des Noteninstituts resultiert. Die personelle Unabhängigkeit ist beim Vorliegen externer Ernennungsinstanzen durch ein Abberufungsverbot ebenso stark eingeschränkt, als wenn das Abberufungsrecht bei externen Instanzen läge. In beiden Fällen hat die Zentralbank keinerlei Einfluß auf die personelle Besetzung der Bankspitze.

\subsection{Abberufung unter Angabe von Gründen}

Die Möglichkeit, Mitglieder der Notenbankleitung beim Vorliegen triftiger Gründe abberufen zu können, erscheint auf den ersten Blick sehr sinnvoll, beseitigt sie doch die Gefahren, die der Notenbank bzw. dem Staat durch Persönlichkeiten, die sich als unfähig oder ungeeignet erweisen, entstehen könnten. Sofern bei den zulässigen Abberufungsgründen politische Motive ausgeschlossen sind, wird nach herrschender Meinung die Unabhängigkeit einer Notenbank nicht oder nur geringfügig beeinträchtigt 200 . Aber auch, wenn eine Abberufung ausschließlich beim Vorliegen triftiger (nicht politischer) Gründe gestattet ist, wie z. B. grober Pflichtverletzung, ist die Gefahr politisch motivierter Abberufungen nicht gänzlich aus dem Weg geräumt. Die Möglichkeit, sich unliebsamer Notenbankmitglieder zu entledigen, hängt vornehmlich davon $a b$, wie exakt die eine Abberufung rechtfertigenden Tatbestände in den Gesetzen erläutert sind. Lassen die Abberufungsgründe große Ermessensspielräume zu, steigt die Gefahr eines Mißbrauchs dieser Regelungen. Dies gilt besonders, wenn über das Vorliegen solcher Gründe

200 Vgl. Hahn, Oswald (1968) Bd. II: a.a.O., S. 46f; Robert, Rüdiger: a.a.O., S. 6f; Uhlenbruck, Dirk (1967 a): a.a.O., S. 88f. 
keine unabhängigen Gutachtergremien entscheiden. Im folgenden wird diese Problematik anhand einiger typischer Abberufungsgründe erläutert.

Dauernde Krankheit kann ein Grund für eine Abberufung eines Notenbankmitglieds sein. Kann eine Person ihr Amt aufgrund einer körperlichen Krankheit nicht mehr ausüben, dürfte dies nach Hahn ${ }^{201}$ keine negativen Folgen für die Unabhängigkeit der Notenbank haben. Problematischer kann dies in Fällen von (vermeintlicher) Geisteskrankheit oder Geistesschwäche sein, wenn die Richtigkeit geldpolitischer Entscheidungen mit einer solchen Begründung in Frage gestellt und eine Abberufung eines Zentralbankfunktionärs verlangt wird. Hier ist es besonders wichtig, daß ein unabhängiges Ärztegremium über das Vorliegen solcher Krankheiten urteilt ${ }^{202}$.

Menschliche Verfehlungen wie kriminelle Betätigungen oder Tatbestände, die die Kreditwürdigkeit eines Notenbankmitglieds in Frage stellen, gelten in der Regel ebenfalls als triftiger Grund zur Amtsenthebung. Auch hier ist es notwendig, exakt festzulegen, welche Art von Verfehlungen eine Person für eine Notenbanktätigkeit ungeeignet werden lassen, um einen Mißbrauch dieser Regelungen zu verhindern ${ }^{203}$. Es muß sichergestellt sein, daß politische Vergehen oder Verfehlungen, die der Aufgabenerfüllung der Person oder dem Ansehen der Notenbank nicht schaden, nicht als Grund vorgeschoben werden können, unbequeme Notenbankmitglieder ihres Amtes zu entheben 204.

Bei einer Abberufungsmöglichkeit aus Gründen der Verletzung der Amtspflichten ist die Gefahr politisch motivierter Abberufungen verhältnismäßig hoch. Solange die Amtspflichten nicht durch genaue Festlegung des Geschäftskreises der Notenbank in den Gesetzen mit einer Aufzählung der zulässigen und untersagten Geschäfte exakt definiert sind, sind unterschiedliche Auslegungen möglich ${ }^{205}$, die die geldpolitischen Entscheidungen im Zweifel anfechtbar machen. Das Gesetz muß beispielsweise klären, ob bereits dann eine Verletzung der Amtspflichten vorliegt, wenn sich die Notenbank weigert, dem Staat innerhalb der zulässigen Höchstgrenzen Kredit zu gewähren206. Ein Mißbrauch dieser Regelungen kann dadurch verhindert werden, daß unter Verletzung der Amtspflichten ausschließlich Verstöße gegen das Notenbankgesetz und andere die Zentralbank betreffende Normen verstanden wird 207.

Vgl. Hahn, Oswald (1968) Bd. II: a.a.O., S. 46.

Vgl. Hahn, Oswald (1968) Bd. II: a.a.O., S. 46.

Vgl. Hahn, Oswald (1968) Bd. II: a.a.O., S. 46.

Vgl. Hahn, Oswald (1968) Bd. II: a.a.O., S. 46.

Vgl. Hahn, Oswald (1968) Bd. II: a.a.O., S. 47.

Vgl. Hahn, Oswald (1968) Bd. II: a.a.O., S. 47.

Vgl. Hahn, Oswald (1968) Bd. II: a.a.O., S. 47. 
Eine Amtsenthebung aufgrund Unfähigkeit eines Notenbankmitglieds läßt der Willkür einen sehr großen Spielraum ${ }^{208}$, weil dies nicht objektiv beurteilbar ist. Die Abberufungsinstanzen können sich mit dieser Begründung relativ unproblematisch unerwünschter Persönlichkeiten in der Führungsriege entledigen.

Ähnliches gilt für Abberufungen aufgrund von Meinungsverschiedenheiten mit der Abberufungsinstanz. Diese Amtsenthebung aus politischen Gründen kommt einer jederzeitigen Abberufungsmöglichkeit ohne Angabe von Gründen sehr nahe. Die Notenbank ist hier völlig von der abberufenden Instanz abhängig.

Welche Auswirkungen haben Abberufungsvorschriften, die eine Amtsenthebung unter Angabe von Gründen erlauben, auf die personelle Unabhängigkeit einer Notenbank? Zunächst muß unterschieden werden zwischen Abberufungsgründen, die politisch motivierte Abberufungen ermöglichen und anderen. Sind Amtsenthebungen aus politischen Gründen möglich, erhält die abberufende Instanz einen großen Entscheidungsspielraum und damit erheblichen Einfluß auf die personelle Besetzung der Leitungsorgane der Bank. Sind dagegen Amtsenthebungen ausschließlich bei Vorliegen von Gründen möglich, die sich nicht dazu eignen, unbequeme Notenbankmitglieder vom Amt zu entfernen, verfügt die Abberufungsinstanz nur über einen geringen Entscheidungsspielraum. Das gilt besonders dann, wenn die Feststellung eines Abberufungstatbestands automatisch eine Amtsenthebung nach sich ziehen muß. Hier ist die Abberufungsinstanz praktisch ohne Einfluß. Ist die Bank selbst die abberufende Instanz, wird ihr Entscheidungsspielraum und damit ihre Unabhängigkeit bezüglich dieses Kriteriums um so größer, je mehr Abberufungsgründe die Notenbankgesetzgebung aufführt. Sind externe Stellen befugt, Abberufungen vorzunehmen, ist bei isolierter Betrachtung des Abberufungskriteriums der Umfang der erlaubten Abberufungsgründe für die personelle Unabhängigkeit des Währungsinstituts unerheblich. Die Notenbank erhält nicht mehr Entscheidungsgewalt bezüglich Abberufungen, wenn die externe Abberufungsinstanz nur wenige Möglichkeiten hat, Amtsenthebungen vorzunehmen. Bezieht man dagegen die Ernennungsinstanz in die Betrachtung mit ein, ändert sich das Bild. Kann die Notenbank ihre Mitglieder selbst rekrutieren und ist sie gleichzeitig Abberufungsinstanz, ist ihre personelle Unabhängigkeit bezüglich des betrachteten Kriteriums um so größer, je mehr Freiheiten sie bei den Abberufungen hat, d.h. je mehr Gründe Amtsenthebungen gestatten. Sind dagegen externe Stellen abberufungsbefugt, ist die Unabhängigkeit der Bank um so weniger gemindert, je geringer die Abberufungsmöglichkeiten sind, weil die Bank so im ganzen mehr Einfluß auf die personelle Besetzung erhält. Im Falle externer Ernennungsinstanzen, kann eine Notenbank als Abberufungsinstanz um so mehr Einfluß auf die personelle Besetzung nehmen, je mehr Gründe Amtsenthebungen rechtfertigen. Kann die Bank dagegen weder Emennungen, noch Abberufungen

Vgl. Hahn, Oswald (1968) Bd. II: a.a.O., S. 47. 
vornehmen, ist der Umfang der möglichen Abberufungsgründe für die personelle Unabhängigkeit der Bank unerheblich, weil das Währungsinstitut in keinem Fall einen Einfluß auf die personelle Besetzung ihrer Organe hat.

\subsection{Jederzeitige Abberufungsmöglichkeit ohne Begründung}

Die Möglichkeit von Amtsenthebungen ohne Angabe von Gründen bewirkt eine völlige personelle Abhängigkeit von der Abberufungsinstanz. Die Notenbank als Abberufungsinstanz genießt hier das höchste $\mathrm{Ma} \beta$ an personeller Unabhängigkeit bezüglich dieses Kriteriums. Umgekehrt besteht die größtmögliche Abhängigkeit der Notenbank, können externe Instanzen die Amtsenthebungen vornehmen.

\subsection{Zusammenfassung}

Die Auswirkung der Abberufungsregelungen auf die personelle Unabhängigkeit einer Notenbank ist nicht nur von den Abberufungsmöglichkeiten, sondern auch von der Ernennungs- und Abberufungsinstanz abhängig. Die folgende Fallunterscheidung differenziert zwischen den möglichen Konstellationen.

a) Notenbank $=$ Abberufungsinstanz

Ist die Notenbank selbst Abberufungsinstanz, ist ihre Unabhängigkeit bezüglich des betrachteten Kriteriums um so größer, je weniger Beschränkungen sie bei der Amtsenthebung von Notenbankmitgliedern unterliegt. Völlige Unabhängigkeit besteht daher, wenn die Notenbank Mitglieder der Führungsriege jederzeit und ohne Angabe von Gründen abberufen kann. Umgekehrt ist sie in ihrer Entscheidungsfreiheit am stärksten beschränkt, wenn Abberufungen generell untersagt sind. Dazwischen liegen Regelungen, bei denen Abberufungen an bestimmte Gründe gebunden sind, vorausgesetzt die Bank ist nicht gezwungen, beim Eintritt der Abberufungsvoraussetzungen die betreffenden Mitarbeiter ihres Amts zu entheben. In diesem Falle wäre die Bank ebenso eingeschränkt wie bei einem generellen Verbot von Abberufungen. Abberufungsregelungen, die Amtsenthebungen nur beim Vorliegen festgelegter Gründe gestatten, können im Extremfall eine ähnlich große Unabhängigkeit bewirken wie jederzeitige Abberufungen ohne $\mathrm{Be}$ gründung, nämlich dann, wenn die Abberufungsbedingungen Amtsenthebungen gestatten, die in einer unterschiedlichen Auffassung der Notenbankpolitik begründet sind.

b) Externe Instanz(en) = Abberufungsinstanz(en)

Sind notenbankfremde Instanzen abberufungsbefugt, ist die konkrete Ausgestaltung der Regelungen für die personelle Unabhängigkeit einer Notenbank irrelevant, wen man die Abberufungsvorschriften isoliert von anderen Kriterien betrachtet. Eine Einschränkung der Entscheidungsfreiheit der externen Instanzen 
durch enge Abberufungsmöglichkeiten ist nicht mit einer erhöhten Entscheidungsfreiheit für die Notenbank verbunden. Die Bank hat in keinem Fall einen Einfluß auf die Amtsenthebungen. Die personelle Unabhängigkeit der Bank ist bezüglich dieses Kriteriums ebenso stark beschränkt wie bei einem generellen Abberufungsverbot.

Betrachtet man allerdings die Abberufungsregelungen im Zusammenhang mit den Ernennungsregelungen, ergibt sich folgendes Bild:

a) Notenbank $=$ Ernennungsinstanz

aa) Generelles Abberufungsverbot

Steht der Bank das alleinige Ernennungsrecht $\mathrm{zu}$, hat sie trotzdem die alleinige Befugnis für die personelle Besetzung ihrer Organe, wenn auch dadurch behindert, daß sie sich von ihren Mitgliedern nicht vor Ende ihrer Amtszeit trennen kann. Die personelle Unabhängigkeit der Bank bleibt daher mit geringer Einschränkung gewahrt.

ab) Notenbank $=$ Abberufungsinstanz

Völlige personelle Unabhängigkeit besteht, wenn die Bank jederzeit und ohne Begründung Funktionäre ihres Amts entheben kann. Jede diese Freiheit beschränkende Regelung mindert die Unabhängigkeit der Bank, die jedoch weitgehend erhalten bleibt, weil das Währungsinstitut auch hier die einzige Instanz ist, die auf die Besetzung ihrer Organe Einfluß nehmen kann. Die Einschränkung der personellen Unabhängigkeit ist hier geringer als beim Vorliegen eines generellen Abberufungsverbots, sofern die Bank beim Vorliegen gesetzlicher festgelegter Abberufungsgründe nicht gezwungen ist, Amtsenthebungen vorzunehmen.

ac) Externe Instanz(en) = Abberufungsinstanz(en)

Externe Stellen können je nach Ausgestaltung der Regelungen erheblichen Einfluß auf die Zusammensetzung der Gremien gewinnen, wenn sie zu Abberufungen befugt sind. Dieser ist am größten, können aus politischen Gründen oder gar ohne Begründung Amtsenthebungen vorgenommen werden. Im Extremfall könnten alle von der Notenbank ernannten Funktionäre wieder abberufen werden. Das wirkt sich besonders stark aus, wenn Wiederernennungen nicht gestattet sind, weil damit der Notenbank genehme Kandidaten unwiederbringlich für Leitungsfunktionen der Bank verloren gehen. Der Einfluß externer Instanzen sinkt um so mehr, je stärker Abberufungen an das Vorliegen bestimmter Gründe gebunden ist, die keine politisch motivierten Amtsenthebungen gestatten und ist am geringsten bzw. gleich Null, sind sie beim Eintritt solcher Abberufungsgründe verpflichtet, die betreffenden Notenbankmitglieder ihres Amts zu entheben. Im letzteren Fall 
ist die personelle Unabhängigkeit der Notenbank ähnlich gering eingeschränkt, wie im Falle eines generellen Abberufungsverbots.

b) Externe Instanz(en) = Ernennungsinstanz(en)

\section{ba) Generelles Abberufungsverbot}

Bei einem generellen Abberufungsverbot verfügen externe Instanzen über den alleinigen Einfluß auf die personelle Besetzung der Notenbankorgane. Die Minderung der Entscheidungsfreiheit der externen Instanz, keine personellen Änderungen vor Ende der jeweiligen Amtszeiten vornehmen zu können, ist nicht mit größerem Einfluß für die Notenbank verbunden und ändert daher nichts an der völligen personellen Abhängigkeit der Bank.

\section{bb) Notenbank $=$ Abberufungsinstanz}

Wie stark der Einfluß der Notenbank auf die Besetzung der Notenbankorgane ist, hängt von der Ausgestaltung der Abberufungsregelungen ab. Die Entscheidungsfreiheit der Bank ist durch die Existenz externer Ernennungsinstanzen bereits stark eingeschränkt. Durch die Möglichkeiten, Abberufungen vorzunehmen, kann dies etwas ausgeglichen werden. Am größten ist die Unabhängigkeit der Bank, wenn sie jederzeit und ohne Begründungen bzw. aus politisch motivierten Gründen Abberufungen vornehmen kann. Die Unabhängigkeit sinkt um so stärker, je weniger Gründe Abberufungen gestatten. Gar keinen Einfluß auf die Abberufungen hat die Bank, wenn sie lediglich beim Vorliegen festgelegter Abberufungsgründe Amtsenthebungen vornehmen muß. Hier hätte sie eine reine Verwaltungsfunktion. In allen Fällen, in denen die Notenbank nicht aus beliebigen Gründen Abberufungen vornehmen kann, kann man von einem wesentlichen Einfluß externer Instanzen auf die personelle Besetzung der Leitungsorgane der Bank sprechen. Die personelle Unabhängigkeit der Notenbank ist hier sehr stark eingeschränkt. Hat die Notenbank umfassende Freiheiten, Abberufungen vorzunehmen, stellt sich die Frage, ob die Ernennungsinstanz oder die Abberufungsinstanz einen größeren Einfluß auf die personelle Zusammensetzung der Bankorgane hat. Hier spielt das Kriterium der Wiederernennungsvorschriften die entscheidende Rolle. Sind Wiederernennungen nicht vorgesehen, schließt die Notenbank mit jeder Abberufung Personen aus dem Kreis der Ernennungsfähigen aus. Damit kann sie ihr nicht genehme Personen dauerhaft aus der Notenbankleitung entfernen und damit im Extremfall den Kreis der Ernennungsfähigen auf von ihr erwünschte Kandidaten beschränken. Dadurch könnte sie sogar einen größeren Einfluß auf die personelle Besetzung der Notenbankleitung gewinnen als die externe Ernennungsinstanz. Sind Wiederernennungen dagegen möglich, ist der Einfluß der Notenbank als Abberufungsinstanz insofern geringer, als die Ernennungsinstanz abberufene Notenbankmitglieder theoretisch gleich wiederernennen 
darf. Im Extremfall kann die Notenbank an der personellen Besetzung der Bankorgane nichts ändern.

bc) Externe Instanz(en) = Abberufungsinstanz(en)

Wie bei einem generellen Abberufungsverbot verfügen auch hier externe Instanzen über den alleinigen Einfluß auf die personelle Besetzung der Notenbankspitze. Die einzelnen Regelungen, wann und aus welchen Gründen abberufen werden darf oder muß, sind ohne Auswirkungen auf die Unabhängigkeit der Bank. Die Notenbank ist personell völlig abhängig.

Abschließend sei noch darauf hingewiesen, daß es für die personelle Unabhängigkeit einer Notenbank unbedeutend ist, ob eine oder mehrere externe Instanzen Einfluß auf die Abberufungen nehmen können 209. Ausschlaggebend für die Auswirkung auf die personelle Autonomie ist letztlich der Grad an Entscheidungsfreiheit der Bank, sei sie nun durch eine oder mehrere externe Instanzen beschränkt.

\subsubsection{Entwicklung eines Schemas zur Beurteilung der personel- len Unabhängigkeit}

Aufgabe ist es nun, aus den oben ermittelten Erkenntnissen über die Einflußkriterien auf die personelle Unabhängigkeit und deren Abhängigkeiten untereinander ein Schema zu entwickeln, anhand dessen sich der Grad an personeller Unabhängigkeit einer Notenbank ermitteln läßt. Hier bietet sich die Form eines Entscheidungsbaums an. Wesentliches Kriterium für die personelle Unabhängigkeit sind die Ernennungsregelungen. Vollkommene personelle Unabhängigkeit kann eine Notenbank nur bei Selbstrekrutierung ihrer Mitglieder erreichen. Die Frage, ob die Notenbank selbst für die Besetzung der Leitungsorgane zuständig ist oder ob externe Instanzen die Emennungsbefugnis haben, entscheidet zudem auch darüber, wie stark und in welcher Richtung sich die übrigen Kriterien auf die personelle Unabhängigkeit auswirken. Der zweite Aspekt, der die personelle Unabhängigkeit einer Notenbank wesentlich beeinflußt, sind die Abberufungsregelungen. Zusammen mit den Ernennungsvorschriften erlauben sie bereits eine grobe Einordnung einer Zentralbank in eine Skala von Unabhängigkeitsgraden. Alle weiteren Kriterien gliedern das Bewertungsschema weiter auf und bewirken eine differenziertere Bestimmung der personellen Unabhängigkeit.

209 Anderer Ansicht: Cäsar, Rolf (1981): a.a.O., S. 127, der die Aufassung vertritt, die personelle Autonomie sei um so stärker beschränkt, je stärker eine externe Instanz an den Abberufungen beteiligt ist und um so geringer, je stärker die Abberufungskompetenzen auf verschiedene Gruppen verteilt sind. 
Das Bewertungsschema (Abb. 1) gliedert sich in 6 Ebenen, die im folgenden näher erläutert werden.

\section{Ebene 1: Ernennung der Entscheidungsmehrheit}

Die erste Ebene klärt die Frage, welche Instanz(en) für die Ernennung der Notenbankleitung zuständig ist (sind). Wie bereits oben dargelegt, ist es für die Unabhängigkeit einer Notenbank unerheblich, wie viele Instanzen an den Ernennungen beteiligt sind. Wichtig ist ausschließlich das Ausmaß, in dem die Bank die Mitglieder ihrer Organe selbst rekrutieren kann. Die Bank kann ihre geldpolitischen Vorstellungen dann durchsetzen, wenn sie mindestens so viele Mitglieder selbst ernennen kann, daß diese die Entscheidungsmehrheit stellen.

Nicht in allen Fällen hat eine Seite den entscheidenden Einfluß auf die Ernennungen der Notenbankleitung. Es ist ebenfalls denkbar, daß Notenbank und externe Instanzen jeweils in gleichem Maße an der personellen Besetzung der Bankorgane beteiligt sind. In einer solchen Patt-Situation kann die Notenbank nicht die Entscheidungsmehrheit ernennen. Es gilt also der rechte Bereich des Entscheidungsbaumes.

\section{Ebene 2: entscheidende Abberufungsinstanz oder Vetorecht bei Abberufungen}

Neben der Frage nach der entscheidenden Ernennungsinstanz ist die Frage am wichtigsten, ob die Notenbank die maßgebliche Abberufungsinstanz ist. Ist die Notenbank dies nicht, kann aber drohende Amtsenthebungen durch ein Vetorecht verhindern, hat sie ebenfalls einen wichtigen Einfluß auf Abberufungen, der es rechtfertigt, diesen Fall zusammen mit der entscheidenden Abberufungsinstanz auf eine Bewertungsstufe zu stellen.

Wenn vorzeitige Abberufungen von Notenbankmitgliedern gänzlich untersagt sind oder ausschließlich regelgebundene Abberufungen vorgenommen werden können, gibt es auch keine Abberufungsinstanz. Hier muß die Frage nach der Notenbank als maßgeblicher entscheidungstreffender Instanz verneint werden.

\section{Ebene 3}

Der Einfluß der Abberufungsinstanz auf die personelle Besetzung der Leitungsorgane einer Notenbank hängt von den Abberufungsmodalitäten im einzelnen ab. Den größten Einfluß hat sie, wenn Amtsenthebungen nicht an das Vorliegen bestimmter Voraussetzungen gebunden sind, sondern willkürlich vorgenommen werden können. Darunter fallen auch Abberufungen aus politischen Gründen. Ein Vetorecht der nicht-abberufenden Instanz kann ebenfalls ohne Angabe von Gründen angewendet werden.

Diese Ebene des Entscheidungsbaumes enthält zudem die Frage nach einem Vetorecht bzgl. Ernennungen. Dazu werden hier zum einen Veto- bzw. Genehmi- 
Sylvia Liebler - 978-3-631-75025-4

Downloaded from PubFactory at 01/11/2019 09:08:34AM

via free access 


\section{Ebene}

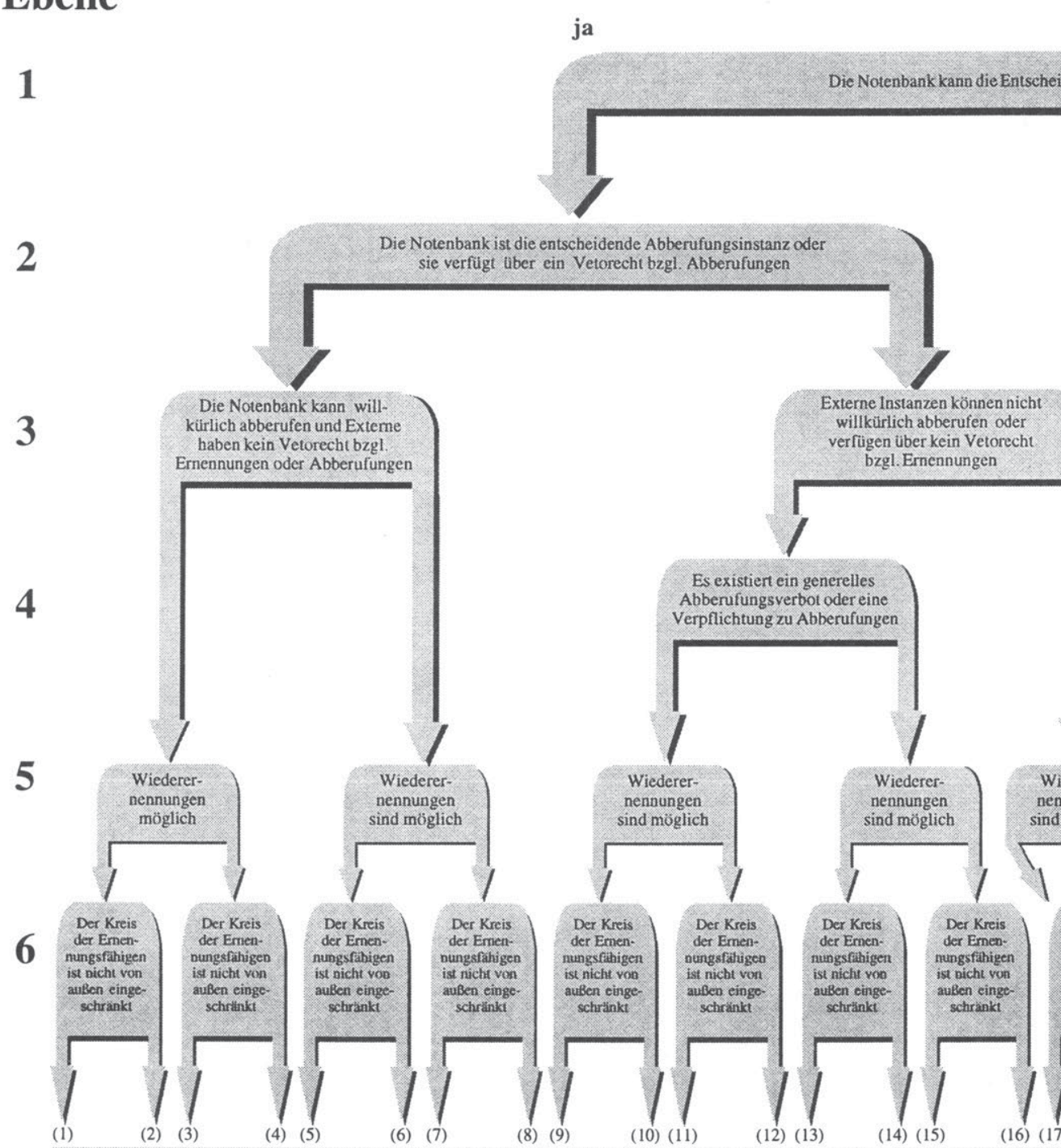

(1)

(2) (3)

(4) (5)

(6) (7)

(10) (11)

(12) (13)

(14) (15)

(16) $(17$

abnehmende Unabhängigk

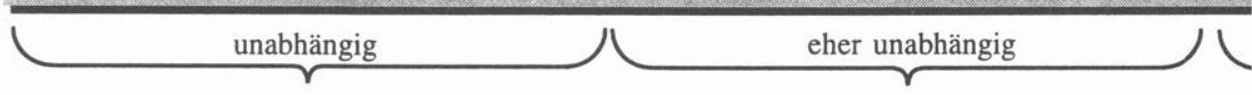

Abb. 1: Schema zur Beurteilung der personellen Unabhängigkeit 
nein

Die Notenbank ist die entscheiden-

de Abberufungsinstanz oder sie verfügt

iber ein Vetorecht bzgl. Abberufungen

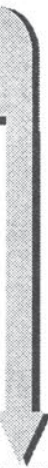

ederer-

nungen

möglich
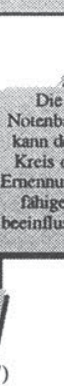

Die Notenbank kann will

Vetorecht bzgl. Ernen-

nungen anwenden
Die Notenbank verfugit über ein Vetorechı bei Ernennungen

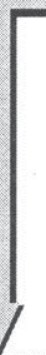

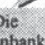

hank

den

reis der

cnnungs

thigen

influssen
(

\section{Wiederemen-}

nungen sind

nicht möglich

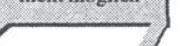

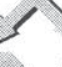

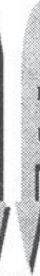

(18)(19)

(20)

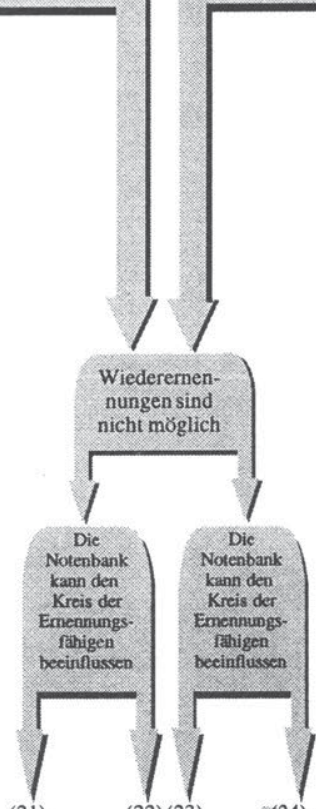

(21)
(22) (23)

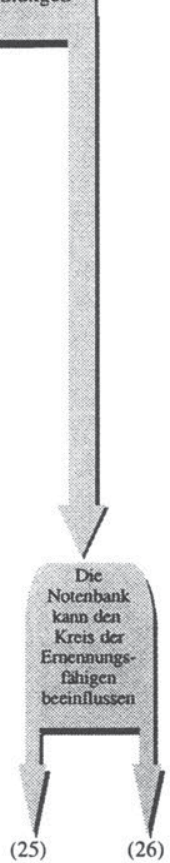

(25)

eher abhängig

abhängig 
Sylvia Liebler - 978-3-631-75025-4

Downloaded from PubFactory at 01/11/2019 09:08:34AM

via free access 
gungsrechte de jure gerechnet, zum anderen aber auch Quasi-Vetorechte, die im Falle eines gleichwertigen Einflusses von Notenbank und externen Instanzen auf die Ernennungen vorliegen können. Hat nämlich jede der beiden Instanzen den gleichen Stimmenanteil bei der Abstimmung über eine Ernennung, ist jede Seite auf Stimmen der anderen Partei angewiesen, wenn sie einen von ihr gewünschten Kandidaten berufen will. Das bedeutet, daß externe Instanzen ohne Zustimmung der Notenbank keine Ernennungen vornehmen können und umgekehrt. Jede der Instanzen verfügt damit quasi über ein Vetorecht. Sie kann die von der jeweils anderen Instanz gewünschten Kandidaten ablehnen, indem sie ihnen keine Stimme gibt. Sie muß dafür ebensowenig Gründe nennen wie im Falle von umfassenden Abberufungsrechten. In seiner Auswirkung kommt ein Vetorecht bei Ernennungen daher einem Recht willkürliche Abberufungen vorzunehmen sehr nahe, sieht man einmal von der Tatsache $a b$, daß Abberufungen eine vorherige Ernennung der Kandidaten voraussetzt. Aus diesem Grund ist die Frage nach $\mathrm{Ab}$ berufungsmöglichkeiten ohne Angabe von Gründen mit der nach einem Vetorecht bei Ernennungen in einer Bewertungsebene zusammengefaßt.

Kann die Notenbank weder Ernennungen noch Abberufungen entscheidend mitgestalten, sind die Abberufungsvorschriften im einzelnen für die personelle Unabhängigkeit unbedeutend, weil der Einfluß der Bank auf die personelle Unabhängigkeit durch eine Veränderung der Abberufungsgründe nicht berührt würde. Das Noteninstitut ist personell völlig abhängig.

\section{Ebene 4: Abberufungsverbot, Verpflichtung zu Abberufungen}

Ist die Notenbank nicht abberufungsbefugt, spielen die über die in Ebene 3 geklärten Fragen hinausgehenden Abberufungsmodalitäten für die personelle Unabhängigkeit nur dann eine Rolle, wenn die Notenbank über die entscheidende Ernennungsbefugnis verfügt. Je größer nämlich die Freiheiten bankfremder Instanzen sind, Abberufungen vorzunehmen, desto mehr mindert dies die personelle Unabhängigkeit der Bank. Können Abberufungen nicht willkürlich vorgenommen werden, sind sie entweder gänzlich untersagt oder sie sind an bestimmte Bedingungen geknüpft. Im letzeren Fall läßt sich unterscheiden zwischen der Möglichkeit und der Verpflichtung der Abberufungsinstanz, beim Eintritt dieser Bedingungen Amtsenthebungen vorzunehmen. Weder bei einem Verbot von Abberufungen noch bei einer Verpflichtung, beim Eintritt bestimmter Voraussetzungen Abberufungen vorzunehmen, kann die Notenbank oder eine andere Instanz auf Abberufungen Einfluß nehmen. Dies ist für die personelle Unabhängigkeit der Zentralbank günstiger als das Vorliegen von Abberufungsrechten Externer, weil die Bank aufgrund ihrer Ernennungsrechte die einzige Instanz ist, die auf die personelle Besetzung der Leitungsorgane Einfluß nehmen kann. 


\section{Ebene 5: Wiederernennungsvorschriften}

Wiederernennungsvorschriften haben insofern eine Auswirkung auf die personelle Unabhängigkeit einer Notenbank, als ein Ausschluß von Wiederernennungen mit jeder abgelaufenen Amtszeit eines Notenbankmitglieds den Kreis der Ernennungsfähigen verkleinert. Dieses Kriterium kann in bestimmten Fällen darüber entscheiden, ob die Notenbank oder externe Instanzen den größeren Einfluß auf die personelle Besetzung der Leitungsorgane der Bank haben. Daher wird die Frage der Wiederernennung aus den sonstigen Kriterien, die den Kreis der Ernennungsfähigen beeinflussen, herausgenommen und getrennt berücksichtigt. Eine Notenbank, die ihre leitenden Mitarbeiter selbst rekrutiert, ist dabei am unabhängigsten, wenn sie Personen, deren Amtszeit abgelaufen ist, erneut ernennen darf. Können externe Instanzen Abberufungen vornehmen, ist die Möglichkeit der Wiederernennung besonders wichtig für die Unabhängigkeit der Bank. Andernfalls könnten bankfremde Instanzen ihr nicht genehme Funktionäre dauerhaft vom Amt entfernen und so empfindlichen Einfluß auf die personelle Besetzung der Bankleitung nehmen. Ist die Notenbank nicht die entscheidende Ernennungsinstanz, spielt die Möglichkeit der Wiederernennung von Mitgliedern der Notenbankleitung nur dann eine Rolle für die personelle Unabhängigkeit der Bank, wenn diese in großem Umfang abberufungsbefugt ist. Hier kann sie bei einem Verbot von Wiederemennungen auf dem Wege der Abberufungen unerwünschte Mitarbeiter dauerhaft von der Notenbankleitung fernhalten und kann so trotz mangelnder Ernennungsbefugnis großen Einfluß auf die personelle Besetzung ihrer Organe nehmen.

Auf der Ebene der Wiederernennungsvorschriften gibt es eine Überschneidung der beiden Äste des Entscheidungsbaums. Sie resultiert aus der Frage, in welchem der beiden Extremfälle, in denen jeweils eine Instanz über die umfangreiche Ernennungsbefugnisse und die andere über umfangreiche Abberufungsbefugnisse verfügt, die Notenbank den größeren Einfluß auf die personelle Besetzung der Bankleitung hat. Entscheidend ist hier die Möglichkeit der Wiederernennung abberufener Notenbankmitglieder. Ist eine Wiederernennung abberufener Personen zulässig, sitzt jeweils die Ernennungsinstanz am längeren Hebel, da sie die Möglichkeit hat, ihres Amts enthobene Funktionäre sofort wiederzuernennen. Im Extremfall würde sich an der Personalzusammensetzung praktisch nichts ändern. Ist dagegen keine erneute Ernennung zulässig, schränkt jede Abberufung den Entscheidungsspielraum der Ernennungsinstanz ein, Persönlichkeiten ihrer Wahl mit einem Amt zu bekleiden. Im Extremfall könnte die Abberufungsinstanz jedes neu ernannte Notenbankmitglied wieder abberufen. Es läßt sich hier nicht eindeutig beantworten, ob eine der beiden Instanzen in diesem Fall über den größeren Einfluß auf die Besetzung der Bankspitze verfügt als die andere. Daher ergibt sich in beiden Fällen ein vergleichbarer Unabhängigkeitsgrad. 
Ebene 6: Kreis der Ernennungsfähigen

Die sechste Ebene berücksichtigt den Kreis der Personen, die prinzipiell ernennungsfähig sind. Eine Notenbank, die ihre Mitarbeiter selbst rekrutieren kann, kann dadurch in ihrer Entscheidungsfreiheit eingeschränkt werden, daß ihr von außen bestimmte Auflagen gemacht werden, welche Anforderungen die Kandidaten zu erfüllen haben. Sind dagegen andere Instanzen ernennungsbefugt, kann die Notenbank auf die personelle Besetzung einwirken, wenn sie den Kreis der Ernennungsfähigen beeinflussen kann, indem sie beispielsweise eine bestimmte fachliche Eignung der Kandidaten verlangt.

Die Bewertung der personellen Unabhängigkeit einer Notenbank anhand des vorliegenden Schemas führt zu einer Einordnung des Instituts auf der Skala von Unabhängigkeitsgraden. Diese sind durch in Klammern gesetzte Ziffern gekennzeichnet, die verdeutlichen sollen, daß es sich hier um eine rein ordinale Skala handelt. Die gleichen Abstände zwischen den Graden bedeuten also keine gleichgroße Differenz an personeller Unabhängigkeit. Die Skala der Unabhängigkeitsstufen wurde in vier Bereiche eingeteilt, nach der die Notenbanken je nach ihrer Bewertung als personell unabhängig, eher unabhängig, eher abhängig oder abhängig eingestuft werden können.

\subsection{Funktionelle Unabhängigkeit}

Die funktionelle Unabhängigkeit ist der Bereich, der direkt mit den geldpolitischen Entscheidungen der Notenbank zusammenhängt. Daher ist er für die Beurteilung der Unabhängigkeit einer Notenbank am bedeutsamsten. Bei der Untersuchung der funktionellen Ebene wird in der Literatur neben den Zielvorgaben und dem Instrumentarium der Zentralbanken besonders das Verhältnis zwischen Staat und Notenbank betrachtet. Dabei geht es u. a. um Fragen der Staatsfinanzierung durch das Noteninstitut und die Einwirkungsmöglichkeiten der Regierung auf die Geldpolitik der Notenbank. Auch werden internationale Erfordernisse und Vereinbarungen zunehmend als Gefahr für die Unabhängigkeit von Notenbanken gewertet.

\subsubsection{Globale Ziele einer Notenbank}

In diesem Kapitel soll der Zusammenhang von Zielen, die der Notenbank per Gesetz zugewiesen werden, und der Unabhängigkeit der Institute untersucht werden. Eine Untersuchung der Wirtschaftsberatungsgesellschaft MMS International Inc. ergab, daß die unabhängigsten Notenbanken das Ziel der Geldwertstabilität be- 
rücksichtigen oder gar in den Mittelpunkt stellen ${ }^{210}$. Caesar 211 definiert Ziele als Handlungsmaximen, an denen sich die Notenbank bei ihrer Aufgabenerfüllung orientieren soll. Als Ziele heutiger Zentralbanken gelten im wesentlichen die Herbeiführung bzw. Erhaltung von Zahlungsbilanzausgleich und Vollbeschäftigung bei stabilem Geldwert ${ }^{212}$, wobei die Geldwertstabilität in der Regel als wesentliche Aufgabe hervorgehoben wird ${ }^{213}$. In vielen Notenbankgesetzen sind die Zielsetzungen der Zentralbank - wenn überhaupt - nur vage formuliert. Ein wesentlicher Grund dafür mag sein, daß Notenbanken mit ihren Mitteln und Möglichkeiten nicht in der Lage sind, diese Ziele alleine zu erreichen 214 . Zudem würde eine über allgemeine Formulierungen hinausgehende gesetzliche Niederlegung der Zielsetzungen jedesmal dann eine Änderung des Gesetzes erfordern, wenn die Bank aufgrund sich wandelnder wirtschaftlicher Voraussetzungen ihre festgelegten Ziele nicht mehr erfüllen kann oder die Verfolgung anderer Ziele als die vorgegebenen in der konkreten Situation vordringlicher wäre215. Der Zentralbank wäre die Möglichkeit genommen, ihre Politik den gegebenen Voraussetzungen flexibel anzupassen. Jedoch wird vielfach kritisiert, daß der Notenbank aus einer unklaren Zielvorgabe durch den Gesetzgeber ein politischer Ermessensspielraum erwächst, der nicht demokratisch legitimiert ist und der in einem demokratischen Rechtsstaat verfassungsrechtliche Bedenken hervorrufen könnte 216.

Hahn 217 unterscheidet in Anlehnung an Veit ${ }^{218}$ zwischen endogenen und exogenen Zielsetzungen einer Notenbank. Endogene Zielsetzungen entspringen den eigenen Zielen und Daten der Zentralbank ${ }^{219}$. Darunter fallen die Ziele der Aufrechterhaltung von Wechselkurs- und Preisstabilität ${ }^{22}$. Exogene Zielsetzungen werden dagegen von außen an die Notenbank herangetragen ${ }^{221}$. Dazu zählt Hahn ${ }^{222}$ das Vollbeschäftigungspostulat, das er dem Zielkreis der Unterstützung

210 Vgl. Buba stands as most independent central bank. G7 Daily Briefing, Washington, September 1, 1995, abgedruckt in: Deutsche Bundesbank: Auszüge aus Presseartikeln Nr. 60 vom 6. September 1995, S. 7.

211 Vgl. Caesar, Rolf (1981): a.a.O., S. 65.

212 Vgl. Hahn, Oswald (1968) Bd. II: a.a.O., S. 49.

213 Vgl. Bernauer, Engelbert : a.a.O., S. 6.

214 Vgl. Keller, Paul: Von den Aufgaben der Notenbank in der Gegenwart, Zürich-St. Gallen 1950, S. 14f; Issing, Otmar (1975): a.a.O., S. 375.

215 Vgl. Keller, Paul: a.a.O., S. 17.

216 Vgl. Issing, Otmar (1975): a.a.O., S. .375

217 Vgl. Hahn, Oswald (1968) Bd. II: a.a.O., S. 49.

218 Vgl. Veit, Otto (1961), a.a.O., S. 101.

219 Vgl. Hahn, Oswald (1968) Bd. II: a.a.O., S. 49.

220 Vgl. Hahn, Oswald (1968) Bd. II: a.a.O., S. 49.

221 Vgl. Hahn, Oswald (1968) Bd. II: a.a.O., S. 49.

222 Vgl. Hahn, Oswald (1968) Bd. II: a.a.O., S. 49. 
der staatlichen Wirtschaftspolitik zurechnet. Alle drei Zielsetzungen beschränken seiner Ansicht nach die Unabhängigkeit einer Notenbank, wobei exogene Zielsetzungen sich nachteilig, endogene dagegen zugunsten der Währungsstabilität auswirken ${ }^{223}$. Auch andere Autoren sehen einen Zusammenhang zwischen der Unabhängigkeit einer Notenbank und den gesetzlich festgelegten Zielvorgaben des Instituts. Cukierman et al. ${ }^{224}$ werten Notenbanken, denen das Gesetz Geldwertstabilität als wesentliches oder ausschließliches Ziel vorgibt, als unabhängig im Gegensatz zu Notenbanken, denen keine expliziten Ziele vorliegen oder die einem Zielkatalog unterworfen sind, der das Ziel der Preisstabilität nicht enhält. Andere vertreten dagegen die Auffassung, der Handlungsspielraum einer Notenbank sei durch die Nennung von Zielen an sich bereits eingeschränkt, weil dadurch alle nicht ausdrücklich genannten Ziele zurückgedrängt werden 225 . Dies gelte um so mehr, je weniger die genannten Ziele miteinander konfligieren ${ }^{226}$. Im Extremfall ist die Notenbank explizit nur einem Ziel verpflichtet. Hier wäre jede Aktivität der Bank, die zulasten des vorgegebenen Ziels erfolgte, gesetzwidrig227. Der Handlungsspielraum einer Notenbank sei daher um so größer, je mehr Zielen die Bank unterworfen ist, je mehr Interpretationsspielräume diese zulassen und je weniger Vorgaben bezüglich einer Gewichtung oder Rangfolge der Ziele vorliegen ${ }^{228}$. Der Ermessensspielraum der Notenbanken bei der Zielfestlegung ist gewöhnlich sehr groß, da auch scheinbar exakt formulierte Zielbenennungen unterschiedlich interpretierbar sind 229 . Selbst wenn beim Vorliegen mehrerer Ziele eine Rangfolge festgelegt ist, liegt es doch im Ermessen der Notenbank festzustellen, wann ein Ziel so weit erfüllt ist, daß weitere mitverfolgt werden können 230 . Für eine Minderung der Unabhängigkeit mit zunehmender Breite des möglichen Zielspektrums wird dagegen das tendenziell dadurch zunehmende Konfliktpotential angeführt 231 . Eine konkrete Zielvorgabe biete dem Staat oder Interessengruppen weniger Angriffsfläche für Pressionen 232. Die Praxis würde zeigen, daß formal unabhängige Notenbanken häufig nur wenigen Zielen oder gar ausschließlich dem Stabilitätsziel verpflichtet seien, wohingegen die Ziele formal weniger

223 Vgl. Hahn, Oswald (1968) Bd. II: a.a.O., S. 50.

224 Vgl. Cukierman, Alex; Webb, Steven B.; Neyapti, Bilin: Measuring the independence of central banks and ist effects on policy outcomes, in: The World Bank economic review, Vol. 6, No. 3, S. 357.

Vgl. Caesar, Rolf (1981): a.a.O., S. 63 und S.76.

226 Vgl. Caesar, Rolf (1981): a.a.O., S. 76.

227 Vgl. Caesar, Rolf (1981): a.a.O., S. 76.

228 Vgl. Caesar, Rolf (1981): a.a.O., S. 76ff.

229 Näher ausgeführt bei Caesar, Rolf (1981): a.a.O., S. 77f.

230 Vgl. Caesar, Rolf (1981): a.a.O., S. 82.

231 Vgl. Caesar, Rolf (1981): a.a.O., S. 82 und 84; Issing, Otmar (1975): a.a.O., S. 375.

232 Vgl. Hahn, Oswald (1968) Bd. II: a.a.O., S. 53. 
unabhängiger Notenbanken häufig unklar formuliert oder konfligierend seien 233 . Castello-Branco und Swinburne ${ }^{234}$ begründen das damit, daß die gesetzliche Ausrichtung einer Notenbank auf ein fixiertes Ziel die Glaubwürdigkeit der Geldpolitik erhöht. Glaubwürdigkeit sei die Grundlage einer die Unabhängigkeit von Zentralbanken unterstützenden Argumentation ${ }^{235}$, weil Fehler bei der Verfolgung eines Ziels nicht mit dem Hinweis auf andere Ziele entschuldigt werden können 236. Zudem träte dies der Neigung der Politiker entgegen, die Transparenz durch Verlagerung der Gewichte zwischen verschiedenen Zielen zu verringern, um damit die Verantwortung der Zentralbank und der politischen Führung abzuschwächen 237 . Desweiteren bestünde bei multiplen makroökonomischen Zielen die Gefahr, daß Regierung und Notenbank verschiedene Mischungen eines grundsätzlich gleichen Zielkatalogs verfolgen. Effektive Koordination und Verantwortlichkeit würden dann eine der Regierungskontrolle unterworfene Notenbank erfordern ${ }^{238}$. Schließlich wird vorgebracht, daß die Geldpolitik als einzelnes Instrument sich nicht gleichzeitig mehreren Zielen verpflichten kann, die zumindest kurzfristig miteinander konfligieren 239.

Zu dem Argument der höheren Glaubwürdigkeit der Geldpolitik bei Ausrichtung der Notenbank auf ein konkretes Ziel und die daraus resultierende Möglichkeit einer klaren Verantwortungszuweisung ist folgendes anzumerken. Eine Notenbank, die beispielsweise explizit einem stabilen Geldwert verpflichtet ist, kann mit den ihr zur Verfügung stehenden Mitteln nur bedingt auf die Geldwertstabilität Einfluß nehmen. Auf wesentliche den Geldwert beeinflussende Bereiche wie Lohnpolitik, Ausgabeverhalten öffentlicher Haushalte etc., hat sie keinen Einfluß. Die ausdrückliche Verpflichtung der Notenbankfunktionäre auf die Geldwertstabilität ermöglicht zwar eine zweifelsfreie öffentliche Kontrolle 240 , andererseits ist die Glaubwürdigkeit der Geldpolitik dadurch eher gefährdet als erhöht, wenn man ihr quasi die alleinige Verantwortung für den Geldwert aufbürdet, der sie nicht gerecht werden kann. Auch der Einwand, effektive Koordination und Verantwortlichkeit bei multiplen makroökonomischen Zielen der Notenbank erfordere eine der Regierungskontrolle unterworfene Notenbank, ist nicht überzeugend. Die gleiche Argumentation ließe sich bei einer Notenbank führen, die nur einem Ziel, z. B. der Geldwertstabilität, verpflichtet wäre. Durch die engen Zusammenhänge zwischen den einzelnen Politikbereichen würde auch hier eine

233 Vgl. Swinburne, Mark; Castello-Branco, Marta: a.a.O., S. 24.

234 Vgl. Swinburne, Mark; Castello-Branco, Marta: a.a.O., S. $24 f$.

235 Vgl. Swinburne, Mark; Castello-Branco, Marta: a.a.O., S. $24 f$.

236 Vgl. Castello-Branco, Marta; Swinburne, Mark: a.a.O., S. 20f.

237 Vgl. Castello-Branco, Marta; Swinburne, Mark: a.a.O., S. 21.

238 Vgl. Swinburne, Mark; Castello-Branco, Marta: a.a.O., S. 25.

239 Vgl. Swinburne, Mark; Castello-Branco, Marta: a.a.O., S. 25.

240 Vgl. Schmitz, Wolfgang (1989): a.a.O., S. 19. 
mangelnde Koordination von Geldpolitik der Notenbank und der allgemeinen Wirtschaftspolitik des Staats dazu führen, daß beide Institutionen gegeneinander arbeiten.

Welchen Einfluß haben die gesetzlich fixierten Ziele nun auf die Unabhängigkeit einer Notenbank. Man könnte argumentieren, daß jegliche gesetzliche Fixierung von Zielen die geldpolitische Entscheidungsfreiheit einer Notenbank einschränkt. In diesem Fall müßte aber bereits das Vorhandensein eines Notenbankgesetzes die Unabhängigkeit einer Notenbank erheblich mindern. Zudem verdanken Notenbanken ihre Existenz der Notwendigkeit, daß bestimmte Aufgaben erfüllt und Ziele erreicht werden müssen. Derartige Argumentationen sind also wenig hilfreich. Die hier verwendete Definition beschränkt Unabhängigkeit auf die Entscheidungsfreiheit der Notenbank bei geldpolitischen Entscheidungen. Damit ist die Unabhängigkeit gemeint, die "währungspolitische Aufgabe nach eigenem Ermessen zu erfüllen und schließt keinesfalls die Kompetenz ein, den Inhalt der eigenen Aufgabe zu bestimmen"241. Für die Unabhängigkeit einer Notenbank ist es also unerheblich, wievielen und welchen Zielen sie unterworfen ist bzw. wie klar diese formuliert sind. Eine Notenbank, die ausschließlich dem Ziel der Geldwertstabilität verpflichtet ist, ist nicht unabhängiger als eine, die allgemein den Zielen des magischen Vierecks unterworfen ist. Das alleinige Ziel der Geldwertstabilität wird einer Notenbank vermutlich die Inflationsbekämpfung erleichtern. Dies ist aber kein Kriterium für Unabhängigkeit.

\subsubsection{Temporäre Ziele einer Notenbank}

In vielen Staaten gibt es Formen von Zwischenzielen, die von den Notenbanken angestrebt werden. Besonders nach den Erfahrungen der weltweiten Inflation von 1973/1974 wurden in vielen Ländern solche Ziele eingeführt 242 . Diese beziehen sich in der Regel auf monetäre Aggregate; aber auch Inflations-243 und Wechselkursziele 244 sind durchaus üblich. Zwischenziele haben eine Reihe von Vorzügen. Leicht zu beobachtende Maßstäbe erleichtern die Erfolgskontrolle der Geldpolitik. Zudem läßt sich daraus leichter ein konkreter Maßnahmenplan erstellen als dies aufgrund der Ausrichtung auf die allgemeine, im Gesetz festgelegte Zielsetzung der Notenbank möglich wäre ${ }^{245}$. Die Möglichkeit der Überwachung

241 Issing, Otmar (1975): a.a.O., S. 375, so auch Poullain, Ludwig: a.a.O., S. 41

242 Vgl. Chrystal, Alec K.: Commentary: The Behavior of Foreign Central Banks: Comparisons and Contrasts with Fed Performance, in: Belongia, Michael T. (Hrsg.): Monetary Policy on the 75th Anniversary of the Federal Reserve System, Boston, Dordrecht, London 1991, S. 86f.

243 Z. B. in Neuseeland.

244 Z. B. in den Niederlanden.

245 Vgl. Swinburne, Mark; Castello-Branco, Marta: a.a.O., S. 29. 
der Notenbank anhand von Zwischenzielen mag in Grenzen auch als Substitut für den oft kritisierten Mangel an demokratischer Legitimation autonomer Notenbanken gelten 246 . Wesentlicher ist aber, daß die Geldpolitik der Notenbank für die Wirtschaftssubjekte berechenbarer wird. Die Gefahr sinkt, daß Wirtschaftssubjekte die Intension der geldpolitischen Aktivitäten der Notenbank mißinterpretieren und daraufhin ihre Entscheidungen an irrigen Annahmen über die künftige Geldpolitik ausrichten ${ }^{247}$. Dies wiederum erleichtert die monetäre Steuerung und reduziert das erforderliche Ausmaß notenbankpolitischer Korrekturmaßnahmen $^{248}$. Andererseits erhöhen Zwischenziele die Gefahr, daß die Geldpolitik an notwendiger Flexibilität verliert 249 .

Wie wirken sich Zwischenzielvorgaben auf die Unabhängigkeit einer Notenbank aus? Zweifellos beschränken sie den Handlungsspielraum des Instituts 250 . Andererseits sind konkrete Zwischenziele geeignet, die Notenbank gegenüber potentiellem Druck von außen zu stärken ${ }^{251}$. Hier könnte man aber wiederum argumentieren, daß dadurch allenfalls eine Verlagerung dieser Pressionen auf den Willensbildungsprozeß zur Festlegung des Zwischenzieles stattfindet 252 .

Gewöhnlich bestimmt die Notenbank selbst das Zwischenziel. Es liegt also eine Selbstbindung des Währungsinstituts vor. Die sich daraus ergebende Einschränkung des Handlungsspielraumes der Bank ist nicht von außen induziert. Insofern ist die Unabhängigkeit der Notenbank nicht berührt. Für den Fall, daß Zwischenziele nicht von der Notenbank selbst, sondern von der Regierung oder anderen externen Instanzen vorgegeben werden, wird der Handlungsspielraum des Währungsinstitutes von außen beschränkt. Doch auch hier liegt keine Einschränkung der Unabhängigkeit vor, weil die Notenbank den Weg selbst bestimmen kann, wie sie dieses Ziel erreichen will. Sie kann ihre geldpolitischen Entscheidungen trotzdem frei treffen. Von externen Instanzen vorgegebene Zwischenziele schränken die Unabhängigkeit also genausowenig ein wie gesetzlich vorgeschriebene Ziele einer Notenbank.

246 Vgl. Rich, Georg: Central Bank Autonomy: A Swiss Perspective, in: Banco Central De Chile (Hrsg.): Seminario "Experiencias sobre Autonomia e la Banca Central", Santiago 1989 , S. 30.

247 Vgl. Rich, Georg (1989): a.a.O., S. 30.

248 Vgl. Caesar, Rolf (1981): a.a.O., S. 120f.

249 Vgl. Swinburne, Mark; Castello-Branco, Marta: a.a.O., S. 30.

250 Vgl. Rich, Georg (1989): a.a.O., S. 29; Caesar, Rolf (1981): a.a.O., S. $119 f$.

251 Vgl. Caesar, Rolf (1981): a.a.O., S. 122.

252 Vgl. Caesar, Rolf (1981): a.a.O., S. $122 f$. 


\subsubsection{Geldpolitisches Instrumentarium}

Eine Notenbank ist nur dann instrumentell unabhängig, wenn sie ihre Instrumente uneingeschränkt einsetzen kann ${ }^{253}$. Das setzt voraus, daß ihr die existierenden geldpolitischen Instrumente prinzipiell zur Verfügung stehen. Sonst würde eine Notenbank, die nur über ein geringes, wenig wirkungsvolles Instrumentarium verfügt, ebenso unabhängig sein wie eine Zentralbank mit umfangreichen schlagkräftigen Mitteln, die sie nach ihrem eigenen Ermessen anwenden darf. Funktionelle Unabhängigkeit erfordert also, daß die Notenbank alle existierenden geldpolitischen Instrumente nach ihrem Ermessen einsetzen darf. Um ihre Unabhängigkeit zu bewahren, muß dies auch für alle Instrumente gelten, die sich erst in Zukunft (z. B. in Anpassung an sich wandelnde wirtschaftliche Gegebenheiten) entwickeln. Insofern kann die Unabhängigkeitsuntersuchung nur eine Zeitpunktanalyse sein und nur eine Aussage über den derzeitigen Unabhängigkeitsgrad einer Zentralbank treffen.

Für die Beurteilung der funktionellen Unabhängigkeit müssen prinzipiell zwei Fragen beantwortet werden?

1. Welche Instrumente stehen der Notenbank prinzipiell zur Verfügung?

2. Wird der Einsatz dieser Instrumente in irgendeiner Form eingeschränkt?

\subsubsection{Prinzipieller Umfang des geldpolitischen Instrumentariums}

Um zu prüfen, ob einer Notenbank die Gesamtheit des geldpolitischen Instrumentariums zur Verfügung steht, muß zunächst geklärt werden, was man unter geldpolitischen Instrumenten versteht. In der Geldpolitik lassen sich Ordnungs- und Prozeßpolitik unterscheiden ${ }^{254}$. Aufgabe der Ordnungspolitik ist die Beeinflussung der Geldordnung und ist Sache der Regierung bzw. des Parlaments. Sie ist nicht Gegenstand der vorliegenden Untersuchung. Die Prozeßpolitik ist die eigentliche Aufgabe der Geldpolitik. Daher versteht man üblicherweise unter geldpolitischen Instrumenten diejenigen der Prozeßpolitik ${ }^{255}$. Mit dem Einsatz dieser Instrumente sollen Geldnachfrage und Geldangebot durch die Veränderung von Zins, Geldmenge und Liquidität beeinflußt werden. Unter geldpolitischen Instrumenten könnte man also alle Instrumente zusammenfassen, die geeignet sind, Geldnachfrage und Geldangebot über die Regulierung von Preis (Zins) und Men-

\footnotetext{
253 Vgl. Müller, Lothar: Die Problematik einer europäischen Zentralbank, in: EuropaArchiv, Folge 12/1990, S. 386; ähnlich auch Hahn, Hugo J.; Siebelt, Johannes: a.a.O., S. 234.

254 Vgl. Dickertmann, Dietrich; Siedenberg, Axel: Instrumentarium der Geldpolitik, Düsseldorf 1984, S. 1.

255 Vgl. Schaal, Peter: Geldtheorie und Geldpolitik, 2. Aufl., München 1989, S. 261.
} 
ge von Geld zu manipulieren, oder allgemeiner ausgedrückt, Instrumente zur Steuerung der Geldversorgung einer Volkswirtschaft.

Es gibt verschiedene Klassifizierungen des geldpolitischen Instrumentariums, von denen hier die wichtigsten kurz aufgeführt werden sollen. In der Regel wird zwischen indirekten und direkten geldpolitischen Instrumenten unterschieden, wobei unter direkten die verschiedenen Arten der Kreditplafondierung und unter indirekten die marktkonformen Mittel verstanden werden 256 . Die direkten Instrumente werden auch als dirigistisch bezeichnet ${ }^{257}$. Sie sind dazu geeignet, den Marktmechanismus außer Kraft zu setzen oder zu verzerren ${ }^{258}$. Schmölders unterscheidet nach klassischem und modernem Instrumentarium der Geldpolitik ${ }^{259}$. $\mathrm{Zu}$ den klassischen Instrumenten zählt er die Diskontpolitik, Offenmarktpolitik, Interventionen an den Devisenmärkten und Moral Suasion, während Mindestreservenund Einlagenpolitik, behördliche Liquiditätskontrollen sowie direkte (selektive) Liquiditätskontrollen unter modernen Mitteln zusammengefaßt sind 260 . Eine andere Differenzierung ist die zwischen primär außenwirtschaftlich ausgerichteten und primär binnenwirtschaftlich ausgerichteten Instrumenten, wobei berücksichtigt werden muß, daß außenwirtschaftlich orientierte Instrumente auch binnenwirtschaftliche Effekte hervorrufen und umgekehrt ${ }^{261}$. Zu den wichtigsten primär binnenwirtschaftlich ausgerichteten Instrumenten gehören Offenmarktpolitik, Refinanzierungspolitik (Rediskont- und Lombardpolitik), Refinanzierungskontingentpolitik, Passiv-Mindestreservepolitik, Einlagenverpflichtung und -politik, Bankenaufsicht ${ }^{262}$, der Erlaß von Anlagevorschriften für die Kreditinstitute, Zinslimitierung oder -fixierung, Aktiv-Mindestreservepolitik und Kreditplafondierung 263. Unter Instrumente mit primär außenwirtschaftlicher Zielrichtung fallen Devisenkurspolitik (Paritätsfestlegung, Interventionen auf dem Kassa- und/oder Terminmarkt, Swapsatzpolitik), Mindestreservepolitik im Dienste außenwirtschaftlicher Absicherung, Bardepot-Pflicht sowie die Politik der administrativen Beschränkungen des Geld- und Kapitalverkehrs ${ }^{264}$. Nachdem nun ein Überblick über das gängige geldpolitische Instrumentarium verschafft wurde, ist zu überle-

256 Vgl. Köhler, Claus: Geldwirtschaft, 1. Bd. Geldversorgung und Kreditpolitik, 2. Aufl., Berlin 1977, S. 232.

257 Vgl. Schaal, Peter: a.a.O., S. 261.

258 Vgl. Schaal, Peter: a.a.O., S. 261.

259 Vgl. Schmölders, Günter (1968): a.a.O., S. 246ff.

260 Vgl. Schmölders, Günter (1968): a.a.O., S. 246ff.

261 Vgl. Caesar, Rolf (1981): a.a.O., S. 86.

262 Wobei hier umstritten ist, ob Bankenaufsicht als echtes Instrument der Geldpolitik betrachtet werden kann; Vgl. Veit, Otto: Grundriß der Währungspolitik, Frankfurt/Main 1969, S. 208.

263 Vgl. Caesar, Rolf(1981): a.a.O., S. 86f.

264 Vgl. Caesar, Rolf (1981): a.a.O., S. 87f. 
gen, wie geprüft werden kann, ob einer Notenbank das existierende geldpolitische Instrumentarium prinzipiell zur Verfügung steht. Folgende Probleme tauchen dabei auf.

\subsection{Gesamtheit des Instrumentariums}

In der Literatur sind zwar die gängigen geldpolitischen Instrumente ausreichend beschrieben, aber daraus läßt sich nicht die Gesamtzahl der existierenden Instrumente ermitteln. Zudem dürfte nicht immer zweifelsfrei zu trennen sein, welches ein selbständiges geldpolitisches Instrument und welches ein Teilbereich oder eine Unterart eines anderen Instruments ist. Da sich die Anzahl existierender geldpolitischer Instrumente nicht eindeutig feststellen läßt, kann man die funktionelle Unabhängigkeit nicht anhand der einer Notenbank zur Verfügung stehenden Instrumente in Relation zur Gesamtheit des Instrumentariums beurteilen.

\subsection{Juristisches und faktisches Instrumentarium}

Es kann Unterschiede geben zwischen dem juristischen und dem faktischen Instrumentarium. In der Regel sind Notenbankgesetze so konstruiert, daß die Anwendung nicht ausdrücklich zugelassener Instrumente verboten ist ${ }^{265}$ und insofern das faktische Instrumentarium dem juristischen entspricht. Aber es ist durchaus üblich, daß Notenbanken ihr Instrumentarium ohne gesetzliche Grundlage weiterentwickeln, sei es in Form von gänzlich neuen Instrumenten oder von qualitativen Veränderungen bereits vorhandener Instrumente 266 . Dies ist erforderlich, um den Anschluß an die "fortschreitende Entwicklung der Geldwirtschaft267" zu behalten. Zudem ist es sinnvoll, neue Instrumente erst zu erproben, bevor sie im Gesetz niedergelegt werden ${ }^{268}$. Es gibt zahlreiche Beispiele, wo Gesetze nachträglich bestätigen, was sich in der Praxis herausgebildet hat ${ }^{269}$. Insofern kann es schwierig sein, den tatsächlichen Umfang des erlaubten Instrumentariums einer Notenbank zu erfassen, wenn man ausschließlich die Notenbankgesetzgebung betrachtet.

265 Vgl. Pfleiderer, Otto: a.a.O., S. 418.

266 Vgl. Caesar, Rolf (1981): a.a.O., S. 93.

267 Schmölders, Günter (1968): a.a.O., S. 223.

268 Vgl. Kerschagl, Richard: Ungelöste Probleme der modernen Währungspolitik, Sonderdruck aus Schmollers Jahrbuch für Gesetzgebung, Verwaltung und Volkswirtschaft, 76. Jg. 4. Heft 1956, S. 96 f.

269 Beispiele dazu z.B. bei Schuppler, Edith: a.a.O., S. 33; Caesar, Rolf (1981): a.a.O., S. 93f. 


\subsection{Durchsetzungsverfahren geldpolitischer Instrumente}

Neben geldpolitischen Instrumenten lassen sich auch die Methoden ihrer Durchsetzung unterscheiden. In der Literatur werden beide häufig nicht ausreichend getrennt. Durchsetzungsverfahren können entweder auf freiwilliger oder auf gesetzlicher Grundlage beruhen. Zu der ersteren Gruppe sind Gentlemen's Agreements und Moral Suasion $270 \mathrm{zu}$ rechnen, während administrative Festlegungen die Verfahren auf gesetzlicher Grundlage darstellen. Unter Gentlemen's Agreements in der Geldpolitik versteht man „befristete freiwillige Vereinbarungen zwischen der Notenbank und den Geschäftsbanken (gegebenenfalls auch weiteren Gruppen), aufgrund deren sich die Banken ohne Rechtszwang schriftlich verpflichten, bei ihrer Geschäftsgebarung jeweils bestimmte gesamtwirtschaftlich relevante Richtlinien einzuhalten“271. Mittels Moral Suasion versucht die Zentralbank, die betroffenen Wirtschaftssubjekte durch Ratschläge zu einem zielkonformen Verhalten im Sinne der Notenbank zu bewegen 272. Theoretisch könnte eine Notenbank auf solchem Wege genau die gleichen Instrumente anwenden mit dem gleichen Ergebnis, das mittels administrativer Durchsetzung erreicht würde. Dies sei am Beispiel des Instruments der Kreditplafondierung verdeutlicht. Bei administrativer Durchsetzung ist die Notenbank beispielsweise befugt, die $\mathrm{Zu}$ wachsrate der Kreditgewährung der Banken auf einen bestimmten Prozentsatz zu begrenzen. Das gleiche Ergebnis könnte sie theoretisch erreichen, indem sie an die Banken appelliert, diese Zuwachsrate nicht zu überschreiten und die NichtBanken zu einer Einschränkung ihrer Kreditnachfrage ermahnt ${ }^{273}$. Ebenso könnte sie mit den Banken entsprechende Verträge über eine Kreditbeschränkung abschließen. In den beiden letzten Fällen ist die Notenbank natürlich auf die Einsicht und Mithilfe der Banken bzw. anderer Wirtschaftssubjekte angewiesen. Für den Umfang des einer Notenbank zur Verfügung stehenden Instrumentariums hat dies folgende Bedeutung. Ist einem Noteninstitut die Anwendung eines Instruments nicht erlaubt, so bezieht sich dieses Verbot in der Regel auf die administrative Anwendung des betreffenden Instruments. Das bedeutet nicht zwangsläufig, daß das Mittel auch nicht auf freiwilliger Basis angewendet werden könnte. Moral Suasion und Gentlemen's Agreements bedürfen als Ergebnis freiwilliger Vereinbarungen zwischen Notenbank und Banken keiner gesetzlichen

270 Moral Suasion und Gentlemen's Agreements werden in der Literatur in der Regel zum geldpolitischen Instrumentarium gezählt, wie z.B. bei Caesar, Rolf (1981): a.a.O., S. 93.

271 Tuchtfeldt, Egon: Gentlemen's Agreements als Instrument der schweizerischen Geldpolitik, in: Andreae, C. A.; Hansmeyer, K. H.; Scherhorn, G. (Hrsg.): Geldtheorie und Geldpolitik, Günter Schmölders zum 65. Geburtstag, Berlin 1968, S. 40.

272 Vgl. Scheithauer, Max: Moral Suasion - ein Instrument der Währungspolitik, in: Österreichisches Bankarchiv Jg. 23, 9/1975, S. 323f.

273 Vgl. Bredemeier, Sonning: Erfahrungen mit der Kreditplafondierung, Berlin 1972, S. 73. 
Grundlage 274. So wurde beispielsweise das Mindestreserveinstrument in der Schweiz lange Zeit 275 mittels freiwilliger Vereinbarungen mit den Banken praktiziert, obwohl es nicht im Gesetz aufgeführt war. Zur Beurteilung der funktionellen Unabhängigkeit muß also neben dem einer Notenbank per Gesetz zur Verfügung stehenden Instrumentarium auch berücksichtigt werden, inwieweit das Institut auf dem Wege freiwilliger Vereinbarungen oder Appellen die Möglichkeit hat, im Gesetz nicht vorgesehene Instrumente anzuwenden. Bei der funktionellen Unabhängigkeit, gemessen an der Einschränkung der Entscheidungsfreiheit, sind daher folgende Abstufungen möglich. Die größte funktionelle Unabhängigkeit besteht, wenn die Notenbank ein Instrument administrativ anwenden darf, weil sie hier die alleinige Entscheidungsbefugnis innehat. Eine Einschränkung der funktionellen Unabhängigkeit liegt vor, wenn ein Instrument im Gesetz nicht vorgesehen ist, $d . h$. eine administrative Durchsetzung nicht möglich ist, aber eine Anwendung auf freiwilliger Basis nicht verboten ist. Die Einschränkung liegt darin, daß die Bank nicht alleine über die Anwendung des Instrumentes entscheiden kann, da sie hier auf die Zustimmung der Adressaten 276 angewiesen ist. Die größte Einschränkung der Entscheidungsfreiheit der Notenbank liegt vor, wenn sie ein betreffendes Instrument weder administrativ noch im Wege freiwilliger Vereinbarungen anwenden darf.

\subsection{Wirkungsgrad der Instrumente}

Ist ermittelt, welche Instrumente eine Notenbank prinzipiell anwenden darf, stellt sich die Frage nach der Gewichtung der einzelnen Instrumente. Muß bei der Beurteilung des Umfanges des einer Notenbank zur Verfügung stehenden Instrumentariums der Wirkungsgrad der einzelnen Instrumente berücksichtigt werden? Ist eine Notenbank, die beispielsweise fünf schlagkräftige Instrumente anwenden darf, funktionell unabhängiger als eine, der die gleiche Anzahl weniger wirkungsvoller Mittel zur Verfügung steht? Ist das der Fall, wie bewertet man die Schlagkraft geldpolitischer Instrumente? Caesar 277 verwendet als Kriterium für die Wirksamkeit geldpolitischer Instrumente das Ausmaß, in dem "unter den konkreten einzel- und gesamtwirtschaftlichen Bedingungen die von der Notenbank angestrebten Wirkungen tatsächlich erreicht werden können"278. Dieses hängt zum einen von den Wirkungsgrenzen der Geldpolitik im allgemeinen und zum anderen

274 Vgl. Caesar, Rolf (1981): a.a.O., S. 94.

275 Erst im 1979 revidierten Nationalbankgesetz ist das Mindestreserveinstrument enthalten

276 Mit Adressaten sind hier nicht zwangsläufig diejenigen gemeint, auf die das Instrument letztlich wirken soll, sondern die Akteure, mit denen die Notenbank die Vereinbarungen treffen möchte

277 Vgl. Caesar, Rolf (1981): a.a.O., S. 95.

278 Caesar, Rolf (1981): a.a.O., S. 95. 
von den Anreizen ab, die die jeweiligen Instrumente bieten, die Adressaten zu einem bestimmten Verhalten zu veranlassen 279 .

$\mathrm{Zu}$ den allgemeinen Effizienzproblemen der Geldpolitik zählen im wesentlichen die Einflüsse der Lohnpolitik, der Finanzpolitik des Staates sowie außenwirtschaftliche Faktoren ${ }^{280}$. Da hiervon alle Instrumente betroffen sind, sollen sie an dieser Stelle nicht näher beleuchtet werden. Neben den allgemeinen Wirkungshemmnissen sind für die Durchschlagskraft einzelner geldpolitischer Instrumente eine Vielzahl von Faktoren von Bedeutung, die im folgenden nur grob umrissen werden. Je mehr die Notenbank beim Einsatz eines Instruments auf die Mitwirkung anderer Wirtschaftssubjekte angewiesen ist, desto geringer ist tendenziell der Wirkungsgrad des Mittels. Damit hängen die Ausweichmöglichkeiten der Adressaten (z. B. Refinanzierungsmöglichkeiten im Ausland, autonome Geldkreisläufe im Nichtbankensektor etc.) eng zusammen ${ }^{281}$, die um so eher genutzt werden, je genauer die Opfer der Notenbankpolitik erkennbar sind (gruppenmäßige Indifferenz) ${ }^{282}$. Die spezifische konjunkturelle Situation ${ }^{283}$ beeinflußt die Wirkung des einzelnen geldpolitischen Mittels ebenso wie die Wirtschaftsstruktur eines Landes oder der Entwicklungsgrad der Finanzmärkte. So kann beispielsweise ein Mangel an gut entwickelten Finanzmärkten und Geldmarktinstrumenten die Notenbank in ihren Möglichkeiten Offenmarktpolitik zu betreiben erheblich einschränken. Ein weiteres Kriterium, das die Effizienz geldpolitischer Instrumente beeinflußt, sind die verschiedenen Time lags der Geldpolitik ${ }^{284}$. Auch Wechselwirkungen mit anderen Instrumenten bewirken je nach Kombination der Instrumente eine unterschiedliche Durchschlagskraft eines geldpolitischen Mittels 285 . Schließlich hängt der Wirkungsgrad auch von der Ausgestaltung des betreffenden Instruments $\mathrm{ab}$. Je umfassender ein Instrument die Adressatenkreise der Geldpolitik abdeckt, desto größer ist die Wirkung ${ }^{286}$. Geldpolitische Mittel

279 Vgl. Caesar, Rolf (1981): a.a.O., S. 95f.

280 Dazu ausführlich bei Caesar, Rolf (1981): a.a.O., S. $99 \mathrm{ff}$.

281 Dazu ausführlich bei Hankel, Wilhelm: Mehr Stabilität durch eine Offenmarktpolitik mit Jedermann - Effizienzbedingungen der Geld- und Kreditpolitik in einer offenen Volkswirtschaft, in: Duwendag, Dieter (Hrsg.): Macht und Ohnmacht der Bundesbank, Frankfurt/M. 1973, S. 151f.

282 Vgl. Caesar, Rolf (1981): a.a.O., S. 96f.

283 Die meisten Instrumente greifen im Boom besser als in Rezession, da sie vorwiegend auf Nachfragesteuerung ausgelegt sind.

284 Dazu ausführlich z.B. bei Badura, Jürgen: Time lags der Geldpolitik, in: Badura, Jürgen; Issing, Otmar (Hrsg.): Geldpolitik, Stuttgart, New York 1980, S. 24-37; Steeb, Guido: Time lags der Geldpolitik, Frankfurt am Main 1978.

285 Als Beispiel sei hier auf die Zangenwirkung von Mindestreserve- und Diskontpolitik hingewiesen.

286 Vgl. Caesar, Rolf (1981): a.a.O., S. 148. 
wirken zudem in unterschiedlichem Ausmaß auf verschiedene Adressaten ${ }^{287}$. Die Notenbank kann dies um so eher berücksichtigen, wenn die geldpolitischen Instrumente auch selektiv angewendet werden können. Auch Ausweichhandlungen der Adressaten werden so eher beeinflußbar.

Diese Vielzahl von Faktoren, die die Wirksamkeit eines Instruments beeinflussen, legt nahe, daß eine generelle Aussage über die Durchschlagskraft einzelner geldpolitischer Mittel nicht getroffen werden kann. Auch im konkreten Einzelfall fällt eine Beurteilung schwer. Zudem gibt es verschiedene Arten von Effizienz eines geldpolitischen Instruments. Geldpolitische Mittel können beispielsweise in stabilitätspolitischer Hinsicht eine andere Effizienz aufweisen als in wachstumspolitischer. Johnson 288 unterscheidet sogar drei Aspekte der geldpolitischer Effizienz, nämlich die strukturelle Effizienz als Wirtschaftlichkeit des Bankgewerbes, die Effizienz im Hinblick auf eine langfristige Wirtschaftspolitik sowie die Effizienz im Hinblick auf die Stabilitätspolitik. Die Effizienz geldpolitischer Instrumente hängt also auch von der jeweiligen Zielsetzung der Geldpolitik ab. Da die Ziele der Geldpolitik kein Kriterium für Unabhängigkeit einer Notenbank sind, ist auch keine Festlegung auf einen konkreten Effizienzbegriff sinnvoll. Spätestens hier wird deutlich, daß eine Effizienzbetrachtung des Instrumentariums im hier benötigten Sinne nicht möglich ist und daher auch keine Gewichtung der einer Notenbank zur Verfügung stehenden Mittel entsprechend ihrer Wirksamkeit. Ist eine solche Gewichtung überhaupt notwendig? Die Unabhängigkeit einer Notenbank mißt sich laut Definition an dem Grad der Entscheidungsfreiheit einer Notenbank beim Einsatz geldpolitischer Mittel. Jedes Instrument, das ihr nicht oder nur begrenzt zur Verfügung steht, mindert diese Entscheidungsfreiheit. Dabei ist es unerheblich, ob es sich um ein schlagkräftiges oder ein weniger wirkungsvolles Instrument handelt. Das Verbot der Anwendung eines schlagkräftigen Instrumentes beschränkt die Entscheidungsfreiheit einer Zentralbank gleichermaßen wie das Verbot eines verhältnismäßig unbedeutenden. Sie kann keines von beiden anwenden, wenn sie dies wollte.

\subsubsection{Anwendungsbeschränkungen des Instrumentariums}

Die Einschränkung der Anwendung prinzipiell erlaubter Instrumente lassen sich nach technisch-institutionellen Einschränkungen und Einschränkungen durch notenbankfremde Instanzen unterscheiden. Technisch-institutionelle Einschränkungen sind - in der Regel gesetzlich festgelegte - Grenzen bei der Anwendung der einzelnen geldpolitischen Instrumente. Der Extremfall ist das völlige Verbot der Anwendung eines geldpolitischen Mittels. Technisch-institutionelle Einschrän-

287 So ist beispielsweise der staatliche Sektor weitaus zinsunempfindlicher als der private.

288 Vgl. Johnson, Harry G.: Problems of Efficiency in Monetary Management, in: Journal of Political Economy, Vol. 76, S. 972. 
kungen zeichnen sich dadurch aus, daß sie ständig in gleichem Umfang vorhanden sind. Die Notenbank kann sich daher auf diesen Mangel im geldpolitischem Instrumentarium einstellen und versuchen, diesen durch den Einsatz anderer Mittel zu kompensieren. Die Bank bleibt die einzige Instanz, die auf die geldpolitischen Entscheidungen Einfluß hat. Im Falle von Einschränkungen durch Externe sind dagegen bankfremde Instanzen am Entscheidungsproze $B$ über den Einsatz geldpolitischer Instrumente beteiligt.

\subsection{Technisch-institutionelle Einschränkungen}

\subsection{Regelungen zur Ausgestaltung geldpolitischer Instrumente}

Die Anwendung der Instrumente kann im Einzelfall näher geregelt sein. So kann z. B. der Einsatz eines Mittels an bestimmte Voraussetzungen geknüpft sein, etwa dergestalt, da $\beta$ das Instrument nur beim Vorliegen bestimmter Bedingungen 289 angewendet werden darf oder auch, $\mathrm{da} \beta$ es in diesem Fall angewendet werden muß. Desweiteren kann der Adressatenkreis geldpolitischer Instrumente näher bestimmt sein. So sind z. B. die direkten Einwirkungsmöglichkeiten in der Regel auf Geschäftsbanken beschränkt und lassen häufig selbst bankähnliche Unternehmen wie Bausparkassen und Versicherungen unberücksichtigt ${ }^{290}$. Ferner kann geregelt sein, ob die Notenbank ein geldpolitisches Instrument nur global oder auch selektiv einsetzen darf. Bei globalem Einsatz wirken die Instrumente gegen jeden, der den Regeln der Anwendung dieser Mittel unterworfen ist, während die Notenbank bei einer differenzierten Ausrichtung geldpolitischer Mittel bestimmte Adressaten besonderen geldpolitischen Maßnahmen unterwirft oder sie davon ausnimmt ${ }^{291}$. Ein selektiver Einsatz ist z. B. nach In- und Ausländern, Kreditarten, Regionen oder Art und Größe der Bank denkbar ${ }^{292}$. Weitere Regelungen zum Einsatz geldpolitischer Instrumente können in Form von Ober- und Untergrenzen von Zinssätzen (Diskont-, Lombardsätze etc.) sowie anderen Sätzen (z. B. Mindestreservesätze) getroffen werden. Schließlich können auch Bestimmungen zur Bemessungsgrundlage die Variationsmöglichkeiten geldpolitischer Instrumente beeinflussen.

Diese Aufzählung möglicher Ansatzpunkte für technisch-institutionelle Einschränkungen erhebt keinen Anspruch auf Vollständigkeit. Sie soll lediglich die Vielfalt der Variationsmöglichkeiten geldpolitischer Instrumente aufzeigen. Festzuhalten ist, daß jede einengende Regelung, die die Anwendung der Instrumente

289 Beispielsweise beim Überschreiten einer bestimmten Inflationsrate.

290 Vgl. Blessing, Karl: a.a.O., S. 491.

291 Vgl. Caesar, Rolf (1981): a.a.O., S. 92.

292 Vgl. Schaal, Peter: a.a.O., S. 261. 
begrenzt, eine Einschränkung der Entscheidungsfreiheit der Notenbank bedeutet. Dies geschieht nicht, weil durch eingrenzende Regelungen womöglich der Wirkungsgrad des Instruments herabgesetzt wird, sondern weil die Notenbank nicht frei über die Ausgestaltung des Instruments entscheiden kann.

\subsection{Mangelnde Infrastruktur}

Es ist denkbar, daß eine Notenbank geldpolitische Instrumente, die ihr prinzipiell zur Verfügung stehen, nicht oder nur beschränkt anwenden kann, weil die notwendigen technischen Voraussetzungen dazu fehlen. Beispielsweise kann ein Mangel an gut entwickelten Finanzmärkten und Geldmarktinstrumenten den Einsatz mancher geldpolitischer Instrumente erschweren oder gar unmöglich machen 293 .

Inwieweit wird durch mangelnde Infrastruktur die funktionelle Unabhängigkeit der Bank gemindert? Die Auswirkungen eines Anwendungsverbots eines Instruments sind für die Notenbank die gleichen als könnte sie das Mittel nur deshalb nicht einsetzen, weil die notwendige Infrastruktur nicht vorhanden ist. Das reicht aber nicht aus, um darin auch die gleiche Einschränkung der Unabhängigkeit der Bank zu sehen. Im Gegensatz zu einem generellen Anwendungsverbot kann die Notenbank das betreffende Instrument sofort anwenden, sobald sich die Infrastruktursituation geändert hat. Zudem könnte sie die Weiterentwicklung der Infrastruktur selbst vorantreiben. Schwierigkeiten beim Einsatz geldpolitischer Mittel aufgrund unzureichender Infrastruktur bewirken daher keine Einschränkung der Unabhängigkeit einer Notenbank.

\subsection{Einschränkungen durch notenbankfremde Instanzen}

Im folgenden werden die theoretischen Möglichkeiten einer Einflußnahme Bankfremder auf geldpolitische Entscheidungen aufgezeigt und deren Auswirkungen auf die funktionelle Unabhängigkeit untersucht.

\subsection{Moralischer Druck}

Eine Notenbank, die Pressionen seitens der Regierung oder anderer externer Instanzen ausgesetzt ist, könnte sich genötigt fühlen, bei ihren geldpolitischen Entscheidungen auf die Wünsche dieser Aktoren Rücksicht zu nehmen. Dabei dürfte es in der Praxis schwierig sein, eine klare Abgrenzung zu finden zwischen einem durch äußeren Druck bewirkten Verhalten der Notenbank und einem freiwilligen Entgegenkommen ihrerseits ${ }^{294}$. Die Rücksichtnahme der Notenbank kann von

Vgl. Swinburne, Mark; Castello-Branco, Marta: a.a.O., S. 37.

Vgl. Caesar, Rolf (1981): a.a.O., S. 140. 
einem gelegentlichen Nachgeben in Ausnahmesituationen bis hin zu einer völligen Unterordnung unter einen Aktor reichen. ${ }^{295}$ Sie liegt immer dann vor, wenn die Notenbank mit Blick auf die Bedürfnisse anderer Instanzen geldpolitische Maßnahmen vorzieht, zurückstellt oder sie anders dosiert als es rein steuerungspolitisch notwendig wäre296. Das Ausmaß, in dem die Notenbank dem Druck anderer Aktoren ausgesetzt ist, ist von verschiedenen Faktoren abhängig. Einige Autoren sind der Auffassung, da $B$ die Wahrscheinlichkeit, da $B$ die Notenbank bei ihren Entscheidungen auf andere Instanzen Rücksicht nimmt, mit dem Umfang ihrer Machtbefugnisse steigt, weil dadurch tendenziell die Konfliktgefahr mit anderen Bereichen zunimmt ${ }^{297}$. Daher bedeute eine Erhöhung des Wirkungsgrads der Geldpolitik nicht unbedingt auch einen Zuwachs an Entscheidungsfreiheit 298 .

Die Haltung der Öffentlichkeit kann den Druck, dem die Notenbank ausgesetzt ist, beeinflussen. Steht sie der Geldpolitik der Notenbank bzw. dem Unabhängigkeitsstatus des Währungsinstituts positiv gegenüber, kann dies der Notenbank helfen, den Pressionen anderer Aktoren standzuhalten und eine Geldpolitik nach eigenem Ermessen zu betreiben. Umgekehrt kann die Notenbank langfristig aber nur dann ihren autonomen Status wahren, wenn sie eine von der breiten Öffentlichkeit akzeptierte Geldpolitik betreibt ${ }^{299}$. Die Bedeutung der öffentlichen Meinung für die Notenbank könnte auch eine Erklärung für die verstärkte Öffentlichkeitsarbeit der Notenbanken seit den 70er Jahren sein 300 .

Quellen für Pressionen, denen die Notenbank ausgesetzt sein kann, liegen $u$. a. in der Koordinierungsverflechtung der Bank mit anderen Aktoren begründet. Besonders der Bereich der Konjunkturpolitik ist durch "ein System koordinierender Maßnahmen für Information und Durchführung"301 gekennzeichnet. Auch haben die zunehmenden internationalen Verflechtungen eine Vielzahl quasi-institutionalisierter Kooperations- und Koordinationsformen hervorgebracht. Je mehr die Notenbank darin eingebunden ist, desto eher könnte sie zu größerer Rücksichtnahme gedrängt werden 302 . Umgekehrt kann sie natürlich auch auf die betreffenden Aktoren Einfluß nehmen ${ }^{303}$.

Vgl. Caesar, Rolf(1981): a.a.O., S. 141.

296 Vgl. Caesar, Rolf (1981): a.a.O., S. 142.

297 Vgl. Caesar, Rolf (1981): a.a.O., S. 117.

298 Vgl. Hansmeyer, Karl Heinrich: a.a.O., S. 162

299 Vgl. Schmitz, Wolfgang (1989): a.a.O., S. 19.

300 Vgl. Caesar, Rolf (1981): a.a.O., S. 140.

301 Hansmeyer, Karl Heinrich: a.a.O., S. 160.

302 Vgl. Caesar, Rolf (1981): a.a.O., S. 145f.

303 Vgl. Caesar, Rolf (1981): a.a.O., S. 145.
} 
$\mathrm{Ob}$ und wenn ja, in welchem Maße die Notenbank auf die Wünsche und Forderungen anderer Aktoren eingeht, läßt sich nur schwer ermitteln. Caesar ${ }^{304}$ versucht beispielsweise, die Einschränkung des Handlungsspielraums der Notenbank aufgrund von Rücksichtnahme auf andere Wirtschaftssubjekte über Bestimmungsfaktoren wie das Konfliktpotential der Geldpolitik und die Konfliktbereitschaft der Beteiligten zu umreißen. Ist aber eine Notenbank, die Pressionen nachgibt oder in ihrer Geldpolitik auf andere Aktoren Rücksicht nimmt, wirklich in ihrer Unabhängigkeit eingeschränkt? Je mehr der Kompetenzbereich der Notenbank ausgeweitet wird, desto größer mag die Gefahr von Konflikten mit und Pressionen von anderen Aktoren sein. Auch die Haltung der Öffentlichkeit, der Verflechtungsgrad mit anderen Instanzen und ähnliches mögen den Druck auf die Notenbank dahingehend beeinflussen, daß diese eine andere Geldpolitik betreibt als sie befürwortet. Aber es ist wenig plausibel, daß dies zu einer Einengung des Handlungsspielraums oder der Entscheidungsfreiheit der Notenbank führen sollte. Eine Zentralbank kann sich moralischem Druck widersetzen, wenn auch gegebenenfalls unter Inkaufnahme von persönlichen Schwierigkeiten oder Konflikten ${ }^{305}$. Solange sie nicht zur Rücksichtnahme bei geldpolitischen Entscheidungen gezwungen werden kann, liegt keine Einschränkung ihrer Unabhängigkeit vor. Nach der hier verwendeten Unabhängigkeitsdefinition hat die Ausübung moralischen Drucks auf die Notenbankleitung keinen Einfluß auf die Unabhängigkeit der Bank.

\subsection{Auskunfts- und Mitteilungspflichten}

Ist eine Notenbank verpflichtet, der Regierung oder anderen Instanzen Auskünfte über ihre geplanten Maßnahmen oder andere die Geldpolitik betreffenden Angelegenheiten zu geben bzw. gibt es institutionalisierte Mitteilungsvereinbarungen, so kann sie ihre geldpolitischen Entscheidungen dennoch frei nach eigenem Ermessen treffen. Ihre Unabhängigkeitsstatus ist davon nicht berührt.

\subsection{Anhörungsrecht}

Gleiches gilt, wenn die Notenbank vor dem Fällen von geldpolitischen Entscheidungen verpflichtet ist, Vertreter der Regierung, der Wirtschaft oder anderer Bereiche anzuhören, um gegebenenfalls deren Standpunkte bei der Entscheidungsfindung zu berücksichtigen. Die Entscheidungsgewalt liegt trotzdem alleine beim Währungsinstitut.

304 Vgl. Caesar, Rolf (1981): a.a.O., S. 112f.

305 Vgl. Hahn, Oswald (1968) Bd. II: a.a.O., S. 84. 


\subsection{Veto- und Genehmigungsrecht}

Eine unmittelbare Einschränkung der Entscheidungsfreiheit der Notenbank liegt vor, wenn andere Aktoren über Veto- oder Genehmigungsrechte bzgl. notenbankpolitischer Entscheidungen der Bank verfügen. Beim Vorliegen von Genehmigungsrechten erfordert das Wirksamwerden geldpolitischer Beschlüsse die ausdrückliche Billigung durch andere Aktoren ${ }^{306}$. Vetorechte bewirken dagegen je nach Ausgestaltung des Rechts eine temporäre Blockierung (aufschiebendes oder suspensives Vetorecht) oder eine Aufhebung (auflösendes Vetorecht) notenbankpolitischer Beschlüsse ${ }^{307}$. Hahn ${ }^{308}$ führt zusätzlich das konstruktive Vetorecht auf, nach dem die begünstigte Instanz die geldpolitischen Entscheidungen der Bank nicht nur aufheben kann, sondern auch an der Neufassung der Beschlüsse beteiligt ist. Die verschiedenen Formen des Vetorechts sowie Genehmigungsrechte wirken sich unterschiedlich stark auf die Unabhängigkeit der Notenbank aus. Eine verhältnismäßig geringe Einschränkung der Unabhängigkeit liegt im Falle des aufschiebenden Vetorechts vor. Die Notenbank braucht ihre Beschlüsse nicht zu ändern. Die Einschränkung ihrer Entscheidungsfreiheit liegt ausschließlich darin, daß sie den Zeitpunkt des Umsetzens der Beschlüsse nicht frei wählen kann. Dies gilt um so stärker, je länger die festgelegte Aufschubfrist ist bzw. je öfter das Recht bezüglich desselben Beratungspunktes angewendet werden darf. Kann das suspensive Vetorecht unbegrenzt oft angewendet werden oder ist die Aufschiebungsfrist sehr lang, hat dies im Extremfall die gleiche Wirkung wie ein auflösendes Vetorecht. Ein auflösendes Vetorecht bewirkt eine große Einschränkung der Entscheidungsfreiheit der Notenbank, die nun gezwungen ist, ihre Beschlüsse zu ändern. Im Gegensatz zum konstruktiven Vetorecht darf sie aber ohne Mitwirkung externer Instanzen eine neue Entscheidung treffen. Theoretisch können diese neuen Beschlüsse jedoch immer wieder mittels Vetorecht außer Kraft gesetzt werden, bis sie den Vorstellungen der Veto einlegenden Instanz entsprechen ${ }^{309}$. Diese gewinnt im Extremfall auf diese Weise einen großen Einfluß auf Notenbankpolitik. Am stärksten ist die Unabhängigkeit der Zentralbank beim Vorliegen eines konstruktiven Vetorechts eingeschränkt. Dieses kommt einem Weisungsrecht sehr nahe, weil die Veto einlegenden Instanzen die notenbankpolitischen Entscheidungen nicht nur aufheben können, sondern an der neuen Beschlußfassung zumindest mitbeteiligt sind. Genehmigungsrechte externer Instanzen haben eine vergleichbare Wirkung auf die Unabhängigkeit einer Notenbank wie ein auflösendes Vetorecht. Beschlüsse, denen die begünstigte Instanz nicht zustimmt, werden von ihr nicht genehmigt. Die Notenbank muß solange ihre

306 Vgl. Caesar, Rolf (1981): a.a.O., S. 135.

307 Vgl. Hahn, Oswald (1968) Bd. II: a.a.O., S. 83.

308 Vgl. Hahn, Oswald (1968) Bd. II: a.a.O., S. 83.

309 Vgl. Hahn, Oswald (1968) Bd. II: a.a.O., S. 83. 
geplanten Entscheidungen ändern bis sie den Vorstellungen der genehmigenden Instanz entsprechen.

\subsection{Rechtliche Anfechtbarkeit geldpolitischer Beschlüsse}

Die Entscheidungsfreiheit einer Notenbank über den Einsatz geldpolitischer Instrumente kann bedeutungslos werden, wenn die Entscheidungen durch externe Instanzen angefochten werden können 310 . Als Beispiel sei hier ein privater Unternehmer angeführt, der durch die Anwendung des währungspolitischen Instrumentariums durch die Notenbank wirtschaftlichen Schaden erleidet ${ }^{311}$. Ist der Rechtsweg ausgeschlossen, liegt keine Einschränkung der Entscheidungsfreiheit der Notenbank vor. Hat der Betroffene dagegen die Chance, gegen die Beschlüsse gerichtlich vorzugehen, ist die Bank womöglich gezwungen ihre Entscheidungen zu ändern und damit in ihrer Unabhängigkeit eingeschränkt. Der Umfang der Einschränkung der Unabhängigkeit liegt dabei je nach Ausgang der Verhandlungen zwischen dem eines Vetorechts und einem Weisungsrecht.

\subsection{Stimmrecht}

Haben Mitglieder der Regierung oder andere bankfremde Aktoren Stimmrecht bei Sitzungen der Notenbankleitung, in denen geldpolitische Beschlüsse gefaßt werden, können sie damit Einfluß auf die dort getroffenen Entscheidungen nehmen. Sie können jedoch als Mitglieder der Leitungsgremien der Bank betrachtet werden. Daher sei hier bzgl. der Auswirkungen von Stimmberechtigung auf die Unabhängigkeit einer Notenbank auf die Ausführungen über die personelle Unabhängigkeit verwiesen.

\subsection{Weisungsrecht}

Weisungsrechte ermöglichen notenbankfremden Aktoren den größten Einfluß auf die Geldpolitik einer Notenbank ${ }^{312}$. Der Bank werden direkt Handlungsanweisungen aufgezwungen. Sie kann ihre Entscheidungen über Umfang, Zeitpunkt und Art des Einsatzes geldpolitischer Instrumente nicht frei treffen.

310 Am Beispiel der Deutschen Bundesbank dargelegt bei Kindermann, Elmar: Die Anfechtung von kreditpolitischen Beschlüssen der Bundesbank, Berlin 1974.

311 Vgl. Lampe, Ortrun: a.a.O., S. 20f.

312 Vgl. Hahn, Oswald (1968) Bd. II: a.a.O., S. 79. 


\subsubsection{Einordnung ausgewählter Einschränkungsbeispiele in die Systematik}

Es gibt einige Bereiche, die als besondere Gefahrenquellen für die Unabhängigkeit einer Notenbank gelten. Dazu zählt neben der Staatsfinanzierung durch die Notenbank v. a. die Forderung an die Notenbank, die allgemeine Wirtschaftspolitik des Staates zu unterstützen. Zunehmend wird auch vor einer Aushöhlung der Unabhängigkeit durch internationale Einflüsse und Verpflichtungen gewarnt. Diese Einschränkungsbeispiele scheinen wichtig genug, um sie gesondert zu betrachten.

\subsection{Staatsfinanzierung durch die Notenbank}

Dem Einsatz der Geldpolitik für eine bequeme Staatsfinanzierung per Notenpresse werden alle größeren Inflationen dieses Jahrhunderts angelastet ${ }^{313}$. Es wird immer wieder darauf hingewiesen, daß sich das Ziel der Preisstabilität nicht mit einem Zwang der Notenbank zur Staatsfinanzierung vereinbaren läßt ${ }^{314}$. Daher sei es erforderlich, die Notenbank von einem solchen Zwang zu befreien 315 . Regelungen, die der Finanzierung von Budgetdefiziten durch die Notenbank enge Grenzen setzen, gelten vielfach auch als Kriterium für eine unabhängige Notenbank ${ }^{316}$. Sie schützten die Zentralbank einmal davor, zu einer Finanzierung der Budgetdefizite des Staates gezwungen zu werden ${ }^{317}$, aber auch quasi vor sich selbst, weil sie möglichen Pressionen seitens der Regierung leichter standhalten kann. So zeigt das Beispiel der Deutschen Reichsbank, daß eine Unterlassung von Staatsfinanzierung nicht automatisch aufgrund der Unabhängigkeit einer Notenbank angenommen werden kann ${ }^{318}$. Dies bestätigt auch eine Studie in den USA, die ergab, daß das Federal Reserve System im Untersuchungszeitraum von 1947 bis 1974 auf Budgetdefizite (-überschüsse) mit einer Vergrößerung (Verringerung) ihres Bestands an Staatspapieren reagiert hat ${ }^{319}$.

Man unterscheidet direkte und indirekte Kreditfinanzierung des Staates durch die Notenbank. Während die Notenbank bei einer direkten Staatsfinanzierung in Form von Buchkrediten oder dem Erstankauf von Staatspapieren von Beginn an selbst als Gläubiger des Staates auftritt, ist bei der indirekten Kreditfinanzierung

313 Vgl. Neumann, Manfred J. M.: a.a.O., S. 99; Hahn, Oswald (1968) Bd. II: a.a.O., S. 60.

314 Vgl. Neumann, Manfred J. M.: a.a.O., S. 99.

315 Vgl. Neumann, Manfred J. M.: a.a.O., S. 99.

316 Vgl. Caesar, Rolf (1982): a.a.O., S. 571; Hahn, Oswald (1968) Bd. II: a.a.O., S. 59ff.

317 Vgl. Neumann, Manfred J. M.: a.a.O., S. 100.

318 Vgl. Schmitz, Wolfgang (1989): a.a.O., S. $20 f$.

319 Vgl. Buchanan, James M.; Wagner, Richard E.: Democracy in deficit, The political legacy of Lord Keynes, New York, San Francisco, London 1977, S. 114ff. 
zunächst das Bankensystem zwischengeschaltet ${ }^{320}$. Die Notenbank kauft Schuldtitel des Staates via Offenmarkt- oder Refinanzierungsoperationen von den Kreditinstituten ${ }^{321}$. Neben der Kreditfinanzierung gibt es zahlreiche weitere Möglichkeiten der finanziellen Heranziehung der Notenbank durch den Staat ${ }^{322}$, wie z. B. die Kassenverwaltung für den Staat, die Verwaltung der Staatsschulden oder die Gewinnausschüttung der Notenbank an den Staat. Letztere könnte dabei für die funktionelle Unabhängigkeit einer Zentralbank von Bedeutung sein, denn sie geht mit einer Zentralbankgeldschöpfung einher ${ }^{323}$, läßt man die Entstehung des Gewinnes außer Betracht ${ }^{324}$. Insofern kann eine Gewinnausschüttung mit einer direkten Kreditvergabe der Notenbank verglichen werden, mit dem Unterschied, da $B$ bei einer Kreditaufnahme Verzinsung und Tilgung vorgeschrieben ist $^{325}$. Um den Effekt der Geldschöpfung zu neutralisieren, müßte er bei der Steuerung der Geldmenge z. B. durch reduzierte Refinanzierungsmöglichkeiten kompensiert werden 326 .

Für eine Begrenzung der Kreditfinanzierung des Staates durch die Notenbank stehen u. a. folgende Formen zur Verfügung. Direkt kann sie über ein absolutes oder relatives Limit für den Bestand an allen oder bestimmten Staatstiteln erfolgen $^{327}$. Indirekt ist dies über eine Begrenzung der Geldschöpfungskapazität des Noteninstituts möglich ${ }^{328}$. Dies ist z. B. in Form von Kontingenten, prozentualer Metalldeckung oder ähnlichem denkbar ${ }^{329}$.

320 Vgl. Caesar, Rolf: Staatsfinanzierung durch die Notenbank - Pro und Contra, in: Socher, Karl; Smekal Christian (Hrsg.): Staatsfinanzierung und Notenbank. Referate und Diskussionszusammenfassungen des Symposiums am 4./5. April 1984 in Innsbruck/Igls; Österreichisches Forschungsinstitut für Sparkassenwesen Bd. 24, Wien 1984, S. 50.

321 Vgl. Caesar, Rolf (1981): a.a.O., S. 133; Caesar, Rolf (1982): a.a.O., S. 571.

322 Vgl. Born, Erich: Die finanzielle Heranziehung der Zentralnotenbank durch den Staat in Europa, Leipzig 1907.

323 Vgl. Schmitz, Wolfgang: Staatsfinanzierung durch die Notenbank aus der Sicht der Geldordnung, in: Socher, Karl; Smekal Christian (Hrsg.): Staatsfinanzierung und Notenbank. Referate und Diskussionszusammenfassungen des Symposiums am 4.15. April 1984 in Innsbruck/Igls; Österreichisches Forschungsinstitut für Sparkassenwesen Bd. 24, Wien 1984, S. 89.

324 Vgl. Caesar, Rolf (1984), a.a.O., S. 50.

325 Vgl. Dickertmann, Dietrich: Staatsfinanzierung und Notenbank aus finanzwirtschaftlicher Sicht, in: Socher, Karl; Smekal Christian (Hrsg.): Staatsfinanzierung und Notenbank.

Referate und Diskussionszusammenfassungen des Symposiums am 4./5. April 1984 in Innsbruck/Igls; Österreichisches Forschungsinstitut für Sparkassenwesen Bd. 24, Wien 1984, S. 129.

326 Vgl. Lusser, Markus: Die volkswirtschaftliche Bedeutung der Schweizerischen Nationalbank, in: Quartalsheft SNB 1/92 S. 71f; Schmitz, Wolfgang (1984): a.a.O., S. 96.

327 Vgl. Hahn, Oswald (1968) Bd. II: a.a.O., S. 64.

328 Vgl. Hahn, Oswald (1968) Bd. II: a.a.O., S. 64.

329 Vgl. Hahn, Oswald (1968) Bd. II: a.a.O., S. 70. 
In vielen Fällen ist die direkte Staatsfinanzierung nicht oder nur bedingt eingeschränkt, weil der Kauf von Regierungsschulden für die Notenbank eine wichtige geldpolitische Steuerungsmöglichkeit darstellt. Doch gibt es selbst bei einem Verbot des Haltens jeglicher Regierungsschulden durch die Notenbank genügend Wege, Defizitfinanzierung zu fördern. Dies ist um so leichter, je besser die Finanzmärkte und -instrumente entwickelt sind ${ }^{330}$. So könnte die Regierung beispielsweise die Notenbank anweisen, in gleicher Höhe Liquidität zuzuführen, wie der Staat im privaten Sektor Schulden aufnimmt ${ }^{331}$. Der gesamte monetäre Effekt wäre der gleiche, als hätte die Notenbank die Staatsschulden direkt finanziert ${ }^{332}$. Es ist ebenfalls denkbar, daß die Regierung die gesetzlichen Beschränkungen nicht beachtet und Mittel besitzt, die Notenbank zu einer Kreditgewährung über die gesetzlich festgelegten Kontingente hinaus zu bewegen oder daß die gesetzlichen Verschuldungsgrenzen jeweils entsprechend dem Finanzierungsbedarf des Staates nach oben angepaßt werden ${ }^{333}$. Deckungsvorschriften und Kontingente können auch durch Kreditaufnahme des Staates im Ausland oder die eigene Zahlungsmittelemission der Regierung (z. B. Münzregal der Bundesregierung) umgangen werden 334 .

Wegen der zahlreichen Ausweichmöglichkeiten sollte die Wirkung gesetzlicher Grenzen für die Staatsfinanzierung durch die Notenbank also nicht überbewertet werden. Trotzdem können sie für die Geldwertstabilität durchaus von Nutzen sein. Solche Limits können der Notenbank auch helfen, möglichen Pressionen seitens der Regierung standzuhalten. Beides ist aber kein Kriterium für Unabhängigkeit. Die Unabhängigkeit mißt sich an dem Ausmaß, in dem die Notenbank geldpolitische Instrumente nach ihrem Ermessen anwenden kann. Sie ist also nur soweit von der Staatsfinanzierung durch die Notenbank betroffen, als die Möglichkeiten der Staatsfinanzierung als geldpolitische Instrumente betrachtet werden können. In einem früheren Abschnitt wurden unter geldpolitischen Instrumenten alle Mittel zusammengefaßt, die geeignet sind, Geldnachfrage und Geldangebot durch die Veränderung von Zins, Geldmenge und Liquidität zu beeinflussen. Offenmarktgeschäfte mit Staatspapieren sind insofern Teil des geldpolitischen Instrumentariums. Auch ein direkter Kredit an den Staat ist ein geldpolitisches Mittel, da er das Geldangebot erhöht. Für die Unabhängigkeit einer Notenbank ist also nur das Halten von Staatsschuld von Bedeutung, sei es durch den Ankauf von Staatspapieren oder über sonstige Kreditformen. Zwei Aspekte spielen dabei eine Rolle. Zum einen ist entscheidend, ob die Notenbank verpflichtet ist, dem

330 Vgl. Swinburne, Mark; Castello-Branco, Marta: a.a.O., S. 33.

331 Vgl. Swinburne, Mark; Castello-Branco, Marta: a.a.O., S. 34.

332 Vgl. Swinburne, Mark; Castello-Branco, Marta: a.a.O., S. 34.

333 Wie es in den USA beobachtet wurde, Vgl. Caesar, Rolf (1982): a.a.O., S. 571f.

334 Vgl. Hahn, Oswald (1968) Bd. II: a.a.O., S. 78f. 
Staat Kredit zu gewähren ${ }^{335}$. Kann die Zentralbank selbst entscheiden, ob sie der Regierung Kredit zur Verfügung stellt, liegt keine Einschränkung ihrer Unabhängigkeit vor. Kann die Regierung die Bank allerdings zur Kreditgewährung anweisen, so ist dies eine erhebliche Minderung der Autonomie des Währungsinstituts. Der zweite Aspekt betrifft den Umfang der gesetzlichen Grenzen zur Staatsfinanzierung. Einige Autoren sind der Meinung, eine Verschärfung der Begrenzung von Staatsfinanzienung durch die Notenbank erhöhe c. p. die Unabhängigkeit des Instituts ${ }^{336}$. Dies ist aber nur der Fall, wenn die Notenbank innerhalb der gesetzlichen Grenzen zur Kreditgewährung verpflichtet ist. Berücksichtigt man, daß das Halten von Staatstiteln ein wichtiges geldpolitisches Mittel darstellt, bewirken Beschränkungen der Kreditgewährung an den Staat nicht nur keine Erhöhung der Unabhängigkeit der Bank, sondern sie mindern sie sogar. Ein Verbot des Haltens von Staatstiteln oberhalb eines bestimmten Kontingents schränkt die Entscheidungsfreiheit der Notenbank ein, nach eigenem Ermessen auch darüber hinaus Kredite an den Staat zu gewähren. Das folgende Schema gibt einen Überblick über die prinzipiellen Möglichkeiten der Kreditfinanzierung des Staates durch die Notenbank und deren Auswirkung auf die Unabhängigkeit der Bank.

Unter den Beschränkungen der Kreditgewährung sind sowohl quantitative Grenzen als auch Bedingungen, die an eine Kreditvergabe geknüpft sind, zusammengefaßt. Letztere können z. B. die Laufzeit oder den Verwendungszweck der Darlehen festschreiben. Sofern die Notenbank diese Bedingungen nicht selbst definiert, schränken sie ihre Entscheidungsfreiheit ein. Zusammen mit der Frage der Verpflichtung der Notenbank zur Kreditvergabe bestimmt das Kriterium der Beschränkung einer Kreditgewährung den Einfluß von Staatsfinanzierung durch die Notenbank auf die Unabhängigkeit des Instituts. Sechs mögliche Konstellationen der Kriterien werden in Abb. 2 unterschieden.

Im Fall 1 gibt es weder gesetzliche Beschränkungen der Staatskreditgewährung noch ist die Notenbank zur Budgetfinanzierung des Staates in irgendeiner Form verpflichtet. Die Entscheidungsfreiheit der Bank ist nicht eingeschränkt. Hier liegt die größtmögliche Unabhängigkeit der Notenbank vor. Das andere Extrem bilden Fälle 4 bis 6 . In keinem dieser Fälle kann die Notenbank über eine Kreditgewährung an den Staat frei entscheiden. Sie ist entweder gezwungen, in unbegrenzter Höhe Kredit zu gewähren (Fall 4) oder sie muß innerhalb gesetzlicher Grenzen den Forderungen der Regierung nachkommen, darüber hinaus darf sie aber keinen Kredit gewähren (Fall 5). Der dritte Fall großer Abhängigkeit liegt vor, wenn ein Kredit der Notenbank an den Staat generell verboten ist (Fall 6). Zwischen den beiden Extremen liegen die Fälle 2 und 3, bei denen die Notenbank in Grenzen über eine Kreditvergabe selbst entscheiden kann und ihre Unabhängigkeit daher

So auch Castello-Branco, Marta; Swinburne, Mark : a.a.O., S. 21.

Vgl. Hahn, Oswald (1968) Bd. II: a.a.O., S. 73. 
nur bedingt eingeschränkt ist. Im Fall 2 darf die Notenbank im Rahmen der gesetzlichen Grenzen dem Staat Kredit gewähren ohne jedoch dazu gezwungen werden zu können. Die Einschränkung der Unabhängigkeit liegt darin, daß über das Limit hinaus keine Kreditvergabe möglich ist. Im Fall 3 ist die Notenbank bis zu einer bestimmten Höhe zur Kreditgewährung verpflichtet. Darüber hinaus ist ihr eine weitere Staatsfinanzierung freigestellt. Sie kann sich so ein gewisses Maß an Entscheidungsfreiheit wahren und dies um so mehr, je enger die Grenzen gesetzt sind, innerhalb derer sie zur Kreditgewährung verpflichtet ist. Darüber, welche dieser beiden zuletzt genannten Fälle die Unabhängigkeit einer Notenbank stärker einschränkt, läßt sich keine genaue Aussage treffen.

\begin{tabular}{|c|c|c|c|}
\hline & $\begin{array}{l}\text { Kreditgewährung } \\
\text { beschränkt }\end{array}$ & $\begin{array}{c}\text { Verpflichtung zur } \\
\text { Kreditvergabe }\end{array}$ & $\begin{array}{l}\text { Unabhängigkeit } \\
\text { der Notenbank }\end{array}$ \\
\hline Fall 1 & nein & nein & am größten \\
\hline Fall 2 & ja & nein & \multirow[b]{2}{*}{ dazwischen } \\
\hline Fall 3 & nein & $\begin{array}{l}\text { innerhalb Kontin- } \\
\text { gent }\end{array}$ & \\
\hline Fall 4 & nein & ja & \multirow{3}{*}{ am geringsten } \\
\hline Fall 5 & ja & ja & \\
\hline Fall 6 & \multicolumn{2}{|c|}{ Kreditgewährung verboten } & \\
\hline
\end{tabular}

Abb. 2: Auswirkung der verschiedenen Formen der Kreditfinanzierung des Staates durch die Notenbank auf die Unabhängigkeit einer Notenbank

Wie lassen sich die Erkenntnisse über die Wirkungen der Staatsfinanzierung auf die Unabhängigkeit einer Notenbank in die bisherigen Ausführungen über die funktionelle Unabhängigkeit einordnen? Zur Beurteilung der funktionellen Unabhängigkeit muß jedes geldpolitische Instrument geprüft werden, ob es der Notenbank prinzipiell zur Verfügung steht und wenn ja, ob dessen Anwendung in technisch-institutioneller Hinsicht oder durch Dritte eingeschränkt ist. Die Möglichkeiten der Staatsfinanzierung, die als geldpolitische Mittel betrachtet werden können, müssen also dementsprechend untersucht werden. Dabei entsprechen die in obiger Tabelle als Beurteilungskriterium aufgeführten Beschränkungen bei der Kreditgewährung technisch-institutioneller Einschränkungen, während eine Verpflichtung zur Kreditvergabe unter die Einschränkung durch Dritte fällt. Hier 
sind neben dem Zwang zur Kreditgewährung auch andere Einschränkungen durch Dritte möglich, wie z. B. ein Vetorecht einer Instanz.

\subsection{Verpflichtung zur Unterstützung der allgemeinen Wirtschaftspoli- tik des Staates durch die Notenbank}

Zwischen Währungspolitik der Notenbank und staatlicher Wirtschaftspolitik sind verschiedene Verhältnisse denkbar. Hahn 337 unterscheidet drei grundlegende Formen. Im Extremfall berücksichtigt die Währungspolitik die Belange der Wirtschaftspolitik überhaupt nicht. Ebenso kann sie die staatliche Wirtschaftspolitik unterstützen, sofern ihre endogenen Belange nicht gestört werden ${ }^{338}$. Im dritten Fall ist die Währungspolitik der Wirtschaftspolitik untergeordnet, wobei es sich um eine dauerhafte oder eine zeitweise Unterordnung in Krisenlagen, wie z. B. Krieg oder Massenarbeitslosigkeit, handeln kann ${ }^{339}$. Eine Unterstützung der allgemeinen Wirtschaftspolitik des Staates ist in Form von Finanzierungshilfen (besonders Kreditgewährung), Zinssubventionen (Politik des billigen Geldes) bzw. durch einen mit staatlichen Maßnahmen koordinierten gleichgeschalteten Einsatz geldpolitischer Instrumente denkbar. Es wird gemeinhin für notwendig erachtet, daß eine Notenbank verpflichtet sein muß, ihre Politik zumindest in Absprache mit den politischen Autoritäten zu betreiben ${ }^{340}$. Es soll hier nicht diskutiert werden, inwieweit es sinnvoll ist, in den Statuten Klauseln zu verankern, die die Notenbank verpflichten, die Wirtschaftspolitik des Staates zu unterstützen. Hier ist von Interesse, ob und wie solche Regelungen die Unabhängigkeit der Notenbank beeinträchtigen. Darüber gibt es in der Literatur geteilte Meinungen. Vielfach wird in Regelungen, die die Notenbank zur Unterstützung der staatlichen Wirtschaftspolitik verpflichten, eine Gefahr für die formale Unabhängigkeit (sofern eine solche vorhanden ist) von Regierungsinstruktionen gesehen ${ }^{341}$. Die formale Unabhängigkeit würde faktisch unterlaufen, weil die Regierung das Recht erhielte, das Währungsinstitut jederzeit zu einem anderen Kurs in der Geldpolitik zu bewegen 342 . Die Notenbank könne sich auch dann nicht gänzlich den Forderungen der Regierung entziehen, wenn die entsprechenden Klauseln ähnlich der deutschen Regelung 343 so weit abgeschwächt würden, daß eine Unterstützung der staatlichen Wirtschaftspolitik nur in Frage kommt, wenn die ei-

337 Vgl. Hahn, Oswald (1968) Bd. II: a.a.O., S. 57.

338 Vgl. Hahn, Oswald (1968) Bd. II: a.a.O., S. 57.

339 Vgl. Hahn, Oswald (1968) Bd. II: a.a.O., S. 57.

340 Vgl. Swinburne, Mark; Castello-Branco, Marta: a.a.O., S. 20.

341 Vgl. Neumann, Manfred J. M.: a.a.O., S. 100; Szagunn, Volkhard: a.a.O., S. 20.

342 Vgl. Neumann, Manfred J. M.: a.a.O., S. 100.

343 Vgl. § 12 Gesetz über die Deutsche Bundesbank vom 26. Juli 1957, im folgenden BBankG. 
gentliche Aufgabenerfüllung der Bank dadurch nicht behindert wird ${ }^{344}$. Andere Stimmen sehen die Handlungsfreiheit der Notenbank durch derartig abgeschwächte Klauseln nicht gefährdet, weil die Bank nach eigenem Ermessen beurteilen kann, inwieweit sie die Unterstützung der staatlichen Wirtschaftspolitik mit ihren Hauptfunktionen für vereinbar hält ${ }^{345}$. Zudem ist bereits die Formulierung "allgemeine Wirtschaftspolitik" interpretationsbedürftig und eröffnet dem Noteninstitut Ermessensspielräume ${ }^{346}$.

$\mathrm{Ob}$ eine Beeinträchtigung der Unabhängigkeit einer Notenbank durch Verpflichtungen, die Wirtschaftspolitik des Staates zu unterstützen, vorliegt, hängt von der Ausgestaltung der Regelungen im Einzelfall ab. In einem früheren Abschnitt wurde bereits dargelegt, daß Ziele und Aufgaben von Zentralbanken im Rahmen dieser Untersuchung nicht als Kriterium für Unabhängigkeit betrachtet werden können und insofern als gegeben gelten. Die Währungssicherung darf also nicht von vorn herein als alleinige Aufgabe von Notenbanken angenommen werden. So wirkt eine zusätzliche (oder auch die alleinige) Aufgabe in Form einer Unterstützung der allgemeinen Wirtschaftspolitik des Staates als solche noch nicht unabhängigkeitsmindernd. Entscheidend ist, ob die Notenbank nach eigenem Ermessen über die Mittel, deren Umfang und Einsatzzeitpunkte entscheiden darf, um die ihr gesetzten Aufgaben und Ziele zu erfüllen. Kann sie das nicht, so ist ihre Unabhängigkeit eingeschränkt.

\subsection{Internationale Einflüsse und Verpflichtungen}

In den letzten Jahrzehnten hat eine Globalisierung der Märkte stattgefunden, die die Welt heute nahezu zu einem einzigen Wirtschaftsraum verbindet ${ }^{347}$. Internationale Arbeitsteilung sowie die Entstehung eines engen Netzes von Handels- und Kapitalströmen haben zu einer zunehmenden Sensitivität einzelner Volkswirtschaften bzgl. Veränderungen auf internationaler Ebene geführt ${ }^{348}$. Eine Vielzahl von Kooperations- und Koordinationsformen zwischen den Staaten bewirkt einen Autonomieverlust der nationalen Wirtschaftspolitiken, der auch Auswirkungen auf die Geldpolitik hat ${ }^{349}$. Auch die Notenbanken können sich dieser Entwick-

344 Vgl. Neumann, Manfred J. M.: a.a.O., S. 100f.

345 Vgl. Gleske, Leonhard: German Central Banking and the Bundesbank's Structure, in: Banco Central De Chile (Hrsg.): Seminario "Experiencias sobre Autonomia e la Banca Central", Santiago 1989, S. 43; Kaiser, Rolf H.: a.a.O., S. 28; Spindler, Joachim v.; Bekker, Willy; Starke, O.-Ernst (1973): a.a.O., S. 263.

346 Vgl. o.V.: Wir heißen Euch hoffen, in: Zeitschrift furr das gesamte Kreditwesen H.23 1967, S. 1056; Caesar, Rolf (1981): a.a.O., S. 169f.

347 Vgl. Preuße, Heinz Gert: a.a.O., S. 2.

348 Vgl. Preuße, Heinz Gert: a.a.O., S. 12.

349 Vgl. Preuße, Heinz Gert: a.a.O., S. 13. 
lung nicht entziehen. Bei den Zentralbanken ist seit dem zweiten Weltkrieg eine immer engere Zusammenarbeit zu beobachten 350 . Daneben gibt es zahlreiche Bestrebungen, nationale Währungsgebiete zu einem einheitlichen Währungsraum zusammenzuführen.

Internationale Einflüsse wirken sich auf die Notenbank und ihre Politik in mehrfacher Hinsicht aus. Zunächst bedeuten sie, daß die Notenbanken in ihrer Entscheidungsfindung die internationalen Gegebenheiten und Verflechtungen berücksichtigen müssen. Häufig sind sie auch Pressionen seitens des Auslands ausgesetzt, ihre Entscheidungen in einer dem Ausland wohlgesonnenen Weise zu treffen $^{351}$. Außenwirtschaftliche Einflüsse wirken sich zudem tendenziell negativ auf die Effizienz der nationalen Geldpolitik aus ${ }^{352}$. Internationale Zins- und Preiszusammenhänge senken die Wirksamkeit der nationalen Geldpolitik ${ }^{353}$ ebenso wie die zahlreichen Möglichkeiten von Wirtschaftssubjekten, geldpolitischen Maßnahmen durch z. B. Refinanzierung im Ausland auszuweichen. All diese Einflüsse sind aber für die Unabhängigkeit einer Notenbank nicht von Bedeutung. Eine Minderung der Effizienz des geldpolitischen Instrumentariums ändert nichts an der Freiheit der Bank, ihre geldpolitischen Entscheidungen nach eigenem Ermessen zu treffen. Möglichen Pressionen aus dem Ausland kann sie sich widersetzen. Die Unabhängigkeit einer Notenbank ist nur dann von internationalen Einflüssen berührt, wenn ihr aufgrunddessen nicht mehr die Gesamtheit des geldpolitischen Instrumentariums zur Verfügung steht oder wenn notenbankfremde Instanzen über Möglichkeiten verfügen, direkt in die Entscheidungsfindung der Bank einzugreifen. Letzteres ist z. B. dann der Fall, wenn die Bank aufgrund internationaler Vereinbarungen Handlungsverpflichtungen unterliegt, vorausgesetzt, sie konnte diese Vereinbarungen nicht entscheidend mitbestimmen.

Die staatlichen Instanzen haben sich in der Regel die Kompetenzen über die internationale Währungspolitik vorbehalten ${ }^{354}$. Dies birgt Konfliktpotential zwischen Regierung und Notenbank und womöglich die Gefahr einer faktischen Aushöhlung des Unabhängigkeits-Status der Bank ${ }^{355}$. Zu den währungspolitischen Kompetenzen, auf die die Notenbanken in der Regel keinen oder nur bedingt Einfluß haben, gehört vor allem die Wahl und Gestaltung des Wechselkurssystems für die eigene Währung. Grundsätzlich besteht die Wahl

350 Vgl. Caesar, Rolf (1981): a.a.O., S. 116.

351 Vgl. Caesar, Rolf: Bundesbank-Autonomie : Internationale Bedrohungen?, in: Wirtschaftsdienst 1988/III, S. 124.

352 Vgl. Hankel, Wilhelm (1970): a.a.O., S. 290.

353 Vgl. Hankel, Wilhelm (1973): a.a.O., S.154f; Caesar, Rolf (1981): a.a.O., S. $102 f$.

354 Vgl. Caesar, Rolf (1981): a.a.O., S. 89.

355 Vgl. Preuße, Heinz Gert: a.a.O., S. 14. 
zwischen einem System fester und flexibler Wechselkurse, wobei auch eine Kombination beider Systeme möglich ist, wie z. B. im EWS. Neben der ordnungspolitischen Grundentscheidung über das Wechselkurssystem muß das Aus$\mathrm{maB}$ der Beeinflussung oder Anpassung der Wechselkurse bestimmt werden. Diese prozeßpolitischen Entscheidungen betreffen in einem Festkurssystem insbesondere die Bedingungen und den Umfang von Paritätsanpassungen, in einem Mischsystem unter Umständen die Bandbreiten, innerhalb derer die Kurse schwanken dürfen und in einem System flexibler Wechselkurse die Devisenmarktinterventionen. Viele Autoren sind der Auffassung, die Unabhängigkeit einer Notenbank erfordere die Übertragung der Verantwortung für die laufende Wechselkurspolitik an die Bank oder zumindest eine enge Einbeziehung der Notenbank in die wechselkurspolitischen Entscheidungen ${ }^{356}$. Eine Regierung, die zur Sicherung des Wechselkurses intervenieren will, müßte sich der Instrumente der Zentralbank bedienen, nämlich in Form von Veränderungen der Devisenreserven oder des Zinssatzes ${ }^{357}$. Je weniger dem Wechselkurs freien Lauf gelassen wird, desto mehr ist die Geldpolitik festgelegt ${ }^{358}$. Eine Notenbank, die gezwungen ist, durch Interventionen den angestrebten Wechselkurs in einen Gleichgewichtskurs zu verwandeln, verliert an Einfluß auf das inländische Preisniveau ${ }^{359}$. Langfristig ist die Bewahrung des inländischen Geldwertes aber nur möglich, wenn sich der Wechselkurs nahe dem Gleichgewichtskurs bewegen kann 360 .

Wie beeinflussen wechselkurspolitische Entscheidungen die Unabhängigkeit einer Notenbank? Die Wahl des Wechselkursregimes per se ist für die Autonomie einer Zentralbank unerheblich. Unabhängigkeitskriterium ist das Ausmaß, in dem die Notenbank über Art, Zeitpunkt und Umfang des Einsatzes geldpolitischer Instrumente frei entscheiden kann. Die Festlegung eines festen Wechselkurses oder die Festlegung von Bandbreiten sind keine geldpolitischen Instrumente im Gegensatz zu Käufen und Verkäufen von Devisen, die die Einhaltung des gewünschten Wechselkurses gewährleisten. Eine Notenbank ist also nicht durch festgelegte Wechselkurse, sondern durch eventuell daraus entstehende Interventionsverpflichtungen in ihrer Unabhängigkeit eingeschränkt. Auch das gilt nur bedingt. Betrachtet man die Stabilität eines bestimmten Wechselkurses als eine der Notenbank vorgebenen Aufgabe oder Zielsetzung, so ist ihre Unabhängigkeit nur dann eingeschränkt, wenn sie nicht frei darüber befinden kann, wie sie dieses Ziel erreichen will. Dies wäre der Fall, wenn die Notenbank verpflichtet ist, bei Über-

356 Vgl. Preuße, Heinz Gert: a.a.O., S. 11; Neumann, Manfred J. M.: a.a.O., S. 101; Swinburne, Mark; Castello-Branco, Marta: a.a.O., S. 40.

357 Vgl. Preuße, Heinz Gert: a.a.O., S. 10.

358 Vgl. Swinburne, Mark; Castello-Branco, Marta: a.a.O., S. 40.

359 Vgl. Neumann, Manfred J. M.: a.a.O., S. 101.

360 Vgl. Neumann, Manfred J. M.: a.a.O., S. 101. 
schreiten des festgelegten Wechselkurses oder der Bandbreite in vorgeschriebener Weise zu intervenieren.

\subsubsection{Zusammenfassung der Einflußfaktoren auf die funktionelle Unabhängigkeit}

In diesem Kapitel wurden mögliche Kriterien für Unabhängigkeit auf ihren tatsächlichen Einfluß auf den funktionellen Unabhängigkeitsgrad untersucht. Es wurde gezeigt, daß globale oder temporäre Ziele, die der Notenbank von außen vorgegeben werden, die funktionelle Unabhängigkeit nicht beeinträchtigen, solange die Notenbank selbst entscheiden kann, mit welchen Mitteln sie diese Ziele erreichen will. Auch der Wirkungsgrad der Instrumente erwies sich als unbedeutend für die funktionelle Unabhängigkeit. Alleiniges Unabhängigkeitskriterium ist der Umfang des geldpolitischen Instrumentariums, das der Zentralbank für ihre Operationen zur Verfügung steht. Dieses Instrumentarium definiert sich zum einen durch die Anzahl der dem Noteninstitut prinzipiell zur Verfügung stehenden geldpolitischen Mittel, zum anderen durch das Ausmaß, in dem die Anwendung der prinzipiell zur Verfügung stehenden Instrumente begrenzt ist. Diese Einschränkungen können in Form von technisch-institutionellen Einschränkungen sowie von verschiedenen Einflußrechten notenbankfremder Instanzen vorliegen. Die Problematik der Ermittlung der Gesamtheit des exisitierenden Instrumentariums liegt darin, daß nicht immer zweifelsfrei feststellbar ist, welches ein selbstständiges Instrument und welches nur ein Teilbereich eines anderen Instrumentes ist. Ferner entspricht das de jure anwendbare Instrumentarium nicht unbedingt dem in der Praxis eingesetzten. Schließlich müssen neben den geldpolitischen Mitteln auch Methoden ihrer Durchsetzung unterschieden werden, nämlich die administrative Anwendung und die verschiedenen Möglichkeiten einer Anwendung auf freiwilliger Basis, wie Moral Suasion und Gentlemen's Agreements. Ein Instrument, das eine Notenbank auf administrativem Wege nicht anwenden darf, kann unter Umständen im Rahmen freiwilliger Vereinbarungen mit den Adressaten angewendet werden. Hier liegt die Einschränkung der Unabhängigkeit darin begründet, daß die Bank nicht alleine über die Anwendung des Instruments entscheiden kann, da sie auf die Zustimmung der Adressaten angewiesen ist.

Zuletzt wurden ausgewählte Einschränkungbereiche auf ihren Einfluß auf die funktionelle Unabhängigkeit untersucht, und zwar die Staatsfinanzierung durch die Notenbank, die Verpflichtung der Notenbank zur Unterstützung der allgemeinen Wirtschaftspolitik des Staates sowie internationale Einflüsse und Verpflichtungen. Bei allen dreien konnte gezeigt werden, daß mögliche Einschränkungen der Unabhängigkeit letztlich immer auf einem Anwendungsverbot, einer nur eingeschränkten Zulässigkeit bestimmter geldpolitischer Instrumente bzw. auf Einflußrechten Externer auf den Einsatz der Mittel beruhen. So können bei der 
Kreditvergabe an den Staat sowohl technisch-institutionelle Einschränkungen vorliegen in Form von qualitativen oder quantitativen Grenzen als auch Einschränkungen durch Externe, wenn die Regierung die Notenbank zur Kreditgewährung anweisen kann oder Dritte einer Kreditvergabe zustimmen müssen. Die Verpflichtung der Notenbank, die allgemeine Wirtschaftspolitik des Staats zu unterstützen, wirkt nur dann unabhängigkeitsmindernd, wenn die Notenbank nicht nach eigenem Ermessen über die Mittel, deren Umfang und Einsatzzeitpunkte entscheiden darf, mit denen sie Unterstützung bewerkstelligen will. Einflüsse aus dem Ausland können die Unabhängigkeit einer Notenbank dann mindern, wenn notenbankfremde Instanzen aufgrund internationaler Vereinbarungen o. ä. über Möglichkeiten verfügen, direkt in die Entscheidungsfindung der Bank einzugreifen. Technisch-institutionelle Einschränkungen können z. B. durch Vereinbarungen über Automatismen entstehen, aufgrunddessen die Notenbank verpflichtet ist, bei Überschreiten festgelegter Bandbreiten von Wechselkursen, in vorgeschriebener Art und Größenordnung zu intervenieren.

\subsubsection{Beurteilung der funktionellen Unabhängigkeit}

\subsubsection{Untersuchungsrelevantes geldpolitisches Instrumentarium}

Um die funktionelle Unabhängigkeit einer Notenbank bestimmen zu können, muß zunächst geklärt werden, welche geldpolitischen Instrumente in die Untersuchung miteinbezogen werden sollen. In einem früheren Kapitel wurde bereits auf die Probleme hingewiesen, die mit der Ermittlung der Gesamtheit des geldpolitischen Instrumentariums zusammenhängen. Hier soll nun ausgehend von den in der einschlägigen Literatur ${ }^{361}$ beschriebenen geldpolitischen Mitteln ein möglichst umfassender Katalog geldpolitischer Instrumente zusammengestellt werden. Die Literatur unterscheidet im wesentlichen folgende geldpolitische Instrumente:

- Refinanzierungspolitik

- Offenmarktpolitik

- Mindestreservepolitik

- Einlagenpolitik

- Bardepotpflicht

- Devisenkurspolitik

- Kreditplafondierung

- Zinslimitierung oder -fixierung.

361 Vgl. Issing, Otmar: Einführung in die Geldpolitik, 4. Aufl. München 1992; Obst, Georg; Hintner, Otto: Geld-, Bank- und Börsenwesen, Stuttgart 1980. 


\section{Refinanzierungspolitik}

Unter Refinanzierungspolitik versteht man gemeinhin die Kreditgewährung der Notenbank an Banken durch den Ankauf von Wechseln (Rediskontkredit) und die Beleihung von Wertpapieren (Lombardkredit) ${ }^{362}$. Damit beeinflußt die Zentralbank die Verwendung vorhandener liquider Mittel ${ }^{363}$. Wechselpensionsgeschäfte sowie andere Käufe der Notenbank am offenen Markt sind theoretisch ebenfalls eine Form von Refinanzierung. Sie werden aber in der Regel der Offenmarktpolitik zugerechnet.

Refinanzierungspolitik zeichnet sich gewöhnlich durch die Beschränkung auf bestimmte Kreditnehmer (meistens Banken), die Verwendung von (ausgewählten) Wertpapieren als Sicherheiten sowie eine meist kurzfristige Orientierung aus. Theoretisch ist aber nicht nur jede Form der Kreditgewährung der Notenbank als geldpolitisches Instrument zu betrachten, sondern jegliche Ausgabe von Zentralbankgeld durch das Institut schlechthin. Die klassische Refinanzierungspolitik deckt somit nur einen kleinen Bereich des Instruments ab, das hier mit Ausgabe von Zentralbankgeld durch die Notenbank bezeichnet werden soll.

Eine Zentralbank verfügt über eine Vielzahl von Möglichkeiten, Zentralbankgeld auf den Markt zu bringen. Kredite lassen sich z. B. hinsichtlich Kreditnehmern (Staat, Kreditinstitute, Private), Laufzeiten (kurz-, mittel-, langfristig), Sicherheiten, Umfang, Zinssatz etc. variieren. Denkbar ist ebenso eine Ausgabe von Zentralbankgeld ohne Rückzahlungs- und Zinszahlungsverpflichtung des Empfängers, z. B. in Form einer Ausschüttung des Notenbankgewinns. Eine Zentralbank, der das Instrument der Ausgabe von Zentralbankgeld in vollem Umfang zur Verfügung steht, muß über alle diese Gestaltungsmöglichkeiten frei entscheiden können.

\section{Offenmarktpolitik}

Mit Offenmarktpolitik wird der Kauf und Verkauf von Wertpapieren durch die Notenbank am offenen Markt für eigene Rechnung bezeichnet ${ }^{364}$. Der Handel auf eigene Rechnung impliziert, daß ein Kauf von Wertpapieren mit einer Schaffung, ein Verkauf von Wertpapieren mit einer Vernichtung von Zentralbankgeld verbunden ist ${ }^{365}$. Teilnehmer am Offenmarktgeschäft sind in der Regel Geschäftsbanken, seltener Nichtbanken. Es läßt sich eine Vielzahl verschiedener Geschäfte unterscheiden, wie z. B. Kassa-, Termin- und Swapgeschäfte.

362 Vgl. Deutsche Bundesbank: a.a.O., S. 46.

363 Vgl. Hettlage, K. M.: a.a.O., S. 274.

364 Vgl. Köhler, Claus: a.a.O., S. 243.

365 Vgl. Issing, Otmar: Einführung in die Geldpolitik, München 1981, S. 59 
Ebenfalls am offenen Markt gehandelt werden neben Wertpapieren aber auch Valuten (Devisenkurspolitik) und Gold. Im Rahmen dieser Arbeit wird der Begriff der Offenmarktpolitik weit ausgelegt und umfaßt den An- und Verkauf von Gold, Wertpapieren und Valuten.

\section{Mindestreservepolitik}

Die Verpflichtung von Banken auf Veranlassung der Notenbank bestimmte Aktiva in Höhe eines festgelegten Prozentsatzes bestimmter Forderungen (AktivReserve) oder Verbindlichkeiten (Passiv-Reserve) zu halten, bezeichnet man als Mindestreservepolitik ${ }^{366}$. Die Mindestreserven sind in der Regel als Sichtguthaben bei der Notenbank, teilweise aber auch in bestimmten Wertpapieren oder anderen Formen zu halten. Eine Erhöhung der Mindestreserven reduziert, eine Senkung erhöht die Möglichkeit der Banken, zusätzliche Kredite zu gewähren ${ }^{367}$.

\section{Einlagenpolitik}

Bei der in Deutschland betriebenen Einlagenpolitik kann die Notenbank die öffentlichen Haushalte verpflichten, ihre flüssigen Mittel (unverzinslich) bei ihr einzulegen. Diese kann die Bestände durch temporäre Verlagerung in das Bankensystem zur kurzfristigen Steuerung des Geldmarktes heranziehen ${ }^{368}$.

\section{Bardepotpflicht}

Die Bardepotpflicht war eine in Deutschland vorübergehend ${ }^{369}$ geltende Regelung, die Gebietsansässige, die sich im Ausland verschuldeten, dazu verpflichtete, einen bestimmten Prozentsatz dieser Verbindlichkeit zinslos bei der Notenbank zu hinterlegen ${ }^{370}$. Damit sollte die Kreditaufnahme der Unternehmen im Ausland beschränkt werden, die die Bundesbank mit ihrem Instrumentarium nicht unmittelbar steuern konnte ${ }^{371}$. Das Instrument ${ }^{372}$ des Bardepots wurde über das $\mathrm{Au}$ Benwirtschaftsgesetz ( $\S 6 \mathrm{a}$ ) geschaffen. Die Bundesregierung, bei der die Kompetenz zum Einsatz dieses Instruments liegt, kann die Ermächtigung zur Festlegung des Bardepots auf die Deutsche Bundesbank übertragen.

Die drei Instrumente Mindestreservepolitik, Einlagenpolitik und Bardepotpflicht erscheinen auf den ersten Blick sehr unterschiedlich. Während sich die Mindest-

366 Vgl. Issing, Otmar (1981): a.a.O., S. 73.

367 Vgl. Hettlage, K. M.: a.a.O., S. 262.

368 Vgl. Deutsche Bundesbank: a.a.O., S. 76.

369 Zwischen 1972 und 1974.

370 Vgl. Deutsche Bundesbank: a.a.O., S. 80.

371 Vgl. Deutsche Bundesbank: a.a.O., S. 80.

372 Wobei durchaus umstritten ist, ob es sich hier um ein geldpolitisches Instrument handelt. 
reservepolitik auf die Verbindlichkeiten oder Aktiva gegenüber Nichtbanken erstreckt und von den Banken zu erfüllen ist, ist das Bardepot eine Verpflichtung der Nichtbanken und betrifft die (Auslands-) Verbindlichkeiten von Nichtbanken ${ }^{373}$. Desweiteren besteht die Mindestreservepflicht permanent, während das Bardepot nur fallweise nach Bedarf angeordnet wird 374 . Die Einlagenpolitik bezieht sich dagegen auf die flüssigen Mittel der öffentlichen Stellen. Die Entscheidung der öffentlichen Haushalte über die Höhe der öffentlichen Guthaben, also über Ausgaben und Einnahmen, bleiben von der Notenbank unberührt ${ }^{375}$. Trotz dieser Unterschiede ist allen drei Instrumenten gemein, daß die Notenbank Wirtschaftssubjekte dazu verpflichten kann, einen bestimmten Anteil ausgewählter Guthaben oder Verbindlichkeiten bei ihr einzulegen bzw. in vorgeschriebener Form zu halten. Insofern könnte man diese drei geldpolitischen Mittel zu einem Instrument zusammenfassen. Aus Gründen der Praktikabilität wird im Rahmen dieser Arbeit jedoch auf eine Einbeziehung von Einlagenpolitik- und bardepotpflichtähnlichen Mitteln verzichtet und die Untersuchung auf die Mindestreservepolitik beschränkt.

\section{Kreditplafondierung}

Mittels Kreditplafondierung kann eine Notenbank die Kreditgewährung der Banken an Nichtbanken administrativ oder aufgrund freiwilliger Vereinbarungen unmittelbar quantitativ begrenzen ${ }^{376}$. Die Plafonds können entweder als absolute Beträge oder als Prozentsatz der Aktiva oder der Passiva der Bankbilanz bestimmt werden 377 .

\section{Zinslimitierung bzw. -fixierung}

Mit dem Setzen von Zinslimitierungen oder Zinsfixierungen greift die Notenbank ebenso wie bei der Kreditplafondierung direkt in die Beziehung zwischen Banken und ihren Kunden ein. Der Einfluß der Notenbank kann sich dabei sowohl auf die Soll- als auch die Habenzinsen der Banken beziehen. Im Gegensatz zu einer Zinspolitik über die Beeinflussung der Refinanzierungskosten entsteht hier kein Time-lag bei der Wirkung dieses Mittels.

Die Mittel der Kreditplafondierung und Zinsfixierung bzw. -limitierung ermöglichen einer Notenbank einen direkten Eingriff in die Kreditvergabeaktivitäten von Banken. Daher werden sie hier zu dem Instrument direkte Einflußnahme auf die Kreditvergabe der Banken zusammengefaßt.

373 Vgl. Issing, Otmar (1981): a.a.O., S. 82.

374 Vgl. Issing, Otmar (1981): a.a.O., S. 82.

375 Vgl. Issing, Otmar (1981): a.a.O., S. 96.

Vgl. Köhler, Claus: a.a.O., S. 232.

Vgl. Bredemeier, Sonning: a.a.O., S. 16. 


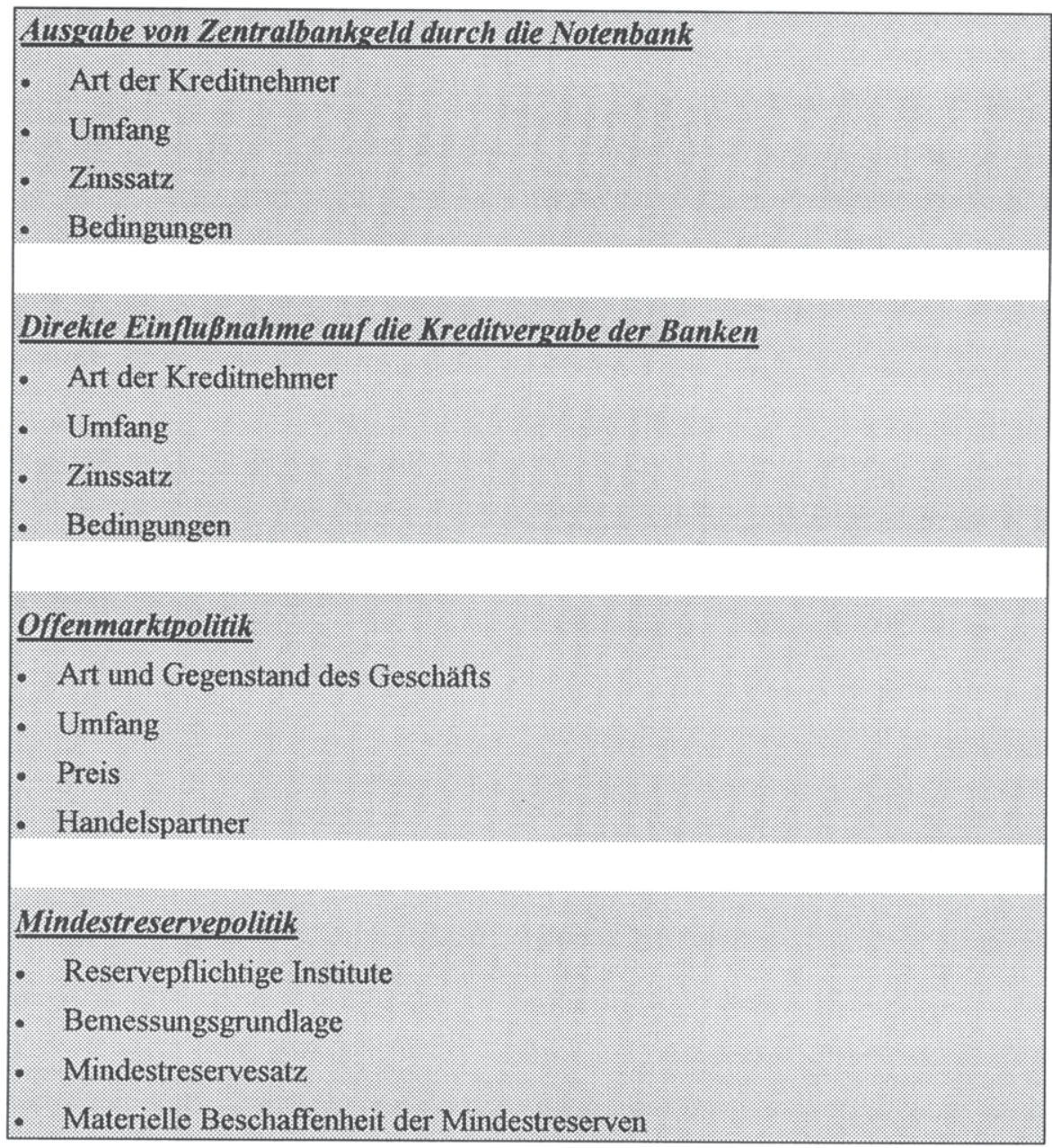

Abb. 3: Geldpolitische Instrumente zur Beurteilung der funktionellen Unabhängigkeit

Die anfangs aufgezählten geldpolitischen Mittel lassen sich also zu folgenden vier Kategorien zusammenfassen:

- Ausgabe von Zentralbankgeld durch die Notenbank

- Offenmarktpolitik 
- direkte Einflußnahme auf die Kreditvergabe der Banken

- Mindestreservepolitik

Die im Anschluß durchzuführende Untersuchung ausgewählter Notenbanken auf ihren Unabhängigkeitsgrad soll auf der Basis dieser vier Kategorien stattfinden. Sie sind ausreichend allgemein formuliert, daß ähnliche aber nicht gleiche geldpolitische Mittel in den verschiedenen Ländern berücksichtigt werden können.

Jedes dieser vier Kategorien wurde in vier Instrumente unterteilt (siehe Abb. 3). Diese werden anhand der Gegebenheiten in den zu betrachtenden Ländern auf mögliche Einschränkungen untersucht und bewertet. Aus den Ergebnissen dieser 16 Instrumente kann schließlich der funktionelle Unabhängigkeitsgrad einer Notenbank ermittelt werden.

Im folgenden sind die Instrumente der vier Kategorien aufgeführt, die anschlieBend näher erläutert werden.

\subsubsection{Ausgabe von Zentralbankgeld durch die Notenbank}

Eine Notenbank, der das Instrument der Ausgabe von Zentralbankgeld unbegrenzt zur Verfügung steht, muß befugt sein, an jeden von ihr festgelegten Adressaten, zu von ihr bestimmten Bedingungen in unbegrenzter Höhe Zentralbankgeld auszugeben. Dazu zählt die Kreditgewährung an den Staat per Erstankauf von Staatspapieren oder die Gewährung von Buchkrediten ebenso wie die klassische Refinanzierung von Banken sowie die Kreditvergabe an Unternehmen oder Privatleute. Desweiteren ist hier die Ausgabe von Zentralbankgeld durch die Notenbank ohne daraus entstehende Zins- und Tilgungsverpflichtungen der Adressaten enthalten.

\subsection{Art der Kreditnehmer}

Die Möglichkeit der Notenbank, über die Empfänger von Zentralbankgeld frei zu entscheiden, kann technisch-institutionell z. B. dadurch gemindert sein, daß eine Ausgabe von Zentralbankgeld grundsätzlich nicht an Nichtbanken oder den Staat gestattet ist oder nur an bestimmte Banken bzw. Bankengruppen möglich ist. Einflußrechte Externer bestehen, wenn Notenbankfremde an der Entscheidung darüber, welchen Institutionen oder Personen die Refinanzierungs- bzw. Kreditmöglichkeiten der Notenbank zur Verfugung stehen sollen, direkt beteiligt sind.

Man könnte nun argumentieren, daß Direktgeschäfte der Notenbank mit jedermann, wie z. B. eine Kreditgewährung an Unternehmen oder Privatleute, nicht wünschenswert ist, weil eine Zentralbank, bei der sich jedermann refinanzieren kann, im Bereich der Kreditgewährung in Konkurrenz zu den Geschäftsbanken treten würde. Die Notenbank würde damit einen Teil ihrer Existenzberechtigung 
verlieren, die sich aus ihrer Funktion als Bank der Banken ergibt. Zudem bestünde die Gefahr eines Verlustes ihrer Unabhängigkeit durch zu enge, direkte wirtschaftliche Verflechtungen 378 . Andererseits leistet die Notenbank damit einen Beitrag zur Versorgung der Wirtschaft mit liquiden Mitteln, was ebenso zu den Aufgaben einer modernen Zentralbank gehört ${ }^{379}$. Die Tatsache, da $B$ in einigen Ländern eine Kreditgewährung der Notenbank auch an Privatleute und Unternehmen durchaus üblich ist, unterstützt die Auffassung, jede Art der Ausgabe von Zentralbankgeld durch die Notenbank als geldpolitisches Instrument zu betrachten.

\subsection{Umfang}

Technisch-institutionelle Einschränkungen hinsichtlich des Umfangs einer Ausgabe von Zentralbankgeld durch die Notenbank liegen beispielsweise bei einer Begrenzung einer Kreditvergabe in Form von gesetzlich festgelegten Kontingenten vor. Ebenso behindert ist eine Notenbank, die bei der Ausgabe von Zentralbankgeld Deckungsvorschriften, Noteneinlöseverpflichtungen oder sonstigen Emissionsbegrenzungen unterliegt. Die Verpflichtung einer Notenbank zur Ausgabe von Zentralbankgeld ist nur dann eine technisch-institutionelle Einschränkung, wenn die Modalitäten der Ausgabe klar fixiert sind und externe Instanzen diesbezüglich keine Einflußrechte besitzen. Dabei muß die Höhe der Ausgabe nicht unbedingt betragsmäßig festgelegt sein. So kann eine Notenbank z. B. eine Verpflichtung zur Ausschüttung ihres Gewinns an den Staat als fixes Datum in ihre Geldpolitik einplanen, ohne daß externe Instanzen darauf Einfluß nehmen können. Dagegen ist eine allgemeine Verpflichtung der Bank zur Kreditvergabe oder sonstigen Ausgabe von Zentralbankgeld - auch wenn deren Höhe betragsmäßig limitiert ist - keine technisch-institutionelle Einschränkung, sondern eine Einschränkung durch Externe, weil hier notenbankfremde Instanzen die Bank zu einer Ausgabe von Geld anweisen können. Einschränkungen durch Externe liegen immer dann vor, wenn notenbankfremde Aktoren über Veto-, Genehmigungs- oder Weisungsrechte auf die Ausgabe von Zentralbankgeld durch die Notenbank Einfluß nehmen können.

\subsection{Zinssatz}

Technisch-institutionelle Einschränkungen hinsichtlich des Zinssatzes für die Ausgabe von Zentralbankgeld liegen bei gesetzlich festgelegten Zinssätzen für Notenbankkredite bzw. Limits in Form von Unter- oder Höchstgrenzen vor. Einschränkungen durch Externe existierten, wenn Notenbankfremde über die Höhe 
der Kreditzinsen der Notenbank oder die Bandbreite, innerhalb derer sie sich bewegen müssen, mittels Weisungs-, Veto- oder Genehmigungsrechten Einfluß nehmen können.

\subsection{Bedingungen}

Aus Gründen der Praktikabilität beschränken sich die berücksichtigten Bedingungen im Rahmen dieser Arbeit auf Laufzeiten und Sicherheiten der Kredite. Die Freiheit der Notenbank, diese nach eigenem Ermessen festzulegen, kann z. B. durch gesetzlich festgelegte Anforderungen an diskont- bzw. lombardfähige Wertpapiere sowie andere Kreditsicherheiten, durch fixierte Beleihungsgrenzen für Sicherheiten, als auch durch die Kreditlaufzeiten betreffende Vorschriften technisch-institutionell eingeschränkt sein. Externe können diese Entscheidungsfreiheit beeinträchtigen sofern sie mittels Veto-, Genehmigungs- oder Weisungsrechten auf die Auswahl der Kreditsicherheiten bzw. die Laufzeiten der Notenbankkredite Einfluß nehmen können.

\subsubsection{Direkte Einflußnahme auf die Kreditvergabe der Banken}

Zur völligen Unabhängigkeit der Notenbank im Rahmen der direkten Einflußnahme auf die Kreditgewährung der Banken muß die Notenbank Umfang, Zinssatz, Bedingungen 380 sowie Art der Kreditnehmer von Bankkrediten festlegen können. Viele Einflußmöglichkeiten auf die Kreditvergabe der Banken fallen eher in den Bereich der Bankenaufsicht als der Währungspolitik. Da bankaufsichtsrechtliche $\mathrm{Maßnahmen} \mathrm{auch} \mathrm{währungspolitische} \mathrm{Auswirkungen} \mathrm{zeigen,} \mathrm{müssen}$ sie hier berücksichtigt werden ${ }^{381}$.

\subsection{Art der Kreditnehmer}

Gesetzliche Regelungen, die den Kreis potentieller Kreditnehmer einschränken, stellen für die Notenbank eine technisch-institutionelle Einschränkung dar. Können dagegen externe Instanzen auf die Entscheidung, welchen Institutionen oder Personen die Kreditmöglichkeiten der Banken zur Verfügung stehen sollen, Einfluß nehmen, liegen Einschränkungen durch Externe vor. Auch hier bedeutet ein Verbot der Notenbank, auf administrativem Wege auf die Art der Kreditnehmer zu regulieren, eine Einschränkung ihrer Unabhängigkeit bzgl. dieses Instruments in Form von Genehmigungsrechten der betroffenen Banken oder Kunden, deren Zustimmung sie bei entsprechenden freiwilligen Vereinbarungen bedarf.

380 Hier wieder aus Gründen der Praktikabilität auf Kreditsicherheiten und Laufzeiten beschränkt.

381 Vgl. Humm, Hubert: Bankenaufsicht und Währungssicherung, Berlin 1989, S. 95. 


\subsection{Umfang}

Die Möglichkeiten einer Notenbank, den Umfang der Kreditvergabe von Banken direkt zu beeinflussen, sind technisch-institutionell eingeschränkt, wenn die Zentralbank nicht befugt ist, Kreditplafondierung auf administrativem Wege anzuwenden oder wenn ihr hinsichtlich der Höhe der Kreditbegrenzung gesetzliche Grenzen gesetzt sind. Zudem stellen auch Richtlinien eine Einschränkung der Einflußmöglichkeiten der Zentralbank dar, die in der Regel weniger als kreditpolitisches Instrument denn zur Sicherstellung der Zahlungsfähigkeit von Kreditinstituten im Rahmen der Bankenaufsicht festgelegt wurden. Dazu zählen beispielsweise Regelungen, die die Kreditgewährung von Banken auf einen bestimmten Prozentsatz ihres Eigenkapitals beschränken. Die Banken müssen diese Richtlinien unabhängig von der Notenbankpolitik beachten, so daß dieser Bereich dem Zugriff des Noteninstituts entzogen ist, sofern sie nicht selbst die richtliniengebende Instanz ist.

Einschränkungen der Unabhängigkeit durch Externe liegen vor, wenn Notenbankfremde auf die Entscheidungen der Notenbank bzgl. des Umfanges der Kreditvergabe der Banken mittels Veto-, Genehmigungs- oder Weisungsrechten Einfluß nehmen können. Einschränkungen in Form eines Genehmigungsrechtes entstehen beispielsweise, wenn der Notenbank eine administrative Anwendung der Kreditplafondierung nicht gestattet ist. Sie kann dieses Instrument daher nur im Rahmen freiwilliger Vereinbarungen mit den betroffenen Banken einsetzen, also mit deren Zustimmung.

\subsection{Zinssatz}

Eine Notenbank kann in ihrer Freiheit, die Zinsen von Kreditinstituten festzusetzen, sowohl technisch-institutionell aufgrund gesetzlich festgelegter Unter- bzw. Höchstgrenzen für Zinsen beschränkt sein als auch durch Einflußnahme Externer in Form von Veto-, Genehmigungs- und Weisungsrechten. Auch hier läßt ein Verbot administrativer Anwendung von Zinsfixierungen oder Zinslimitierungen durch die Notenbank nur entsprechende freiwillige Vereinbarungen mit den betreffenden Banken zu, deren Genehmigung die Zentralbank dafür bedarf.

Strenggenommen müßten zu technisch-institutionellen Einschränkungen auch die sog. Wucherparagraphen gerechnet werden. Diese verbieten u. a. den Banken, von ihren Kreditnehmern einen Zins zu verlangen, der über eine festgelegte Höchstgrenze hinausgeht oder der den marktüblichen Zins um mindestens einen bestimmten Satz übersteigt. Es wird jedoch auf eine Berücksichtigung von Wucheregelungen bei der Beurteilung der Unabhängigkeit einer Notenbank verzichtet, da sie weder bankaufsichtsrechtlichen noch geldpolitischen Hintergrund haben. Zudem ist es das Ziel der Notenbank, auf das Marktniveau der Zinssätze 
Einfluß zu nehmen. Wucherzinsen zeichnen sich hingegen dadurch aus, daß sie weit oberhalb des Marktzinsniveaus liegen.

\subsection{Bedingungen}

Technisch-institutionelle Einschränkungen hinsichtlich Kreditbedingungen bei der Kreditvergabe der Banken sind alle gesetzlichen Regelungen zu Laufzeit und Sicherheiten von Bankkrediten, die für die Einflußträger auf die Kreditbedingungen bindend sind. Dies können beispielsweise gesetzlich fixierte Beleihungsgrenzen für Immobilien oder die Beleihung von Wertpapieren beim Ankauf von Effekten auf Kredit sein. Einschränkungen durch Externe können vorliegen, wenn Notenbankfremde über die Regelungen zu Laufzeit, Sicherheiten von Krediten entscheiden, oder diesbezüglichen Entscheidungen der Notenbank zustimmen müssen bzw. über Vetorechte verfügen. Eine Notenbank, die keine Möglichkeit hat, auf administrativem Wege die Laufzeiten oder Sicherheiten von Krediten zu regeln, kann nur im Rahmen freiwilliger Vereinbarungen mit Banken oder Kreditnehmern darauf Einfluß nehmen. Sie bedarf diesbezüglich also der Zustimmung der betroffenen Banken bzw. Kreditnehmer und ist daher in ihrer Entscheidungsfreiheit bzgl. der Kreditbedingungen der Banken in Form eines Genehmigungsrechts eingeschränkt.

\subsubsection{Offenmarktpolitik}

Eine Notenbank, der das Instrument der Offenmarktpolitik i.w.S. voll zur Verfügung steht, muß befugt sein, Wertpapiere, Gold und Devisen auf eigene Rechnung in beliebigem Umfang am offenen Markt zu kaufen oder verkaufen. Dabei muß sie freie Hand hinsichtlich ihrer Handelspartner und der Art der Geschäfte haben.

\subsection{Art und Gegenstand des Geschäfts}

Je nach Art und Gegenstand von Offenmarktgeschäften zeigen sich unterschiedliche geldpolitische Wirkungen. So beeinflußt beispielsweise der Handel mit langfristigen Wertpapieren unmittelbar die Zinssätze am Kapitalmarkt, während der Kauf und Verkauf von kurzfristigen Papieren auf die Zinssätze am Geldmarkt einwirkt ${ }^{382}$. Die Einbeziehung des Handels mit langfristigen Papieren kann die Durchschlagskraft der Geldpolitik vergrößern, weil durch die Einwirkung auf die Kapitalmarktzinsen stärker beeinflußt werden kann, in welche Anlageform die volkswirtschaftlichen Ersparnisse hinfließen. Ist einer Notenbank prinzipiell der Abschluß bestimmter Geschäftsarten der Offenmarktpolitik (Termin-, Kassa-,

Vgl. Bernhuber Max; Hauck Hartwig: a.a.O., S. 44. 
Swap-, etc.) nicht gestattet, bedeutet das für sie eine technisch-institutionelle Einschränkung hinsichtlich dieses Instruments. Gleiches gilt für Beschränkungen in der Auswahl des Handelsgegenstandes (Wertpapiere, Gold, Devisen). Einschränkungen der Unabhängigkeit durch Externe liegen vor, wenn externe Instanzen auf die Entscheidung der Notenbank über die Art der zu tätigenden Offenmarktgeschäfte durch Weisungs-, Veto- oder Genehmigungsrechte Einfluß nehmen können.

\subsection{Preis}

Gesetzlich festgelegte Preise oder Preisbereiche für den An- und Verkauf von Wertpapieren, Gold und Devisen durch die Notenbank stellen technischinstitutionelle Einschränkungen dar. Darunter fallen z. B. auch feste Goldparitäten der Währungen, die der Notenbank die Möglichkeit nehmen, mit Gold oder Devisen zu von ihr gesetzten Preisen zu handeln. Das Wesen der Offenmarktpolitik impliziert, daß ein Handel nur mit Zustimmung beider Handelspartner zustande kommt. Verlangt die Notenbank Preise, die weit oberhalb der Marktpreise liegen, wird ein Geschäft kaum zustande kommen. Eine Einschränkung ihrer Entscheidungsfreiheit und damit ihrer Unabhängigkeit ist damit aber nicht verbunden. Verlangt das Gesetz dagegen, daß sich die Notenbank nur Geschäfte zu Marktpreisen schließt, bedeutet dies eine technisch-institutionelle Einschränkung. Einschränkungen durch Externe liegen vor, wenn notenbankfremde Instanzen auf die Preisentscheidung der Notenbank per Weisungs-, Genehmigung- oder Vetorecht Einfluß nehmen können.

\subsection{Umfang}

Technisch-institutionelle Einschränkungen entstehen der Notenbank durch gesetzliche Grenzen für den Umfang von An- und Verkauf von Wertpapieren, Gold und Devisen, aber auch durch die Verpflichtung, bestimmte Geschäfte zu betreiben. Diese Einschränkungen können beispielsweise in Form direkter Kontingente vorliegen, aber auch indirekt in Form von Deckungsquoten oder Noteneinlösevorschriften, die die Möglichkeit der Notenbank begrenzen, durch den Ankauf von Werten Zentralbankgeld auszugeben. Ebenfalls als technisch-institutionelle Einschränkungen sind Interventionsverpflichtungen der Notenbank zu werten, auf deren Entstehung die Bank keinen entscheidenden Einfluß hatte. Einflußrechte Dritter liegen vor, wenn externe Instanzen Entscheidungen treffen können, die den Umfang der Offenmarktgeschäfte betreffen, den Entscheidungen der Notenbank zustimmen müssen oder sie durch Vetorechte verhindern bzw. verschieben können. 


\subsection{Handelspartner}

Notenbanken können Offenmarktgeschäfte theoretisch mit jedermann schließen. Die Auswirkungen auf den Liquiditätsstatus der Geschäftsbanken sind unterschiedlich, je nachdem, ob die Notenbank mit Nichtbanken oder mit Kreditinstituten Offenmarktgeschäfte tätigt ${ }^{383}$. Während bei Offenmarktgeschäften mit Banken nur ein Aktivtausch in Form einer Umschichtung zwischen Primär- und Sekundärliquidität stattfindet, verändert der Handel der Notenbank mit Nichtbanken den Notenumlauf außerhalb der Banken und damit das aktive Geldvolumen $^{384}$. Jede gesetzliche Beschränkung potentieller Handelspartner bedeutet daher für die Notenbank eine technisch-institutionelle Einschränkung. Einschränkungen durch Externe liegen vor, wenn notenbankfremde Instanzen (mit)bestimmen können, mit wem die Notenbank Offenmarktgeschäfte tätigt.

\subsubsection{Mindestreservepolitik}

Eine Notenbank, die im Rahmen der Mindestreservepolitik völlig autonom ist, muß befugt sein, von ihr ausgewählte Kreditinstitute dazu zu verpflichten, einen von ihr festgelegten Anteil bestimmter Guthaben oder Verbindlichkeiten bei ihr einzulegen oder in bestimmter Form zu halten.

\subsection{Reservepflichtige Institute}

Die Unabhängigkeit einer Notenbank ist hinsichtlich des Instruments reservepflichtige Institute eingeschränkt, wenn sie nicht alleine die Auswahl der zur Haltung von Mindestreserven verpflichteten Banken treffen kann. Diese Einschränkung kann aufgrund gesetzlicher Regelungen technisch-institutionell bedingt sein. Dabei könnte beispielsweise die Mindestreservepflicht nur für ausgewählte Banken bzw. Bankengruppen zulässig sein oder mehr Institute zum Halten von Mindestreserven verpflichtet sein als die Notenbank beabsichtigt. Auch bankfremde Instanzen können durch Einflußrechte die Möglichkeiten der Zentralbank einschränken, die reservepflichtigen Banken zu bestimmen. Dies gilt beispielsweise für den Fall, daß eine administrative Anwendung der Mindestreservepolitik nicht gestattet ist. Hier kann die Notenbank dieses Instrument nur im Rahmen freiwilliger Vereinbarungen mit den betroffenen Kreditinstituten anwenden.

383 Vgl. Bernhuber Max; Hauck Hartwig: Funktionen und Instrumente der Zentralbanken in den EWG und in Österreich. Wiener Studien zur Wirtschafts- und Sozialpolitik, Wien 1965, S. 44.

384 Vgl. Veit, Otto (1961), a.a.O., S. 268 


\subsection{Bemessungsgrundlage}

Die Reservepflicht kann sich am Bestand oder am Zuwachs bestimmter Forderungen oder Verbindlichkeiten der Kreditinstitute orientieren. Gesetzliche Regelungen können den diesbezüglichen Gestaltungsspielraum einer Notenbank einengen, z. B. durch Beschränkung der Mindestreservepflicht auf ausgewählte Verbindlichkeiten. Einschränkungen durch Externe liegen vor, wenn notenbankfremde auf die Gestaltung der Bemessungsgrundlagen Einfluß durch Weisungs-, Zustimmungs oder Vetorechte nehmen können.

\subsection{Mindestreservesatz}

Eine unabhängige Notenbank muß den Mindestreservesatz frei bestimmen können. Liegen diesbezüglich gesetzlich festgelegte Unter- oder Obergrenzen vor, handelt es sich um eine technisch-institutionelle Einschränkung der Unabhängigkeit bzgl. dieses Instruments. Einschränkungen durch Externe liegen vor, wenn notenbankfremde Instanzen über die Höhe der Sätze entscheiden oder sie direkt beeinflussen können. Auch hier gilt wieder bei einem Verbot einer administrativen Anwendung des Mindestreserveinstruments, daß die Notenbank beim Einsatz dieses Mittels und damit auch bei der Festsetzung der Reservesätze der Zustimmung der betroffenen Banken bedarf.

\subsection{Materielle Beschaffenheit der Mindestreserve}

Eine bezüglich des Instruments der materiellen Beschaffenheit der Mindestreserven unabhängige Notenbank muß befugt sein, zu entscheiden, in welcher Form die Mindestreserven gehalten werden sollen. Neben einer Sichteinlage bei der Notenbank ist beispielsweise auch eine Stillegung bei den betroffenen Instituten denkbar oder eine Anlage in bestimmten Wertpapieren. Eine Mindestreservepflicht in Form einer unverzinslichen Einlage bei der Notenbank bedeutet eine Schmälerung der Rentabilität des Geschäfts inländischer Banken, die daher bestrebt sein werden, sich dieser Verpflichtung durch Verlagerung ihrer Tätigkeit an Plätze, die derartige Interessenbeeinträchtigungen nicht kennen, zu entziehen ${ }^{385}$. Dadurch könnte dieses Instrument deutliche Verluste in seiner Wirksamkeit erleiden. Die Möglichkeit der Notenbank, die Beschaffenheit der Reserven zu bestimmen, gibt ihr z. B. die Möglichkeit, solche Umgehungsreaktionen zu reduzieren.

Bestimmt das Gesetz, in welcher Form die reservepflichtigen Institute ihre Mindestreserven halten müssen, liegt eine technisch-institutionelle Einschränkung dieses Instruments vor. Einschränkungen der Unabhängigkeit durch Externe be-

385 Vgl. Siebelt, Johannes: a.a.O., S. 199. 
stehen, wenn notenbankfremde Instanzen die Entscheidung über die geforderte materielle Beschaffenheit der Mindestreserve direkt beeinflussen können. Dies ist z. B. der Fall bei einem Verbot einer administrativen Anwendung von Mindestreservepolitik, die die Notenbank bei Einsatz dieses Instruments zu freiwilligen Vereinbarungen mit den betroffenen Instituten zwingt. Hier haben die betroffenen Banken auch ein Zustimmungsrecht bei der Festlegung der materiellen Beschaffenheit der zu haltenden Reserven.

\subsubsection{Bewertungsschema zur Beurteilung geldpolitischer Instrumente}

Für die Beurteilung der funktionellen Unabhängigkeit ist nun zu untersuchen, inwieweit einer Notenbank die vier Kategorien mit ihren einzelnen Bereichen zur Verfügung stehen. Die Entscheidungsfreiheit einer Notenbank kann hinsichtlich jedes Instruments durch verschiedene Formen technischer-institutioneller Einschränkungen sowie Einschränkungen durch Externe beeinträchtigt sein.

Bei den technisch-institutionellen Einflüssen werden drei Abstufungen unterschieden:

a) Das Instrument steht der Notenbank technisch-institutionell uneingeschränkt zur Verfügung.

b) Das Instrument steht der Notenbank zwar prinzipiell zur Verfügung; sein Einsatz ist aber technisch-institutionell eingeschränkt.

c) Die Anwendung des Instruments ist generell verboten, d.h. nicht nur auf administrativem Wege, sondern auch im Rahmen freiwilliger Vereinbarungen.

Bei den Einflüssen durch Externe beim Einsatz der Instrumente lassen sich vier Stufen unterscheiden:

a) Es bestehen keine Einflußrechte Externer hinsichtlich des Instruments.

b) Es existiert ein aufschiebendes Vetorecht Externer hinsichtlich des Instruments.

c) Es existiert ein aufhebendes Vetorecht oder Genehmigungsrecht Externer hinsichtlich des Instruments.

d) Es existiert ein Weisungsrecht oder konstruktives Vetorecht Externer hinsichtlich des Instruments. 


\begin{tabular}{|c|c|c|c|}
\hline & $\begin{array}{c}\text { Instrument } \\
\text { technisch- } \\
\text { institutionell } \\
\text { nicht einge- } \\
\text { schränkt }\end{array}$ & $\begin{array}{c}\text { Instrument } \\
\text { technisch- } \\
\text { institutionell } \\
\text { eingeschränkt }\end{array}$ & $\begin{array}{c}\text { Instrument ver- } \\
\text { boten }\end{array}$ \\
\hline $\begin{array}{c}\text { keine Einfluß- } \\
\text { rechte Dritter }\end{array}$ & & & \\
\hline $\begin{array}{c}\text { aufschiebendes } \\
\text { Veto }\end{array}$ & & & \\
\hline $\begin{array}{c}\text { aufhebendes } \\
\text { Veto, Genehmi- } \\
\text { gungs-recht }\end{array}$ & & & \\
\hline $\begin{array}{c}\text { Weisungsrecht, } \\
\text { konstruktives } \\
\text { Vetorecht }\end{array}$ & & & \\
\hline
\end{tabular}

Abb. 4: Einflußmöglichkeiten auf den Einsatz geldpolitischer Instrumente

Die verschiedenen Kombinationsmöglichkeiten von Einflüssen, denen eine Notenbank bei der Anwendung eines Instruments unterliegen kann, sind in Abb. 4 zusammengefaßt.

Für jedes der Einflußrechte Externer müssen die verschiedenen Formen technisch-institutioneller Einschränkungen unterschieden werden. Die Anzahl der Kombinationsmöglichkeiten reduziert sich dadurch, daß im Falle eines prinzipiellen Verbots der Anwendung eines Instruments auch keine Einflußrechte Externer existieren können.

Die größtmögliche Unabhängigkeit bezüglich eines geldpolitischen Instruments liegt vor, wenn es der Notenbank uneingeschränkt zur Verfügung steht, d.h. wenn seine Anwendung weder durch technisch-institutionelle Einschränkungen noch durch Einflußrechte Externer beeinträchtigt ist. Das andere Extrem bildet der Fall, $\mathrm{da}$ die Anwendung eines Instruments prinzipiell nicht gestattet ist bzw. Weisungsrechte Externer vorliegen. Alle anderen Kombinationsmöglichkeiten sind im Bereich dazwischen angesiedelt.

Nun stellt sich die Frage, ob die Unabhängigkeit durch technisch-institutionelle Einschränkungen oder durch Einflußrechte Externer stärker gemindert wird. Für beides lassen sich Argumente finden. Für einen geringeren Einfluß von Einwirkungsmöglichkeiten Notenbankfremder auf die Unabhängigkeit spricht, daß die Anwendung der Instrumente hier nicht in jedem Fall eingeschränkt ist. Wenn die bankfremden Instanzen ihre Rechte nicht wahrnehmen, kann die Notenbank ihre 
Politik unbehindert betreiben. Dagegen erschweren oder verhindern technischinstitutionelle Einschränkungen den Einsatz bestimmter geldpolitischer Mittel immer in gleichem Umfang. Andererseits sind technisch-institutionelle Einschränkungen für die Notenbank kalkulierbar. Sie kann sich auf den Mangel einstellen und versuchen, diesen durch den Einsatz anderer Instrumente oder Instrumentenkombinationen zu kompensieren. Zudem ist sie die einzige Instanz, die Einfluß auf die geldpolitischen Entscheidungen nimmt. Externe Instanzen können dagegen durch Einflußrechte im Extremfall der Notenbank jeglichen Einfluß auf ihre Politik nehmen, zumal zu erwarten ist, daß sie immer dann ihre Rechte wahrnehmen werden, wenn die geldpolitischen Entscheidungen der Notenbank nicht in deren Sinne getroffen werden. Daher ist man geneigt, Einschränkungen der Unabhängigkeit einer Notenbank durch Einflußrechte Externer tendenziell höher zu bewerten als die durch technisch-institutionelle Einschränkungen verursachten. Hier muß man jedoch näher differenzieren.

Ist einer Notenbank der Einsatz eines Instruments prinzipiell nicht gestattet, hat weder sie noch irgendeine andere Instanz einen Einfluß auf dessen Gestaltung. Verfügen dagegen externe Instanzen über ein aufschiebendes oder aufhebendes Vetorecht oder ein Genehmigungsrecht bzgl. dieses Instruments, steht der Notenbank dieses geldpolitische Mittel prinzipiell zur Verfügung. Gegen ihren Willen darf sie nicht zu einem Einsatz gezwungen werden. Im ungünstigsten Fall darf sie dieses Instrument nicht anwenden, weil sein Einsatz von der Genehmigungsinstanz nicht gestattet wird. Die Bank hat also hier mehr Entscheidungsfreiheit als wäre die Anwendung des Instruments prinzipiell nicht gestattet. Verfügen dagegen externe Instanzen über ein Weisungsrecht bzgl. eines Instruments, hat die Notenbank ebensowenig Entscheidungsbefugnisse über die Gestaltung dieses geldpolitischen Mittels als wäre die Anwendung des Instruments prinzipiell nicht gestattet. Da jedoch notenbankfremde Instanzen beim Vorliegen eines Weisungsrechts direkt die Richtung der Politik mitbestimmen können, beeinträchtigen Weisungsrechte die Unabhängigkeit einer Notenbank stärker als stünde der Zentralbank der entsprechende Bereich des Instrumentariums prinzipiell nicht zur Verfügung.

Neben der Möglichkeit, daß die Anwendung eines geldpolitischen Mittels prinzipiell nicht gestattet ist, ist auch der Fall denkbar, daß eine Zentralbank das Mittel zwar anwenden darf, aber Zeitpunkt und Art des Einsatzes exakt vorgeschrieben ist. Es handelt sich dabei um eine Art Automatismus, der beim Eintritt festgelegter Voraussetzungen in Kraft tritt. Hier haben wie im Falle eines Anwendungsverbots eines Mittels weder die Notenbank noch andere Instanzen einen Einfluß auf dessen Anwendung. Daher hat dieser Fall die gleichen Auswirkungen auf die Unabhängigkeit einer Notenbank wie das Verbot des Instruments. 
Damit ergänzt sich die Auflistung möglicher Einschränkungen beim Einsatz geldpolitischer Mittel wie folgt:

a) keine Einflußrechte Externer bzgl. des Einsatzes eines geldpolitischen Mittels,

b) aufschiebendes Vetorecht Externer bzgl. des Einsatzes eines geldpolitischen Mittels,

c) aufhebendes Vetorecht Externer bzgl. des Einsatzes eines geldpolitischen Mittels,

d) Der Einsatz des geldpolitischen Mittels ist prinzipiell verboten bzw. es gibt einen Automatismus hinsichtlich seiner Anwendung,

e) Weisungsrecht Externer bzgl. des Einsatzes eines geldpolitischen Mittels

Die Reihenfolge kennzeichnet dabei eine zunehmende Abhängigkeit einer Zentralbank.

Bei der Erstellung des Bewertungsschemas muß noch ein weiterer Punkt berücksichtigt werden. So, wie sich die vier hier betrachteten Kategorien in einzelne Instrumente unterteilen lassen, bestehen auch die Instrumente jeweils aus einer Anzahl von Subinstrumenten, die sich wiederum beliebig unterteilen lassen. Problematisch wird dies dadurch, daß mögliche Einflußrechte Externer nicht zwangsläufig ein gesamtes Instrument betreffen, sondern womöglich nur Teilbereiche davon. Dies muß bei einer Bewertung der Instrumente berücksichtigt werden. Daher wird eine zusätzliche Differenzierung getroffen, je nachdem, ob die Einflußrechte Externer ein Instrument nur partiell oder insgesamt betreffen. Für technisch-institutionelle Einschränkungen stellt sich dieses Problem nicht, da es dafür nur die beiden Möglichkeiten „technisch-institutionell eingeschränkt“" oder „nicht eingeschränkt“ gibt, vorausgesetzt das geldpolitische Mittel steht prinzipiell zur Verfügung.

Es ergibt sich das in Abb. 5 dargestellte Bewertungsschema, wobei die Reihenfolge jeweils abnehmende Unabhängigkeitsgrade kennzeichnet.

Die größtmögliche Unabhängigkeit bzgl. eines Instruments mit der Bewertung A liegt vor, wenn weder Einflußrechte Externer bestehen noch technischinstitutionelle Einschränkungen. Die Stufen B bis D tragen der Tatsache Rechnung, daß eine Zentralbank einen größeren Einfluß auf die Gestaltung eines Teilbereichs von einem Instrument hat, wenn externe Instanzen diesbezüglich über Veto- oder Genehmigungsrechte verfügen, als wenn der Bank die Anwendung dieses Instruments gänzlich untersagt ist. Darf ein Instrument nicht angewendet werden, bedeutet das eine technisch-institutionelle Einschränkung des gesamten Instruments. Bestehen Veto- oder Genehmigungsrechte notenbankfremder Instanzen für das gesamte geldpolitische Mittel, können diese zusätzlich noch tech- 
nisch-institutionell eingeschränkt sein. Daraus ergibt sich für für die Veto- und Genehmigungsrechte eine zusätzliche Differenzierung nach einer technischinstitutionellen Einschränkung (Bewertungsstufen $\mathrm{E}$ bis $\mathrm{H}$ ).

\begin{tabular}{|c|c|c|}
\hline Einflubrechte Externer & $\begin{array}{l}\text { technisch- } \\
\text { institutionell einge- } \\
\text { schränkt }\end{array}$ & $\begin{array}{l}\text { Bewer- } \\
\text { tung }\end{array}$ \\
\hline keine Einflußrechte Externer & nein & A \\
\hline aufschiebendes Vetorecht partiell & nein & $\mathrm{B}$ \\
\hline $\begin{array}{l}\text { aufhebendes Vetorecht, Genehmi- } \\
\text { gungsrecht partiell }\end{array}$ & nein & $\mathrm{C}$ \\
\hline $\begin{array}{l}\text { keine Einflußrechte Externer bzw. } \\
\text { partielle Einschränkung durch auf- } \\
\text { schiebendes oder aufhebendes } \\
\text { Vetorecht oder Genehmigungs- } \\
\text { recht }\end{array}$ & ja & $\mathrm{D}$ \\
\hline aufschiebendes Vetorecht gesamt & nein & $\mathrm{E}$ \\
\hline aufschiebendes Vetorecht gesamt & ja & $\mathrm{F}$ \\
\hline $\begin{array}{l}\text { aufhebendes Vetorecht, Genehmi- } \\
\text { gungsrecht gesamt }\end{array}$ & nein & G \\
\hline $\begin{array}{l}\text { aufhebendes Vetorecht, Genehmi- } \\
\text { gungsrecht gesamt }\end{array}$ & $\begin{array}{l}\text { sowohl bei administra- } \\
\text { tivem Einsatz als auch } \\
\text { bei Anwendung auf } \\
\text { dem Wege freiwilliger } \\
\text { Vereinbarungen }\end{array}$ & $\mathrm{H}$ \\
\hline- & $\begin{array}{l}\text { Instrument verboten } \\
\text { oder Automatismus }\end{array}$ & I \\
\hline Weisungsrecht partiell & nein & $\mathrm{J}$ \\
\hline Weisungsrecht partiell & ja & $\mathrm{K}$ \\
\hline Weisungsrecht gesamt & - & $\mathrm{L}$ \\
\hline
\end{tabular}

Abb. 5: Bewertung der möglichen Einschränkungen der funktionellen Unabhängigkeit

Das aufhebende Vetorecht bzw. Genehmigungsrecht bedarf näherer Erläuterung. Eine technisch-institutionelle Einschränkung wird hier nur dann berücksichtigt, 
wenn sie sowohl für adminstrative als auch für nicht administrative Anwendungen des Instruments gelten. Genehmigungsrechte können einmal vorliegen, wenn der administrative Einsatz eines Instruments an die Bewilligung einer externen Instanz gebunden ist, aber auch, wenn eine administrative Anwendung des Instruments nicht gestattet ist und die Notenbank auf diesbezügliche freiwillige Vereinbarungen mit den Banken angewiesen ist. Im ersten Fall können zusätzlich technisch-institutionelle Einschränkungen beim administrativen Einsatzes des geldpolitischen Mittels vorliegen. Der Notenbank steht es jedoch weiterhin offen, diese technisch-institutionellen Einschränkungen zu umgehen, indem sie statt administrativer Anwendung des Instruments entsprechende freiwillige Vereinbarungen mit den Betroffenen schließt. Würde man diese technisch-institutionellen Einschränkungen, die nur bei administrativer Anwendung des geldpolitischen Mittels vorliegen, bei der Bewertung berücksichtigen, erhielte man ein unrichtiges Ergebnis. Eine Notenbank, die ein Instrument unter keinen Umständen administrativ anwenden kann, würde unabhängiger abschneiden, als eine, der wie bei der anderen Bank sämtliche Möglichkeiten freiwilliger Vereinbarungen offenstehen und die zusätzlich die Wahl hat, das betreffende Instrument technischinstitutionell eingeschränkt und nach Bewilligung durch eine externe Instanz administrativ einzusetzen. In keinem der beiden Fälle verfügt die Notenbank eindeutig über größere Befugnisse. Daher werden in diesem Fall (Bewertungsstufe H) die technisch-institutionellen Einschränkungen nicht berücksichtigt.

Darf die Zentralbank ein Instrument gar nicht anwenden, also weder administrativ noch im Wege freiwilliger Vereinbarungen, oder ist die Anwendung mit einem Automatismus verbunden, auf den weder die Bank noch eine andere Instanz einen Einfluß haben, schränkt dies die Unabhängigkeit des Instituts stärker ein als wäre sie bei der Anwendung auf die Zustimmung anderer angewiesen (Bewertungsstufe I). Einflußrechte Externer gibt es in diesem Fall nicht. Die Bewertungsstufen $\mathrm{J}$ bis K kennzeichnen das Vorliegen von Weisungsrechten notenbankfremder Instanzen. Auch ein nur partiell geltendes Weisungsrecht wird hier als stark unabhängigkeitsmindernd eingestuft, weil dies die einzige Möglichkeit Externer ist, direkten Einfluß auf die Richtung der Notenbankpolitik zu nehmen. Liegen Weisungsrechte nur für einen Teilbereich eines Instruments vor, ist es noch sinnvoll, nach zusätzlich vorliegenden technisch-institutionellen Einschränkungen zu differenzieren. Existiert dagegen ein das gesamte Instrument umfassendes Weisungsrecht, schränkt dies die Unabhängigkeit bezüglich dieses Instruments so stark ein, daß mögliche technisch-institutionelle Einschränkungen zu vernachlässigen sind. Hier ist in allen Fällen die höchste Abhängigkeitsstufe erreicht. Die Zentralbank hat keinerlei Einfluß auf die Gestaltung der Geldpolitik. 


\subsubsection{Auswertung des Bewertungsschemas für die funktionelle Unabhän- gigkeit}

Nach der Beurteilung der geldpolitischen Instrumente anhand des Schemas in Abb. 5 erhält man 16 Bewertungen, die auf einer Skala von A bis L liegen. Die Wahl von Buchstaben als Bewertungsstufen soll verdeutlichen, da $B$ es sich hier um eine ordinale Skala handelt, bei dem A die Stufe größtmöglicher funktioneller Unabhängigkeit und $L$ die Stufe größtmöglicher funktioneller Abhängigkeit einer Notenbank kennzeichnet. Wie oben bereits dargelegt, kann der Einfluß jedes geldpolitischen Instruments auf die Unabhängigkeit einer Notenbank als gleich hoch betrachtet werden, da nicht die Effizienz eines Instruments für die Unabhängigkeit ausschlaggebend ist, sondern die Frage, ob die Notenbank über den Einsatz eines geldpolitischen Mittels selbständig entscheiden kann. Zur vergleichenden Beurteilung der funktionellen Unabhängigkeit von Notenbanken wird der Median als Lageparameter für ordinalskalierte Merkmale herangezogen. Für die hier auftretenden 16 Merkmale ergibt sich dieser Zentralwert nach Sortierung der Einzelmerkmale in alphabetischer Reihenfolge durch das Intervall $\left[\mathrm{X}_{\mathrm{n} / 2}, \mathrm{X}_{\mathrm{n} / 2+1}\right]$, bzw. $\left[\mathrm{X}_{8}, \mathrm{X}_{9}\right]^{386}$.

Die Medianwerte zwischen A und L, die man auf diese Weise erhält, entsprechen nun nicht mehr den Buchstaben und den dazugehörigen Merkmalen hinsichtlich der Kombination aus technisch-institutionellen Einschränkungen und Einflußrechten Externer, wie sie in Abb. 5 aufgefuihrt sind. Sie werden in folgende vier Bereiche eingeteilt, die jeweils eine Unabhängigkeitsstufe kennzeichnen.

\begin{tabular}{|c|c|}
\hline Bewertungsstufe & $\begin{array}{c}\text { Grad an funktioneller } \\
\text { Unabhängigkeit }\end{array}$ \\
\hline A bis C & unabhängig \\
D bis F & eher unabhängig \\
G bis I & eher abhängig \\
J bis L & abhängig \\
\hline
\end{tabular}

Abb. 6: Abstufungen funktioneller Unabhängigkeit

386 Vgl. Bamberg, Günter: Statistik, 2. Aufl., München, Wien, Oldenbourg 1982, S. 17. 


\subsection{Zusammenfassende Bewertung der Unabhängigkeit von No- tenbanken}

Die Unabhängigkeit von Notenbanken hat einen institutionellen, vermögensrechtlichen, personellen und funktionellen Aspekt. Wie oben dargelegt haben institutionelle und vermögensrechtliche Regelungen per se keinen Einfluß auf die Unabhängigkeit einer Notenbank. Thre Auswirkungen lassen sich letztlich auf die personelle bzw. funktionelle Unabhängigkeit zurückführen, so daß die Betrachtung dieser beiden Bereiche die gesamte Unabhängigkeitsproblematik abdeckt. Personelle und funktionelle Unabhängigkeit lassen sich jedoch nicht ohne weiteres zu einer einzigen Bewertung zusammenfassen. Während die funktionelle Unabhängigkeit die geldpolitischen Entscheidungen direkt betrifft und damit als Kernstück der Unabhängigkeit einer Notenbank betrachtet werden kann, läßt sich der Einfluß der personellen Unabhängigkeit auf die gesamte Unabhängigkeit einer Notenbank nicht eindeutig feststellen. Eine Einflußnahme notenbankfremder Instanzen auf die personelle Besetzung der Leitungsgremien einer Notenbank behindert die Bank zwar in ihrer die Personalpolitik betreffenden Entscheidungsfreiheit. Ein Eingriff in die geldpolitischen Entscheidungen des Währungsinstituts, der nach der hier verwendeten Definition die Unabhängigkeit mindert, ist damit aber nur indirekt möglich. Die personelle Besetzung der Gremien durch externe Ernennungsinstanzen muß nicht zwangsläufig bedeuten, daß die Notenbankmitglieder ihre geldpolitischen Entscheidungen den Wünschen dieser Instanzen anpassen werden ${ }^{387}$. Die ernennende Instanz kann das Verhalten einer zu ernennenden Person nicht voraussehen ${ }^{388}$. Wie schon zu Beginn der Arbeit dargelegt, spielt hier u. a. die Persönlichkeit der Notenbankmitglieder eine große Rolle. Es ist dennoch anzunehmen, daß die Ernennungsinstanzen ihre Wahl so treffen, daß eine größtmögliche Beeinflussung der geldpolitischen Entscheidungen in ihrem Sinne gewährleistet ist. Daher ist eine gänzliche Nichtbeachtung des personellen Aspekts bei der Beurteilung der Unabhängigkeit einer Notenbank nicht gerechtfertigt. Die funktionelle Unabhängigkeit stellt jedoch den Kern der Bewertung dar. Die personelle Unabhängigkeit kann allenfalls als Ergänzung dienen. Dabei ist davon auszugegehen, daß der Einfluß der Notenbankfunktionäre auf die Geldpolitik und damit auch tendenziell der Einfluß der Ernennungsinstanzen um so größer ist, je weniger Beeinträchtigungen der funktionellen Autonomie eines Noteninstituts vorliegen. Dagegen spielt es für eine völlig weisungsabhängige Notenbank nur eine äußerst untergeordnete Rolle, wer die Mitglieder der Notenbankleitung ernennt.

387 Vgl. Brüggemann, Gerd: Präsidentenwahl und Fed., in: Bankinformation 4/88, S. 2.

388 Vgl. Hahn, Oswald (1968) Bd. II: a.a.O., S. 40. 
Da die entwickelten Beurteilungsschemen für die funktionelle und personelle Unabhängigkeit keine absoluten Bewertungen, sondern nur die Bildung von Rangfolgen von Notenbanken anhand ihrer Unabhängigkeit zulassen, kann eine zusammenfassende Wertung der Unabhängigkeit ebenfalls nur in Form einer Rangordnung erfolgen. Diese wird grundlegend anhand der Wertungen der funktionellen Unabhängigkeit ermittelt. Die personelle Unabhängigkeit wird nur dann herangezogen, wenn die funktionelle Unabhängigkeit zweier Länder den gleichen Wert aufweist. In diesem Fall wird das Land mit der größeren personellen Unabhängigkeit als unabhängiger gewertet.

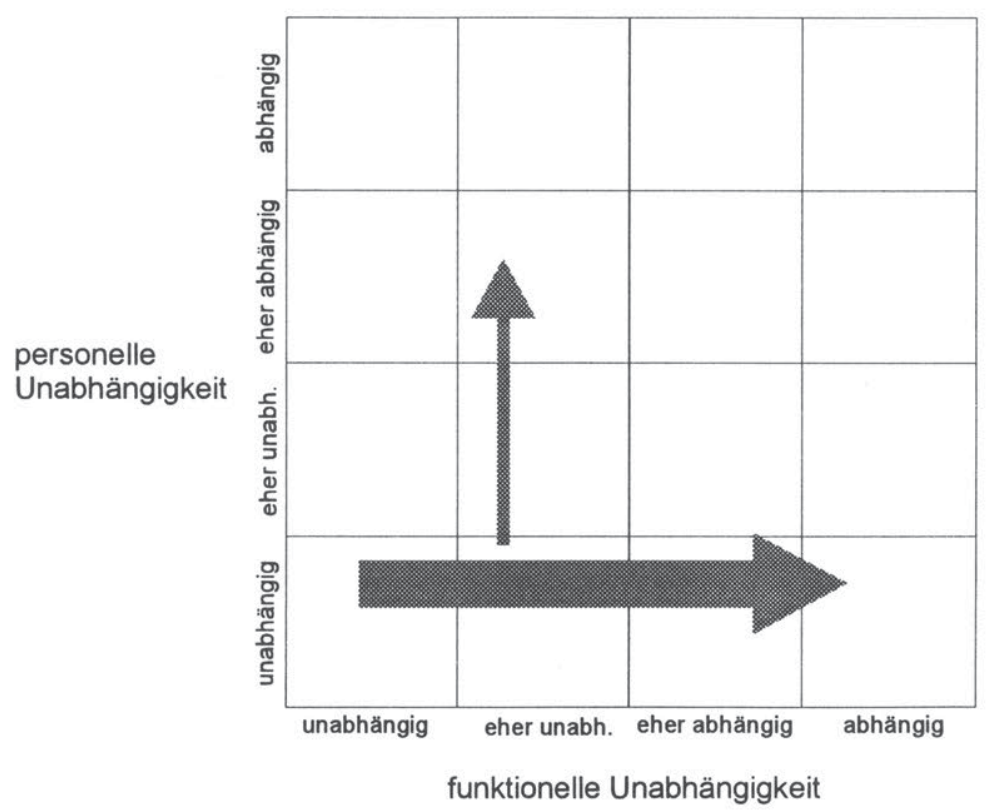

Abb. 7: Portfolio der funktionellen und personellen Unabhängigkeit

Die Wertungen für die personelle und funktionelle Unabhängigkeit können in einem Portfolio (Abb. 7) abgetragen werden. Links unten liegt der Bereich mit der größten Unabhängigkeit einer Notenbank, rechts oben mit der geringsten. Die Pfeile verdeutlichen, wie sich aus dem Portfolio die Rangfolgen der Unabhängigkeit verschiedener Notenbanken herauslesen lassen. Der dicke Pfeil gibt die Richtung sinkender Unabhängigkeit im funktionellen Sinn und damit die Richtung der gesamten Unabhängigkeit an. Der dünne Pfeil weist die Richtung sinkender 
Unabhängigkeit bei gleichwertiger funktioneller Unabhängigkeit mehrer Notenbanken.

\subsection{Ermittlung des Zusammenhangs zwischen dem Unabhängig- keitsgrad von Notenbanken und der Inflationsentwicklung}

Ein probates Mittel zur Ermittlung des Zusammenhanges zwischen zwei Merkmalen ist die Korrelationsanalyse. Wie oben gezeigt, wurde die Unabhängigkeit von Notenbanken anhand nicht metrisch skalierter Ausprägungen beurteilt. Da es sich bei den Unabhängigkeitsgraden um ordinalskalierte Merkmale im Sinne der deskriptiven Statistik handelt, muß die Korrelationsanalyse aufgrund von Ranginformationen erfolgen. Zur Ermittlung des Zusammenhangs zwischen den Unabhängigkeitsgraden von Notenbanken und den Inflationsraten bietet sich der Rangkorrelationskoeffizient von Spearman an, der zur Überprüfung der Korrelation ordinalskalierter Merkmale dient. Dieser ergibt sich aus folgender Formel:

$$
r_{s}=1-\frac{6 \sum d_{i}^{2}}{n\left(n^{2}-1\right)} \quad \text { mit } \quad d_{i}=R\left(x_{i}\right)-R\left(y_{i}\right)^{389}
$$

$\mathrm{R}\left(\mathrm{x}_{\mathrm{i}}\right)$ kennzeichnet die Rangwerte der Unabhängigkeitgrade der betrachteten Notenbanken und $\mathrm{R}\left(\mathrm{y}_{\mathrm{i}}\right)$ die Rangwerte der kumulierten Inflationsraten der zu betrachtenden Länder für den Untersuchungszeitraum. Dabei erhält das Land mit der abhängigsten Notenbank den Rang 1, das mit der unabhängigsten den Rang $\mathbf{n}$. Dabei ist $\mathrm{n}$ die Anzahl der zu untersuchenden Notenbanken. Ebenso wird dem Land mit der höchsten kumulierten Inflationsrate der Rang 1 zugewiesen, dem Land mit der niedrigsten Inflation der Rang $\mathrm{n}$. Bei Banken mit gleichbewerteten Unabhängigkeitsgraden bzw. Ländern, die gleiche kumulierte Inflationsraten aufweisen, verwendet man das arithmetische Mittel der entsprechenden Rangwerte.

Anhand dieses Spearmanschen Rangkorrelationskoeffizienten kann nun auch überprüft werden, ob die zu Beginn der Arbeit aufgestellte Hypothese, die Unabhängigkeit einer Notenbank hat keinen signifikanten Einfluß auf die Geldwertstabilität, zutrifft. Dazu wird die sog. Hotelling-Pabst-Statistik als Prüfgröße verwendet. Diese lautet:

$D=\sum_{i=1}^{n} d_{i}^{2}$ mit $\quad d_{i}=R\left(x_{i}\right)-R\left(y_{i}\right)^{390}$.

389 Vgl. Hauser, Siegfried: Statistische Verfahren zur Datenbeschaffung und Datenanalyse, Freiburg im Breisgau 1981, S. 195.

390 Vgl. Hartung, Joachim: Statistik: Lehr- und Handbuch der angewandten Statistik, 6. Aufl., München, Wien 1987, S. 556f. 
In diesem Test wird die Hypothese dann zum Niveau $\alpha$ verworfen, wenn $D<h_{n ; \alpha / 2} \operatorname{oder} D>h_{n ; 1-\alpha / 2}$.

Die kritischen Werte $h_{n ; \alpha}$ liegen für Grundgesamtheiten $\mathbf{n} \leq 30$ in tabellarischer Form ${ }^{391}$ vor, wobei weiterhin gilt:

$h_{n, 1-\alpha}=\frac{1}{3} n\left(n^{2}-1\right)-h_{n ; \alpha}$.

Mit der hier aufgezeigten Testmethode ist es nun möglich, den Zusammenhang zwischen der Inflationsentwicklung und dem Unabhängigkeitsgrad von Notenbanken für mehrere Länder zu quantifizieren, was im folgenden anhand ausgewählter Länder empirisch untersucht werden soll.

391 Vgl. Hartung, Joachim: a.a.O., S. 557. 
Sylvia Liebler - 978-3-631-75025-4

Downloaded from PubFactory at 01/11/2019 09:08:34AM

via free access 


\section{Ermittlung des Unabhängigkeitsgrads der Notenbanken aus- gewählter Länder}

Im folgenden soll die personelle und funktionelle Unabhängigkeit ausgewählter Notenbanken anhand der beiden entwickelten Bewertungsschemen ermittelt werden.

Als Grundgesamtheit der für diese Untersuchung in Frage kommenden Notenbanken wurden wirtschaftlich dominierende Länder mit im Untersuchungszeitraum (1975 bis 1990) demokratischen Strukturen ausgewählt. Diesen Anforderungen entsprechen etwa 25 Länder. Viele Länder v.a. in Lateinamerika entfallen etwa, weil sie in dieser Periode durch starke politische Umbrüche und zeitweise Militärdiktaturen geprägt waren. Kleine Volkswirtschaften wurden ebenfalls nicht berücksichtigt, weil sie häufig an starke Währungen gekoppelt sind oder zumindest in ihrer Geldpolitik stark von diesen beeinflußt werden.

Die Wahl fiel auf acht Industrieländer mit vergleichbaren politischen und marktwirtschaftlichen Strukturen, nämlich Deutschland, Schweiz, USA, Italien, Großbritannien, Frankreich, Japan und die Niederlande.

Bei der Untersuchung werden nur die im Zeitraum von 1975 bis 1990 gültigen Regelungen berücksichtigt.

\subsection{Deutschland}

Die Deutsche Bundesbank wurde 1957 mit dem Gesetz über die Deutsche Bundesbank vom 26. Juli 1957 errichtet ${ }^{392}$. Sie entstand aus der zweistufig aufgebauten Bank Deutscher Länder, deren bis dahin selbständige Landeszentralbanken durch Umwandlung zu Hauptverwaltungen Teil der Bundesbank wurden 393 . Die Bundesbank ist eine bundesunmittelbare juristische Person öffentlichen Rechts mit derzeitigem Sitz in Frankfurt am Main ${ }^{394}$. Ihre Organe sind der Zentralbankrat, das Direktorium sowie die Vorstände der Landeszentralbanken, wobei sich der Zentralbankrat aus den Direktoriumsmitgliedern und den Vorständen der Landeszentralbanken zusammensetzt ${ }^{395}$.

392 Vgl. Deutsche Bundesbank: a.a.O., S. 5.

393 Vgl. Deutsche Bundesbank: a.a.O., S. 5.

394 Vgl. Deutsche Bundesbank: a.a.O., S. 5.

395 Vgl. Deutsche Bundesbank: a.a.O., S. 6. 


\subsubsection{Personelle Unabhăngigkeit}

\subsubsection{Ernennungsinstanzen (Ebene 1)}

Die Mitglieder des Direktoriums, bestehend aus dem Präsidenten, dem Vizepräsidenten sowie bis $\mathrm{zu}$ acht weiteren Mitgliedern, werden von der Bundesregierung vorgeschlagen und nach Anhörung des Zentralbankrats vom Bundespräsidenten bestellt ${ }^{396}$. Die Landeszentralbankpräsidenten werden vom Bundesrat vorgeschlagen und nach Anhörung des Zentralbankrats ebenfalls vom Bundespräsidenten ernannt. Der Bundespräsident hat hierbei das Recht, ihm unterbreitete Vorschläge abzulehnen ${ }^{397}$. Die Anhörung des Zentralbankrats beinhaltet dagegen keine durchsetzbaren Rechte zur Verhinderung eines Vorschlages des Bundesrats oder der Bundesregierung398. Die Bundesbank hat daher keine Entscheidungsbefugnis bei der Besetzung ihrer Leitungsorgane.

Fazit:

Die Notenbank kann die Entscheidungsmehrheit nicht ernennen.

\subsubsection{Abberufungsinstanzen (Ebene 2)}

Über die Abberufung von Mitgliedern der Notenbankleitung enthält das BBankG keine ausdrücklichen Vorschriften. In der Literatur besteht jedoch weitgehend Einigkeit darüber, daß für mögliche Abberufungen jene Stellen zuständig wären, denen Vorschlags- bzw. Bestellungsrechte der betreffenden Notenbankmitglieder zustehen ${ }^{399}$. Damit verfügt die Bundesbank nicht über den entscheidenden Einfluß über etwaige Amtsenthebungen der Mitglieder ihrer Entscheidungsgremien.

Fazit:

Die Bundesbank ist weder die entscheidende Abberufungsinstanz noch kann sie Abberufungen durch ein Vetorecht verhindern. Da sie auch gegen Ernennungen kein Veto einlegen kann, sind nähere Abberufungsmodalitäten sowie Wiederernennungsvorschriften für die Bewertung der personellen Unabhängigkeit der Deutschen Bundesbank nicht von Bedeutung.

396 Vgl. § 7 Abs. 3 BBankG.

397 Vgl. Braun, Karlpeter: a.a.O., S. 109.

398 Vgl. Kaiser, Rolf H.: a.a.O., S. 30.

399 Vgl. Starke, Otto-Ernst (1957 a): a.a.O., S. 612; Kaiser, Rolf H.: a.a.O., S. 38; Siebelt, Johannes: a.a.O., S. 175; Bernauer, Engelbert: a.a.O., S. 114. 


\subsubsection{Kreis der Ernennungsfahigen (Ebene 6)}

Das BBankG schreibt in $\S 7$ Abs. 2 und $\S 8$ Abs. 3 eine besondere fachliche Eignung der Zentralbankratsmitglieder vor. Der in Frage kommende Personenkreis für die Besetzung der Bankorgane ist dadurch stark eingeschränkt ${ }^{400}$. Es ist aber an keiner Stelle näher ausgeführt, welche Kenntnisse im einzelnen gefordert werden, wodurch die Vorschlagsinstanz ein weitgehendes Interpretationsrecht erhält ${ }^{401}$. Unterschiedliche Auffassungen über die fachliche Eignung führten daher schon desöfteren zu Kritik an der Auswahl der Kandidaten 402.

Die Gehälter und Ruhegehälter der leitenden Bundesbankangestellten sind nicht an beamtenrechtliche Maßstäbe gebunden ${ }^{403}$. Sie werden durch Verträge mit dem Zentralbankrat geregelt, die jedoch der Zustimmung der Bundesregierung bedürfen 404 . Das BBankG läßt damit der Bundesbank bewußt freie Hand bei der Frage der Gehälter der Zentralbankratsmitglieder, damit hervorragende Persönlichkeiten für die Ämter gewonnen werden können, ohne daß die Gefahr besteht, $\mathrm{da} ß$ diese zu den Geschäftsbanken abwandern ${ }^{405}$. Das Zustimmungsrecht der Bundesregierung zu den Verträgen ( $\S 7$ Abs. 4 und $\S 8$ Abs. 5) kann in diesem Zusammenhang nicht zur Ablehnung unliebsamer ZBR-Mitglieder führen 406 .

\section{Fazit:}

Die Bundesbank kann durch ihren Einfluß auf die Besoldung der Notenbankmitglieder auf den Kreis der Ernennungsfähigen Einfluß nehmen.

\subsubsection{Beurteilung der personellen Unabhängigkeit}

Die personelle Unabhängigkeit der Deutschen Bundesbank ist stark eingeschränkt. Sie erreicht mit Ziffer 25 die vorletzte Bewertungsstufe des Entscheidungsbaums in Abb. 1 und damit den Bewertungsgrad abhängig.

\footnotetext{
400 Vgl. Kloten, Norbert: a.a.O., S. 8.

401 Vgl. Kaiser, Rolf H.: a.a.O., S. 31 f.

402 Beispiele bei: Caesar, Rolf (1982): a.a.O., S. 572; Kaiser, Rolf H.: a.a.O., S. $31 \mathrm{ff}$; Muthesius, Volkmar (1976): a.a.O., S. 756; o. V.: Karriere-Knick, in: Der Spiegel vom 21.6.1976, S. 78; o. V.: Warum ausgerechnet die?, in: Der Spiegel vom 19.7.1976, S. 23; o. V.: Nicht zu viele Verwaltungsfachleute, in: Zeitschrift für das gesamte Kreditwesen 1976, S. 461; Hahn, Oswald: Zentralbankrat. Praktiker.../...oder Politiker, in: Zeitschrift für das gesamte Kreditwesen 1976, S. 525f.

403 Vgl. Uhlenbruck, Dirk (1967 a): a.a.O., S. 87.

404 Vgl. Woll, Artur: a.a.O. S. 193.

405 Vgl. Beck, Heinz: a.a.O, S. 120.

406 Vgl. Kaiser, Rolf H.: a.a.O., S. 37.
} 


\subsubsection{Funktionelle Unabhängigkeit}

\subsubsection{Instrumentenübergreifende Regelungen}

$\S 12$ Satz 2 BBankG bildet die Grundlage der Entscheidungsfreiheit der Deutschen Bundesbank ${ }^{407}$. Er bescheinigt der Bundesbank Weisungsfreiheit von der Bundesregierung bei der Ausübung der Befugnisse, die ihr nach dem Gesetz zustehen. Das bedeutet, da $B$ die Bundesbank nur in Auftragsangelegenheiten an Weisungen gebunden werden kann ${ }^{408}$. Aufgrund ihrer Rechtsform als bundesunmittelbare juristische Person öffentlichen Rechts ist die Bundesbank von jeglicher Fach- bzw. Dienstaufsicht durch die Regierung oder einzelne Ressorts verschont ${ }^{409}$. Es gibt lediglich Aufsichtsrudimente, wie beispielsweise die $\mathrm{Zu}$ stimmung der Bundesregierung zur Veröffentlichung der Bundesbanksatzung 410 und die Prüfung des Jahresabschlusses durch den Bundesrechnungshof ${ }^{411}$. Die Möglichkeit der Rechtsaufsicht der Bundesregierung über die Bundesbank tangiert die geldpolitischen Entscheidungen der Bank nicht ${ }^{412}$. Auch vor dem Parlament muß die Bundesbank ihre Politik nicht verantworten413. Die geldpolitischen Maßnahmen der Bundesbank sind ferner nicht gerichtlich anfechtbar, solange die Bank den Rahmen ihrer gesetzlichen Ermächtigung nicht überschreitet 414 .

Die Eigentumsrechte des Bundes als Eigner des Grundkapitals der Deutschen Bundesbank sind auf Vorschriften über die Gewinnverteilung beschränkt ${ }^{415}$. Das Eigentum berechtigt die Bundesregierung nicht zur Einflußnahme auf die $\mathrm{Ge}-$ schäftsführung der Bank ${ }^{416}$.

$\S 12$ BBankG verpflichtet die Notenbank zur Unterstützung der allgemeinen Wirtschaftspolitik der Bundesregierung, soweit ihre Aufgabe gewahrt bleibt. Laut Gesetz ist die Hauptfunktion der Bundesbank, die Stabilität der Währung zu si-

\footnotetext{
407 Vgl. Grimberg, Rainer: Rechtsprobleme der Swapsatzpolitik der Bundesbank. Legitimation und Rechtsnatur, Schriften des Instituts für internationales Recht des Spar-, Giround Kreditwesens an der Universität Mainz, Bd. 7, Berlin 1974, S. 67.

408 Vgl. Spindler, Joachim v.; Becker, Willy; Starke, O.-Ernst (1973): a.a.O., S. 266.

409 Vgl. Kaiser, Rolf H.: a.a.O., S. $22 f$.

410 Vgl. § 34 BBankG.

411 Vgl. § 26 BBankG.

412 Vgl. Kaiser, Rolf H.: a.a.O., S. 25.

413 Vgl. Bachmann, Gerhard: Die geldpolitische Rolle der Bundesbank, Bad Honnef 1981, S,. 6.

414 Vgl. Knieper, Rolf: Korrekturen an der Autonomie der Deutschen Bundesbank, in: Gewerkschaftliche Monatshefte 1975, S. 792.

415 Vgl. Kloten, Norbert: a.a.O., S. 8.

416 Vgl. Könneker, Wilhelm: Die Deutsche Bundesbank, Frankfurt/Main 1973, S. 22.
} 
chern. Das bedeutet, daß die Gefolgschaftspflicht der Bundesbank gegenüber der Bundesregierung dann endet, wenn die allgemeine Wirtschaftspolitik ,geeignet ist, eine Zerrüttung des Geldwertes herbeizuführen"417. Die Bank ist nicht verpflichtet, auf Geheiß der Regierung die Währung zu benachteiligen 418 . Zudem erhält sie dadurch einen weitgehenden Ermessensspielraum, daß der Begriff allgemeine Wirtschaftspolitik nicht näher bestimmt ist ${ }^{419}$ Überdies entscheidet die Bundesbank, wann die Unterstützung der Wirtschaftspolitik der Regierung ihre Aufgabe der Währungssicherung beeinträchtigt ${ }^{420}$. Theoretisch kann die Bank in ihrem Aufgabenbereich jede Politik betreiben, die nach ihrer Einschätzung angemessen ist ${ }^{421}$. Eine Einschränkung ihrer Unabhängigkeit liegt hier nicht vor.

Mitglieder der Bundesregierung sind zur Teilnahme an den Sitzungen des Zentralbankrats berechtigt. Sie haben kein Stimmrecht, können aber Anträge stellen. Desweiteren können sie die Beschlußfassung - nicht jedoch einen einmal gefaßten Beschluß - der Bank bis zu zwei Wochen aussetzen 422 . Dieses suspensive Vetorecht kann für einen bestimmten Antrag nur einmal ausgeübt werden ${ }^{423}$. Es soll bewirken, daß Meinungsverschiedenheiten zwischen Bundesregierung und Bundesbank im Wege der Übereinkunft geschlichtet werden ${ }^{424}$. Auch, wenn dieses Recht offiziell bisher nie angewendet wurde 425 , bedeutet dies eine Einschränkung der funktionellen Unabhängigkeit der Deutschen Bundesbank. Es bewirkt, daß keines der im folgenden zu bewertenden geldpolitischen Instrumente eine höhere Unabhängigkeitskategorie als E erreichen kann.

417 Uhlenbruck, Dirk: Die Grenzen der währungspolitischen Gefolgschaftstreue der Deutschen Bundesbank gegenüber der Regierung, in: Der Betrieb 1/1967 b, S. 2.

418 Vgl. Schacht, Hjalmar: Die Politik der Deutschen Bundesbank, München 1970, S. 18.

419 Vgl. o. V.: Wir heißen Euch hoffen, a.a.O., S. 1056.

420 o. V.: Bundesregierung und Bundesbank, in: Monatsberichte der Deutschen Bundesbank 24. Jg. Nr. 8/1972, S. 16.

421 Vgl. Schmidt, Reiner: Die Zentralbank im Verfassungsgefüge der Bundesrepublik Deutschland, in: Instrumente der sozialen Sicherung und der Währungssicherung in der Bundesrepublik Deutschland und in Italien, Beiheft 5 zu "Der Staat", Berlin 1981, S.66. Vgl. Hahn, Oswald (1968) Bd. II: a.a.O., S. 221 f. Vgl. Prost, Gerhard: Wandlungen im deutschen Notenbankwesen, München 1972, S. 69.

Vgl. Spindler, Joachim v.; Becker, Willy; Starke, O.-Ernst (1973): a.a.O., S. 272.

Es ist allerdings anzunehmen, daß einer Anwendung des Vetorechts möglicherweise dadurch vorgebeugt wurde, daß der Zentralbankrat Beschlußfassung bereits mehrfach auf Bitten der Regierung verschoben hat, Vgl. Caesar, Rolf(1981): a.a.O., S. 185 F.98. 


\subsubsection{Ausgabe von Zentralbankgeld durch die Notenbank}

\subsection{Art der Kreditnehmer}

Die Bundesbank darf Kredite nur an Kreditinstitute und öffentliche Verwaltungen gewähren ${ }^{426}$. Im Gegensatz dazu durfte die Reichsbank auch Handelswechsel von Unternehmen annehmen ${ }^{427}$. Externe Instanzen haben keinen Einfluß auf die Auswahl der Kreditnehmer bei der Bundesbank.

\section{Bewertung: $F$}

Es liegt eine technische Einschränkung vor aufgrund der Begrenzung der möglichen Kreditnehmer der Notenbank auf Banken und staatliche Stellen. Einschränkungen durch Externe gibt es neben dem allgemeinen aufschiebenden Vetorecht der Regierung nicht.

\subsection{Umfang}

Die Deutsche Bundesbank hat keine Deckungsvorschriften für die D-Mark einzuhalten. Sie unterliegt keinen Emissionsgrenzen bei der Ausgabe von Zentralbankgeld 428. Dagegen ist die direkte Kreditvergabe der Bundesbank an die öffentliche Hand an strenge Vorschriften gebunden. Ein Erstankauf von Staatspapieren durch die Notenbank ist verboten. Das Gesetz schreibt desweiteren Kreditplafonds in Form von absoluten DM-Beträgen fest (wobei von der Bundesbank angekaufte oder zum Kauf zugesagte Schatzwechsel angerechnet werden), bis zu denen die Bundesbank besonders privilegierten öffentlichen Verwaltungen (Bund, Länder, Bundesbahn Bundespost, ERP-Sondervermögen, Lastenausgleichsfonds) kurzfristige Kredite gewähren darf ${ }^{429}$. Die Höchstgrenzen für die Vergabe von Kassenkrediten an die öffentliche Hand verbriefen aber keinen Anspruch auf Kredit ${ }^{430}$. Die Bundesbank kann den öffentlichen Stellen die Ausnutzung des Kassenverstärkungskredits nach eigenem Ermessen verweigern oder an Bedingungen knüpfen 431 .

426 Vgl. Obst, Georg; Hintner, Otto: a.a.O., S. 125.

427 Vgl. Fögen, Hermann (1969): a.a.O., S. 109.

428 Im Gegensatz dazu war die BDL bei der Notenemission an ein Kontingent gebunden, das sie allerdings in Grenzen selber beeinflussen konnte, Vgl. Siebelt, Johannes: a.a.O., S. 197.

429 Vgl. § 20 BBankG (Seit dem 1.1.1994 sind auch keine Kassenkredite der Notenbank an den Staat möglich).

430 Vgl. Bank für Internationalen Zahlungsausgleich Basel (Hrsg.): Acht europäische Zentralbanken, Frankfurt am Main 1963, S. 103; Spindler, Joachim v.; Becker, Willy; Starke, O.-Ernst (1973): a.a.O., S. 427.

431 Vgl. Spindler, Joachim v.; Becker, Willy; Starke, O.-Ernst (1973): a.a.O., S. 428. 
Für die Höhe der Kreditgewährung der Bundesbank in Form von Diskont- und Lombardkrediten gibt es keine gesetzlichen Beschränkungen ${ }^{432}$. Die Bundesbank setzt den Gesamtrahmen der Rediskontkontingente fest, die sie auf die Kreditinstitute aufteilt ${ }^{433}$. Dabei berücksichtigt sie die individuellen Verhältnisse der kreditsuchenden Banken, indem sie die Rediskontkontingente für jedes Kreditinstitut getrennt festsetzt. Dazu dient ein 1974 von ihr entwickeltes Bemessungsverfahren, das die haftenden Mittel, die individuelle Geschäftsstruktur und den Umfang des vorhandenen Wechselmaterials der betreffenden Banken miteinbezieht ${ }^{434}$. Ferner berücksichtigt sie, ob die jeweilige Bank die Grundsätze des Bundesaufsichtsamts für das Kreditwesen über das Eigenkapital und die Liquidität beachtet sowie ihr sonstiges Geschäftsgebaren 435 . Die Bundesbank hat ferner die Befugnis, die Inanspruchnahme der Plafonds aus währungspolitischen Gründen zu verweigern oder an Bedingungen zu knüpfen ${ }^{436}$. Desweiteren kann sie durch Gewährung von Sonder-Rediskontlinien bestimmte Wirtschaftsbereiche fördern, wie z. B. zum Zwecke der Mittelstands- und Exportfinanzierung437. Kreditinstitute haben keinen Anspruch auf Refinanzierung bei der Bundesbank.

Die Art der Gewinnverwendung ist der Bundesbank genau vorgeschrieben. Der Restgewinn nach Abzug bestimmter Rücklagen muß an den Bund abgeführt werden ${ }^{438}$. Dadurch ist die Bank zu einer Ausgabe von Zentralbankgeld verpflichtet, ohne daß sie oder bankfremde Instanzen darauf Einfluß nehmen können.

\section{Bewertung: $F$}

Die Bundesbank unterliegt technisch-institutionellen Einschränkungen aufgrund der Begrenzungen ihrer Möglichkeiten zur Kreditvergabe an den Staat sowie die Vorschriften zur Gewinnverwendung. Neben dem allgemeinen aufschiebenden Vetorecht der Regierung existieren keine weiteren Einschränkungen durch Externe.

432 Vgl. Gaddum, Johann Wilhelm: Die Geldverfassung in der Bundesrepublik Deutschland, in: Die Bank 7/86, S. 339.

433 Vgl. Deutsche Bundesbank: a.a.O., S. 47.

434 Vgl. Deutsche Bundesbank: a.a.O., S. 47; näheres zum Berechnungsverfahren der Rediskontkontingente bei Waschmann, Wolf-Peter: Die Rechtsnatur der quantitativen und qualitativen Beschränkungen im Diskontgeschäft der Deutschen Bundesbank, Diss. Hamburg 1977, S. 12ff.

435 Vgl. Deutsche Bundesbank: a.a.O., S. 47.

436 Vgl. Könneker, Wilhelm (1973): a.a.O., S. 64.

437 Dazu Dickertmann, Dietrich: a.a.O., S. 138ff.

438 Vgl. §27 BBankG. 


\subsection{Zinssatz}

Bei der Festsetzung der Zinssätze für ihre Kredite ist die Bundesbank völlig autonom. Das Gesetz schreibt weder für die Höhe des Diskont- und Lombardsatzes eine Ober- oder Untergrenze fest ${ }^{439}$ noch gibt es gesetzlichen Regelungen zu den Zinssätzen von Kassenkrediten an den Staat. Üblicherweise verwendet die Bank den Diskontsatz auch für die im Rahmen der gesetzlichen Plafonds an die öffentlichen Hand gegebenen Kassenkredite ${ }^{440}$.

\section{Bewertung: $\mathrm{E}$}

Neben dem allgemeinen aufschiebenden Vetorecht der Regierung gibt es weder technisch-institutionelle Einschränkungen noch andere Einschränkungen durch Externe.

\subsection{Bedingungen}

Das BBankG legt Mindestanforderungen für diskontfähige Wechsel und lombardfähige Wertpapiere fest. Eine Kreditgewährung an Banken zu anderen als in $\S 19$ BBankG angegebenen Sicherheiten sieht das Gesetz nicht vor. Bei diesen Regelungen liegt weniger eine währungspolitische Zielsetzung als die Sicherheit der von der Notenbank gewährten Kredite zugrunde441. Die Bundesbank kauft grundsätzlich nur gute Handelswechsel, wobei die Entscheidung über die Bonität in ihrem Ermessen liegt ${ }^{442}$. Sie kann innerhalb des gesetzlichen Rahmens bestimmte Wechselgattungen von der Diskontierung ausschließen oder sie explizit zulassen 443 . Dies ermöglicht ihr eine differenzierte Bekämpfung kreditpolitisch und volkswirtschaftlich unerwünschter Tendenzen. Es gibt ferner gesetzlich festgelegte Beleihungsgrenzen für lombardfähige Wertpapiere ${ }^{444}$. Lombard- und Diskontkredite sind längstens auf 3 Monate befristet. Kredite an den Staat sind auf kurzfristige Überbrückungskredite beschränkt, wobei die Bundesbank innerhalb dieser gesetzlichen Grenzen die Laufzeit bestimmt ${ }^{445}$. Einflußrechte notenbankfremder Instanzen auf die Regelung von Laufzeit und Sicherheiten von Notenbankkrediten gibt es nicht.

439 Vgl. Deutsche Bundesbank: a.a.O., S. 48f.

440 Vgl. Deutsche Bundesbank: a.a.O., S. 49.

441 Vgl. Waschmann, Wolf-Peter: a.a.O., S. 20.

442 Vgl. Spindler, Joachim v.; Becker, Willy; Starke, O.-Ernst (1973): a.a.O., S. 50.

443 Vgl. Spindler, Joachim v.; Becker, Willy; Starke, O.-Ernst (1973): a.a.O., S. 50, Waschmann, Wolf-Peter: a.a.O., S. 21.

444 Vgl. § 19 BBankG.

445 Vgl. Könneker, Wilhelm (1973): a.a.O., S. 64f. 


\section{Bewertung: $F$}

Die gesetzlichen Regelungen bzgl. den diskont- und lombardfähigen Wertpapieren, die Beleihungsgrenzen sowie die begrenzten Laufzeiten der Kredite bedeuten eine technisch-institutionelle Einschränkung in diesem Bereich. Einschränkungen durch Externe neben dem allgemeinen aufschiebenden Vetorecht gibt es nicht.

\subsubsection{Direkte Einflußnahme auf die Kreditvergabe der Banken}

\subsection{Art der Kreditnehmer}

Es gibt keine gesetzlichen Richtlinien, die die Art der Kreditnehmer der Geschäftsbanken beschränkt. Die Bundesbank darf auf administrativem Wege keinen Einfluß auf die Kreditnehmerstruktur nehmen. Freiwillige Vereinbarungen diesbezüglich bedürfen der Zustimmung der Betroffenen.

\section{Bewertung: G}

Es gibt keine technisch-institutionellen Grenzen. Einschränkungen durch Externe gibt es wiederum in Form von Genehmigungsrechten derjenigen, mit denen die Notenbank freiwillige Vereinbarungen trifft.

\subsection{Umfang}

Die Deutsche Bundesbank hat keine Möglichkeit, die Kreditaufnahme von Nichtbanken auf administrativem Wege direkt zu beschränken ${ }^{446}$. Bestrebungen der Bundesbank im Jahre 1972, durch eine Novelle zum BBankG die Möglichkeit einer Kreditplafondierung zu schaffen, sind u. a. wegen der umstrittenen Kompetenzaufteilung zwischen Bundesbank und Bundesregierung im Sande verlaufen ${ }^{447}$. Da das BBankG eine administrative Anwendung von Kreditplafondierungen nicht gestattet, kann die Zentralbank eine solche Kreditbegrenzung nur im Rahmen freiwilliger Vereinbarungen mit den Banken, sei es durch Gentlemen's Agreements, Verträge, Empfehlungen oder ähnliches, herbeiführen. Dazu bedarf es der Zustimmung der betroffenen Banken, die somit quasi über ein Genehmigungsrecht verfügen.

446 Vgl. Deutsche Bundesbank: a.a.O., S. 44.

447 Vgl. Christians, F. W.: a.a.O., S. 4, näheres zu der Diskussion bei: Issing, Otmar (1975): a.a.O., S. 367f; Duwendag, Dieter: Einführung: Macht und Ohnmacht der Bundesbank?, in: Duwendag, Dieter (Hrsg.): Macht und Ohnmacht der Bundesbank, Frankfurt/M 1973, S. 7f; o. V.: Zuviel Macht für die Bundesbank, in: Wirtschaftswoche Nr.8/1973, S. 54. 
In Deutschland gibt es verschiedene Regelungen im Rahmen der Bankenaufsicht, die die Kreditvergabe der Banken direkt begrenzen. Diese Normen stellen langfristige und starre Regelungen dar, die nicht wie kreditpolitische Maßnahmen flexibel den jeweiligen währungspolitischen Forderungen angepaßt werden 448 . Insofern können sie nicht als geldpolitisches Instrument betrachtet werden, sondern nur als mögliche Ursache technisch-institutioneller Einschränkung der Mittel, die der Bundesbank zur Lenkung der Kreditvergabe der Banken zur Verfügung stehen. Im Falle freiwilliger Vereinbarungen mit den Banken über eine Kreditbegrenzung müßte die Bundesbank diese Richtlinien beachten. Die kreditbegrenzenden Regelungen sind im wesentlichen die Paragraphen 10 und 11 KWG, die von den Kreditinstituten ein angemessenes haftendes Eigenkapital sowie jederzeit eine ausreichende Zahlungsbereitschaft verlangen. Die nähere Ausgestaltung dieser sehr allgemein gehaltenen Normen in Form von Grundsätzen sind in das Ermessen des Bundesaufsichtsamts für das Kreditwesen gestellt ${ }^{449}$. Grundsatz I legt beispielsweise fest, daß Kredite und Beteiligungen das 18-fache des haftenden Eigenkapitals nicht übersteigen dürfen. ${ }^{450}$. Das bedeutet eine direkte Begrenzung der Kreditvergabemöglichkeiten der Banken. Um auszuschließen, daß generelle bankaufsichtsrechtliche Maßnahmen mit der Kreditpolitik der Bundesbank in Konflikt geraten, können die Grundsätze nur im Einvernehmen mit der Bundesbank aufgestellt werden 451 . Die Bank kann diese Richtlinien dadurch maßgeblich mitgestalten ${ }^{452}$. Daher liegt in diesem Falle keine technisch-institutionelle Einschränkung vor.

\section{Bewertung: $\mathrm{H}$}

Das Verbot einer administrativen Anwendung von Kreditplafondierung bewirkt eine Einschränkung der Entscheidungsfreiheit der Notenbank durch Externe in Form von Genehmigungsrechten derjenigen Banken, die die Notenbank zu einer Begrenzung der Kreditvergabe bewegen möchte. Technisch-institutionelle Einschränkungen liegen nicht vor.

\subsection{Zinssatz}

Mit der dritten Novellienung des KWG 1984 wurde die Ermächtigung des Bundesaufsichtsamts für das Kreditwesen zum Erlaß von Rechtsverordnungen aufgehoben, mit denen Obergrenzen für Soll- und Habenzinsen festgelegt werden

\footnotetext{
448 Vgl. Humm, Hubert: a.a.O., S. 109.

449 Vgl. Obst, Georg; Hintner, Otto: a.a.O., S. 183.

450 Vgl. Obst, Georg; Hintner, Otto: a.a.O., S. 184.

451 Vgl. Humm, Hubert: a.a.O., S. 96.

452 Vgl. Siebelt, Johannes: a.a.O., S. 206.
} 
konnten 453 . Diese Konditionenregelungen konnten nur im Einvernehmen mit der Bundesbank getroffen werden 454 . Die auf dieser gesetzlichen Grundlage erlassene Zinsverordnung vom 1.3.1965 bewirkte während ihrer zweijährigen Geltungsdauer eine besonders enge Bindung der Sollzinsen an den Diskontsatz ${ }^{455}$. Die verschiedenen Höchstsätze für Kredite und Einlagen, die von den Geschäftsbanken nicht überschritten werden durften, wurden mit jeder Diskontsatzänderung neu festgelegt ${ }^{456} .1967$ wurde die Verordnung aufgehoben und keine weiteren Anordnungen über die Zinsgestaltung der Banken mehr erlassen ${ }^{457}$. Seither können sich die Zinsen frei am Markt bilden 458 . Heute können weder seitens der Bundesbank noch seitens des Bundesaufsichtsamts oder anderer Institutionen Anordnungen hinsichtlich der Zinsgestaltung der Banken getroffen werden. Freiwilligen Vereinbarungen der Notenbank mit den betroffenen Banken steht jedoch nichts im Wege. Hier ist die Notenbank wiederum auf die Zustimmung der Kreditinstitute angewiesen, die damit über ein Genehmigungsrecht verfügen.

\section{Bewertung: $G$}

Die Bundesbank konnte weder vor noch kann sie seit der KWG-Novellierung 1984 auf eigene Initiative hin administrative Regelungen hinsichtlich der Zinsgestaltung der Banken treffen. Die Zinsverordnungen nach $\S 23 \mathrm{KWG}$ vor der Novellierung konnten nur auf Initiative und Entscheidung des Bundesaufsichtsamts getroffen werden, so daß die Bundesbank gegen den Willen des Bundesaufsichtsamts keinen administrativen Einfluß auf die Bankzinsen nehmen konnte. Der Bundesbank bleibt nur die Möglichkeit der Einflußnahme auf die Kreditzinsen der Banken über entsprechẹnde freiwillige Vereinbarungen mit den Banken.

\subsection{Bedingungen}

Es gibt keine gesetzlichen Richtlinien, die Laufzeiten und Sicherheiten von Bankkrediten regulieren. Die Deutsche Bundesbank darf auf administrativem Wege keinen Einfluß auf Laufzeiten oder Sicherheiten von Bankkrediten nehmen. Freiwillige Vereinbarungen diesbezüglich bedürfen der Zustimmung der Betroffenen.

\footnotetext{
453 Vgl. Humm, Hubert: a.a.O., S. 109.

454 Vgl. Humm, Hubert: a.a.O., S. 119.

455 Vgl. Schuster, Leo (1967): a.a.O., S. $119 f$.

456 Vgl. Deutsche Bundesbank: a.a.O., S. 54.

457 Vgl. Humm, Hubert: a.a.O., S. 109.

458 Vgl. Obst, Georg; Hintner, Otto: a.a.O., S. 196
} 


\section{Bewertung: G}

Einschränkungen durch Externe gibt es in Form von Genehmigungsrechten, weil die Notenbank nur auf dem Wege freiwilliger Vereinbarungen auf die Kreditbedingungen Einfluß nehmen kann.

\subsubsection{Offenmarktpolitik}

\subsection{Art und Gegenstand des Geschäfts}

Die Deutsche Bundesbank ist befugt, Gold, Devisen und bestimmte Wertpapiere zu kaufen bzw. verkaufen. Für ihre Offenmarktoperationen mit Wertpapieren stehen ihr bundesbankfähige Wechsel, Schatzwechsel, Schatzanweisungen, Schuldverschreibungen und Schuldbuchforderungen des Bundes, seiner Sondervermögen oder der Länder sowie andere zum amtlichen Börsenhandel zugelassenen Schuldverschreibungen 459 zur Verfügung 460 . Damit erstreckt sich die Skala der Möglichkeiten auf alle Fristigkeiten, auf Geldmarktpapiere und auf Kapitalmarktpapiere 461 .

Das BBankG enthält mit $\S 15$ eine Art Generalklausel, die besagt, daß die Bundesbank die Grundsätze für ihr Offenmarktgeschäft mit Wertpapieren festlegt. Diese gewährt der Bank ausreichenden Spielraum für Variationen der Geschäftsarten im Wertpapierbereich ${ }^{462}$. Ferner ist sie befugt, alle Arten von Devisentransaktionen durchzuführen ${ }^{463}$. Zwar sind die einzelnen Geschäfte, wie z. B. Swap-Geschäfte und Outright-Operationen am Devisenterminmarkt, im BBankG nicht ausdrücklich erwähnt, aber durch die umfassende Zuständigkeit der Bundesbank im Devisengeschäft gedeckt ${ }^{464}$. Notenbankfremde Instanzen können weder auf die Art noch den Umfang von Offenmarktoperationen der Bundesbank Einfluß zu nehmen.

459 Seit der Neufassung des BBankG am 22. Oktober 1992 kann die Bundesbank auch Schuldverschreibungen für Offenmarktgeschäfte verwenden, die nicht zum amtlichen Börsenhandel zugelassenen sind.

460 Vgl. § 21 BBankG.

461 Vgl. Büschgen, H. E.: Offenmarktpolitische Interventionen der Deutschen Bundesbank am Rentenmarkt - und auch am Aktienmarkt?, in: Die Aktiengesellschaft, 17. Jg. 1972, S. 211.

462 Vgl. Schuppler, Edith: a.a.O., S. 41.

463 Vgl. Adebahr, H.: Währungstheorie und Währungspolitik, Außenwirtschaft Bd. I, Berlin 1978, S. 386.

464 Vgl. Deutsche Bundesbank: a.a.O., S. 77. 


\section{Bewertung: $F$}

Die gesetzliche Begrenzung der offenmarktfähigen Papiere schränkt die Bundesbank technisch-institutionell ein. Einschränkungen durch Externe liegen neben dem allgemeinen aufschiebenden Vetorecht der Regierung nicht vor.

\subsection{Umfang}

In Deutschland gibt es keine Notendeckungsvorschriften oder Emissionsbegrenzungen, die eine indirekte Einschränkung von Offenmarktoperationen bewirken könnten. Überdies existieren auch keine gesetzlichen Grenzen für den An- und Verkauf von zur Offenmarktpolitik zugelassenen Wertpapieren, Gold und Devisen ${ }^{465}$. Die Bestimmung, daß die Bundesbank die zur Offenmarktpolitik zugelassenen Wertpapiere „zur Regelung des Geldmarktes“ 466 handeln darf, soll v. a. klarstellen, daß Offenmarktgeschäfte nicht zur Verbesserung der Befriedigung des Kreditbedarfs der Schuldner getätigt werden dürfen ${ }^{467}$. Diese Regelung ist insofern keine technisch-institutionelle Einschränkung der Unabhängigkeit, als die Bank selbst darüber befinden kann, welche Geschäfte zur Regelung des Geldmarktes notwendig sind.

Nun muß geprüft werden, inwieweit die Interventionsverpflichtungen, denen die Bundesbank im Rahmen des EWS unterliegt, eine Einschränkung ihrer Unabhängigkeit bewirkt. Die beteiligten Notenbanken haben sich verpflichtet, die Leitkurse innerhalb der Bandbreiten zu verteidigen 468 . Änderungen der Bandbreiten der Wechselkurse fallen ausschließlich in die Kompetenz der Regierung 469. Zur Einhaltung der Bandbreiten sind die Zentralbanken zu Interventionen verpflichtet, wenn eine Währung ihren Leitkurs nach oben oder unten erreicht 470 . Diese müssen grundsätzlich in den Währungen der teilnehmenden Staaten erfolgen und stellen sich gewöhnlich als An- und Verkauf am Devisenmarkt dar ${ }^{471}$. Doch ist das Europäische Währungssystem kein Abkommen auf Regierungsebene - im Gegensatz zum Bretton-Woods-System -, sondern allein eine Vereinbarung zwischen Notenbanken 472. Die Bundesbank könnte es rein formal gesehen im Falle geldwertschädlicher Konflikte wieder aufkündigen, ohne daß die Bundes-

\footnotetext{
465 Vgl. §19 Satz 8 BBankG.

$466 \S 21$ BBankG.

467 Vgl. Siebelt, Johannes: a.a.O., S. 204.

468 Vgl. Deutsche Bundesbank: a.a.O., S. 25.

469 Vgl. Arndt, Hans-Joachim: Von der politischen zur plangebundenen Autonomie - Die Bundesbank in der parlamentarischen Demokratie, in: Duwendag, Dieter (Hrsg.): Macht und Ohnmacht der Bundesbank, Frankfurt/M. 1973, S. 25.

Vgl. Siebelt, Johannes: a.a.O., S. 121.

Vgl. Siebelt, Johannes: a.a.O., S. 121. 
regierung zustimmen müßte. ${ }^{473}$ Zudem erlaubt eine Übereinkunft mit der Regierung von 1978 der Bundesbank, sich von einzelnen Wechselkursen zurückzuziehen, wenn sie einen ernsthaften Konflikt mit inländischen monetären Zielen $\operatorname{sieht}{ }^{474}$. Die Interventionsverpflichtungen können daher nicht als Einschränkungen der Entscheidungsfreiheit der Bundesbank hinsichtlich des Devisenhandels. Notenbankfremde Instanzen können auf den Umfang der Geschäfte der Bundesbank mit Gold, Devisen oder Wertpapieren keinen Einfluß nehmen.

\section{Bewertung: $\mathrm{E}$}

Die Deutschen Bundesbank unterliegt bei der Entscheidung über den Umfang von Offenmarktgeschäften keinen technisch-institutionellen Beschränkungen. Neben dem allgemeinen aufschiebenden Vetorecht der Regierung gibt es auch keine Möglichkeiten Externer, darauf Einfluß zu nehmen.

\subsection{Preis}

Das BBankG ermächtigt die Bundesbank zu Wertpapiertransaktionen am offenen Markt zu Marktsätzen475. Das bedeutet, daß die Notenbank keine willkürlichen, abseits des Marktgeschehens liegenden Kurse für Wertpapiertransaktionen wählen darf $\mathrm{f}^{46}$. Daraus läßt sich aber keine technisch-institutionelle Beschränkung ableiten, weil die Bundesbank die Marktbedingungen durch ihre Teilnahme an diesem Markt wesentlich beeinflussen kann ${ }^{477}$. Zudem verbietet ihr das Gesetz nicht, von ihr erwünschte Marktzinssätze anzustreben ${ }^{478}$. Die Bundesbank setzt die Sätze für die Wertpapier-Offenmarktgeschäfte fest und überläßt den $\mathrm{Ge}$ schäftsbanken damit die Initiative zu kaufen bzw. zu verkaufen 479 .

Für den Handel mit Gold und Devisen gibt es keine gesetzlich geregelten Preisgrenzen. Externe haben auf die Preissetzung bei Offenmarktgeschäften der Bundesbank keinen Einfluß.

\section{Bewertung: E}

Die Bundesbank hat bei der Preisgestaltung ihrer Offenmarktoperationen freie Hand. Es gibt weder technisch-institutionelle Einschränkungen noch Einflußrechte Dritter neben dem allgemeinen aufschiebenden Vetorecht der Regierung.

\footnotetext{
473 Vgl. Schmitz, Wolfgang (1989): a.a.O., S. 20.

474 Vgl. Emminger: D-Mark, Dollar, Währungskrisen, Stuttgart 1986, S. $361 \mathrm{f}$.

475 Vgl. § 21 BBankG.

476 Vgl. Deutsche Bundesbank: a.a.O., S. 66.

477 Vgl. Siebelt, Johannes: a.a.O., S. 204.

478 Vgl. Siebelt, Johannes: a.a.O., S. 204.

479 Vgl. Schuster, Leo (1967): a.a.O., S. 126.
} 


\subsection{Handelspartner}

Nach $\S 20$, Abs. 1, Nr. 3 BBankG bzw. $§ 22$ in Verbindung mit $\S 19$, Abs. 1, Nr. 7 BBankG ist sie befugt, mit jedermann Offenmarktgeschäfte zu betreiben 480 . Sie dehnte erstmals 1967 den Kreis der potentiellen Marktpartner auf Nichtbanken aus 481 . Auch darf sie Gold und Devisen mit jedermann handeln ${ }^{482}$. Es gibt keine Einflußrechte Dritter auf Entscheidung der Bundesbank über ihre Partner bei Offenmarktgeschäften.

\section{Bewertung: $E$}

Neben dem allgemeinen aufschiebenden Vetorecht der Regierung gibt es weder technisch-institutionelle Einschränkungen noch andere Einflußrechte Dritter auf die Auswahl der Marktpartner der Bundesbank für ihre Offenmarktoperationen.

\subsubsection{Mindestreservepolitik}

\subsection{Reservepflichtige Institute}

Die Mindestreservepflicht betrifft grundsätzlich alle Kreditinstitute ${ }^{483}$. Die Bundesbank ist befugt, einzelne Institutsgruppen von der Mindestreservepflicht zu befreien bzw. sie dazu zu verpflichten ${ }^{484}$. Einflüsse Externer auf die Auswahl der mindestreservepflichtigen Institute gibt es nicht.

\section{Bewertung: $\mathrm{E}$}

Hinsichtlich der Auswahl der mindestreservepflichtigen Institute unterliegt die Deutsche Bundesbank weder technisch-institutionellen Einschränkungen noch Einschränkungen durch Externe abgesehen von dem allgemeinen aufschiebenden Vetorecht der Regierung.

\subsection{Bemessungsgrundlagen}

Das BBankG beschränkt die Positionen, die die Bundesbank für mindestreservepflichtig erklären kann, auf Verbindlichkeiten der Kreditinstitute aus Sichteinlagen, befristeten Einlagen, Spareinlagen sowie aus aufgenommenen kurz- und mittelfristigen Geldern, ausgenommen der Verbindlichkeiten gegenüber anderen

480 Vgl. Hankel, Wilhelm (1973): a.a.O., S. 158.

481 Vgl. Spindler, Joachim v.; Becker, Willy; Starke, O.-Ernst (1973): a.a.O., S. 59.

482 Vgl. § 19 BBankG.

483 Vgl. Beckh, Susanne: Das Instrumentarium der Deutschen Bundesbank seit dem Übergang zur Geldmengensteuerung, Berlin 1990, S. 95.

Vgl. Deutsche Bundesbank: a.a.O., S. 57. 
mindestreservepflichtigen Kreditinstituten ${ }^{485}$. Die Bundesbank kann die Reservepflicht für den Bestand oder den Zuwachs dieser Verbindlichkeiten anordnen bzw. einzelne Verbindlichkeiten bei der Berechnung ausnehmen ${ }^{486}$. Eine AktivMindestreservepolitik darf die Notenbank dagegen nicht betreiben. Externe haben keinen Einfluß auf die Festsetzung der Bemessungsgrundlage für die Mindestreserven.

\section{Bewertung: $F$}

Die gesetzlich begrenzten reservepflichtigen Positionen bedeuten eine technischinstitutionelle Einschränkung für die Notenbank. Einschränkungen durch Externe gibt es neben dem allgemeinen aufschiebenden Vetorecht der Regierung nicht.

\subsection{Mindestreservesatz}

$\S 16$ BBankG schreibt Höchstsätze für die Mindestreserven vor, die die Bundesbank nicht überschreiten darf. Innerhalb dieser Grenzen kann sie die Sätze nach eigenem Ermessen festsetzen, ohne daß Externe diesbezügliche Einflußrechte haben. Sie ist zudem befugt, die Mindestreservesätze nach Art und Höhe der Verbindlichkeiten sowie nach Institutsgruppen zu staffeln 487 .

\section{Bewertung: $\mathrm{F}$}

Die gesetzlichen Höchstgrenzen für die Mindestreservesätze bedeuten eine technisch-institutionelle Einschränkung. Einschränkungen durch Externe liegen neben dem allgemeinen aufschiebenden Vetorecht der Regierung nicht vor.

\subsection{Materielle Beschaffenheit der Mindestreserven}

Das Gesetz bestimmt die Einlegung der Mindestreserven auf einem Girokonto bei der Bundesbank ${ }^{488}$. Externe haben auf die materielle Beschaffenheit der Mindestreserven keinen Einfluß.

\section{Bewertung: I}

Das Gesetz schreibt die materielle Beschaffenheit der Mindestreserven vor. Weder die Bundesbank noch externe Instanzen haben diesbezüglich Gestaltungsmöglichkeiten. Dieses Instrument steht daher nicht zur Variation zur Verfügung.

\footnotetext{
485 Vgl. § 16 BBankG.

486 Vgl. Deutsche Bundesbank: a.a.O., S. 58f.

487 Vgl. Deutsche Bundesbank: a.a.O., S. 58f.

488 Vgl. § 16 BBankG.
} 


\subsubsection{Zusammenfassende Beurteilung der funktionellen Unabhängigkeit der Deutschen Bundesbank}

Aufgrund der oben ermittelten Werte für die in Abb. 5 aufgeführten 16 Instrumente ergibt sich ein Zentralwert von F. Damit ist die Deutsche Bundesbank funktionell eher unabhängig.

\subsection{Schweiz}

Die Schweizerische Nationalbank nahm 1907 ihre Tätigkeit auf und löste die bis dahin bestehenden 36 privaten und kantonalen Emissionsinstitute $a b^{489}$. Sie ist eine privatrechtliche Aktiengesellschaft nach Obligationenrecht, der das Nationalbankgesetz öffentliche Aufgaben übertragen hat 490 . Ihre Organe setzen sich aus der Hauptversammlung der Aktionäre, dem Bankrat, dem Bankausschuß, den Lokalkomitees, der Revisionskommission, dem Direktorium und den Lokaldirektionen zusammen 491 . Die gesetzlichen Befugnisse der Aktionärsversammlung beschränken sich im wesentlichen auf Kompetenzen formalrechtlicher Natur 492 . Die Träger der Geldpolitik sind der Bankrat, der Bankausschuß und das Direktorium.

Bei der Beurteilung der funktionellen Unabhängigkeit der schweizerischen Nationalbank sind im Untersuchungszeitraum drei Phasen zu unterscheiden. Bis 1971 waren die gesetzlichen Mittel, die der Notenbank zur Erfüllung ihrer Aufgaben zur Verfügung standen, eng begrenzt. Daher war sie gezwungen, ihre Politik weitgehend auf dem Wege der Kooperation mit dem Bund und Gentlemen's Agreements mit den Banken durchzuführen. Ein 1968 eingebrachter Entwurf zur Revision des Nationalbankgesetzes scheiterte im Parlament wegen gehegten Zweifeln an seiner Verfassungsmäßigkeit ${ }^{493}$. Daher erließen die Behörden im Herbst 1971 einen dringlichen Bundesbeschluß über den Schutz der Währung sowie einen im Dezember 1972 über Maßnahmen auf dem Gebiete des Kreditwe-

489 Vgl. Mast, Hans J.: Schweizerische Nationalbank, in: Regul, Rudolf; Wolf, Herbert (Hrsg.): Das Bankwesen im größeren Europa, Schriftenreihe Europäische Wirtschaft, Bd. 67, Baden-Baden 1974, S. 149.

490 Vgl. Gemper, Bodo B.: Der Schweizerische Geldmarkt nach der Revision des Nationalbankgesetzes, in: Österreichisches Bank-Archiv, 28. Jg. 1979, S. 358.

491 Vgl. Spindler, Joachim v.; Becker, Willy; Starke, O.-Ernst: Die Deutsche Bundesbank, Stuttgart 1957, S. 16.

492 Vgl. Bank für Internationalen Zahlungsausgleich Basel: a.a.O., S. $371 \mathrm{f}$

493 Vgl. Stoffers, Erich: Die Notenbanken der Länder, in: Regul, Rudolf und Wolf, Herbert (Hrsg.): Das Bankwesen im größeren Europa, Baden-Baden 1974, S. 153. 
sens, wodurch die Nationalbank eine Reihe neuer Interventionsmittel erhielt 494. Bei diesen Bundesbeschlüssen handelt es sich um ein Notrecht, das längstens drei Jahre laufen darf und spätestens nach einem Jahr vom Volk genehmigt werden muß495. Sie wurden in modifizierter Form mehrfach verlängert ${ }^{496}$. Schließlich erfolgte mit der Revision des Nationalbankgesetzes vom 15. Dezember 1978497 die Überführung bewährter Notrechtsmaßnahmen in ordentliches Recht 498 . Es muß also die Phase bis zu den Bundesbeschlüssen, die Zeitspanne während der Gültigkeitsdauer der Bundesbeschlüsse und schließlich die Periode seit der Revision des Nationalbankgesetzes 1978 betrachtet werden.

\subsubsection{Personelle Unabhängigkeit}

\subsubsection{Ernennungsinstanzen (Ebene 1)}

Der Bankrat besteht aus 40 Mitgliedern, von denen 15 von der Generalversammlung der Aktionäre und 25 vom Bundesrat ernannt werden ${ }^{499}$. Ihm obliegt die allgemeine Beaufsichtigung des Geschäftsganges und der Geschäftsführung der Bank sowie die Wahl der Mitglieder des Bankausschusses und das Vorschlagsrecht für die Wahl der Mitglieder des Direktoriums ${ }^{500}$. Der Bankausschuß setzt sich aus dem Präsidenten und Vizepräsidenten des Bankrates sowie sechs weiteren Mitgliedern des Bankrates zusammen ${ }^{501}$. Er ist mit der näheren Aufsicht und Kontrolle der Bank beauftragt und reicht über den Bankrat an den Bundesrat konkrete Vorschläge für die Wahl der Direktoriumsmitglieder ein ${ }^{502}$. Zudem muß er vor der Änderung der offiziellen Zinssätze der Nationalbank konsultiert werden, besitzt aber kein Vetorecht ${ }^{503}$. Das Direktorium, das die eigentlichen geldpolitischen Entscheidungen triff, besteht aus 3 Mitgliedern, die vom Bundesrat ernannt werden ${ }^{504}$. Der Bundesrat ist dabei an die Vorschläge des Bankrates

\footnotetext{
494 Vgl. Menzel, Ch.; Tanner, U., Bearb.: Schweizerische Nationalbank. Aufgaben, Instrumente, Organisation, o. O. 1979, S. 9.

495 Vgl. Stoffers, Erich: a.a.O., S. 154.

496 Vgl. Menzel, Ch.; Tanner, U.: a.a.O., S. 10.

497 Vgl. Inkraftsetzung 1. August 1979

498 Vgl. Menzel, Ch.; Tanner, U.: a.a.O., S. 10.

499 Vgl. Lampe, Ortrun: a.a.O., S. 60.

500 Vgl. Schmid, Beat: a.a.O., S. 43.

501 Vgl. Schmid, Beat: a.a.O., S. 43.

502 Vgl. Schmid, Beat: a.a.O., S. 43.

503 Vgl. Rich, Georg (1989): a.a.O., S. 26.

504 Vgl. Bank für Internationalen Zahlungsausgleich Basel: a.a.O., S. 376.
} 
nicht gebunden 505 . Dem Bankrat fehlt damit die Möglichkeit einer aktiven Entscheidungsbefugnis 506 .

Fazit:

Für die Ernennung der Direktoriumsmitglieder ist der Bundesrat zuständig. Die Nationalbank kann somit nicht die Entscheidungsmehrheit in der die Geldpolitik bestimmenden Instanz bestellen.

\subsubsection{Abberufungsinstanzen (Ebene 2)}

Die Berufung von Mitgliedern der Notenbankleitung erfolgt durch einseitigen Hoheitsakt ${ }^{507}$. Eine Kündigung durch die Notenbank ist nicht möglich, sondern nur durch den Bundesrat als Ernennungsinstanz ${ }^{508}$.

\section{Fazit:}

Die Notenbank ist weder die entscheidende Abberufungsinstanz noch kann sie durch ein Vetorecht eine Abberufung von Mitgliedern der Bankleitung verhindern. Damit sind weitere Abberufungsmodalitäten sowie Wiederernennungsvorschriften für die Bewertung der personellen Unabhängigkeit der Schweizerischen Nationalbank unbedeutend.

\subsubsection{Kreis der Ernennungsfihigen (Ebene 6)}

Die leitenden Mitglieder der Notenbankleitung müssen in der Schweiz niedergelassene Schweizerbürger sein ${ }^{509}$ und dürfen während ihrer Amtszeit weder dem Parlament, den Kantonsregierungen oder dem Bankrat angehören 510 . Die Gehälter der Notenbankmitglieder werden vom Bankrat festgelegt, müssen aber von der Regierung gebilligt werden 511 . Die Notenbankleitung kann daher über die Besoldungsregelungen nur bedingt Einfluß auf den Kreis der Ernennungsfähigen nehmen.

Fazit:

Die Nationalbank kann auf den Kreis der Ernennungsfähigen durch ihren Einfluß auf die Besoldung der Notenbankmitglieder Einfluß nehmen.

\footnotetext{
505 Vgl. Schmid, Beat: a.a.O., S. 44.

506 Vgl. Schmid, Beat: a.a.O., S. 45.

507 Vgl. Schmid, Beat: a.a.O., S. 46.

508 Vgl. Schmid, Beat: a.a.O., S. 46.

509 Vgl. Bank für Internationalen Zahlungsausgleich Basel: a.a.O., S. 372.

510 Vgl. Caesar, Rolf (1981): a.a.O., S. 219.

511 Vgl. Rich, Georg (1989): a.a.O., S. 26.
} 


\subsubsection{Beurteilung der personellen Unabhängigkeit}

Die personelle Unabhängigkeit der Schweizerischen Nationalbank ist stark eingeschränkt. Sie erreicht mit Ziffer 25 die vorletzte Bewertungsstufe des Entscheidungsbaums in Abb. 1 und damit den Unabhängigkeitsgrad abhängig.

\subsubsection{Funktionelle Unabhängigkeit}

\subsubsection{Instrumentenübergreifende Regelungen}

Um sicherzustellen, daß die Geldpolitik der Notenbank in groben Zügen mit der allgemeinen Wirtschaftspolitik der Regierung harmoniert, sind die Schweizerische Eidgenossenschaft und die Notenbank verpflichtet, sich bei wichtigen Entscheidungen zu informieren und ihre Politik aufeinander abzustimmen ${ }^{512}$. In keinem Fall ist die Billigung des anderen erforderlich ${ }^{513}$. Das Gesetz gewährt zwar der Schweizerischen Eidgenossenschaft durch eine Anzahl von Wahl- und Genehmigungskompetenzen ${ }^{514}$ eine umfassende Aufsicht über die Notenbank. Sie spielt jedoch im wesentlichen für die personelle Unabhängigkeit eine Rolle. Die Regierung ist nicht befugt, der Bank in geld- und währungspolitischen Entscheidungen Weisungen zu erteilen ${ }^{515}$. Währungspolitische Entscheidungen der Notenbank können nicht auf gerichtlichem Wege angefochten werden 516 . Ebensowenig vermag das Bundesgericht Kompetenzkonflikte zwischen Notenbankleitung und Regierung zu schlichten 517 .

Die Befugnisse des Parlaments beschränken sich darauf, das Notenausgabeprivileg der Notenbank alle 20 Jahre zu erneuern und auf Angelegenheiten, die das Anteilseigentum der Bank und deren Gewinne betreffen ${ }^{518}$. Die Schweizerische Nationalbank ist eine Aktiengesellschaft, deren Aktien an der Börse gehandelt werden ${ }^{519}$. Anteilseigner haben keine Möglichkeit, auf geldpolitische Entscheidungen der Bank Einfluß zu nehmen.

512 Vgl. Lusser, Markus (1988): a.a.O., S. 4.

513 Vgl. Swinburne, Mark; Castello-Branco, Marta: a.a.O., S. $20 f$.

514 Vgl. Art. 63 Nationalbankgesetz.

515 Vgl. Braun, Karlpeter: a.a.O., S. 51.

516 Vgl. Schmid, Beat: a.a.O., S. 50f.

517 Vgl. Schmid, Beat: a.a.O., S. 51.

518 Vgl. Rich, Georg (1989): a.a.O., S. 26.

519 Vgl. Menzel, Ch.; Tanner, U., a.a.O., S. 3. 


\subsubsection{Ausgabe von Zentralbankgeld durch die Notenbank}

\subsection{Art der Kreditnehmer}

Das Gesetz befugt die Notenbank zur Kreditgewährung an Banken und den Staat. Sie darf aber auch direkt dem Handel, der Industrie oder Landwirtschaft Kredit erteilen, nämlich in Form von direkten Diskontkrediten und Lombardvorschüssen $^{520}$. Externe können keinen Einfluß darauf nehmen, welchen Instanzen die Notenbank Kredit gewährt.

\section{Bewertung: A}

Es liegen weder technisch-institutionelle Einschränkungen noch Einflußrechte externer Instanzen hinsichtlich der Art der Kreditnehmer vor.

\subsection{Umfang}

Die Schweizerische Nationalbank darf Notenbankgeld nur gegen Gold und Golddevisen oder durch die Gewährung kurzfristiger Kredite schaffen ${ }^{521}$. Das Gesetz schreibt eine Mindestgolddeckung von $40 \%$ der im Umlauf befindlichen Noten vor $^{522}$. Der Revisionsentwurf des Nationalbankgesetzes sah zwar eine Streichung dieser Regelung vor ${ }^{523}$; sie wurde aber dennoch beibehalten. Dadurch wird die Handlungsfreiheit der Nationalbank bzgl. des Umfangs ihrer Ausgabe von Zentralbankgeld beschränkt. Eine Einlösungsverpflichtung von Noten in Gold besteht seit 1936 nicht mehr $^{524}$.

Eine Buchkreditgewährung der Notenbank an den Staat ist ausdrücklich untersagt $^{525}$. Die einzige Möglichkeit zur direkten Staatsfinanzierung besteht in einer Diskont- oder Lombardkreditgewährung der Notenbank, über deren Höhe die Notenbank entscheiden kann ${ }^{526}$. Zur Staatsfinanzierung ist die Nationalbank durch Gesetz in keiner Weise verpflichtet ${ }^{527}$.

Dem Bankensektor stehen zur kurzfristigen Liquiditätsbeschaffung bei der Notenbank Diskont- und Lombardkredite sowie die Pensionierung von Sterilisie-

520 Vgl. Menzel, Ch.; Tanner, U.: a.a.O., S. 8.

521 Vgl. Mast, Hans J.: a.a.O., S. 150.

522 Vgl. Stoffers, Erich: a.a.O., S. 150.

523 Vgl. Ritzmann, Franz: Zum Instrumentarium der Schweizerischen Nationalbank. Kritische Betrachtungen, Bern, Stuttgart 1977, S. 122.

524 Vgl. Stoffers, Erich: a.a.O., S. 150.

525 Vgl. Caesar, Rolf (1981): a.a.O., S. 218.

526 Vgl. Caesar, Rolf (1981): a.a.O., S. 218.

527 Vgl. Caesar, Rolf (1982): a.a.O., S. 571. 
rungsreskriptionen und kurzfristige Dollar-Franken-Swaps zur Verfügung 528 . Die Notenbank ist in der Höhe der Kreditgewährung keinen gesetzlichen Beschränkungen unterworfen. Externe Instanzen können die Notenbank nicht zur Refinanzierung der Banken anweisen. Das Währungsinstitut kann Kredite gewähren, muß aber nicht 529 .

Die Verwendung der Notenbankgewinne ist in der Bundesverfassung und im Nationalbankgesetz umfassend geregelt ${ }^{530}$. Die Nationalbank ist verpflichtet, ihren Gewinn abzüglich betriebswirtschaftlicher und volkswirtschaftlicher Reserven nach festgelegten Regeln an die Aktionäre, die Kantone und den Bund zu verteilen 531 . Dabei dürfen die Reserven $2 \%$ des Grundkapitals nicht übersteigen 532 . Die Dividende der Aktionäre ist auf maximal 6\% begrenzt. Die Kantone haben einen Anspruch auf 80 Rappen je Kopf der Bevölkerung, den die Notenbank, falls die Rechnungsergebnisse der Bank dies nicht gestatten, in den darauffolgenden Jahren zu erfüllen hat ${ }^{533}$. Diese Regelungen zwingen die Notenbank zu einer Ausgabe von Zentralbankgeld, auf die sie selbst nur sehr bedingt Einfluß hat.

\section{Bewertung: D}

Die Emissionsbegrenzungen der Notenbank, das Verbot einer Buchkreditgewährung an den Staat sowie die Gewinnverteilungsvorschriften bewirken eine technisch-institutionelle Einschränkung der Unabhängigkeit bzgl. des betrachteten Instruments. Externe Instanzen haben auf den Umfang der Ausgabe von Zentralbankgeld durch die Notenbank keinen Einfluß.

\subsection{Zinssatz}

Das Direktorium der Nationalbank ist alleinig zuständig für die Festsetzung des offiziellen Diskontsatzes und des Zinsfußes für Darlehen ${ }^{534}$. Es gibt keine gesetzlichen Höchstgrenzen oder Richtlinien, die die Bank beachten muß. In der Regel verwendet sie nur einen offiziellen Diskontsatz $\mathrm{z}^{535}$. Sie darf aber auch spezielle Sätze zur Anwendung bringen, wie sie es beispielsweise für die Diskontierung von Wechseln, die aus der Finanzierung von behördlich angeordneten

528 Vgl. Menzel, Ch.; Tanner, U.: a.a.O., S. 12f.

529 Vgl. Felder, Karl R.: Die Schweizerische Nationalbank. Auftrag und Instrumentarium, NZZ-Schriften zur Zeit, 35, Zürich 1976, S. 13.

530 Vgl. Lusser, Markus (1992): a.a.O., S. 69.

531 Vgl. Lusser, Markus (1992): a.a.O., S. 69.

$532 \mathrm{Vgl}$. Bank für Internationalen Zahlungsausgleich Basel: a.a.O., S. 369.

533 Vgl. Bank für Internationalen Zahlungsausgleich Basel: a.a.O., S. 369.

$534 \mathrm{Vgl}$. Bank für Internationalen Zahlungsausgleich Basel: a.a.O., S. 375

$535 \mathrm{Vgl}$. Bank für Internationalen Zahlungsausgleich Basel: a.a.O., S. 401. 
Pflichtlagern herrühren, tut ${ }^{536}$. Auch hat sie mehrfach bestimmten strukturschwachen Branchen Vorteile im Exportgeschäft durch Gewährung von Vorzugskonditionen beim Rediskont gewährt 537 .

\section{Bewertung: A}

Die Nationalbank ist bei der Festlegung ihrer Kreditzinsen völlig frei. Es gibt weder technisch-institutionelle Einschränkungen noch Einschränkungen durch Externe.

\subsection{Bedingungen}

Art. 14 Ziffer 1 Nationalbankgesetz stellt an die Diskont- und Lombardfähigkeit der dem Noteninstitut einzureichenden Papiere bestimmte Anforderungen. So durfte die Notenbank bis zur Gesetzesrevision 1979 nur Forderungen diskontieren, deren Restlaufzeit nicht länger als drei Monate beträgt ${ }^{538}$. Die maximale Verfallszeit wurde dann auf sechs Monate verlängert ${ }^{539}$. Die Nationalbank ist nur befugt, auf die Schweiz lautende Wechsel und Checks mit mindestens zwei guten Unterschriften, Schatzanweisungen des Bundes, Schatzanweisungen der Kantone und Gemeinden mit der Unterschrift einer Bank, belehnbare Schuldverschreibungen auf die Schweiz sowie eidgenössische Schuldbuchforderungen zur Diskontierung anzunehmen. Lombardkredite dürfen nur gegen Verpfändung von Schuldverschreibungen des Bundes, eidgenössischen Schuldbuchforderungen, diskontierbaren Wechseln und Gold gewährt werden ${ }^{540}$. Aktien und Genossenschaftsanteile darf die Nationalbank nicht beleihen ${ }^{541}$.

Für Lombardkredite gibt es eine zehntägige Kündigungsfrist, so daß die Notenbank die Laufzeit gut steuern kann ${ }^{542}$. Der Notenbank steht es ebenso offen, die Restlaufzeiten der rediskontierbaren Papiere zu reduzieren oder die Annahme einzelner Titel überhaupt abzulehnen ${ }^{543}$. Eine Kreditvergabe an die öffentliche Hand kann sie an Bedingungen knüpfen ${ }^{544}$. Externe Instanzen haben keinen Einfluß auf die Laufzeiten und Sicherheiten von Krediten der Notenbank.

$536 \mathrm{Vgl}$. Bank für Internationalen Zahlungsausgleich Basel: a.a.O., S. 401.

537 Vgl. Caesar, Rolf (1981): a.a.O., S. $236 f$.

538 Vgl. Kilgus, Ernst: Das neue schweizerische Notenbankgesetz, in: Österreichisches Bank-Archiv, 28. Jg. 1980, S. 5.

539 Vgl. Kilgus, Ernst: a.a.O., S. 5.

540 Vgl. Art. 14 Ziffer 4 Nationalbankgesetz.

541 Vgl. Art. 14 Ziffer 4 Nationalbankgesetz.

542 Vgl. Bank für Internationalen Zahlungsausgleich Basel: a.a.O., S. 402.

543 Vgl. Felder, Karl R.: a.a.O., S. 13.

544 Vgl. Bank für Internationalen Zahlungsausgleich Basel: a.a.O., S. 401. 


\section{Bewertung: D}

Es liegt eine technisch-institutionelle Einschränkung vor aufgrund der gesetzlichen Festlegung der diskont- und lombardfähigen Papiere. Einschränkungen durch notenbankfremde Instanzen gibt es nicht.

\subsubsection{Direkte Einflußnahme auf die Kreditvergabe der Banken}

\subsection{Art der Kreditnehmer}

Das Bundesgesetz über die Banken und Sparkassen (im folgenden Bankengesetz) gibt der Nationalbank mit Art. 8 einige Mittel zur Kapitalexportkontrolle in die Hand. Sie kann u. a. bestimmte Bankkredite an das Ausland genehmigungspflichtig erklären ${ }^{545}$ und kann diese Genehmigung verweigern oder an Bedingungen knüpfen ${ }^{546}$. Dadurch ist die Nationalbank in diesem Bereich in der Lage auch auf die Art der Kreditnehmer Einfluß nehmen.

\section{Bewertung: D}

Die Möglichkeiten der Nationalbank, auf die Art der Kreditnehmer der Banken Einfluß zu nehmen, sind technisch-institutionell eingeschränkt, weil sie auf Kreditoren im Ausland begrenzt sind.

\subsection{Umfang}

Mit Art. 8 ermächtigt das Bankengesetz die Nationalbank, Bankkredite an das Ausland, die 10 Millionen Franken übersteigen 547 und länger als 12 Monate laufen, genehmigungspflichtig zu erklären ${ }^{548}$. Die Nationalbank darf die Bewilligung mit Rücksicht auf die Landeswährung, die Gestaltung des Zinsfußes auf dem Geld- und Kapitalmarkt oder die Gesamtinteressen des Landes verweigern oder an Bedingungen knüpfen ${ }^{549}$.

Eine allgemeine Kreditplafondierung auf administrativem Wege gestattete das Bundesgesetz über die Schweizerische Nationalbank vom 23.12.1953 hingegen nicht. Die Notenbank schlo $B$ daher entsprechende Abkommen mit den Banken $^{550}$. So wurden z. B. zur Eindämmung des Baubooms 1951 - 1957 Gentle-

545 Vgl. Stoffers, Erich: a.a.O., S. 153.

546 Vgl. Stoffers, Erich: a.a.O., S. 153.

547 Die Notenbank darf die Untergrenze von 10 Millionen Franken auch reduzieren.

548 Vgl. Stoffers, Erich: a.a.O., S. 153.

549 Vgl. Stoffers, Erich: a.a.O., S. 153.

550 Vgl. Ittensohn, Jacques: Schweizer Beispiel: "Wenig Staat", in: Zeitschrift für das gesamte Kreditwesen 1/1959, S. 32. 
men's Agreements zur gezielten Kreditbegrenzung mit 1600 Teilnehmern aus Banken, Versicherungsgesellschaften, öffentlichen Fondsverwaltungen, Immobilienanlagetrusts, Pensionskassen sowie Fürsorgeeinrichtungen der öffentlichen Hand und der Privatwirtschaft getroffen 551 . Für Kreditbegrenzungen im Rahmen freiwilliger Vereinbarungen benötigt die Nationalbank die Zustimmung der betroffenen Institute. Der Bundesbeschluß über Geld- und Kreditpolitik vom 19.12.1975 ermöglichte schließlich eine administrative Kreditbegrenzung. Diese war der Kompetenz des Bundes unterstellt ${ }^{552}$. Bei der Ausführung hatte die Notenbank jedoch weitreichende Freiheiten. Sie bestimmte die Zuwachsrate der Kredite und konnte bei bestimmten Krediten Ausnahmen sowie im Einzelfall $\mathrm{Zu}-$ satzquoten bewilligen 553 . Der Nationalbank war es zudem auch weiterhin freigestellt, Abkommen mit den Banken über Kreditbegrenzungen zu treffen. Die Regelungen des Bundesbeschlusses wurden nicht in das neue Notenbankgesetz vom 1.7.1979 übernommen ${ }^{554}$. Seither bleibt der Nationalbank wieder ausschließlich die Möglichkeit freiwilliger Vereinbarungen, zur Kreditbegrenzung.

Eine nicht geldpolitisch motivierte Begrenzung der Kreditvergabekapazitäten liegt schließlich in der Vollziehungsverordnung zum Bundesgesetz über die Banken und Sparkassen vom 17. Mai 1972, die den Kreditinstituten eine bestimmte Eigenkapital- und Liquiditätshaltung vorschreibt ${ }^{555}$.

\section{Bewertung: D}

Die Schweizerische Nationalbank besitzt nur hinsichtlich. der Kreditvergabe an das Ausland gewisse administrative Befugnisse. Das Instrument der Beeinflussung des Umfangs der Kreditvergabe der Banken steht ihr daher nur technischinstitutionell eingeschränkt zur Verfügung. Eine weitere technisch-institutionelle Einschränkung liegt in den Liquiditäts- und Eigenkapitalvorschriften der Banken, auf die die Notenbank keinen Einfluß hat.

\subsection{Zinssatz}

Prinzipiell bleibt die Entwicklung der Zinssätze in der Schweiz weitgehend dem freien Spiel von Angebot und Nachfrage überlassen. Auf die Zinsgestaltung der Kreditinstitute gegenüber ihren Kunden hat die Notenbank keinen Einfluß. Entscheidungen über die Variation der Soll- und Habenzinsen erfolgen durch die sog. Zinskonvenien der Züricher Banken, die Beschlüsse über die Privatdiskontsätze

551 Dazu und weitere Beispiele bei Gal, M.: Erfahrungen der Schweiz mit der Kreditplafondierung, in: Kredit und Kapital, 4. Jg. 1971, S. 197ff.

552 Vgl. Schuster, Leo: Neues Nationalbankgesetz, in: Die Bank 7/79, S. 340.

$553 \mathrm{Vgl}$. Bundesbeschluß über Geld- und Kreditpolitik vom 19.12.1975, Art.3 Satz 2, 3, 8 .

554 Vgl. Schuster, Leo (1979): a.a.O., S 340.

555 Vgl. Bär, Hans J.: The Banking System of Switzerland, 4. Aufl., Zürich 1973, S. 53ff. 
durch die Bankiervereinigung556. Die Notenbank steht nur beratend zur Seite 557 . Auch Art. 10 des Bankengesetzes bringt der Notenbank keine weitergehenden Befugnisse. Er verpflichtet alle Kreditinstitute mit einer Bilanzsumme von mindestens 20 Millionen Franken die Nationalbank zu benachrichtigen, wenn sie beabsichtigen, den Zins für Kassenobligationen zu erhöhen 558 . Die Nationalbank kann jedoch allenfalls durch Empfehlungen darauf hinwirken, daß die Änderung unterbleibt, verschoben oder in modifizierter Form durchgeführt wird ${ }^{559}$. Sie darf keine bindenden Auflagen machen 560 .

Bewertung: G

Die Notenbank hat neben Empfehlungen bzw. freiwilligen Vereinbarungen, die die Zustimmung der betroffenen Banken voraussetzen, keine Möglichkeit einer Einflußnahme auf die Bankzinsen.

\subsection{Bedingungen}

Auf die Kreditbedingungen kann die Notenbank nur bei Krediten an das Ausland einwirken ${ }^{561}$. Sonstige Regelungen kann sie nur über entsprechende Vereinbarungen mit den betroffenen Banken treffen.

\section{Bewertung: D}

Die Beschränkung direkter Einwirkungsmöglichkeiten der Nationalbank auf bestimmte Auslandskredite, bedeutet eine technisch-institutionelle Einschränkung für die Notenbank. Einflußrechte Externer gibt es keine.

\subsubsection{Offenmarktpolitik}

\subsection{Art und Gegenstand des Geschäfts}

Die Schweizerische Nationalbank ist befugt, mit Devisen Offenmarktgschäfte zu betreiben ${ }^{562}$. Seit der Reform des Nationalbankgesetzes kann die Nationalbank

556 Vgl. Caesar, Rolf (1981): a.a.O., S. 221.

557 Vgl. Caesar, Rolf (1981): a.a.O., S. 221.

558 Vgl. Veit, Otto (1961), a.a.O., S. 653.

559 Vgl. Stoffers, Erich: a.a.O., S. 152.

560 Vgl. Veit, Otto (1961), a.a.O., S. 652f.

561 Vgl. Art.8 Satz 3 Bankengesetz.

$562 \mathrm{Vgl}$. Kleinewefers, Henner: Inflation und Inflationsbekämpfung in der Schweiz, Frauenfeld 1976, S. 202. 
Devisenoperationen mit Laufzeiten bis zu 24 Monaten abschließen (vorher 3 Monate $)^{563}$.

Das Bundesgesetz über die Schweizerische Nationalbank vom 23.12.53 Art. 14 legte fest, welche Papiere die Notenbank im Rahmen von Offenmarktoperationen an- und verkaufen darf. Danach war die Notenbank befugt zum An- und Verkauf von Schatzanweisungen und Schuldverschreibungen des Bundes und der Bundesbahnen, eidgenössischen Schuldbuchforderungen, Schuldverschreibungen der Kantone und der Kantonalbanken im Sinne des Bundesgesetzes über die Banken und Sparkassen, Pfandbriefen der schweizerischen Pfandbriefzentralen sowie Wechseln und Checks auf das Ausland, die bestimmte Kriterien erfüllen. Die Durchschlagskraft der Offenmarktpolitik war v. a. durch einen Mangel an offenmarktpolitischer „Munition“ begrenzt ${ }^{564}$. Zudem mußte sich die Notenbank ihr monetäres Abschöpfungspotential am offenen Markt „leihen“565. Sie erhielt vom Bund ausschließlich zum Zwecke der Abschöpfung von Geldmarktliquidität Schatzanweisungen (Sterilisierungsreskriptionen), deren Zinsbelastung die Nationalbank trug und deren Erlös auf einem Sperrkonto der Nationalbank sterilisiert wurde ${ }^{566}$. Das revidierte Nationalbankgesetz von 1979 erweiterte die offenmarktpolitischen Möglichkeiten der Notenbank zusätzlich auf den An- und Verkauf von leicht realisierbaren Schuldverschreibungen anderer schweizerischer Banken und Gemeinden und gab der Nationalbank die Möglichkeit, die Sterilisierungsreskriptionen durch notenbankeigene verzinsliche Schuldverschreibungen mit einer maximalen Laufzeit von zwei Jahren abzulösen ${ }^{567}$. Die Nationalbank steht es ferner offen, Obligationen internationaler Organisationen oder ausländischen Banken mit einer Laufzeit bis zu zwölf Monaten kaufen und verkaufen 568 . Hinsichtlich der Art der Geschäfte unterliegt die Nationalbank keinen Beschränkungen. Externe haben keinen Einfluß auf die Art und Gegenstand der Offenmarktgeschäfte der Nationalbank.

\section{Bewertung: D}

Technisch-institutionell eingeschränkt hinsichtlich Art und Gegenstand der Offenmarktoperationen ist die Notenbank dadurch, daß die Gattung der von ihr handelbaren Papiere gesetzlich festgelegt ist. Einflußrechte Externer bestehen nicht.

563 Vgl. Kilgus, Ernst: a.a.O., S. 6.

564 Vgl. Caesar, Rolf (1981): a.a.O., S. 221.

565 Vgl. Gemper, Bodo B.: a.a.O., S. 361.

566 Vgl. Gemper, Bodo B.: a.a.O., S. 361.

567 Vgl. Menzel, Ch.; Tanner, U.: a.a.O., S. 12.

568 Vgl. Kilgus, Ernst: a.a.O., S. 6. 


\subsection{Umfang}

Dem Umfang der offenmarktpolitischen Aktivitäten sind durch die erforderliche Golddeckung der im Umlauf befindlichen Noten technisch-institutionelle Grenzen gesetzt. Zum Ankauf von Gold oder Devisen ist die Nationalbank im Untersuchungszeitraum befugt, aber nicht verpflichtet. Bis zum Übergang zu einem flexiblen Franken-Wechselkurs im Jahr 1973 war sie jedoch gezwungen, in dem Umfang Devisen- und Goldbestände entgegenzunehmen, als dies zur Erfüllung der ihr übertragenen Aufgabe, die Währung auf der Parität zu halten, notwendig war ${ }^{569}$. Seither kann der Schweizer Franken frei floaten 570 . Die Wechselkurspolitik gehört seitdem zum Aufgabenbereich der Notenbank, die jedoch ihre Politik nur mit Rücksprache mit dem Bundesrat festlegen kann ${ }^{571}$. Der An- und Verkauf von Devisen ist heute ein Hauptinstrument zur Steuerung der Geldmenge $^{572}$.

\section{Bewertung: D}

Der Gestaltungsfreiheit der Nationalbank hinsichtlich des Umfangs offenmarktpolitischer Maßnahmen erfährt insofern eine technisch-institutionelle Einschränkung, als eine Golddeckung von mindestens 40 Prozent der im Umlauf befindlichen Noten gewährleistet sein muß. Restriktionen aufgrund von Interventionsverpflichtungen gibt es seit 1973 nicht mehr. Notenbankfremde Instanzen können nicht in die offenmarktpolitischen Entscheidungen der Notenbank eingreifen.

\subsection{Preis}

Bis 1973 war die Notenbank verpflichtet, die ihr angebotenen Devisen zu fixen Kursen gegen Franken anzukaufen ${ }^{573}$. Seither unterliegt sie keinen einschränkenden Vorschriften hinsichtlich der Preisgestaltung bei Offenmarktgeschäften mehr. Das Noteninstitut nutzt diese Freiheit auch zur Förderung einzelner Wirtschaftsbereiche. So hat sie zuweilen die in Schwierigkeiten geratene auslandsorientierte Wirtschaft durch Devisentermingeschäfte zu besonders günstigen Konditionen unterstützt ${ }^{574}$.

569 Vgl. Bank für Internationalen Zahlungsausgleich Basel: a.a.O., S. 405.

570 Vgl. Menzel, Ch.; Tanner, U.: a.a.O., S. 9f.

571 Vgl. Menzel, Ch.; Tanner, U.: a.a.O., S. 7.

572 Vgl. Achterberg, Erich: Coyne oder die unabhängige Notenbank, in: Zeitschrift für das gesamte Kreditwesen H.16 1961, S. 69.

573 Vgl. Menzel, Ch.; Tanner, U.: a.a.O., S. 11.

574 Vgl. Caesar, Rolf (1981): a.a.O., S. 237; Schmid, Beat: a.a.O., S. 76. 


\section{Bewertung: A}

Die Schweizerische Nationalbank unterliegt keinerlei Beschränkungen hinsichtlich ihrer Preisgestaltung bei Offenmarktgeschäften.

\subsection{Handelspartner}

Hinsichtlich der Handelspartner unterliegt die Nationalbank keinerlei Beschränkungen. Mit der Revision des Notenbankgesetzes wurde zugleich eine Neuordnung des Schweizerischen Geldmarktes mit einer Erweiterung des Teilnehmerkreises vorgenommen, was die Offenmarktpolitik der Nationalbank wirkungsvoller werden ließ575.

\section{Bewertung: A}

Die Schweizerische Nationalbank unterliegt hinsichtlich der Wahl ihrer Partner für Offenmarktgeschäfte keinerlei Beschränkungen.

\subsubsection{Mindestreservepolitik}

Im Nationalbankgesetz vom 23. Dezember 1953 war das Mindestreserveinstrument nicht enthalten ${ }^{576}$. Daher hat die Notenbank lange Zeit mit den Banken Gentlemen's Agreements über die Haltung von Pflichtreserven geschlossen 577. Durch den Bundesbeschluß über Geld- und Kreditpolitik vom 19.12.1975 wurde der Bundesrat schließlich ermächtigt, bestimmte Finanzinstitutionen der Mindestreservepflicht zu unterwerfen. Das bedeutet, daß der Notenbank dieses Mittel nicht jederzeit und kurzfristig anwenden konnte, sondern nur aufgrund eines Parlamentsbeschlusses. Diese Zeitverzögerung hatte zudem den Effekt einer Frühwarnung der betroffenen Banken ${ }^{578}$. Seit der Revision des Nationalbankgesetzes 1979 steht der Nationalbank das Mindestreserveinstrument als reguläres geldpolitisches Mittel zur Verfügung579.

\subsection{Reservepflichtige Institute}

Solange die Notenbank das Mindestreserveinstrument nicht auf administrativem Wege einsetzen konnte, unterlagen nur diejenigen Banken der Mindestreservepflicht, mit denen die Notenbank entsprechende Vereinbarungen geschlossen

575 Vgl. Schuster, Leo (1979): a.a.O., S 341.

$576 \mathrm{Vgl}$. Ittensohn, Jacques: a.a.O., S. 31.

577 Vgl. Mader, Richard: Die Mindestreservepolitik im internationalen Vergleich, in: Die Bank 3/1989, S. 132; Ittensohn, Jacques: a.a.O., S. 31 f.

578 Vgl. Kilgus, Emst: a.a.O., S. 7.

579 Vgl. Gemper, Bodo B.: a.a.O., S. 360. 
hatte. Erst seit dem Bundesbeschluß von 1975 sind alle Banken und die ihnen nach dem Bundesgesetz vom 8. November 1934 über die Banken und Sparkassen gleichgestellten Unternehmen mindestreservepflichtig580. Eine Ausnahme bilden kleine Banken mit einer Bilanzsumme von unter 20 Mio. Franken, die wegen des zu hohen Verwaltungsaufwands im Verhältnis zu dem Abschöpfungsbetrag von der Mindestreservepflicht befreit sind 581 .

Bewertung: bis $1979 \mathrm{G}$

seit 1979 D

Bis 1975 verfügten die Banken, die die Notenbank der Mindestreservepflicht unterstellen wollten, über ein Genehmigungsrecht. Aufgrund der Anordnungsbefugnis des Bundesrats lag zur Zeit des Notrechts wiederum eine Einschränkung durch Genehmigungsrecht vor, auch wenn die Nationalbank die Ausgestaltung des Instruments selbst bestimmen konnte. Seit der Revision des Nationalbankgesetzes sind nur besonders kleine Banken von der Mindestreservepflicht ausgenommen. Dies bedeutet eine technisch-institutionelle Einschränkung für die Nationalbank. Einschränkungen durch Externe gibt es nicht.

\subsection{Bemessungsgrundlagen}

Bis Ende 1975 konnte die Notenbank die Bemessungsgrundlagen für Mindestreserven nur im Rahmen freiwilliger Vereinbarungen mit den betroffenen Banken festlegen. Eine administrative Festlegung der Bemessungsgrundlage ist erst seit dem Bundesbeschluß von 1975 möglich, der jedoch die Mindestreservepolitik in die Kompetenz des Bundes stellte. Seit 1979 kann die Schweizerische Nationalbank ohne Einfluß Notenbankfremder über den Einsatz der Mindestreservepolitik und damit auch über die Bemessungsgrundlagen entscheiden. Die Mindestguthaben können nach dem Bestand und dem Zuwachs von Bankenkreditoren auf Sicht und auf Zeit, Kreditoren auf Sicht und auf Zeit, Spareinlagen, Depositen- und Einlagehefte sowie Kassenobligationen mit einer Laufzeit von weniger als 5 Jahren bemessen werden ${ }^{582}$. Eine Mindestreservepflicht auf Aktiva sieht das Gesetz nicht vor. Der Nationalbank steht es frei, treuhänderische Verpflichtungen in die Berechnung der Mindestguthaben einzubeziehen oder einzelne Bilanzpositionen auszunehmen 583 .

580 Vgl. Bundesbeschluß über Geld- und Kreditpolitik vom 19.12.1975, Art. 2 Satz 1.

581 Vgl. Zimmermann, Theo: Strukturwandel und Entwicklungstendenzen im schweizerischen Bankensystem, Suttgart 1988, S. 40 F. 1.

582 Vgl. Bundesbeschluß über Geld- und Kreditpolitik vom 19.12.1975, Art. 2 Satz 2.

583 Vgl. Bundesbeschluß über Geld- und Kreditpolitik vom 19.12.1975, Art. 2, Satz 5. 
Bewertung: bis $1979 \mathrm{G}$

seit 1979 D

Bis 1979 war das Instrument der Mindestreserve immer an ein Genehmigungsrecht notenbankfremder Instanzen gebunden, nämlich bis 1975 an das der Banken, mit denen freiwillige Übereinkommen geschlossen wurde und später an die Anordnung des Bundesrats. Die technisch-institutionellen Einschränkungen bei der administrativen Anwendung spielten hier für die Bewertung keine Rolle, weil sie durch freiwillige Vereinbarungen mit den betroffenen Banken umgangen werden konnten. Erst seit der Revision 1979 kann die Nationalbank die Bemessungsgrundlagen für die Mindestreservehaltung unter Berücksichtigung technischinstitutioneller Einschränkungen selbständig festsetzen.

\subsection{Mindestreservesatz}

Solange die Notenbank keine rechtliche Möglichkeit zur administrativen Anwendung des Mindestreserveinstruments hatte, konnte sie auch die Mindestreservesätze nicht selbständig festsetzen. Sie benötigte die Zustimmung der betroffenen Banken, sei es in der Form, daß die Banken jeder einzelnen Änderung zustimmen mußten oder daß die Notenbank innerhalb von mit den Banken vereinbarten Grenzen die Sätze frei wählen durfte. Der Bundesbeschluß von 1975 setzte für die einzelnen Verbindlichkeiten und hier jeweils nach Bestand und Zuwachs getrennte Höchstgrenzen für die Reservesätze fest, die die Notenbank einzuhalten hatte ${ }^{584}$. Auch das neue Nationalbankgesetz schreibt der Notenbank maximale Prozentsätze vor ${ }^{585}$. Innerhalb der gesetzlichen Grenzen darf sie die Mindestreservesätze sowohl nach Art und Laufzeit der Verbindlichkeiten als auch nach Zuwachs oder Bestand staffeln. Die Nationalbank ist befugt, für Einlagen von Ausländern höhere Sätze zu verlangen 586 . Externe Instanzen haben seit 1975 keinen Einfluß mehr auf die Festsetzung der Mindestreservesätze.

Bewertung: bis 1979 G

seit 1979 D

Die seit 1975 geltenden Höchstgrenzen für die Mindestreservesätze bedeuten eine technisch-institutionelle Einschränkung für die Nationalbank. Innerhalb dieser Grenzen darf die Bank ohne Einflüsse Externer die Mindestreservesätze festlegen. Die Anordnungsbefugnis des Bundesrats zur Zeit des Notrechts, die die Nationalbank erst zum Einsatz des Mindestreserveinstruments befähigte, schränkte

584 Im einzelnen siehe Bundesbeschluß über Geld- und Kreditpolitik vom 19.12.1975, Art. 2, Satz 2.

585 Vgl. Menzel, Ch.; Tanner, U.: a.a.O., S. 13.

586 Vgl. Menzel, Ch.; Tanner, U.: a.a.O., S. 13. 
die Unabhängigkeit der Bank hinsichtlich des betrachteten Kriteriums in Form eines Genehmigungsrechts ein. Die technisch-institutionelle Einschränkung aufgrund der Höchstgrenzen kam hier nicht zum Tragen, weil sie durch darüber hinausgehende freiwillige Vereinbarungen mit den betroffenen Banken hätten umgangen werden können.

\subsection{Materielle Beschaffenheit der Mindestreserven}

Auch die materielle Beschaffenheit der Mindestreserven konnte bis 1975 nicht administrativ von der Nationalbank festgelegt werden. Das Noteninstitut war auf die Zustimmung der betroffenen Banken angewiesen. Seit dem Bundesbeschluß von 1975 sind die betroffenen Banken verpflichtet, die Mindestguthaben bei der Nationalbank auf besonderen, unverzinslichen Konten zu halten ${ }^{587}$, über die sie nicht verfügen können 588 . In Ausnahmefällen darf die Nationalbank davon abgehen 589 .

\section{Bewertung: bis $1979 \mathrm{G}$}

\section{seit 1979 D}

Bis 1975 verfügten die Banken, mit denen die Nationalbank Vereinbarungen über das Halten von Mindestreserven schloß, über ein Genehmigungsrecht. Die Anordnungsbefugnis des Bundesrats bedeutete zur Zeit des Notrechts wiederum eine Einschränkung durch Genehmigungsrecht. Seit 1979 kann die Nationalbank die Ausgestaltung des Instruments unter Berücksichtigung technisch-institutioneller Einschränkungen selbst bestimmen.

\subsubsection{Zusammenfassende Beurteilung der funktionellen Unabhängigkeit der Schweizerischen Nationalbank}

Aufgrund der oben ermittelten Werte für die in Abb. 5 aufgeführten 16 Instrumente ergibt sich sowohl für den Zeitraum bis 1979 als auch nach 1979 ein Zentralwert in Höhe von D. Damit ist die Schweizerische Notenbank funktionell eher unabhängig.

\subsection{USA}

Die gesetzlichen Bestimmungen über das Notenbankwesen in den USA sind im Federal Reserve Act festgelegt. Es gibt keine zentrale Notenbank, sondern ein

587 Vgl. Bundesbeschluß über Geld- und Kreditpolitik vom 19.12.1975, Art. 2, Satz 1.

588 Vgl. Mader, Richard:a.a.O., S. 132.

589 Vgl. Bundesbeschluß über Geld- und Kreditpolitik vom 19.12.1975, Art. 2, Satz 6. 
zweistufiges Notenbanksystem (Federal Reserve System = FRS), bestehend aus zwölf Federal Reserve Banks und der verwaltungsmäßigen Spitze in Washington, dem Board of Governors ${ }^{590}$. Trotz der föderalen Struktur konzentriert sich die Befehlsgewalt auf den Board, während die Federal Reserve Banken lediglich ausführende Organe sind, die Banknoten ausgeben und auch die sonstigen Notenbankgeschäfte führen ${ }^{591}$. Der Kurs der Offenmarktpolitik wird von dem zwölfköpfigen Federal Open Market Committee (FOMC) bestimmt, in dem jedoch die Mitglieder des Boards die Stimmenmehrheit stellen ${ }^{592}$. Insofern ist die Frage der Ernennungsinstanzen nur für das Zentralorgan in Washington interessant.

\subsubsection{Personelle Unabhängigkeit}

\subsubsection{Ernennungsinstanzen (Ebene 1)}

Die sieben Mitglieder des Boards werden vom Präsidenten der Vereinigten Staaten mit Zustimmung des Senats ernannt ${ }^{593}$. Das FRS hat also keinen Einfluß auf die personelle Besetzung ihres Leitungsorgans.

\section{Fazit:}

Das FRS kann nicht die Entscheidungsmehrheit des Board of Governors ernennen.

\subsubsection{Abberufungsinstanzen (Ebene 2)}

Der Präsident der USA kann Mitglieder des Federal Reserve Board mit Zustimmung des Senats abberufen 594 .

\section{Fazit:}

Das FRS ist weder entscheidende Abberufungsinstanz noch kann sie Abberufungen des Präsidenten der USA durch ein Vetorecht verhindern. Damit sind die näheren Abberufungsmodalitäten und Wiederernennungsvorschriften für die Bewertung der personellen Unabhängigkeit des FRS nicht von Bedeutung.

590 Vgl. Spindler, Joachim v.; Becker, Willy; Starke, O.-Ernst (1973): a.a.O., S. 15.

591 Vgl. Geiger, Helmut: Aspekte einer gemeinsamen Europäischen Notenbank, in: Sparkasse 5/89, S. 201.

592 Vgl. Englert, Michael: a.a.O., S. 22.

593 Vgl. Section 10, Article 1 of the Federal Reserve Act.

594 Vgl. Hahn, Oswald (1968) Bd. II: a.a.O., S. 229. 


\subsubsection{Kreis der Ernennungsfahigen (Ebene 6)}

Das Gesetz sieht für die Mitglieder des Board keine besondere fachliche Eignung vor, ordnet aber an, daß jeweils immer nur ein Mitglied aus einem Federal Reserve District ernannt werden darf und, daß der Präsident für eine angemessene Vertretung der Interessen des Geld- und Kreditwesens, der Landwirtschaft, der Industrie und des Handels sowie der Regionen des Landes zu achten hat ${ }^{595}$. Dem Board of Governors dürfen ferner keine Senatoren und Angehörigen des Repräsentantenhauses angehören 596 .

Die Besoldungshöhe für die Mitglieder des Währungsrats ist gesetzlich festgelegt 597 .

Fazit:

Der Kreis der Ernennungsfähigen ist durch gesetzliche Regelungen eingegrenzt. Das FRS kann keinen Einfluß auf den Kreis der Ernennungsfähigen nehmen.

\subsubsection{Beurteilung der personellen Unabhängigkeit}

Das FRS ist personell völlig abhängig. Es erreicht mit Ziffer 26 die letzte Bewertungsstufe des Entscheidungsbaums in Abb. 1 und damit den Bewertungsgrad abhängig.

\subsubsection{Funktionelle Unabhängigkeit}

\subsubsection{Instrumentenübergreifende Regelungen}

Der Federal Reserve Board ist explizit bei der Bestimmung und Durchführung der Geldpolitik unabhängig von der Regierung598. Er ist dem Kongreß gegenüber verantwortlich und muß diesem zweimal jährlich Bericht erstatten ${ }^{599}$. Weil die Position der Zentralbank auf einer Delegation der Macht des Kongresses beruht, behält dieser sich das Recht vor, der Bank Empfehlungen zu geben, ohne jedoch eine direkte Weisungsbefugnis zu besitzen 600 .

595 Vgl. Braun, Karlpeter: a.a.O., S. 128.

596 Vgl. Hahn, Oswald (1968) Bd. II: a.a.O., S. 129.

597 Vgl. Section 10, Article 1 of the Federal Reserve Act.

598 Vgl. Siebelt, Johannes: a.a.O., S. 240.

599 Vgl. Boreham, Gordon F.; Bodkin, Ronald G.: Money, Banking and Finance, The Canadian context, Toronto Ontario 1988, S. 193.

600 Vgl. Swinburne, Mark; Castello-Branco, Marta: a.a.O., S. 21. 
Das Gesetz enthält keine Verpflichtung der Notenbank, die Wirtschaftspolitik der Regierung zu unterstützen601. In der Praxis sorgen jedoch häufige Kontakte und Zusammenkünfte von Regierungs- und Notenbankvertretern für die notwendige Koordinierung von Notenbankpolitik und der allgemeinen Wirtschafts- und Finanzpolitik 602 . Es gibt in den USA keine Instanz, die einen Konflikt zwischen beiden Bereichen lösen könnte, so daß die Koordination allein vom guten Willen der Beteiligten abhängt ${ }^{603}$. In $\S 10$ des Federal Reserve Act findet sich eine Bestimmung, die besagt, daß in den Fällen, in denen die Befugnisse des Board of Governors mit denen des Schatzamtes in Widerspruch stehen, die der Notenbank zustehenden Befugnisse unter der Überwachung und Kontrolle des Schatzamtes auszuüben sind 604 . Da jedoch kaum die Befugnisse, sondern vielmehr unterschiedliche Ansichten über die zu verfolgende Politik die Ursache von Konflikten sind, ist diese Bestimmung für die Praxis völlig unbedeutend und wurde auch nie zur Lösung eines Konfliktes herangezogen605. Die Tatsache, daß diese Bestimmung in der amerikanischen Literatur kaum erwähnt wird und die Unabhängigkeit des Federal Reserve Systems gegenüber dem Schatzamt betont wird, bestätigt die Bedeutungslosigkeit dieser Regelung606.

Das Kapital der Federal Reserve Banken wird von Geschäftsbanken gehalten, die dadurch zu Mitgliedsbanken des Zentralbanksystems werden607. Während die National Banks zum Beitritt verpflichtet sind, ist den State Banks die Mitgliedschaft freigestellt ${ }^{608}$. Die Teilhaberschaft der Mitgliedsbanken impliziert nicht die Rechte, die Aktionären üblicherweise zustehen609. Die Banken verfügen weder über Weisungs- noch Genehmigungs- oder Vetorechte gegenüber den für geldpolitische Entscheidungen zuständigen Gremien 610 .

Das Federal-Reserve-Gesetz enthält keine systematische Darstellung der Befugnisse des Boards oder eine Aufstellung der währungspolitischen Instrumente611. Es gibt lediglich einen relativ unbestimmten Rahmen vor, innerhalb dessen der Board tätig werden kann612. Dem Board fällt damit die Verantwortung für die

\footnotetext{
601

Vgl. Siebelt, Johannes: a.a.O., S. 240.

603 Vgl. Bernauer, Engelbert: a.a.O., S. 97.

603 Vgl. Bernauer, Engelbert: a.a.O., S. 97

604 Vgl. Braun, Karlpeter: a.a.O., S. 147.

605 Vgl. Bernauer, Engelbert: a.a.O., S. 96.

606 Vgl. Braun, Karlpeter: a.a.O., S. 147.

607 Vgl. Braun, Karlpeter: a.a.O., S. 125.

608 Vgl. Braun, Karlpeter: a.a.O., S. 142f.

609 Vgl. Englert, Michael: a.a.O., S. 134.

610 Vgl. Caesar, Rolf (1981): a.a.O., S. 264.

611 Vgl. Braun, Karlpeter: a.a.O., S. 130.

612 Vgl. Braun, Karlpeter: a.a.O., S. 130.
} 
Auslegung und Ergänzung des Gesetzes zu ${ }^{613}$. Er gibt dazu regulations heraus, die das Gesetz interpretieren 614 .

Zusammenfassend läßt sich festhalten, daß die funktionelle Unabhängigkeit des FRS durch keine instrumentenübergreifenden Regelungen beeinträchtigt ist.

\subsubsection{Ausgabe von Zentralbankgeld durch die Notenbank}

\subsection{Art der Kreditnehmer}

Wenn eine andere Form der Mittelbeschaffung nicht besteht, dürfen die Reservebanken Noten, Ziehungen und Wechsel für natürliche Personen und Gesellschaften diskontieren sowie direkte Darlehen an Industrie- oder Handelsfirmen gewähren 615 .

Diskontkredite konnten bis 1980 nur an Mitgliedsbanken gewährt werden616. Da den State Banks im Gegensatz zu den National Banks die Mitgliedschaft freigestellt ist, konnten sie selbst darüber entscheiden, ob sie durch eine Mitgliedschaft zu potentiellen Kreditnehmern beim FRS wurden617. Mit dem am 31.3.1980 von Präsident Carter unterzeichneten Depository Institutions Deregulation and Monetary Control Act erhielten auch non-member-banks Zugang zu Rediskontkrediten der Notenbank 618 .

\section{Bewertung: A}

Das FRS unterliegt hinsichtlich der Art ihrer Kreditnehmer keinerlei Beschränkungen. Die Tatsache, daß bis 1980 nur Mitgliedsbanken des FRS Diskontkredite in Anspruch nehmen konnten, war keine technisch-institutionelle Einschränkung für die Notenbank, weil es jeder Bank offenstand, freiwillig Mitglied und damit kreditberechtigt zu werden. Eine Notenbank kann letztendlich nur den Banken Kredit gewähren, die mit ihrem Kreditwunsch an sie herantreten.

\footnotetext{
613 Vgl. Braun, Karlpeter: a.a.O., S. 130.

614 Vgl. Braun, Karlpeter: a.a.O., S. 131.

$615 \mathrm{Vgl}$. Section 13 of the Federal Reserve Act.

616 Vgl. Englert, Michael: a.a.O., S. 19.

617 Zudem können die Geschäftsbanken problemlos ihren Status als National Bank in den

618 Vgl. Englert, Michael: a.a.O., S. 19. einer State Bank umwandeln und umgekehrt, Vgl. Englert, Michael: a.a.O., S. 53.
} 


\subsection{Umfang}

Banken können bei der Notenbank Kredite auf dem Wege der Rediskontierung und der Lombardierung aufnehmen 619 . In den USA gibt es keine offiziellen Grenzen für Rediskontkontingente ${ }^{620}$. Einen Anspruch auf Refinanzierung haben die Banken nicht ${ }^{621}$.

Eine Kreditgewährung des FRS an den Staat über den Direktankauf von Staatspapieren beim Schatzamt ist bis zu einer festgelegten Höhe gestattet 622 . Eine Verpflichtung zur Finanzierung der öffentlichen Haushalte gibt es nicht 623 . Neben der Begrenzung des Erstankaufs von Staatspapieren durch die Notenbank gibt seit 1917 eine Obergrenze für Federal Debt unabhängig von der Finanzierungsart ${ }^{624}$. Die ursprüngliche Grenze des Second Liberty Bond Act of 1917 wurde im Laufe der Jahre regelmäßig erhöht ${ }^{625}$. Da die Begrenzung der Staatsschuld bei der Notenbank unabhängig von der Finanzierungsart gilt, betrifft sie neben der direkten Staatsfinanzierung auch offenmarktpolitische Operationen mit Staatspapieren sowie Ankäufe oder Beleihung von Staatspapieren zu Refinanzierungszwecken 626 .

Die Notenbank ist verpflichtet, den Mitgliedsbanken aus dem Jahresgewinn eine kumulative Dividende von 6\% auszuschütten 627 . Ein Teil des Gewinns wird zur Stärkung der Rücklagen eingehalten 628 . Der Restbetrag muß an das Schatzamt abgeführt werden ${ }^{629}$. Die Notenbank ist dadurch zu einer festgelegten Ausgabe von Zentralbankgeld verpflichtet, auf die weder sie noch eine externe Instanz Einfluß nehmen kann.

\section{Bewertung: D}

Technisch-institutionelle Einschränkungen liegen aufgrund der Grenzen bei der direkten Staatsfinanzierung sowie der Regelungen zur Gewinnverwendung vor. Einflußrechte durch Externe gibt es keine.

\footnotetext{
619 Vgl. Haase, Heidrun: Die Lombardpolitik der Zentralnotenbanken, Berlin 1962, S. 119.

620 Vgl. Caesar, Rolf (1981): a.a.O., S. 271.

621 Vgl. Haase, Heidrun: a.a.O., S. 119.

622 Vgl. Veit, Otto (1961), a.a.O., S. 680.

623 Vgl. Caesar, Rolf (1982): a.a.O., S. 571.

624 Vgl. Hahn, Oswald (1968) Bd. II: a.a.O., S. 180.

625 Vgl. Hahn, Oswald (1968) Bd. II: a.a.O., S. 180.

626 Vgl. Caesar, Rolf (1982): a.a.O., S. 571.

$627 \mathrm{Vgl}$. Section 7, Article 1 of the Federal Reserve Act.

628 Vgl. Wettlaufer, Hans-Dieter: Der Gewinn der Notenbank in volkswirtschaftlicher Sicht, Idstein 1987, S. 63.

629 Vgl. Englert, Michael: a.a.O., S. 24.
} 


\subsection{Zinssatz}

Das FRS kann die Zinssätze für ihre Kreditvergabe selbständig festsetzen. Die Diskontsätze bestimmt jede Federal Reserve Bank für sich, so daß innerhalb der USA unterschiedliche Sätze zur Anwendung kommen können630. Vor Inkrafttreten der Sätze ist jedoch die Zustimmung des Board of Governors notwendig, der die Federal Reserve Banken auch zu einer Änderung der Sätze veranlassen kann631.

\section{Bewertung: A}

Das FRS hat bei der Festsetzung ihrer Kreditzinsen völlig freie Hand. Es gibt keine Einflußrechte Externer.

\subsection{Bedingungen}

Der Federal Reserve Act von 1913 sah eine Kreditgewährung ausschließlich mittels Diskontierung von Handelswechseln vor ${ }^{632}$. Da der Handelswechsel in den USA wenig gebräuchlich ist, wurde später auch eine Gewährung von Darlehen gegen Solawechsel, die entweder von den Bankkunden oder der Bank selbst ausgestellt sind, gestattet ${ }^{633}$. Das Gesetz enthält Vorschriften hinsichtlich der maximalen Laufzeit der Kredite sowie nähere Regelungen zu den Sicherheiten, gegen die das FRS Kredite gewähren darf634.

\section{Bewertung: D}

Technisch-institutionelle Einschränkungen liegen insofern vor, als das Gesetz nähere Regelungen zu den Laufzeiten von Krediten sowie den Werten trifft, die das FRS als Kreditsicherheiten akzeptieren darf. Einschränkungen durch Externe liegen nicht vor.

\subsubsection{Direkte Einflußnahme auf die Kreditvergabe der Banken}

\subsection{Art der Kreditnehmer}

Das FRS hat keine Möglichkeit administrativ auf die Art der Kreditnehmer der Banken Einfluß zu nehmen. Zum Zwecke des Verbraucherschutzes gibt es in den USA Gesetze, die die Diskriminierung von Personen bei der Kreditvergabe der

\footnotetext{
630 Vgl. Braun, Karlpeter: a.a.O., S. 132.

631 Vgl. Braun, Karlpeter: a.a.O., S. 132.

632 Vgl. Haase, Heidrun: a.a.O., S. 121.

633 Vgl. Haase, Heidrun: a.a.O., S. 121.

634 Vgl. Haase, Heidrun: a.a.O., S. $125 \mathrm{ff}$.
} 
Banken wegen ihrer Rasse, ihres Alters, Religion, Familienstands oder anderer Eigenschaften verbietet ${ }^{635}$. Es liegen daher keine technisch-institutionellen Einschränkungen vor, die die Notenbank beim Treffen freiwilliger Vereinbarungen mit den Banken oder potentiellen Kreditnehmern berücksichtigen müßte.

Bewertung: $\mathrm{G}$

Das FRS kann die Art der Kreditnehmer nur im Rahmen freiwilliger Vereinbarungen mit Banken oder deren potentiellen Darlehensnehmern beeinflussen. Technisch-institutionelle Beeinträchtigungen gibt es keine.

\subsection{Umfang}

1969 ermächtigte der Kongreß die Notenbank zu weitreichenden Kreditkontrollen636. Das FRS kann seither nach ausdrücklicher Bewilligung durch den Präsidenten der Vereinigten Staaten quantitative Limits für sämtliche Kreditkategorien festsetzen637.

Ferner gibt es zahlreiche gesetzliche Bestimmungen im Rahmen der Bankenaufsicht, die die Kreditvergabe der Banken direkt begrenzen, wie z. B. die Begrenzung von Großkrediten auf ein Vielfaches des haftenden Eigenkapitals 638 .

\section{Bewertung: $\mathrm{H}$}

Das Recht zur administrativen Anwendung von Kreditbegrenzungen ist durch das Genehmigungsrecht des Präsidenten gemindert. Technisch-institutionelle Einschränkungen liegen aufgrund der gesetzlichen Regelungen im Rahmen der Bankenaufsicht vor.

\subsection{Zinssatz}

Das FRS ist seit 1969 autorisiert, auf Ersuchen des Präsidenten für sämtliche Kreditkategorien Höchstzinssätze festzulegen 639 .

\footnotetext{
635 Vgl. Hütz, Gerhard: Die Bankenaufsicht in der Bundesrepublik Deutschland und in den USA: Ein Rechtsvergleich, Berlin 1990, S. 180.

636 Vgl. o. V.: USA: Ermächtigung zu Kreditkontrollen, in: Neue Züricher Zeitung, Zürich, vom 23. Dezember 1969, abgedruckt in: Deutsche Bundesbank: Auszüge aus Presseartikeln, Nr. 101 vom 30.12.1969, S. 5.

637 Vgl. o. V.: USA: Ermächtigung zu Kreditkontrollen: a.a.O., S. 5.

638 Vgl. Hütz, Gerhard: a.a.O., S. $172 \mathrm{f}$.

639 Vgl. o. V.: USA: Ermächtigung zu Kreditkontrollen: a.a.O., S. 5.
} 


\section{Bewertung: G}

Die Bindung der Befugnis der Bank zur Festlegung von Höchstzinssätzen an die Billigung des Präsidenten der Vereinigten Staaten bedeutet für die Notenbank eine Einschränkung in Form eines Genehmigungsrechts.

\subsection{Bedingungen}

Der Board of Governors ist befugt, sogenannte Margin Requirements festzulegen $^{640}$. Dabei handelt es sich um Beleihungsgrenzen für die Beleihung von auf Kreditbasis erworbenen Wertpapieren. Eine Festsetzung der Margin Requirements auf 100 Prozent bedeutet, daß eine Beleihung der betroffenen Wertpapiere ausgeschlossen ist 641 . Die Notenbank kann zwischen einer Nichtbeleihungsgrenze von 25 - 100\% für verschiedene Wertpapiergattungen und zwischen verschiedenen Verleihern wählen 642 .

Ferner ist das FRS ermächtigt, auf Ersuchen des Präsidenten der Vereinigten Staaten für sämtliche Kreditarten Fälligkeiten vorzuschreiben ${ }^{643}$. Diesbezüglich ist die Bank von der Genehmigung Externer abhängig.

Bewertung: D

Die Notenbank kann nur im Bereich der Sicherheiten für Kredite zum Erwerb von Wertpapieren völlig selbständig auf die Kreditbedingungen der Banken Einfluß nehmen. Das bedeutet für das FRS eine technisch-institutionelle Einschränkung. In allen anderen Bereichen ist sie auf freiwillige Vereinbarungen mit den Banken oder Kreditnehmern und damit auf deren Genehmigung angewiesen oder von der Billigung des Präsidenten abhängig.

\subsubsection{Offenmarktpolitik}

Das FRS ist seit 1913 ermächtigt Offenmarktgeschäfte zu betreiben 644 . Die Richtlinien dafür legt das FOMC fest, das aus den sieben Mitgliedern des Board of Governors sowie fünf Mitgliedern der Federal Reserve Banks besteht.

\subsection{Art und Gegenstand des Geschäfts}

Die amerikanische Notenbank tätigt Offenmarktgeschäfte sowohl auf dem Geldals auch auf dem Kapitalmarkt ${ }^{645}$. Die Wertpapiere, mit denen sie Offenmarkt-

640 Vgl. Boreham, Gordon F.; Bodkin, Ronald G.: a.a.O., S. 254.

641 Vgl. Braun, Karlpeter: a.a.O., S. 132.

642 Vgl. Englert, Michael: a.a.O., S. 37.

643 Vgl. o. V.: USA: Ermächtigung zu Kreditkontrollen: a.a.O., S. 5.

644 Vgl. Caesar, Rolf (1981): a.a.O., S. 270. 
politik betreiben darf, sind im Federal Reserve Act in Section 14 festgelegt 646 . Die Offenmarktpolitik mit Wertpapieren erstreckt sich in erster Linie auf den Kauf und Verkauf von durch die Bundesregierung emittierten Bundesschuldverschreibungen ${ }^{647}$. Sie darf ferner mit Gold sowie seit 1962 auf heimischen und ausländischen Kassa- und Terminmärkten mit Devisen handeln648. Hinsichtlich der Kategorien von Offenmarktgeschäften unterliegt die Federeal Reserve keinen Beschränkungen.

\section{Bewertung: D}

Der im Federal Reserve Act festgelegte Katalog der zu Offenmarktoperationen zugelassenen Wertpapiere bedeutet eine technisch-institutionelle Einschränkung durch gesetzliche Festlegung der Wertpapiere. Einflußrechte notenbankfremder Instanzen auf Art und Gegenstand von Offenmarktgeschäften liegen nicht vor.

\subsection{Umfang}

Die oben angesprochene, unabhängig von der Finanzierungsart geltende Obergrenze für "Federal Debt" betrifft auch offenmarktpolitische Operationen mit Staatspapieren ${ }^{649}$. Sie stellt somit eine technisch-institutionelle Einschränkung für die Notenbank dar.

Mit dem Eintritt der USA in den Zweiten Weltkrieg traf die Notenbank mit dem Schatzamt eine Vereinbarung, in der sie sich verpflichtete, die Zinssätze für Regierungsanleihen auf niedrigem Niveau zu halten 650 . Das bedeutete, daß sie zur Kursstützung unbeschränkt Staatsanleihen ankaufen mußte und dadurch weitgehend die Kontrolle über die Geldmenge verlor 651 . Diese Kursstützungen wurde auch nach dem Zweiten Weltkrieg fortgesetzt ${ }^{652} .1951$ stellte eine weitere Übereinkunft mit dem Schatzamt, der sog. Accord von 1951, die Bank von diesen Verpflichtungen frei653. Auch heute noch arbeitet die Notenbank eng mit dem Schatzamt zusammen, dergestalt, daß die Bank in der Regel den Plazierungswün-

645 Vgl. OECD: Monetary Policy in the United States, OECD Monetary Studies Series, Paris 1974 , S. $43 \mathrm{f}$.

646 Vgl. The New York Clearing House Association: The Federal Reserve Re-Examined, New York 1953, S. 52.

647 Vgl. Englert, Michael: a.a.O., S. 34.

648 Vgl. Section 14, Article 2 of the Federal Reserve Act; Guba, Jürgen: Der Wandel der amerikanischen Notenbankpolitik, Frankfurt am Main 1989, S. 252.

649 Vgl. Hahn, Oswald (1968) Bd. II: a.a.O., S. 180.

650 Vgl. Englert, Michael: a.a.O., S. 17.

651 Vgl. Englert, Michael: a.a.O., S. 17.

652 Vgl. Englert, Michael: a.a.O., S. 17.

653 Vgl. Englert, Michael: a.a.O., S. 17. 
schen der Treasury durch entsprechende offenmarktpolitische Maßnahmen nachkommt und dadurch auch die Zinslast für den Staat in Grenzen hält654. Die Entscheidungsfreiheit darüber liegt jedoch alleine beim FRS, so daß daraus keine Einschränkung der Unabhängigkeit erwächst.

\section{Bewertung: D}

Die Obergrenze für Federal Debt bedeutet eine technisch-institutionelle Einschränkung hinsichtlich des Umfanges von Offenmarktoperationen. Einschränkungen durch Externe liegen nicht vor.

\subsection{Preis}

Offenmarktoperationen mit Wertpapieren werden überwiegend auf dem Auktionsweg durchgefuihrt ${ }^{655}$. Dazu holt die Federal Reserve Angebote von den Dealern ein und entscheidet sich für einen bestimmten Zinssatz mit dem sich daraus automatisch ergebendem Volumen oder ein bestimmtes An- oder Verkaufsvolumen mit dem dazugehörigem Zuteilungssatz ${ }^{656}$. Die Zuteilung erfolgt nach dem amerikanischen Verfahren; das bedeutet, da $B$ der genannte Bietungssatz auch zu zahlen ist ${ }^{657}$. Interventionen auf dem Devisenmarkt erfolgen zu Marktpreisen 658 .

\section{Bewertung: A}

Hinsichtlich der Preisgestaltung bei Offenmarktgeschäften unterliegt das FRS keinerlei Beschränkungen.

\subsection{Handelspartner}

Der Offenmarktausschuß übermittelt nach jeder Sitzung seinem Mandatar, der Federal Reserve Bank of New York, eine Richtlinie mit dem jeweiligen offenmarktpolitischen Kurs 659 . Der Federal Reserve Bank of New York obliegt die Durchführung der Offenmarktpolitik. Sie schließt die Geschäfte prinzipiell mit einem festen Kreis von Wertpapierhändlern, den sogenannten Primary Dea-

654 Vgl. Englert, Michael: a.a.O., S. 101.

655 Vgl. Guba, Jürgen: a.a.O., S.245.

656 Vgl. Guba, Jürgen: a.a.O., S.245f.

657 Vgl. Guba, Jürgen: a.a.O., S.245.

658 Vgl. Guba, Jürgen: a.a.O., S.252.

$659 \mathrm{Vgl}$. Heller, H. Robert: Notenbanksystem und Geldpolitik in den USA, in: Zeitschrift für Wirtschaftspolitik 37. Jahrg. 1988, S. 109. 
lern660. Die amerikanische Notenbank darf Offenmarktgeschäfte jedoch mit inund ausländischen Banken, Unternehmen oder Privaten abschließen661.

Bewertung: A

Das FRS unterliegt hinsichtlich der Auswahl der Handelspartner für Offenmarktgeschäfte keinerlei Beschränkungen.

\subsubsection{Mindestreservepolitik}

\subsection{Reservepflichtige Institute}

Mit dem am 31.3.1980 von Präsident Carter unterzeichneten Depository Institutions Deregulation and Monetary Control Act wurde die Mindestreservepflicht nicht mehr auf Mitgliedsbanken beschränkt, sondern auf alle Bankinstitute ausgedehnt 662 . V. a. in den Siebziger Jahren verließen viele State Banks aus Wettbewerbsgründen das System und konnten somit die Reservehaltung senken, weil für sie dann die deutlich niedrigere Mindestreservepflicht der Bundesstaaten galt 663 . Mit dem International Banking Act 1978 sind auch Zweigstellen und Filialen ausländischer Banken mindestreservepflichtig664.

Bewertung: bis $1980 \mathrm{D}$

seit 1980 A

Die Beschränkung der Reservepflicht bis 1980 auf Mitgliedsbanken stellte für das FRS eine technisch-institutionelle Einschränkung dar. Seit 1980 ist die Zentralbank in der Auswahl reservepflichtiger Kreditinstitute nicht mehr behindert.

\subsection{Bemessungsgrundlagen}

Das Mindestreservesystem der USA ist passivseitig665. Die Banken sind verpflichtet, einen bestimmten Prozentsatz ihrer Sicht- und Termindepositen als Mindestreserve zu halten 666 .

660 Vgl. Guba, Jürgen: a.a.O., S. 244.

661 Vgl. Section 14, Article 1 of the Federal Reserve Act

662 Vgl. Englert, Michael: a.a.O., S. 19.

663 Die niedrigere Mindestreservebelastung ergab sich daraus, daß die Reserven auch in Form von Staatspapieren und Interbankeinlagen gehalten werden konnten, d.h. verzinslich, Vgl. Mader, Richard:a.a.O., S. 129.

664 Vgl. Puckler, Godehard: Das Bank- und Börsenwesen in den USA, 2. Aufl., Frankfurt/Main 1986, S. 16.

665 Vgl. Mader, Richard:a.a.O., S. 128. 


\section{Bewertung: D}

Die Beschränkung der mindestreservepflichtigen Positionen auf die Passivseite bedeutet für das FRS eine technisch-institutionelle Einschränkung.

\subsection{Mindestreservesatz}

Die Mindestreservesätze legt der Board of Governors fest ${ }^{667}$. Der Board kann die Sätze nach Art und Höhe der einzelnen Arten der reservepflichtigen Verbindlichkeiten staffeln, um der spezifisch amerikanischen Bankenstruktur gerecht $\mathrm{zu}$ werden 668 . Dabei legt das Gesetz für die einzelnen Arten von Verbindlichkeiten jeweils Ober- und Untergrenzen für die Reservesätze fest, innerhalb deren der Board of Governors frei entscheiden kann 669 .

\section{Bewertung: D}

Die Unter- und Obergrenzen der Mindestreservesätze schränken die Unabhängigkeit der Notenbank bzgl. dieses Instruments in technisch-institutioneller Hinsicht ein. Einflußrechte Externer liegen nicht vor.

\subsection{Materielle Beschaffenheit der Mindestreserven}

Ursprünglich waren die Banken verpflichtet, ihre Mindestreserven als Guthaben beim FRS zu halten 670 . Seit 1959 ist die Notenbank ermächtigt, auch eine Reservehaltung in Bargeld zu dulden671.

\section{Bewertung: D}

Mindestreservehaltung ist nur in Form von Guthaben bei der Notenbank oder Bargeld möglich. Das bedeutet für die Notenbank eine technisch-institutionelle Einschränkung. Einflußrechte Externer hinsichtlich der Art der Mindestreservehaltung liegen nicht vor.

666 Vgl. Donner, O.: Mindestreservenpolitik in den USA, in: Zeitschrift für das gesamte Kreditwesen, 18/1952, S. 467.

667 Vgl. Siebelt, Johannes: a.a.O., S. 239f.

668 Vgl. Englert, Michael: a.a.O., S. 36.

669 Vgl. Young, Ralph A.: a.a.O., S. 125.

670 Vgl. Donner, O.: a.a.O., S. 467.

671 Vgl. Furth, Herbert J.: International Regulations and the Federal Reserve System, in: Prochnow, Herbert V. (Ed.): The Federal Reserve System, New York 1960, S. 81. 


\subsubsection{Zusammenfassende Beurteilung der funktionellen Unabhängigkeit des Federal Reserve Systems}

Aufgrund der oben ermittelten Werte für die in Abb. 5 aufgeführten geldpolitischen Instrumente ergibt sich sowohl für den Zeitraum bis 1981 als auch nach 1981 ein Zentralwert von D. Damit ist das Federal Reserve System funktionell eher unabhängig.

\subsection{Italien}

Die Banca d'Italia mit Sitz in Rom erhielt 1926 erstmalig den Charakter einer Zentralbank mit besonderen Befugnissen gegenüber den anderen Banken672. Sie ist seit 1936 eine juristische Person öffentlichen Rechts, deren Kapital jedoch in Namensaktien aufgeteilt ist, die von bestimmten Banken und Versicherungen erworben werden können673. Ihre Organe sind die Generalversammlung der Anteilseigner, der Zentrale Verwaltungsrat und der Verwaltungsrats-Ausschuß sowie der Gouverneur, der Generaldirektor und der Vizegeneraldirektor 674 . Intern beaufsichtigt wird die Verwaltung vom Revisionsrat und von den Zensoren675. Die Beiräte und Direktoren der Zweigstellen sind die ausführenden Außenorgane 676 . Die geldpolitischen Handlungsbefugnisse der Banca d'Italia konzentrieren sich uneingeschränkt in der Person des Gouverneurs als höchstem Exekutivorgan der Bank ${ }^{677}$. Dabei wird er vom Generaldirektor und Vizegeneraldirektor unterstützt, die ihn in allen Funktionen bei Abwesenheit oder Verhinderung vertreten 678 . Über die Aufteilung der Arbeit unter den dreien enthält die Satzung nur allgemeine Richtlinien, so daß alle drei Mitglieder der Exekutive als entscheidungstreffende Instanz betrachtet werden können und damit als das für die Beurteilung der personellen Unabhängigkeit interessante Gremium.

672 Vgl. Bank für Internationalen Zahlungsausgleich Basel (Hrsg.): a.a.O., S. 247.

673 Vgl. Il Codice Bancario Fascista. Disposizioni per la difesa del risparmio e per la disciplina della funzione creditizia (Regio decreto-legge 12 marzo 1936-XIV, n. 375) Art. 20.

674 Vgl. Bank für Internationalen Zahlungsausgleich Basel: a.a.O., S. 254.

675 Vgl. Bank für Internationalen Zahlungsausgleich Basel: a.a.O., S. 254.

676 Vgl. Bank für Internationalen Zahlungsausgleich Basel: a.a.O., S. 254.

677 Vgl. Merusi, Fabio: Die verfassungsrechtliche Stellung der Zentralbank in Italien, in: Instrumente der sozialen Sicherung und der Währungssicherung in der Bundesrepublik Deutschland und in Italien, Beiheft 5 zu "Der Staat", Berlin 1981, S. 97.

Vgl. Bank für Internationalen Zahlungsausgleich Basel: a.a.O., S. $260 \mathrm{ff}$. 


\subsubsection{Personelle Unabhängigkeit}

\subsubsection{Ernennungsinstanzen (Ebene 1)}

Gouverneur, Generaldirektor und Vizegeneraldirektor werden vom Verwaltungsrat der Bank ernannt. Dazu bedarf es einer notwendigen Anwesenheit von mindestens zwei Dritteln der Mitglieder des Verwaltungsrats sowie zustimmendes Votum von mindestens zwei Dritteln der Anwesenden 679. Ferner ist die Zustimmung der Regierung mittels Präsidialerlaß erforderlich, und zwar auf Vorschlag des Ministerpräsidenten in Abstimmung mit dem Schatzminister und nach Anhörung des Ministerrates 680 . Dem Ministerrat obliegt somit nur eine hindernde Aufsichtsbefugnis ${ }^{681}$. Der Verwaltungsrat besteht aus dem Gouverneur der Bank sowie zwölf weiteren Mitgliedern, die in der Generalversammlung der Aktionäre bei den Hauptzweigstellen der Bank gewählt werden 682 . Das bedeutet, daß die Exekutive von einem Organ der Notenbank ernannt wird. Die Regierung kann lediglich durch Verweigerung ihrer Zustimmung die Ernennung einzelner Persönlichkeiten verhindern.

Fazit:

Die Notenbank kann die Entscheidungsmehrheit ernennen.

\subsubsection{Abberufungsinstanzen (Ebene 2)}

Abberufungen erfolgen auf dem gleichen Wege wie Ernennungen. Der Zentrale Verwaltungsrat kann Abberufungen nach Genehmigung des Ministerpräsidenten im Einvernehmen mit dem Schatzminister und nach Anhörung des Ministerrates vornehmen ${ }^{683}$. Auch hier ist ein Gremium der Notenbank die eigentliche entscheidende Instanz, wobei den Regierungsvertretern faktisch ein Vetorecht zukommt.

Fazit:

Die Notenbank ist die entscheidende Abberufungsinstanz.

679 Vgl. Merusi, Fabio: a.a.O., S. 91.

680 Vgl. Merusi, Fabio: a.a.O., S. 96.

681 Vgl. Merusi, Fabio: a.a.O., S. 91.

682 Vgl. Bank für Internationalen Zahlungsausgleich Basel: a.a.O., S. 256.

683 Vgl. Bank für Internationalen Zahlungsausgleich Basel: a.a.O., S. 268. 


\subsubsection{Ernennungs- und Abberufungsmodalitäten (Ebene 3)}

Die Abberufungsinstanz verfügt über eine jederzeitige Abberufungsmöglichkeit 684 . Ebenso wie bei den Ernennungen bedürfen Amtsenthebungen der $\mathrm{Zu}$ stimmung der Regierungsvertreter ${ }^{685}$. Diese verfügen somit über ein Vetorecht.

Fazit:

Das Vetorecht externer Instanzen bzgl. Ernennungen und Abberufungen verhindert willkürliche Abberufungen.

\subsubsection{Wiederernennungsvorschriften (Ebene 5)}

Wiederemennungsvorschriften sind bei der Banca d'Italia insofern überflüssig, als die Verträge der Notenbankleitung unbefristet sind 686.

Fazit:

Wiederernennungen sind nicht möglich.

\subsubsection{Kreis der Ernennungsfahigen (Ebene 6)}

Die Mitglieder der Notenbankleitung müssen italienische Staatsbürger sein 687 . Sie dürfen weder in der freien Wirtschaft tätig sein noch dürfen sie irgendein anderes politisches Amt bekleiden688. Der Verwaltungsrat vereinbart die Bezüge der Notenbankleitung sowie die sonstigen Bedingungen 689 . Diese Vereinbarungen bedürfen der Zustimmung der Regierung690.

Fazit:

Der Kreis der Ernennungsfähigen ist von außen beschränkt.

\subsubsection{Beurteilung der personellen Unabhängigkeit}

Die personelle Unabhängigkeit der Banca d' Italia ist mit Ziffer 8 auf der Bewertungsskala weitgehend gewahrt. Die Bank ist personell unabhängig.

\footnotetext{
684 Vgl. Caesar, Rolf (1981): a.a.O., S. 409.

685 Vgl. Merusi, Fabio: a.a.O., S. 91.

686 Vgl. Merusi, Fabio: a.a.O., S. 91.

687 Vgl. Statute of Bank of Italy, Art. 17.

$688 \mathrm{Vgl}$. Statute of Bank of Italy, Art. 59f.

689 Vgl. Bank für Internationalen Zahlungsausgleich Basel: a.a.O., S. 257.

690 Vgl. Bank für Internationalen Zahlungsausgleich Basel: a.a.O., S. 257f.
} 


\subsubsection{Funktionelle Unabhängigkeit}

\subsubsection{Instrumentenübergreifende Regelungen}

Die Handlungsbefugnisse der Banca d'Italia stehen ausschließlich dem Gouverneur $\mathrm{zu}^{691}$. Darunter fallen alle Befugnisse, die nach dem Statut nicht ausdrücklich dem Verwaltungsrat oder dem Interministeriellen Ausschuß für das Kreditund Sparwesen zugewiesen sind 692 . Dem Verwaltungsrat stehen keinerlei Mitbestimmungsrechte bei der Erfüllung der öffentlichen Aufgaben der Zentralbank $z^{603}$. Der Interministerielle Ausschuß (Comitato Interministriale per il Credito ed il Risparmio = CICR) bestimmt die Grundzüge der Politik der Notenbank ${ }^{694}$. Dieser besteht ausschließlich aus Mitgliedern der Regierung und wird vom Schatzminister geleitet ${ }^{695}$. Die Notenbank ist verpflichtet, die Anordnungen dieses Gremiums auszuführen696. Der Gouverneur der Bank hat zwar das Recht an den Sitzungen des Ausschusses teilzunehmen, besitzt aber kein Stimmrecht ${ }^{697}$. Aufgrund der Anordnungsbefugnis des CICR bzgl. der Grundzüge der Geld-, Kredit- und Devisenpolitik gilt die italienische Notenbank de jure als weisungsgebunden und stark abhängig von der Regierung698. Im Rahmen dieser Untersuchung ist eine solche Beurteilung $\mathrm{zu}$ voreilig. Es steht fest, daß sich die Notenbank mit ihren Interventionen grundsätzlich an die Richtlinien der Regierung halten muß699. Eine Notenbankpolitik, die im Widerspruch mit der Linie der Regierung steht, wäre undenkbar ${ }^{700}$. Die Notenbank genießt jedoch weitgehende Freiheiten bei der Auslegung der vom Ministerrat festgelegten Ziele und den Richtlinien zu deren Realisierung ${ }^{701}$. Damit verbunden ist ein umfangreicher

691 Vgl. Merusi, Fabio: a.a.O., S. 97.

692 Vgl. Merusi, Fabio: a.a.O., S. 93.

693 Vgl. Merusi, Fabio: a.a.O., S. 96.

694 Vgl. Stoffers, Erich: a.a.O., S. 134.

695 Vgl. Masera, Francesco: Struttura e funzioni della Banca d'Italia, in: Quaderni sardi di economia, 4/1987, S. 296.

696 Vgl. Stoffers, Erich: a.a.O., S. 134.

697 Vgl. Bernauer, Engelbert: a.a.O., S. 103.

698 So z.B. bei Papier, Hans-Jürgen: Die Zentralbank im Verfassungsgefüge - Generalbericht, in: Instrumente der sozialen Sicherung und der Währungssicherung in der Bundesrepublik Deutschland und in Italien, Beiheft 5 zu "Der Staat", Berlin 1981, S. 116; Schmitz, Wolfgang (1989): a.a.O., S. 18.

699 Vgl. Bank für Internationalen Zahlungsausgleich Basel: a.a.O., S. 251.

700 Vgl. Bank für Internationalen Zahlungsausgleich Basel: a.a.O., S. 251.

701 Vgl. Bank für Internationalen Zahlungsausgleich Basel: a.a.O., S. 250f; Papier, HansJürgen: a.a.O., S. 116. 
Handlungsspielraum bei der Auswahl von Art, Form und Zeitpunkt des Einsatzes geldpolitischer Mittel ${ }^{702}$.

Der faktische Handlungsspielraum der Banca d'Italia gilt als ungleich größer als er nach den rein formalen Regelungen den Anschein erweckt. Der Bank wird aufgrund ihrer fachlichen Kompetenz in geldpolitischen Fragen auch ohne Stimmrecht ein erheblicher Einfluß auf die Willensbildung des Interministeriellen Ausschusses nachgesagt, der jedoch mit der Stärke der Persönlichkeit des jeweiligen Notenbankgouverneurs schwankt ${ }^{703}$. Der faktische Handlungsspielraum aufgrund der Persönlichkeit des Gouverneurs kann für die Bewertung der funktionellen Unabhängigkeit nicht berücksichtigt werden, da im Falle ernsthafter Meinungsverschiedenheiten zwischen der Notenbank und dem Interministeriellen Ausschuß schnell deutlich würde, welche Partei de jure am längeren Hebel sitzt. Bedeutsamer ist, was in einem früheren Kapitel unter Ziele einer Notenbank behandelt wurde. Dort wurde dargelegt, daß Ziele, denen eine Zentralbank unterworfen ist bzw. Aufgaben, die ihr gestellt werden, als solche die funktionelle Unabhängigkeit nicht beeinträchtigen, solange die Bank über die Mittel, mit denen sie dies erreichen will, frei befinden kann. Diese These findet dort ihre Grenze, wo die Ziele bzw. Aufgaben, die der Bank gestellt werden, so konkret sind, $\mathrm{da} ß$ sie hinsichtlich des Einsatzes der einzelnen geldpolitischen Mittel einer Weisung gleichkommen. Die Entscheidung darüber, ob die Banca d'Italia aufgrund der Anordnungsbefugnis des CICR zur völlig abhängigen Notenbank wird, hängt also davon ab, wie konkret diese Richtlinien vorgegeben werden.

\subsubsection{Ausgabe von Zentralbankgeld durch die Notenbank}

\subsection{Art der Kreditnehmer}

Die Notenbank bestimmt ohne jegliche äußere Mitwirkung, welche Banken zur Refinanzierung zuzulassen sind ${ }^{704}$. Die Banca d'Italia darf nur von Banken eingereichtes Material zum Rediskont annehmen705. Seit 1936 darf die Bank mit Privaten zwar keine Diskontgeschäfte betreiben ${ }^{706}$; Lombardkredite darf sie da-

\footnotetext{
702 Vgl. Papier, Hans-Jürgen: a.a.O., S. 116; Europäische Gemeinschaften Währungsausschuß: Die Währungspolitik in den Ländern der Europäischen Wirtschaftsgemeinschaft, Institutionen und Instrumente, 0. O. 1972, S. 210.

703 Vgl. Lampe, Ortrun: a.a.O., S. 59; Papier, Hans-Jürgen: a.a.O., S. 116f; Bernauer, Engelbert: a.a.O., S. 103; Hahn, Oswald (1968) Bd. II: a.a.O., S. 232; Goodman, John B.: a.a.O., S. 340.

704 Vgl. Merusi, Fabio: a.a.O., S. 98.

705 Vgl. Schuster, Leo (1967): a.a.O., S. 121.

706 Vgl. Bank für Internationalen Zahlungsausgleich Basel: a.a.O., S. 277.
} 
gegen auch an Private gewähren 707 . Kredite an den Staat sind in verschiedenen Formen möglich ${ }^{708}$.

Bewertung: A

Die Banca d'Italia darf sowohl dem Staat, Banken als auch Privaten Kredit gewähren. Sie unterliegt daher keinerlei Beschränkungen hinsichtlich ihrer Kreditnehmer.

\subsection{Umfang}

Die Banca d'Italia kann die Menge der in Umlauf zu setzenden Banknoten frei bestimmen ${ }^{709}$. Es gibt weder eine Verpflichtung, zur Deckung des umlaufendes Geldes bestimmte Reserven zu halten noch andere gesetzliche Begrenzungen für die Ausgabe von Banknoten ${ }^{710}$.

Die Bank bestimmt selbständig den Umfang, in dem sich die Banken bei ihr refinanzieren können ${ }^{711}$. Dabei verwendet sie keine Rediskontkontingente, sondern sie kann Refinanzierungswünsche nach eigenem Ermessen erfüllen oder ablehnen ${ }^{712}$. Sie darf ohne Abgabe einer Erklärung auch solche Wechsel zurückweisen, die den qualitativen Anforderungen genügen ${ }^{713}$. Neben Rediskontkrediten gewährt die Notenbank dem Bankensystem auch Lombardkredite ${ }^{714}$.

Die Notenbank gewährt ferner dem Devisenamt (Ufficio Italiano dei Cambi) 715 Kredite auf Vertragsbasis. Es gibt kein Gesetz, das die Notenbank zu einer Kreditvergabe an das Devisenamt verpflichtet 716 .

Dem Staat kann die Banca d'Italia Kredite in Form von Kassenkrediten und über den Erwerb staatlicher Schuldtitel gewähren ${ }^{717}$. Zur Erleichterung seiner Kassenführung steht dem Schatzamt ein Kontokorrentkredit in Höhe 14 Prozent der jeweiligen Haushaltsausgaben, ausschließlich der vermögenswirksamen Ausgaben,

707 Vgl. Europäische Gemeinschaften Währungsausschuß: a.a.O., S. 231.

708 Vgl. Stoffers, Erich: a.a.O., S. 135.

709 Vgl. Merusi, Fabio: a.a.O., S. 98.

710 Vgl. Merusi, Fabio: a.a.O., S. 98.

711 Vgl. Merusi, Fabio: a.a.O., S. 98.

712 Vgl. Stoffers, Erich: a.a.O., S. 135.

713 Vgl. Schuster, Leo (1967): a.a.O., S. 148.

714 Vgl. Europäische Gemeinschaften Währungsausschuß: a.a.O., S. 231.

715 Auf das Devisenamt wird im Abschnitt über die Offenmarktpolitik näher eingegangen.

716 Vgl. Bank für Internationalen Zahlungsausgleich Basel: a.a.O., S. 289.

717 Vgl. Stoffers, Erich: a.a.O., S. 135. 
zu, der nicht überschritten werden darf 718 . Bis zu dieser Höhe ist die Notenbank zur Kreditgewährung verpflichtet ${ }^{719}$. Bis 1981 war die Banca d'Italia ebenfalls verpflichtet, bei den Auktionen übriggebliebene Schuldverschreibungen des Staates zu übernehmen ${ }^{720} .1981$ wurde diese Verpflichtung abgeschafft ${ }^{721}$. Für den Direktankauf von Staatspapieren durch die Notenbank gibt es keine gesetzliche Grenze 722.

Von dem Gewinn der Notenbank werden bis zu $20 \%$ an die ordentlichen Rücklagen abgeführt und eine Dividende von höchstens $6 \%$ des Nominalkapitals an die Aktionäre gezahlt 723 . Der Restbetrag kann auf Vorschlag des Verwaltungsrats und nach Bewilligung durch den Schatzminister bis zu weiteren $20 \%$ des Reingewinns etwaigen Sonderfonds und außerordentlichen Rücklagen zugeführt werden oder maximal $4 \%$ als zusätzliche Dividende ausgeschüttet werden 724 . Der Restbetrag fällt dem Staat $z^{725}$. Zusätzlich hat die Notenbank eine jährliche globale Stempelsteuer an den Staat zu entrichten, in Höhe von 1/10 des Diskontsatzes (mind. aber 0,5\%) auf den Betrag der umlaufenden Banknoten und geldähnlichen Namenspapiere abzüglich des Wertes der Goldreserven und der auf Grund von Lombardkrediten an den Staat ausgegebenen Banknoten ${ }^{726}$.

Bewertung: bis $1981 \mathrm{~J}$

seit $1981 \mathrm{D}$

Dem Umfang der Ausgabe von Zentralbankgeld durch die Notenbank sind nach oben hin keine Grenzen gesetzt. Die Pflicht der Bank zur Zahlung der Stempelsteuer sowie die Regelungen zur Gewinnverwendung bedeuten für die Bank eine technisch-institutionelle Einschränkung. Bis 1981 schränkte die Verpflichtung der Bank zur Gewährung eines Überziehungskredits an den Staat die Unabhängigkeit des Instituts zusätzlich in Form eines partiellen Weisungsrechts ein.

718 Vgl. Europäische Gemeinschaften Währungsausschuß: a.a.O., S. 229 (Im Oktober 1993 wurde der Überziehungskredit an den Staat abgeschafft, Vgl. Tobias Piller: Banca d'Italia - Ein Hort der Kontinuität im unruhigen Italien, in: FAZ 11.12.1993, S. 12).

719 Vgl. Europäische Wirtschaftsgemeinschaft: Die währungspolitischen Instrumentarien in den Mitgliedsstaaten der Europäischen Wirtschaftsgemeinschaft, Brüssel 1962, S. 183.

720 Vgl. Goodman, John B.: a.a.O., S. 340.

721 Vgl. Goodman, John B.: a.a.O., S. 340.

722 Vgl. OECD: Monetary Policy in Italy, OECD Monetary Studies Series, Paris 1973, S. 11 .

723 Vgl. Bank für Internationalen Zahlungsausgleich Basel: a.a.O., S. 250.

724 Vgl. Bank für Internationalen Zahlungsausgleich Basel: a.a.O., S. 250.

725 Vgl. Bank für Internationalen Zahlungsausgleich Basel: a.a.O., S. 250.

726 Vgl. Bank für Internationalen Zahlungsausgleich Basel: a.a.O., S. 276. 


\subsection{Zinssatz}

Änderungen des Diskontsatzes sowie der anderen von der Bank berechneten Zinsen können nur im Zusammenwirken mit dem Schatzminister getroffen werden 727 . Sie werden auf Vorschlag des Gouverneurs durch Dekret des Schatzministers beschlossen ${ }^{728}$. Der Lombardsatz entspricht in der Regel dem Diskontsatz ${ }^{729}$.

\section{Bewertung: G}

Die Bewilligungspflicht des Schatzministers bei den Entscheidungen hinsichtlich der Zinsgestaltung für Notenbankkredite bedeutet eine Einschränkung der funktionellen Unabhängigkeit durch Genehmigungsrecht.

\subsection{Bedingungen}

Die Satzung der Banca d'Italia bestimmt den Kreis der diskont- und lombardfähigen Papiere ${ }^{730}$. Zum Rediskont zugelassen sind Handelswechsel, Schecks auf italienische Bankplätze, Schatzwechsel, Zinsscheine staatlicher oder staatlich garantierter Wertpapiere und Lagerscheine ${ }^{731}$. Eingereichte Wechsel müssen mindestens zwei als zahlungsfähig bekannte Unterschriften tragen und ihre Restlaufzeit darf vier Monate nicht übersteigen 732 . Lombardkredite können auf Schuldverschreibungen des Staates, vom Schatzamt emittierte Schatzwechsel, staatlich verbürgte Wertpapiere oder Titel, deren laufende Verzinsung der Staat garantiert sowie Hypothekenpfandbriefe der Realkreditinstitute und gesetzlich gleichgestellte Papiere gewährt werden 733 . Ferner sind auch Goldmünzen, Seide und Lagerscheine zum Lombard zugelassen 734 . Die als Sicherheiten für Lombardkredite verpfändeten Papiere oder Waren dürfen nur bis zu $85 \%$ ihres Wertes beliehen werden ${ }^{735}$. Diskont- und Lombardkredite haben einen Höchstlaufzeit von 4 Monaten 736 .

727 Seit Februar 1992 obliegt dem Gouverneur die alleinige Entscheidungsbefugnis zur Veränderung der Leitzinsen, Vgl. Tobias Piller: a.a.O., S. 12.

728 Vgl. Bank für Internationalen Zahlungsausgleich Basel: a.a.O., S. 299.

729 Vgl. Bernhuber, Max; Hauck, Hartwig: a.a.O., S. 39.

730 Vgl. Bank für Internationalen Zahlungsausgleich Basel: a.a.O., S. 278.

731 Vgl. Stoffers, Erich: a.a.O., S. 135.

732 Vgl. Europäische Gemeinschaften Währungsausschuß: a.a.O., S. 232.

733 Vgl. Europäische Gemeinschaften Währungsausschuß: a.a.O., S. $233 \mathrm{f}$.

734 Vgl. Europäische Gemeinschaften Währungsausschuß: a.a.O., S. 234.

735 Vgl. Europäische Wirtschaftsgemeinschaft: a.a.O., S. 172.

736 Vgl. Europäische Wirtschaftsgemeinschaft: a.a.O., S. 170. 


\section{Bewertung: D}

Die gesetzliche Festlegung der als Kreditsicherheiten zugelassenen Werte sowie die Laufzeitbegrenzung der Kredite bedeutet für die Banca d'Italia eine technischinstitutionelle Einschränkung.

\subsubsection{Direkte Einflußnahme auf die Kreditvergabe der Banken}

1947 wurden die Bankaufsichtsfunktionen des Ende des zweiten Weltkriegs aufgelösten Inspektorats für das Kredit- und Sparwesen an die Banca d'Italia abgegeben ${ }^{737}$. Dadurch wurden die Aufgaben der Währungsordnung sowie die Aufgaben der Bankenaufsicht in einem Rechtsträger zusammengefaßt $\mathrm{t}^{738}$. Das oberste Bankenaufsichtsorgan ist der Interministerielle Ausschuß für das Kreditund Sparwesen ${ }^{739}$. In Übereinstimmung mit den Beschlüssen des Ministerausschusses erläßt der Schatzminister Verordnungen für das Kredit- und Sparwesen sowie alle sonstigen mit der Bankenaufsicht zusammenhängenden Bestimmungen ${ }^{740}$. Die Notenbank ist lediglich mit der technischen Durchführung der Bankenkontrolle betraut und steht insofern in Abhängigkeit des Ausschusses ${ }^{741}$. Jedoch handelt es sich bei den Beschlüssen des Interministeriellen Ausschusses im wesentlichen um Richtlinien allgemeiner Art, so daB der Notenbank in einigen Bereichen eigene Befugnisse bei der Umsetzung dieser Richtlinien bleiben 742 .

\subsection{Art der Kreditnehmer}

Die Banca d'Italia kann auf administrativem Wege keinen Einfluß auf die Art der Kreditnehmer der Banken nehmen. Es gibt in Italien eine Form von Kredit, die der Bankenaufsicht der Notenbank zumindestens teilweise entzogen ist ${ }^{743}$. Dieser sogenannte erleichterte Kredit war ursprünglich als Anreiz für Unternehmen strukturschwacher Zonen bzw. aus in Schwierigkeiten geratenen Branchen gedacht, entwickelte sich aber schließlich zu einer Hauptform der Unternehmensfinanzierung, die zumindestens teilweise auf den öffentlichen Finanzen lastet ${ }^{744}$.

\footnotetext{
737 Vgl. Merusi, Fabio: a.a.O., S. 89.

738 Vgl. Merusi, Fabio: a.a.O., S. 89.

739 Vgl. Bernhuber, Max; Hauck, Hartwig: a.a.O., S. 19.

740 Vgl. Bank für Internationalen Zahlungsausgleich Basel: a.a.O., S. 291f.

741 Vgl. Bernhuber, Max; Hauck, Hartwig: a.a.O., S. 19; Pecchioli, Rinaldo, M.: Bankenaufsicht in den OECD-Ländern: Entwicklungen und Probleme, Baden-Baden 1989, S. 251.

742 Vgl. Bank für Internationalen Zahlungsausgleich Basel: a.a.O., S. 292.

743 Vgl. Merusi, Fabio: a.a.O., S. 105.

744 Vgl. Merusi, Fabio: a.a.O., S. 104.
} 
Die Banca d'Italia kann diese Kredite nicht steuern ${ }^{745}$. Thre Ausgestaltung ist genau durch Gesetz geregelt ${ }^{746}$. Diese Regelungen stellen auch bestimmte Anforderungen an deren Empfänger, die die Notenbank nicht beeinflussen kann 747 .

\section{Bewertung: $\mathrm{H}$}

Die Notenbank kann auf die Art der Kreditnehmer nur im Rahmen freiwilliger Vereinbarungen und damit mit Zustimmung der betroffenen Banken bzw. Kreditoren Einfluß nehmen. Die gesetzlichen Regelungen hinsichtlich den Anforderungen an die Kreditnehmer des erleichterten Kredits stellen eine technischinstitutionelle Einschränkung für die Bank dar.

\subsection{Umfang}

Die Banca d'Italia ist ermächtigt, Höchstgrenzen für die Kreditgewährung der Banken festzusetzen 748 . Im Juli 1973 beschränkte sie erstmals die Kreditexpansion der Banken 749 . Sie gibt in etwa halbjährlichen Abständen die zulässigen Zuwachsraten für die einzelnen Monate bzw. Quartale an ${ }^{750}$. Desweiteren kann sie den Umfang der Kreditvergabe der Banken direkt dadurch beeinflussen, daß Kredite, die ein Fünftel der Eigenmittel einer Bank übersteigen, ihrer Genehmigung bedürfen 751 . Da die Eigenmittel der italienischen Banken relativ niedrig sind, untersteht somit ein bedeutender Teil des Kreditvolumens der unmittelbaren Kontrolle der Notenbank ${ }^{752}$. Der Interministerielle Ausschuß kann ebenfalls durch den Erlaß von Vorschriften über das Verhältnis zwischen den verschiedenen Aktivgeschäften der Kreditinstitute sowie Vorschriften über Sicherheitsleistungen der Banken zur Risikobegrenzung bei der Zunahme der Kreditvergabe auf die Kreditgewährung der Banken Einfluß nehmen ${ }^{753}$. Da es sich hier weniger um geldpolitisch motivierte, häufig veränderte Vorschriften als um feststehende bankaufsichtsrechtliche Regelungen handelt, bedeuten sie für die Notenbank nur eine technisch-institutionelle Einschränkung.

745 Vgl. Merusi, Fabio: a.a.O., S. 104.

746 Vgl. Merusi, Fabio: a.a.O., S. 104.

747 Vgl. Merusi, Fabio: a.a.O., S. 104.

748 Vgl. Europäische Gemeinschaften Währungsausschuß: a.a.O., S. 211.

749 Vgl. Stoffers, Erich: a.a.O., S. 137.

750 Vgl. Pfisterer, Hans: Zur Notenbankpolitik der EG-Partnerstaaten, in: Sparkasse 2/81, S. 51f.

751 Vgl. Schuster, Leo (1967): a.a.O., S. 145.

752 Vgl. Bernhuber, Max; Hauck, Hartwig: a.a.O., S. 61.

753 Vgl. Europäische Wirtschaftsgemeinschaft: a.a.O., S. 187. 


\section{Bewertung: D}

Die Banca d'Italia verfügt $u$. a. durch die Ermächtigung zur Kreditplafondierung über weitgehenden Einfluß auf den Umfang der Kreditvergabe der Banken. Eine technisch-institutionelle Einschränkung besteht aufgrund der Möglichkeiten des Interministeriellen Ausschusses zum Erlaß bestimmter bankaufsichtsrechtlicher Vorschriften.

\subsection{Zinssatz}

Obergrenzen von Soll- und Habenzinsen werden von der Notenbank entsprechend den Beschlüssen des CICR angewiesen ${ }^{754}$. Ein weiterer Einfluß auf die Kreditzinsen geht von staatlichen Zinssubventionen aus, die insbesondere im Rahmen der Regionalpolitik gewährt werden 755 .

\section{Bewertung: L}

Die Festlegung von Obergrenzen für die Sollzinsen durch den Interministeriellen Ausschuß bedeutet für die Notenbank eine Weisung und damit die höchstmögliche Einschränkung ihrer Entscheidungsfreiheit. Die Auswirkungen der staatlichen Zinssubventionen auf die Unabhängigkeit der Bank können daher vernachlässigt werden.

\subsection{Bedingungen}

Die Banca d'Italia kann auf administrativem Wege keinen Einfluß auf die Bedingungen der Kreditgewährung der Banken nehmen, so daß ihr nur der Weg über freiwillige Vereinbarungen mit den Banken bleibt. Die Ausgestaltung des oben angesprochenen erleichterten Kredits ist genau durch Gesetz geregelt ${ }^{756}$. Auf die dort festgelegten Bedingungen hat die Notenbank keinen Einfluß.

\section{Bewertung: $\mathrm{H}$}

Eventuelle freiwillige Vereinbarungen mit den Banken hinsichtlich der Kreditvergabebedingungen erfahren durch die gesetzlichen Regelungen zum erleichterten Kredit eine technisch-institutionelle Einschränkung.

\subsubsection{Offenmarktpolitik}

In Italien werden Offenmarktoperationen von drei Institutionen getätigt. Neben der Banca d'Italia führt auch das Schatzamt gelegentlich Operationen mit Schatz-

754 Vgl. Papier, Hans-Jürgen: a.a.O., S. 116.

755 Vgl. Stoffers, Erich: a.a.O., S. 137.

756 Vgl. Merusi, Fabio: a.a.O., S. 104. 
anweisungen durch, die offenmarktpolitische Zielsetzung haben 757 . Ferner schließt das Deviseninstitut Swapgeschäfte (Devisen gegen Lire) mit den Banken 758. Beim Devisenamt liegen die außenwirtschaftlichen Kompetenzen in der Wirtschaftspolitik 759 . Es handelt sich um ein öffentlich-rechtliches Institut mit eigener Rechtsfähigkeit und unabhängiger Geschäftsführung 760 . Es untersteht der Aufsicht des Schatzministeriums ${ }^{761}$ und wird vom Gouverneur der Notenbank geführt ${ }^{762}$. Ursprünglich besaß das Devisenamt das ausschließliche Recht zum Devisenhandel, welches schrittweise durch ein System dynamischer Aufsicht ersetzt wurde, das sich auf die Geschäftsbanken als Agenten der Zentralbank stützt ${ }^{763}$. Heute regelt es den Devisenverkehr, überwacht die Einhaltung der Devisenvorschriften und gewährt dem Schatzamt Devisenkredite ${ }^{764}$. Im Rahmen der ihm von den Devisengesetzen zuerkannten Befugnisse kann das Devisenamt auch der Notenbank Anweisungen geben 765 .

\subsection{Art und Gegenstand des Geschäfts}

Die Banca d'Italia ist ermächtigt, Schatzwechsel und Regierungsschuldverschreibungen sowie von der Regierung garantierte Schuldverschreibungen zu kaufen und zu verkaufen 766 . Ferner kann sie Gold und Goldwährungen handeln ${ }^{767}$. Der Handel mit Devisen ist dagegen Sache des Devisenamts und damit der Notenbank entzogen, auch wenn die Notenbank die Mittel für den Devisenankauf zur Verfügung stellt ${ }^{768}$.

\section{Bewertung: D}

Die Beschränkung der Offenmarktgeschäfte auf gesetzlich festgelegte Papiere sowie die beim Devisenamt liegende Befugnis zum Handel mit Devisen bedeutet für die Notenbank eine technisch-institutionelle Einschränkung.

757 Vgl. Europäische Wirtschaftsgemeinschaft: a.a.O., S. 174.

758 Vgl. Europäische Wirtschaftsgemeinschaft: a.a.O., S. 175.

759 Vgl. Stoffers, Erich: a.a.O., S. 135.

760 Vgl. Bank für Internationalen Zahlungsausgleich Basel: a.a.O., S. 272.

761 Vgl. Bank für Internationalen Zahlungsausgleich Basel: a.a.O., S. 288.

762 Vgl. Merusi, Fabio: a.a.O., S. 101.

763 Vgl. Merusi, Fabio: a.a.O., S. 101.

764 Vgl. Stoffers, Erich: a.a.O., S. 135.

765 Vgl. Bank für Internationalen Zahlungsausgleich Basel: a.a.O., S. 289.

766 Vgl. Europäische Wirtschaftsgemeinschaft: a.a.O., S. 174.

767 Vgl. Statute of Bank of Italy, Art. 41 (6).

$768 \mathrm{Vgl}$. Europäische Gemeinschaften Währungsausschuß: a.a.O., S. 211. 


\subsection{Umfang}

Die Banca d'Italia kann die Menge der in Umlauf zu setzenden Banknoten frei bestimmen ${ }^{769}$. Es gibt keine Notendeckungsvorschriften oder Emissionsbegrenzungen ${ }^{770}$, die zu einer Einschränkung des Umfangs von Offenmarktgeschäften der Notenbank führen könnten. Es gibt zudem keine gesetzlichen Grenzen weder für den An- und Verkauf von Staatspapieren durch die Notenbank ${ }^{771}$ noch für den Handel mit Gold772. Die Bank tätigt diese Geschäfte nach eigenem Ermessen 773 . Offenmarkt- und offenmarktähnliche Geschäfte des Schatzamtes haben keinerlei Auswirkungen auf die Unabhängigkeit der Notenbank. Sie beeinflussen lediglich die Effizienz der geldpolitischen Maßnahmen der Notenbank.

Bewertung: A

Der Umfang der Offenmarktgeschäfte der Notenbank ist nicht beschränkt.

\subsection{Preis}

Die Banca d'Italia betreibt bei ihren Geschäften mit Staatspapieren eine variable Preispolitik 774 . Sie ist diesbezüglich keinerlei Beschränkungen unterworfen. Seit der Auflösung des Bretton Woods Systems, in dem die Notenbank zu unbegrenztem Ankauf von Gold zu einem nach dem Dollarkurs festgesetzten Preis verpflichtet war, gibt es auch hier keine Beschränkungen mehr.

\section{Bewertung: A}

Hinsichtlich der Preisgestaltung bei ihren offenmarktpolitischen Operationen unterliegt die Notenbank keinen Beschränkungen.

\subsection{Handelspartner}

Die Banca d'Italia tätigt ihre offenmarktpolitischen Operationen unter Einschaltung von Maklern und Banken775. Hinsichtlich der Handelspartner für Offenmarktgeschäfte gibt es keine Beschränkungen.

769 Vgl. Merusi, Fabio: a.a.O., S. 98.

770 Vgl. Merusi, Fabio: a.a.O., S. 98.

771 Vgl. Bank für Internationalen Zahlungsausgleich Basel: a.a.O., S. 286.

772 Vgl. Bank für Internationalen Zahlungsausgleich Basel: a.a.O., S. 276.

773 Vgl. Europäische Gemeinschaften Währungsausschuß: a.a.O., S. 241.

774 Vgl. Europäische Gemeinschaften Währungsausschuß: a.a.O., S. 241.

775 Vgl. Menzel, Ch.; Tanner, U.: a.a.O., S. 242. 


\section{Bewertung: A}

Es gibt weder technisch-institutionelle Einschränkungen noch Einflußrechte Externer hinsichtlich der Offenmarktgeschäfte der Notenbank.

\subsubsection{Mindestreservepolitik}

Mindestreserven dienen in Italien seit 1947 als währungspolitisches Instrument. Das Bankengesetz schreibt vor, daß die Banken bestimmte Relationen zwischen Aktiv- und Passivpositionen einzuhalten haben 776. Die Maßnahmen der Mindestreservepolitik werden vom Interministeriellen Ausschuß getroffen und von der Notenbank als Anweisungen bekanntgegeben ${ }^{777}$. Damit unterliegt die Banca d'Italia in allen Bereichen der Mindestreservepolitik den Weisungen des Ausschusses. Alle vier Instrumente müssen daher mit Bewertungsstufe $L$ beurteilt werden.

\subsection{Reservepflichtige Institute}

Der Vorschrift zur Haltung von Mindestreserven unterliegen alle Kreditinstitute mit Ausnahme einiger Spezialinstitute ${ }^{778}$.

\subsection{Bemessungsgrundlagen}

Berechnungsgrundlage für die Mindestreservehaltung in Italien sind Sicht-, Termin- und Spareinlagen der Nichtbanken und der Spezialkreditinstitute sowie Verbindlichkeiten gegenüber Gebietsfremden ${ }^{779}$. Der Reservesatz wird auf teils auf den Zuwachs und teils auf den Bestand der reservepflichtigen Verbindlichkeiten angewendet 780 .

\subsection{Mindestreservesatz}

Die Befugnis zur Änderung der Mindestreservesätze liegt beim Interministeriellen Ausschuß für das Kredit- und Sparwesen 781 . Seit 1975 besteht ein einheitlicher Reservesatz für alle Einlagenkategorien. Vorher boten verschiedene Reservesätze

776 Vgl. Il Codice Bancario Fascista Art. 32. f.

777 Vgl. Papier, Hans-Jürgen: a.a.O., S. 116.

778 Vgl. Tobler, Ewald: Entwurf eines schweizerischen Mindestreservesystems auf der Grundlage ausländischer Methoden und Erfahrungen, Zürich 1967, S. 46.

779

780

Vgl. Stoffers, Erich: a.a.O., S. 136.

Vgl. Mader, Richard:a.a.O., S. 128.

Vgl. Tobler, Ewald: a.a.O., S. 49 (Heute ist die Banca d'Italia furr die Festsetzung der Mindestreserven der Banken zuständig, Vgl. o. V.: Die italienische Zentralbank wird von der Regierung unabhängig, in: FAZ vom 12.11.1993, S.15). 
für verschiedene Einlagen- und Kreditinstitutsgruppen die Möglichkeit, durch Mittelumschichtungen zwischen einzelnen Bankengruppen bzw. Einlagenkategorien die Mindestreserveerfordernis zu verringern ${ }^{782}$.

\subsection{Materielle Beschaffenheit der Mindestreserven}

Den italienischen Banken steht es frei, ihre Mindestreserven entweder als Guthaben auf einem Konto oder in Form von Schatzwechseln bei der Banca d'Italia zu deponieren 783. Bei der Notenbank gehaltenes Mindestreserveguthaben wird mit dem gleichen Satz verzinst wie die zuletzt emittierten Schatzwechsel ${ }^{784}$. Die Kosten dafür trägt das Schatzamt ${ }^{785}$. Das Schatzamt kann die Notenbank anweisen, diese in Bar einbezahlten Reserven in öffentlichen Wertpapieren anzulegen und den Ertrag an den Staat abzufuihren ${ }^{786}$.

\subsubsection{Zusammenfassende Beurteilung der funktionellen Unabhängigkeit der Banca d'Italia}

Aufgrund der oben ermittelten Werte für die in Abb. 5 aufgeführten geldpolitischen Instrumente ergibt sich für den Zeitraum bis 1981 ein Zentralwert zwischen $G$ und $H$ und damit der Grad eher abhöngig und seit 1981 ein Zentralwert zwischen $\mathrm{D}$ und $\mathrm{G}$ und damit der Grad eher unabhängig.

\subsection{Großbritannien}

Die Bank von England wurde 1694 errichtet mit dem Zweck der Förderung des öffentlichen Wohles der Bevölkerung 787. Ihre Hauptverwaltung ist in London. 1946 wurde die Bank mit Inkrafttreten des Bank of England Act und der Satzung verstaatlicht, in dem der Staat die Aktionäre auskaufte ${ }^{788}$.

Die Bank von England wird vom Court of Directors geleitet, bestehend aus dem Präsidenten, dem Vizepräsidenten sowie 16 Direktoren ${ }^{789}$. Von diesen 16 Direktoren stammen 12 aus der Privatwirtschaft. Sie sind ehrenamtlich tätig und üben

782 Vgl. Mader, Richard:a.a.O., S. 129.

783 Vgl. Tobler, Ewald: a.a.O., S. 49.

784 Vgl. Tobler, Ewald: a.a.O., S. 48.

785 Vgl. Tobler, Ewald: a.a.O., S. 48.

786 Vgl. Bank für Internationalen Zahlungsausgleich Basel: a.a.O., S. 285.

787 Vgl. Bank für Internationalen Zahlungsausgleich Basel: a.a.O., S. 127 und 129.

788 Vgl. Bank für Internationalen Zahlungsausgleich Basel: a.a.O., S. 128

789 Vgl. Bank für Internationalen Zahlungsausgleich Basel: a.a.O., S. 130. 
eine allgemeine Aufsicht über die Tätigkeit der Zentralbank aus ${ }^{790}$. Die anderen 4, von denen 3 aus der Zentralbankadministration und einer aus dem Schatzamt stammt, sind hauptamtlich tätig791. Zusammen mit dem Gouverneur und dem Vizegouverneur bilden letztere in der Praxis das informelle Exekutivkomitee, das sich mit Fragen der alltäglichen Politik der Bank beschäftigt ${ }^{792}$.

\subsubsection{Personelle Unabhăngigkeit}

\subsubsection{Ernennungsinstanzen (Ebene 1)}

Alle Mitglieder der Notenbankleitung werden von der Krone auf Vorschlag des Premierministers oder des Kabinetts ernannt ${ }^{793}$. Die Notenbank selbst hat keine Mitwirkungsrechte.

Fazit:

Die Notenbank kann nicht die Entscheidungsmehrheit ihrer Leitungsorgane ernennen.

\subsubsection{Abberufungsinstanzen (Ebene 2)}

Es ist davon auszugehen, daß mögliche Abberufungen nur von den Ernennungsinstanzen vorgenommen werden können, weil die Literatur bei der Diskussion der Abberufungsmodalitäten nur von einem Recht der Regierung spricht ${ }^{794}$.

\section{Fazit:}

Die Notenbank ist weder die entscheidende Abberufungsinstanz noch kann sie drohende Abberufungen verhindern. Damit sind die näheren Abberufungsmodalitäten und die Wiederernennungsvorschriften für die Beurteilung der personellen Unabhängigkeit der Bank von England unbedeutend.

790 Vgl. o. V.: Vergleichende Studie zur Autonomie der Zentralbanken in der Bundesrepublik Deutschland, Frankreich und Großbritannien, in: Udvalgte forskningsdokumenter / Europa-Parlamentet, Generaldirektoratet for Forskning, 1989, S. 39.

791 Vgl. o. V.: Vergleichende Studie zur Autonomie der Zentralbanken in der Bundesrepublik Deutschland, Frankreich und Großbritannien: a.a.O., S. 39.

792 Vgl. o. V.: Vergleichende Studie zur Autonomie der Zentralbanken in der Bundesrepublik Deutschland, Frankreich und Großbritannien: a.a.O., S. 39.

793 Vgl. Swinburne, Mark; Castello-Branco, Marta: a.a.O., S. 31 f.

794 Vgl. Bonin, Konrad v.: Zentralbanken zwischen funktioneller Unabhängigkeit und politischer Autonomie, Baden-Baden 1979, S. 120. 


\subsubsection{Kreis der Ernennungsfahigen (Ebene 6)}

Für eine Berufung in den Court of Directors ist keine bestimmte Qualifikation oder Zugehörigkeit zu einer bestimmten Gruppe erforderlich. Von einer Berufung ausgeschlossen sind $u$. a. Ausländer, Regierungsmitglieder, Abgeordnete des Unterhauses oder bezahlte Staatsbeamte ${ }^{795}$. Der Court of Directors setzt die Gehälter des Gouverneurs und der Direktoren der Bank selbst fest ohne Mitwirkung und Kenntnis des Schatzamtes oder einer anderen staatlichen Stelle ${ }^{796}$.

Fazit:

Die Notenbank hat durch die Befugnis, die Gehälter ihrer Führungspersönlichkeiten selbst festzulegen, einen bedingten Einfluß auf den Kreis der Ernennungsfähigen.

\subsubsection{Beurteilung der personellen Unabhängigkeit}

Die Bank von England erreicht mit Ziffer 25 die vorletzte Bewertungsstufe des Entscheidungsbaums in Abb. 1 und damit den personellen Unabhängigkeitsgrad abhängig.

\subsubsection{Funktionelle Unabhängigkeit}

\subsubsection{Instrumentenübergreifende Regelungen}

In Großbritannien wird die Währungspolitik traditionell797 von der Regierung festgelegt ${ }^{798}$. Das Schatzamt zeigt die große Linie auf, während die Notenbank nur als Berater und Vollstrecker der Geldpolitik agiert ${ }^{799}$. Die Verantwortung für wichtige geldpolitische Entscheidungen liegt bei der Regierung800. Der Bank of England Act gibt dem Schatzkanzler in Art. 4 (1) ein Weisungsrecht gegenüber

795 Vgl. Bank für Internationalen Zahlungsausgleich Basel: a.a.O., S. 130.

796 Vgl. Uhlig, J.: Bank von England: verstaatlicht und doch "unabhängig", in: Zeitschrift für das gesamte Kreditwesen 23. Jg. 1970, S. 602; Bonin, Konrad v.: a.a.O., S. 120.

797 Der Radcliffe-Ausschuß erklärte 1959 hierzu: „Wir distanzieren uns von einer Auffassung, die stillschweigend oder ausdrücklich aus manchen Zeugenaussagen herausgeklungen hat, daß es nämlich das öffentliche Interesse erfordere, die völlige Unabhängigkeit der Notenbank von jeglichen politischen Einflüssen sicherzustellen. Wir teilen diesen Glauben nicht, so sehr er anderen Volkswirtschaften oder Staatssystemen angemessen sein mag.", in: Richebächer, Kurt: Die Bank von England als "Kreatur" des Schatzkanzlers, in: Zeitschrift für das gesamte Kreditwesen 12. Jg. 1959, S. 858.

Vgl. Lampe, Ortrun: a.a.O., S. 56.

799 Vgl. Castello-Branco, Marta; Swinburne, Mark: a.a.O., S. 20.

800 Vgl. Lampe, Ortrun: a.a.O., S. 56. 
der Bank, das besagt, daß „the treasury may from time to time give such directions to the Bank, as, after consultations with the governor of the Bank, they think necessary in the public interest". Die Notenbank ist an den geldpolitischen Entscheidungen nicht beteiligt; sie muß nur angehört werden. Das Weisungsrecht des Schatzkanzlers ist so weit gefaßt, daß es eine völlige Weisungsgebundenheit der Bank von England bedeutet ${ }^{801}$. Daran ändert auch die Tatsache nichts, daß diese Regelung weniger zur täglichen Einmischung der Regierung in die Notenbankgschäfte geschaffen wurde als zur Verdeutlichung, daß im Konfliktfall das Finanzministerium das letzte Wort hat ${ }^{802}$. Alle hier betrachteten geldpolitischen Instrumente müssen daher mit dem höchsten Abhăngigkeitsgrad bewertet werden, unabhängig von der Ausgestaltung des Instrumentariums. Daher wird im folgenden nur ein kurzer Überblick über die geldpolitischen Mittel in Großbritannien gegeben.

Die Bank von England ist in der Art ihrer Bankgeschäfte durch gesetzliche Bestimmungen praktisch nicht behindert. Das angewandte geldpolitische Instrumentarium hat sich aus der Praxis entwickelt und ist in keiner gesetzlichen Bestimmung niedergelegt ${ }^{803}$. Dies eröffnet der Bank instrumentelle Möglichkeiten, die über die Befugnisse der meisten anderen Notenbanken hinausgehen ${ }^{804}$. Das Gesetz ermächtigt die Notenbank, von den Banken Informationen zu verlangen, ihnen Empfehlungen zu geben und - mit Ermächtigung des Schatzamtes ihnen Weisungen zu erteilen ${ }^{805}$. Es gibt keine näheren Bestimmungen darüber, zu welchem Zweck die Bank von diesem Recht Gebrauch machen soll oder welcher Art die Empfehlungen bzw. Weisungen an die Banken sein sollen ${ }^{806}$. Dies ermöglicht der Bank von England grundsätzlich, den Kreditinstituten ihr Handeln bis in alle Einzelheiten vorzuschreiben ${ }^{807}$.

\subsubsection{Ausgabe von Zentralbankgeld durch die Notenbank}

Die Bank von England nimmt eine wichtige Rolle im Rahmen der Staatsfinanzierung ein. Sie ist verpflichtet, für die Finanzierung eventueller Fehlbeträge im öffentlichen Haushalt zu sorgen und darüber hinaus das Debt Management nach

801 Vgl. Caesar, Rolf (1981): a.a.O., S. 354f.

802 Vgl. Cairncross, Alec: The Bank of England: Relationsships with the Government, the Civil Service, and Parliament, in: Toniolo, Gianni: Central bank's independence in historical perspective, Berlin, New York 1988, S. 68.

Vgl. Bonin, Konrad v.: a.a.O., S. 101f.

Vgl. Caesar, Rolf (1981): a.a.O., S. 357f.

805 Vgl. Bonin, Konrad v.: a.a.O., S. 101.

806 Vgl. Bonin, Konrad v.: a.a.O., S. 101.

807 Vgl. Caesar, Rolf (1981): a.a.O., S. 359. 
den Richtlinien des Schatzkanzlers durchzuführen ${ }^{808}$. Die direkte Staatsfinanzierung durch die Notenbank ist traditionell auf kurzfristige Überbrückungskredite (ways and means advances) beschränkt, deren Obergrenzen und Dauer das Parlament jährlich neu festlegt ${ }^{809}$. Darüber hinausgehende Kredite sind durch das Gesetz in keiner Weise oder Höhe untersagt oder begrenzt ${ }^{810}$. Auch für den Erwerb von Staatstiteln gibt es keinerlei Grenzen im Bankgesetz ${ }^{811}$. Die Bank von England muß ihren Gewinn teils über Besteuerung 812 teils durch direkte Abführung an das Schatzamt bzw. den staatlichen Devisenausgleichsfonds abführen und leistet damit einen bedeutenden Beitrag zur Haushaltsfinanzierung813.

Die Notenbank gewährt Refinanzierungskredite im wesentlichen an spezialisierte Diskonthäuser, die ihrerseits für den Liquiditätsausgleich der Banken sorgen 814 . Falls sie entsprechende Sicherheiten bieten, können auch Privatpersonen Darlehen von der Notenbank erhalten 815 . Die Notenbank ist immer bereit, Wechsel aufzunehmen, die ihren Güteanforderungen entsprechen 816 . So dürfen im Diskont- und Lombardgeschäft hereingenommene Wechsel höchstens eine Laufzeit von drei Monaten haben ${ }^{817}$. Es gibt keine offiziellen Bestimmungen darüber, welche Papiere die Bank in das Refinanzierungsgeschäft aufnehmen darf 818 . Die Diskonthäuser nehmen diese unbegrenzte Refinanzierungsquelle jedoch nur ungern in Anspruch, weil der Diskontsatz stets oberhalb der Marktsätze liegt ${ }^{819}$. Der veröffentlichte Diskontsatz ist ein Minimumsatz, der bei Mängeln an den eingereichten Kreditunterlagen erhöht werden kann ${ }^{820}$. Der Lombardsatz ist nicht fest an den Diskontsatz gekoppelt ${ }^{821}$. Für die Änderung der Refinanzierungssätze benötigt die Zentralbank die Zustimmung des Schatzkanzlers ${ }^{822}$.

808 Vgl. Caesar, Rolf (1981): a.a.O., S. 356.

809 Vgl. Bonin, Konrad v.: a.a.O., S. 103f.

810 Vgl. Dohnanyi, Klaus von (Hrsg.): Notenbankkredit an den Staat, Baden-Baden 1986, S. 77.

811 Vgl. Hahn, Oswald (1968) Bd. II: a.a.O., S. 177.

812 Die Gewinne aus dem eigentlichen Bankgeschäft der Notenbank unterliegen der Körperschaftsteuer.

813 Vgl. Wettlaufer, Hans-Dieter: a.a.O., S. 66f.

814 Vgl. Veit, Otto (1961), a.a.O., S. 626.

815 Vgl. Haase, Heidrun: a.a.O., S. 105.

816 Vgl. Veit, Otto (1961), a.a.O., S. 628.

817 Vgl. Haase, Heidrun: a.a.O., S. 104.

818 Vgl. Haase, Heidrun: a.a.O., S. 104.

819 Vgl. Veit, Otto (1961), a.a.O., S. 628.

820 Vgl. Haase, Heidrun: a.a.O., S. 105.

821 Vgl. Haase, Heidrun: a.a.O., S. 105.

822 Vgl. o. V.: Vergleichende Studie zur Autonomie der Zentralbanken in der Bundesrepublik Deutschland, Frankreich und Großbritannien: a.a.O., S. 39. 


\subsubsection{Direkte Einflußnahme auf die Kreditvergabe der Banken}

$\S 4$ (3) des Bank of England Act von 1946 regelt das Verhältnis zwischen Notenbank und Kreditinstituten. Es ermächtigt die Notenbank, von den Banken Informationen zu verlangen, ihnen Empfehlungen zu geben und ihnen Weisungen zu erteilen. Damit verfügt die Notenbank theoretisch über sämtliche Möglichkeiten einer Einflußnahme auf die Kreditgewährung der Banken. Weisungen bedürfen jedoch der Genehmigung des Schatzamtes 823 .

Die Kreditplafondierung war bis 1971 in Großbritannien ein wichtiges geldpolitisches Mittel ${ }^{824}$. Sie galt grundsätzlich für alle Geldinstitute einschließlich der Sekundärbanken und umfaßte die gesamte Kreditgewährung in Pfund Sterling an die private Wirtschaft und das Ausland ${ }^{825}$. Kredite an die öffentliche Hand, an verstaatlichte Industrien sowie Wertpapiererwerb waren davon ausgenommen 826 . Im September 1971 wurde die Kreditplafondierung sowie die bisherigen Liquiditätsvorschriften durch neue, für alle Kreditinstitute geltende Mindestreserve- und Liquiditätsbestimmungen ersetzt.

\subsubsection{Offenmarktpolitik}

Für Offenmarktgeschäfte fehlt in Großbritannien jegliche gesetzliche Basis. Es gibt weder Bestimmungen über die Wertpapiere, die Gegenstand der Offenmarktpolitik sein können noch Regelungen, die der Bank von England bestimmte Rechte hinsichtlich der Offenmarktpolitik zuweisen ${ }^{827}$. Damit sind der Einflußnahme des Schatzamts keinerlei Grenzen gesetzt ${ }^{828}$. Das Schatzamt bestimmt die allgemeinen Richtlinien sowie einzelne taktische Entscheidungen, deren Durchführung sie größtenteils der Bank von England überläßt829. Aufgrund der hohen Staatsverschuldung hat die Offenmarktpolitik in Großbritannien eine besondere Bedeutung ${ }^{830}$. Die Bank von England stellt ihre Offenmarktpolitik zu einem erheblichen Teil in den Dienst des Debt Management ${ }^{831}$. Die Abwicklung der Of-

823 Vgl. Haase, Heidrun: a.a.O., S. 99.

824 Vgl. Stoffers, Erich: a.a.O., S. 130.

825 Vgl. Stoffers, Erich: a.a.O., S. 130.

826 Vgl. Stoffers, Erich: a.a.O., S. 130.

827 Vgl. Könke, Jörn: Die institutionelle Koordination von Geld- und Finanzpolitik in Großbritannien, Berlin 1971, S. 77.

828 Vgl. Könke, Jörn: a.a.O., S. 77.

829 Vgl. Könke, Jörn: a.a.O., S. 77.

830 Vgl. o. V.: Vergleichende Studie zur Autonomie der Zentralbanken in der Bundesrepublik Deutschland, Frankreich und Großbritannien: a.a.O., S. 40.

831 Vgl. Stoffers, Erich: a.a.O., S. 129. 
fenmarktoperationen geschieht im wesentlichen über Diskonthäuser, aber die Notenbank kann auch direkt mit den Geschäftsbanken Geschäfte tätigen ${ }^{832}$.

Im Bereich der äußeren Währungspolitik verleiht der Exchange Control Act von 1947 dem Schatzamt weitreichende Befugnisse 833 . Der Notenbank obliegt lediglich die technische Abwicklung der entsprechenden Transaktionen ${ }^{834}$. Die gesamten Gold- und Devisenreserven des Landes sind im Besitz des Staates und damit der Notenbank als Mittel der Zentralbankpolitik entzogen 835 . Mit dem 1932 errichteten Währungsausgleichsfonds soll primär unangemessenen Schwankungen des Sterlingkurses entgegengewirkt werden und zum anderen für die Sicherung und Verwendung des Gold- und Devisenbestandes im öffentlichen Interesse gesorgt werden ${ }^{836}$. Der Währungsausgleichsfonds gehört dem Staat. Die Notenbank, die den Fonds verwaltet, handelt lediglich als dessen Agent ${ }^{837}$.

\subsubsection{Mindestreservepolitik}

Das Instrument der Mindestreservepolitik existiert in Großbritannien erst seit der Einführung des sog. Competition and Credit Control System im Jahre 1971838. Bis dahin gab es bestimmte Liquiditätsrichtsätze und eine Art Mindestreserve in Form von verzinslichen Sondereinlagen bei der Notenbank nur für die Londoner und Schottischen Clearingbanken ${ }^{839}$. Heute unterliegen alle Banken zwei Arten von Mindestreserven. Die Notenbank schreibt zum einen verzinsliche Pflichteinlagen auf den Einlagenbestand, zum anderen gestaffelte unverzinsliche Sondereinlagen auf die Überschreitung des vorgegebenen Einlagenwachstums vor ${ }^{840}$. Die Bank von England kann gesetzlich bindende Anweisungen bzgl. der Mindestreserveerfordernis nur mit Zustimmung der Regierung geben ${ }^{841}$. Andernfalls ist sie auf freiwillige Übereinkünfte mit den Banken oder Empfehlungen angewiesen ${ }^{842}$.

832 Vgl. Batten, Dallas S.; Blackwell, Michael P.; Kim, In-Su; Nocera, Simon E.; Ozeki, Yuzuru: The Conduct of Monetary Policy in the Major Industrial Countries, International Monetary Fund, Washington D.C., July 1990, Occasional Paper No.70, S. 22.

833 Vgl. Stoffers, Erich: a.a.O., S. 129.

834 Vgl. o. V.: Vergleichende Studie zur Autonomie der Zentralbanken in der Bundesrepublik Deutschland, Frankreich und Großbritannien: a.a.O., S. 39.

835 Vgl. Hahn, Oswald (1968) Bd. I: a.a.O., S. 159.

836 Vgl. Bank für Internationalen Zahlungsausgleich Basel: a.a.O., S. 150.

837 Vgl. Bank für Internationalen Zahlungsausgleich Basel: a.a.O., S. 151.

838 Vgl. Caesar, Rolf (1981): a.a.O., S. 360.

839 Vgl. Caesar, Rolf (1981): a.a.O., S. 360.

840 Vgl. Pfisterer, Hans (1981): a.a.O., S. 52.

841 Vgl. Swinburne, Mark; Castello-Branco, Marta: a.a.O., S. 37f.

842 Vgl. Swinburne, Mark; Castello-Branco, Marta: a.a.O., S. 37f. 


\subsubsection{Zusammenfassende Beurteilung der funktionellen Unabhängigkeit der Bank von England}

Obgleich der Bank von England ein umfangreiches geldpolitisches Instrumentarium zur Verfügung steht, muß sie aufgrund des allgemeinen Weisungsrechts des Schatzkanzlers mit Bewertungsstufe L der Abb. 5 und damit als funktionell $a b$ hängig bewertet werden.

\subsection{Frankreich}

Die Banque de France entstand aus einer 1800 gegründeten gewöhnlichen Bank, die erst in mehreren Etappen das flächendeckende Notenausgabeprivileg erhielt ${ }^{843}$. Durch ständige Novellierung der Grundsatzung von 1808 war ein Konglomerat von 53 Gesetzen, Verordnungen und Abkommen entstanden, das in einer bereinigten Satzung vom 31. Dezember 1936 zusammengefaßt wurde844. Die Banque de France wurde 1945 verstaatlicht und erhielt damit unbefristet das alleinige Notenausgabeprivileg 845 . Ihre Aufgaben und Ziele sind nicht gesetzlich niedergelegt ${ }^{846}$.

Die Bankleitung besteht aus dem Gouverneur und zwei Vizegouverneuren ${ }^{847}$. Der Notenbankleitung beigeordnet ist der Generalrat, dem neben dem Notenbankgouverneur und den beiden Stellvertretern neun weitere Mitglieder angehören 848 .

\subsubsection{Personelle Unabhăngigkeit}

\subsubsection{Ernennungsinstanzen (Ebene 1)}

Der Gouverneur wird wie seine Stellvertreter auf Vorschlag des Finanz- und Wirtschaftsministers und nach erfolgter Zustimmung des Ministerrats durch Dekret des Staatspräsidenten ernannt ${ }^{849}$. Von den neun weiteren Mitgliedern des

843 Vgl. Bank für Internationalen Zahlungsausgleich Basel: a.a.O., S. 167.

844 Vgl. Bank für Internationalen Zahlungsausgleich Basel: a.a.O., S. $170 \mathrm{f}$

845 Vgl. Bank für Internationalen Zahlungsausgleich Basel: a.a.O., S. 167f.

$846 \mathrm{Vgl}$. Bank für Internationalen Zahlungsausgleich Basel: a.a.O., S. 171.

847 Vgl. Bank für Internationalen Zahlungsausgleich Basel: a.a.O., S. 172.

848 Vgl. o. V.: Vergleichende Studie zur Autonomie der Zentralbanken in der Bundesrepublik Deutschland, Frankreich und Großbritannien: a.a.O., S. 37.

$849 \mathrm{Vgl}$. Bouveret, Andreas, Michael: Die zentralen Lenkungsorgane der französischen Kreditwirtschaft. Struktur und Strukturwandel im Zentralbank- und Bankenaufsichtssystem Frankreichs, Würzburg 1979, S. 11. 
Generalrats werden 8 vom Wirtschafts- und Finanzminister ernannt; einer wird von der Belegschaft gewählt ${ }^{850}$. Das einzige Organ, dessen personelle Besetzung bankintern beschlossen wird, ist ein Beirat, der jedoch keine Entscheidungskompetenzen hat.

Fazit:

Die Notenbank kann nicht die Entscheidungsmehrheit ernennen.

\subsubsection{Abberufungsinstanzen (Ebene 2)}

Der Staatspräsident kann die Notenbankleitung jederzeit - auch aus politischen Gründen - abberufen ${ }^{851}$.

Fazit:

Die Notenbank ist weder entscheidende Abberufungsinstanz noch kann sie Abberufungen durch ein Vetorecht verhindern. Damit sind die weiteren Abberufungsmodalitäten und Wiederernennungsvorschriften für die Bewertung der personellen Unabhängigkeit der Banque de France unbedeutend.

\subsubsection{Kreis der Ernennungsfahigen (Ebene 6)}

Die Mitglieder der Bankleitung dürfen während der Dauer ihres Amtes weder dem Parlament angehören noch in privaten Industrie-, Handels- oder Finanzunternehmen engagiert sein ${ }^{852}$. Die Notenbank selbst hat keinen Einfluß auf den Kreis der Ernennungsfähigen.

\section{Fazit:}

Die Notenbank kann den Kreis der Ernennungsfähigen nicht beeinflussen.

\subsubsection{Beurteilung der personellen Unabhängigkeit}

Die Banque de France ist mit Bewertungsstufe 26 des Entscheidungsbaums in Abb. 1 personell abhängig.

$850 \mathrm{Vgl}$. o. V.: Vergleichende Studie zur Autonomie der Zentralbanken in der Bundesrepublik Deutschland, Frankreich und Großbritannien: a.a.O., S. 37.

851 Vgl. o. V.: Vergleichende Studie zur Autonomie der Zentralbanken in der Bundesrepublik Deutschland, Frankreich und Großbritannien: a.a.O., S. 36; Swinburne, Mark; Castello-Branco, Marta: a.a.O., S. 33; Caesar, Rolf (1982): a.a.O., S. 572.

852 Vgl. Bank für Internationalen Zahlungsausgleich Basel: a.a.O., S. 173. 


\subsubsection{Funktionelle Unabhängigkeit}

\subsubsection{Instrumentenäbergreifende Regelungen}

Die Beurteilung der funktionellen Unabhängigkeit der Banque de France ist in der Literatur sehr einheitlich. Die meisten Quellen betonen die besondere Abhängigkeit der Bank und ihre Funktion als reinem Regierungsinstrument ${ }^{853}$. Diese Abhängigkeit bestand bis 1984 im wesentlichen von dem übergeordneten Nationalen Kreditrat ${ }^{854}$. Dieser setzte sich aus dem Wirtschafts- und/bzw. Finanzminister ${ }^{855}$, der den Vorsitz führt, dem Notenbankgouverneur als seinem Stellvertreter sowie Repräsentanten der staatlichen Verwaltung, der Banken und Finanzierungsinstitute, der Sozialpartner und der Handelskammern zusammen ${ }^{856}$. Aufgrund der Sitz- und Stimmenregelung wurde er jedoch durch die Regierung dominiert ${ }^{857}$. Der Nationale Kreditrat bestimmte die Grundzüge der Währungspolitik und verfügte zudem über Entscheidungsbefugnisse über den Einsatz bestimmter geldpolitischer Instrumente 858 . Er beriet den Finanz- und Wirtschaftsminister in Fragen des Bankwesens ${ }^{859}$. Ferner war er für die Kreditpolitik und die monetäre Strategie der Banken zuständig860. So hatte er beispielsweise umfangreiche Befugnisse hinsichtlich der Regelung der Bankkonditionen ${ }^{861}$.

Der Nationale Kreditrat in bisheriger Form wurde im Juli 1984 aufgelöst und seine Funktionen auf zwei neue Organe, das Comité de la réglementation bancaire und das Comité des établissements de crédit, übertragen ${ }^{862}$. Das Comité de la réglementation bancaire, das im Rahmen der Regierungsanweisungen allgemeine

853 So z.B. Becker, Wolfgang: Das währungspolitische Instrumentarium in der Bundesrepublik Deutschland und in Frankreich - Ein Vergleich, Diss. Hamburg 1985, S. 22; Caesar, Rolf (1982): a.a.O., S. 574; o. V.: Zuviel Macht für die Bundesbank, a.a.O., S. 55; Boreham, Gordon F.; Bodkin, Ronald G.:a.a.O., S. 194.

Seit Ende 1993 ist die französische Notenbank formal weisungsunabhängig. Vgl. Veit, Otto (1961), a.a.O., S. 184.

855 Das Gesetz überläßt der Regierung die Entscheidung darüber, ob der Finanz- oder der Wirtschaftsminister der Präsident des Kreditrats sein soll. In den meisten französischen Nachkriegsregierungen wurden beide Ressorts zusammengelegt, so daß sich das Entscheidungsproblem nicht stellte, Vgl. Bouveret, Andreas Michael: a.a.O., S. 88.

Vgl. Stoffers, Erich: a.a.O., S. 124.

Vgl. Caesar, Rolf(1982): a.a.O., S. 570.

Vgl. Lampe, Ortrun: a.a.O., S. 58; Hahn, Oswald (1968) Bd. I: a.a.O., S. 174.

Vgl. Mersch, Margrit: Die Banque de France: Organisation und Operationen, Berlin 1972, S. 72.

860 Vgl. o. V.: Vergleichende Studie zur Autonomie der Zentralbanken in der Bundesrepublik Deutschland, Frankreich und Großbritannien: a.a.O., S. 37.

861 Vgl. Mersch, Margrit: a.a.O., S. 75.

862 Vgl. Becker, Wolfgang: a.a.O., S. 27. 
bankgewerbliche Richtlinien aufstellt, besteht aus dem Wirtschafts- und Finanzminister als Präsidenten, dem Gouverneur der Notenbank als Vizepräsidenten, je einem Vertreter der Gewerkschaften und des Bankgewerbes sowie zwei Personen mit besonderer fachlicher Eignung863. Das Comité des établissements de crédit ist ein Sonderorgan der Bankenaufsicht, das sich aus einem nicht-ständigen Mitglied aus der Branche des geprüften Kreditinstituts sowie fünf gesetzlichen Mitgliedern zusammensetzt ${ }^{864}$. Unter der alten Bezeichnung des Nationalen Kreditrats wurde ein neues Gremium geschaffen, das ausschließlich mit Beratungsfunktionen in Fragen der Geldpolitik und des Bankwesens betraut ist ${ }^{865}$. Er besteht aus 53 gesetzlichen Mitgliedern unter dem Vorsitz des Wirtschafts- und Finanzministers 866 .

Die folgenden Ausführungen stützen sich auf die Rechtslage bis Juli 1984, da sich an dem Umfang der Einschränkung der Entscheidungsfreiheit der Notenbank durch die Neuregelungen nichts geändert hat. Nur die Gremien, die diese Einschränkung bewirken, sind andere geworden.

Einige Autoren sprechen von dem Recht der Regierung, der Notenbank über den Nationalen Kreditrat Weisungen zu erteilen ${ }^{867}$. Ein direktes Weisungsrecht der Regierung gibt es hingegen nicht, auch wenn sein Nichtvorhandensein nirgends ausdrücklich festgelegt ist ${ }^{868}$. Das Verhältnis zwischen Regierung, Notenbank und Nationalem Kreditrat ist im Gesetz nur sehr vage formuliert. Das Gesetz über die Bank von Frankreich ermächtigt die Banque de France, sich zu allen Problemen, die das Geldwesen betreffen, zu äußern ${ }^{869}$. Ferner wirkt sie bei der Ausarbeitung der Geldpolitik mit und beteiligt sich an deren Durchführung870. Das Gesetz bestimmt außerdem, daß die Geldpolitik durch die Regierung unter Mitwirkung des Conseil National du Credit im Rahmen seiner Zuständigkeiten festgelegt wird871. Es geht davon aus, daß die Regierung und nicht die Bank die allgemeinen geldpolitischen Beschlüsse faßt und daher die Regierung im Konfliktfall auch über ein Weisungsrecht gegenüber der Notenbank verfügen muß872. Die währungspolitischen Beschlüsse des Nationalen Kreditrates machen zu ihrer

863 Vgl. Becker, Wolfgang: a.a.O., S. 27.

864 Vgl. Becker, Wolfgang: a.a.O., S- 28.

865 Vgl. Becker, Wolfgang: a.a.O., S. 27.

866 Vgl. Becker, Wolfgang: a.a.O., S. 28.

867 Vgl. Caesar, Rolf (1982): a.a.O., S. 570; Bernauer, Engelbert: a.a.O., S. 4.

868 Vgl. Wolff, Karl Friedrich: Die Leitungsorgane der Bankwirtschaft in Frankreich, Diss. Tübingen 1962, S. 107

869 Vgl. LOI n $73-7$ du 3 janvier 1973, Art. 4: abgedruckt in: Bonin, Konrad v.: a.a.O., S. 248.

870 Vgl. Bonin, Konrad v.: a.a.O., S. 132.

871 Vgl. Bonin, Konrad v.: a.a.O., S. 132.

872 Vgl. Bonin, Konrad v.: a.a.O., S. 146 
Durchführung regelmäßig ein Tätigwerden der Banque de France notwendig873. Diese können rechtlich als Weisungen verstanden werden, die die Notenbank zu befolgen hat ${ }^{874}$.

Das Gesetz vom 2. Dezember 1945 gestattet dem Nationalen Kreditrat, seine Entscheidungen in wichtigen Bereichen durch die Banque de France ausführen zu lassen 875 . Es läßt offen, ob die Notenbank selbst darüber entscheiden kann, ob sie diesen Beschlüssen nachkommt ${ }^{876}$. Nach herrschender Auffassung tritt die Notenbank dabei lediglich als Vertreter des Staates auf und ist auch hier an die Weisungen des Nationalen Kreditrates gebunden 877 .

Ebenfalls für eine regierungsabhängige Notenbank spricht die Tatsache, daß die Regierung jederzeit ohne Mitwirkung des Parlaments neue Verordnungen erlassen kann, die die Verwaltung und die Geldpolitik der Bank neuregeln ${ }^{878}$. Die Banque de France hätte keine rechtliche Möglichkeit, beispielsweise ein Dekret der Regierung zu verhindern, daß die Bank ausdrücklich den Weisungen des Staates unterwerfen würde 879 .

Zwei Regelungen sprechen gegen eine Beurteilung der Banque de France als völlig weisungsabhängiges Institut. Seit einer Änderung der Statuten im Jahre 1973 verfügt ein Vertreter der Regierung, der Zensor, über ein aufschiebendes Vetorecht gegen alle Beschlüsse des Generalrats ${ }^{880}$. Entscheidungen des Generalrats sind nur gültig, wenn der Zensor ihnen nicht widerspricht ${ }^{881}$. Der Gouverneur der Bank kann im Falle eines Widerspruchs des Zensors zu einem von ihm gewählten Zeitpunkt einen neuen Beschluß fassen ${ }^{882}$. Das Gesetz enthält keine Aussage darüber, ob der Zensor gegen den neuen Beschluß erneut Einspruch erheben kann ${ }^{883}$. Das Vetorecht des Zensors wurde zur Überwindung von Meinungsunterschieden zwischen der Bank und dem Staat eingeführt ${ }^{884}$. Ein umfassendes Weisungsrecht staatlicher Stellen bedarf aber keiner zusätzlichen Einflußmög-

873 Vgl. Bonin, Konrad v.: a.a.O., S. 147.

874 Vgl. Bonin, Konrad v.: a.a.O., S. 147.

875 Vgl. The Law of December 2, 1945, Art. 13: abgedruckt in: Aufricht, Hans: Central Bank Legislation: A Collection of Central Bank, Monetary and Banking Laws, published by the IMF Washington, D.C. 1967, S. 205f.

876 Vgl. Bonin, Konrad v.: a.a.O., S. 142.

877 Vgl. Bonin, Konrad v.: a.a.O., S. 142 und dortige Literatur.

878 Vgl. Bonin, Konrad v.: a.a.O., S. 147.

879 Vgl. Bonin, Konrad v.: a.a.O., S. 147.

$880 \mathrm{Vgl}$. o. V.: Vergleichende Studie zur Autonomie der Zentralbanken in der Bundesrepublik Deutschland, Frankreich und Großbritannien: a.a.O., S. 37.

881 Vgl. Bonin, Konrad v.: a.a.O., S. 132.

882 Vgl. Bonin, Konrad v.: a.a.O., S. 144.

883 Vgl. Bonin, Konrad v.: a.a.O., S. 144.

884 Vgl. Bonin, Konrad v.: a.a.O., S. 144. 
lichkeiten der Regierung mittels Vetorecht, da jede Meinungsverschiedenheit durch die Erteilung einer Weisung gelöst werden könnte. Andererseits ist der Weg über ein Vetorecht diplomatischer und geräuschloser und daher für die alltägliche Zusammenarbeit von Notenbank und Regienung besser geeignet. Direkte Weisungen sind dadurch nicht ausgeschlossen.

Ebenfalls in einem gewissem Widerspruch zu einer generellen Weisungsabhängigkeit der Bank stehen die Regelungen zur Staatsfinanzierung durch die Notenbank. Das Gesetz sieht vor, daß die Banque de France darüber entsprechende Vereinbarungen mit der Regierung treffen soll885. Dies setzt eine gewisse Selbständigkeit und eigenen Entscheidungsspielraum der Notenbank voraus ${ }^{886}$. Ein Verzicht auf gesonderte Regelungen in diesem Bereich würde bedeuten, daß die Regierung unbegrenzt zur Finanzierung der Staatsausgaben auf die Notenbank Zugriff nehmen könnte ${ }^{887}$. Dies rechtfertigt eine Ausnahme dieses Bereiches aus der generellen Weisungsbefugnis. Eingeschränkt wird diese Einflußmöglichkeit der Notenbank jedoch dadurch, daß diese Vereinbarungen einer Entscheidung des Generalrats bedürfen, die wiederum durch das aufschiebende Vetorecht des Zensors zumindestens verzögert werden können ${ }^{888}$.

De facto verfügt die Banque de France über eine beträchtliche Unabhängigkeit, die die gesetzlichen Regelungen nicht vermuten lassen. Der Nationale Kreditrat besitzt weder eine eigene Rechtspersönlichkeit noch eigene finanzielle Mittel oder eigene Abteilungen - abgesehen von einem bei der Notenbank unterhaltenen Generalsekretariat -, so daß die Vorbereitung und Auswertung der Beschlüsse bei der Banque de France liegen ${ }^{889}$. In der Praxis bestätigt der Nationale Kreditrat die Vorschläge, die die Notenbank erarbeitet hat ${ }^{890}$. Ein besonderer Einfluß auf die Entscheidungen des Nationalen Kreditrates wird der Notenbank aufgrund der Funktion des Gouverneurs der Banque de France als Vizepräsident des Rates zugeschrieben, der in der Regel die Präsidentschaft ausübt ${ }^{891}$. Der Finanzund/bzw. Wirtschaftsminister, de jure Präsident des Rates, kann seine Befugnisse dem Gouverneur der Bank übertragen ${ }^{892}$. Dennoch ist sie formalrechtlich das Exekutivorgan des Nationalen Kreditrates und muß als solches bewertet werden.

Vgl. Bonin, Konrad v.: a.a.O., S. 147.

Vgl. Bonin, Konrad v.: a.a.O., S. 147.

Vgl. Bonin, Konrad v.: a.a.O., S. 148.

Vgl. Bonin, Konrad v.: a.a.O., S. 149.

Vgl. Mersch, Margrit: a.a.O., S. 84f.

Vgl. Mersch, Margrit: a.a.O., S. 83.

Vgl. Mersch, Margrit: a.a.O., S. 23.

Vgl. Mersch, Margrit: a.a.O., S. 62. 
Im Konfliktfall kann der Rat bzw. die Regierung den maßgeblichen Einfluß ausüben893.

Zusammenfassend läßt sich sagen, daß die Banque de France eindeutig durch die Regierung dominiert wird. Mit Ausnahme der Möglichkeiten direkter Staatsfinanzierung durch die Notenbank, bei denen die Banque de France durch das Treffen von Vereinbarungen mit der Regierung quasi ein Vetorecht besitzt, können externe Instanzen maßgeblichen Einfluß nehmen. Selbst Entscheidungen, die offiziell der Notenbank zustehen, werden zuweilen von der Regierung gefällt oder zumindestens vorzeitig verkündet ${ }^{894}$. Auch, wenn ein generelles Weisungsrecht der Regierung nicht explizit im Gesetz niedergelegt ist, kommt man nicht umhin, die Banque de France als weisungsabhängige Notenbank zu bewerten. Daher wird im folgenden nur ein kurzer Überblick über das der Banque de France zur Verfügung stehende geldpolitische Instrumentarium gegeben.

\subsubsection{Ausgabe von Zentralbankgeld durch die Notenbank}

Bei der Emission von Banknoten unterliegt die Banque de France keinen gesetzlichen Beschränkungen ${ }^{895}$. Golddeckungs- und -einlösungsvorschriften wurden 1928 bzw. 1936 aufgehoben 896 .

Die Banque de France kann dem Staat nur dann direkte Kredite gewähren, wenn sie per Gesetz dazu autorisiert wird897. Die Höhe der Direktverschuldung wird zwischen dem Gouverneur der Bank und dem Finanzminister vereinbart und vom Parlament ratifiziert ${ }^{898}$. Diese Kredite dienen allein der kurzfristigen Überbrükkung von Kassenfehlbeträgen ${ }^{899}$. Ferner gewährt die Notenbank dem Schatzamt Kredite gegen Diskontierung sogenannter obligations cautionées 900 sowie sonstiger von Schuldnern des Staates an öffentliche Kassen gegebener Wechsel ${ }^{901}$. Auch der Umfang dieser Kredite ist Gegenstand von Vereinbarungen zwischen

893 Vgl. Bonin, Konrad v.: a.a.O., S. 142.

894 Vgl. Caesar, Rolf (1981): a.a.O., S. 340f.

895 Vgl. Hahn, Oswald (1968) Bd. II: a.a.O., S. 188.

896 Vgl. Bouveret, Andreas, Michael: a.a.O., S. 39.

897 Vgl. Bouveret, Andreas Michael: a.a.O., S. 48.

898 Vgl. Europäische Gemeinschaften Währungsausschuß: a.a.O., S. 138; o. V.: Vergleichende Studie zur Autonomie der Zentralbanken in der Bundesrepublik Deutschland, Frankreich und Großbritannien: a.a.O., S. 38.

899 Vgl. Dohnanyi, Klaus von: a.a.O., S. 76.

900 Das sind solawechsel-ähnliche Papiere, die von Steuer- und Zollpflichtigen ausgestellt werden.

901 Vgl. Stoffers, Erich: a.a.O., S. 125; Bonin, Konrad v.: a.a.O., S. 148. 
Regierung und Notenbank, die vom Parlament ratifiziert werden müssen902. Die Banque de France tätigt keine Erstankäufe von Staatspapieren.

Die Diskontpolitik liegt prinzipiell im Zuständigkeitsbereich der Banque de France ${ }^{903}$. De jure legt der Generalrat die Diskont- und Lombardsätze fest ${ }^{904}$. In der Praxis werden solche Entscheidungen jedoch stets nach Rücksprache mit dem Finanzminister getroffen ${ }^{905} .1948$ wurde die Befugnis zur Erteilung von Rediskontkontingenten offiziell vom Nationalen Kreditrat auf die Notenbank übertragen 906 . Die Rediskontkontingente konnten gegen Strafzins überschritten werden ${ }^{907}$. Seit der Aufhebung der Rediskontkontingente 1971 haben die Banken kein Recht mehr auf Refinanzierung908. Die Notenbank kann über die Erteilung von Diskont- und Lombardkrediten frei entscheiden 909 . Sie muß diese Entscheidungen nicht begründen ${ }^{910}$. Eine Ausnahme bildet die Verpflichtung der Notenbank gemäß dem Gesetz vom 24. Juli 1936, kurzfristige Staatspapiere mit einer Restlaufzeit von drei Monaten sowie bestimmte Wechsel zur Finanzierung von Getreidevorräten unbegrenzt zu diskontieren ${ }^{911}$. Seit dem 26. Juni 1957 ist diese Rediskontierungsverpflichtung von öffentlichen Papieren auf von Privaten gehaltene öffentliche Wechseln beschränkt ${ }^{912}$.

Die Banque de France darf Diskont- und Lombardkredite auch an Privatpersonen vergeben ${ }^{913}$. Der Kreis der diskont- und lombardfähigen Papiere ist gesetzlich festgelegt ${ }^{914}$. Es können Handels- und Finanzwechsel sowie bestimmte staatliche Wechsel rediskontiert werden. Verschiedene Grundgeschäfte bedürfen der vorherigen Rediskontzusage der Notenbank ${ }^{915}$. Diese kann durch Erteilung oder Nichterteilung von Diskontzusagen selektive Kreditpolitik betreiben ${ }^{916}$. Die Banque de France ist ferner ermächtigt, Dauer, Inhalt und Form sowie die allge-

\footnotetext{
902 Vgl. Bonin, Konrad v.: a.a.O., S. 148.

903 Vgl. Hahn, Oswald (1968) Bd. I: a.a.O., S. 174

904 Vgl. Europäische Gemeinschaften Währungsausschuß: a.a.O., S. 165; Mersch, Margrit: a.a.O., S. 29.

905 Vgl. Bank für Internationalen Zahlungsausgleich Basel: a.a.O., S. 195.

906 Vgl. Wolff, Karl Friedrich: a.a.O., S. 116.

907 Vgl. Schuster, Leo (1967): a.a.O., S. 146.

908 Vgl. Stoffers, Erich: a.a.O., S. 126.

909 Vgl. Caesar, Rolf (1981): a.a.O., S. 323.

910 Vgl. Caesar, Rolf (1981): a.a.O., S. 323.

911 Vgl. Wolff, Karl Friedrich: a.a.O., S. 144; Europäische Gemeinschaften Währungsausschuß: a.a.O., S. 162.

912 Vgl. Mersch, Margrit: a.a.O., S. 140

913 Vgl. Bouveret, Andreas Michael: a.a.O., S. 41.

914 Im einzelnen Vgl. Europäische Gemeinschaften Währungsausschuß: a.a.O., S. 164ff.

915 Vgl. Stoffers, Erich: a.a.O., S. 125.

916 Vgl. Europäische Gemeinschaften Währungsausschuß: a.a.O., S. 183.
} 
meinen Bedingungen für die Gewährung von Diskont- und Lombardkrediten zu fixieren ${ }^{917}$. Sie verbietet etwa, daß das Schatzamt seine eigenen Papiere zum Diskont bei der Notenbank einreichen kann 918 . Neben der mengen- und bonitätsmäßigen Prüfung wird die Zustimmung zur Refinanzierung auch von der Verwendung des Kredits gemäß der Zielsetzung des Wirtschaftsplans abhängig gemacht 919 .

Der Generalrat entscheidet entsprechend den gesetzlichen Bestimmungen und nach Zustimmung der Regierung über die Höhe der aus den Gewinnen zu bildenden Rücklagen sowie die Höhe der an den Staat als Alleinaktionär zu zahlenden Dividende 920 .

\subsubsection{Direkte Einflußnahme auf die Kreditvergabe der Banken}

Alle Einflußmöglichkeiten der Banque de France auf die Kreditvergabe der Banken beziehen sich nur auf die privaten Banken, nicht jedoch auf die öffentlichen und halb-öffentlichen Finanzinstitute, auf die in Frankreich über $80 \%$ des Geschäftsvolumens entfällt ${ }^{921}$. Letztere unterliegen direkt der Aufsicht der Regierung 922 .

Der Nationale Kreditrat hat erheblichen Einfluß auf die Kreditvergabe der Banken. Die Verbraucherkredite dürfen eine von ihm festgelegte Höchstgrenze in Bezug auf die haftenden Mittel nicht überschreiten ${ }^{923}$. Ferner setzt er einen Höchstbetrag für Kredite in Prozent des Gesamtkaufpreises fest ${ }^{924}$.

Bis 1970 enthielten die Gesetze keinen ausdrücklichen Hinweis auf das Instrument der Kreditplafondierung925. Das Recht zur direkten Begrenzung der Kreditgewährung durch die kreditpolitischen Entscheidungsträger wurde aus den Bestimmungen abgeleitet, die ihnen die Aufgabe der Überwachung der Kreditgewährung der Banken überträgt ${ }^{926}$. Die Kreditplafondierung erfolgte als bloße Empfehlung des Notenbankgouverneurs an die Banken ${ }^{927} 1970$ wurde die offi-

917 Vgl. Bouveret, Andreas Michael: a.a.O., S. 41.

918 Vgl. Bouveret, Andreas Michael: a.a.O., S. 42.

919 Vgl. Géronomus, René: Notenbank und Bankenkontrolle in Frankreich - Ein Vergleich mit der Bundespublik Deutschland -, in: Bank-Betrieb, 9. Jg. 1969, S. 383.

920 Vgl. Bouveret, Andreas Michael: a.a.O., S. 15.

921 Vgl. Obst, Georg; Hintner, Otto: a.a.O., S. 206.

922 Vgl. Bouveret, Andreas Michael: a.a.O., S. 123.

923 Vgl. Europäische Gemeinschaften Währungsausschuß: a.a.O., S. 184.

924 Vgl. Europäische Gemeinschaften Währungsausschuß: a.a.O., S. 184.

925 Vgl. Bredemeier, Sonning: a.a.O., S. 90.

926 Vgl. Bredemeier, Sonning: a.a.O., S. 90.

927 Vgl. Europäische Gemeinschaften Währungsausschuß: a.a.O., S. 181. 
zielle Rechtsgrundlage geschaffen, die die Banque de France ausdrücklich zu einer administrativen Festsetzung eines Höchstbetrages für die Ausdehnung des Kreditvolumens ermächtigte ${ }^{928}$. Dabei steht dem Nationalen Kreditrat formell die Entscheidungsbefugnis über die Kreditplafondierung $\mathrm{zu}^{929}$. Die Kreditbegrenzung kann sich sowohl auf die Steigerungsraten des Kreditvolumens als auch auf dessen absolute Höhe beziehen 930 . Ferner kann sie flexibel für alle oder einzelne Kreditinstitute gelten sowie auf bestimmte Kreditarten beschränkt werden 931 . Diese Einflußmöglichkeiten auf die Kreditvergabe beziehen sich nicht auf die öffentlichen und halb-öffentlichen Finanzinstitute. Um die sich daraus ergebenden Umgehungsmöglichkeiten zu vermeiden, weist die Regierung die ihr unterstellten Finanzinstitute immer dann zu Kreditbegrenzungen an, wenn die Notenbank die Plafondierungen verordnet ${ }^{932} .1970$ wurde der Kreis der Kreditinstitute, die der Kreditplafondierung der Notenbank unterliegen, erheblich erweitert ${ }^{933} .1987$ wurden die quantitativen Kreditkontrollen aufgehoben 934 . Die Möglichkeit einer Kreditplafondierung besteht aber noch fort ${ }^{935}$.

In Frankreich unterliegen Großkredite der Genehmigungspflicht durch die Notenbank $^{936}$. Ein Großkredit liegt vor, wenn die Bankschulden eines Kreditnehmers bei seinen sämtlichen Bankverbindungen 10 Millionen Franc übersteigt ${ }^{937}$. Eine weitere Begrenzung der Kreditgewährung der Banken stellt die Begrenzung der Summe der von Banken oder Finanzierungsinstituten gewährten Verbraucherkredite auf ein bestimmtes Vielfaches der Eigenmittel des finanzierenden Instituts 938 .

Die Regelung der Bankenkonditionen fallt in Frankreich in den Aufgabenbereich des Nationalen Kreditrats 939 . Er kann u. a. Ober- und Untergrenzen für Soll- und Habenzinsen festsetzen ${ }^{940}$. Bis 1966 waren die Mindestkonditionen für Bankkredite an Wirtschaftsunternehmen und Private aufgrund einer Vorschrift des Na-

\footnotetext{
928 Vgl. Europäische Gemeinschaften Währungsausschuß: a.a.O., S. 181.

929 Vgl. Bredemeier, Sonning: a.a.O., S. 91.

930 Vgl. Obst, Georg; Hintner, Otto: a.a.O., S. 207.

931 Vgl. Obst, Georg; Hintner, Otto: a.a.O., S. 207.

932 Vgl. Bredemeier, Sonning: a.a.O., S. 92.

933 Vgl. Bredemeier, Sonning: a.a.O., S. 96.

934 Vgl. Mader, Richard:a.a.O., S. 130.

935 Vgl. Obst, Georg; Hintner, Otto: a.a.O., S. 207.

936 Vgl. Bernhuber, Max; Hauck, Hartwig: a.a.O., S. 61

937 Vgl. Géronomus, René: a.a.O., S. 383.

938 Vgl. Bernhuber Max; Hauck Hartwig: a.a.O., S. 60.

939 Vgl. Wolff, Karl Friedrich: a.a.O., S. 83.

940 Vgl. Wolff, Karl Friedrich: a.a.O., S. 83ff.
} 
tionalen Kreditrates eng an die Diskontsätze der Banque de France gebunden ${ }^{941}$. Der Kreditrat legte dabei Mindestzinssätze fest, die von den Banken überschritten werden können ${ }^{942}$. Seither dürfen die Banken ihre Kreditkonditionen frei bestimmen $^{943}$. Das Gesetz gegen den Zinswucher vom 28. Dezember 1966 setzt jedoch Höchstsätze für Sollzinsen fest ${ }^{944}$.

Der Nationale Kreditrat legt maximale, nach Warengruppen differenzierte Kreditlaufzeiten fest und bestimmt Mindestanzahlungen 945 .

\subsubsection{Offenmarktpolitik}

Die Banque de France ist durch Verordnung vom 17. Juni 1938 zu Offenmarktgeschäften am Geldmarkt berechtigt ${ }^{946}$. Danach darf sie innerhalb der vom Generalrat festgesetzten Grenzen und $\mathrm{zu}$ den von ihm fixierten Bedingungen kurzfristige marktfähige Papiere der öffentlichen Hand sowie private diskontfähige Effekten am offenen Markt kaufen und verkaufen 947 . Mit langfristigen Papieren darf die Notenbank keine Offenmarktoperationen durchführen 948 . Der Teilnehmerkreis bei Offenmarktgeschäften mit Wertpapieren ist in Frankreich auf Banken beschränkt ${ }^{949}$. Die Banque de France kennt keine Offenmarktgeschäfte mit Privaten 950 . Sie wickelt die Geschäfte über Diskonthäuser $a b$, die dabei eine Vermittlerstellung zwischen der Notenbank und den Kreditinstituten einnehmen 951 .

Die Banque de France ist befugt, auf eigene Rechnung oder auf Rechnung Dritter alle Gold- oder Devisengeschäfte auszuführen ${ }^{952}$. Ferner verwaltet sie den Devisenstabilisierungsfonds für Rechnung des Staates, den der Gesetzgeber im Hinblick auf den Ausgleich zwischen dem Franc und ausländischer Valuta geschaffen hat ${ }^{953}$. Dabei ist sie Weisungen des Finanz- und Wirtschaftsministers unterwor-

941 Vgl. Stoffers, Erich: a.a.O., S. 126.

942 Vgl. Bernhuber, Max; Hauck, Hartwig: a.a.O., S. 35.

943 Vgl. Europäische Gemeinschaften Währungsausschuß: a.a.O., S. 147.

944 Vgl. Europäische Gemeinschaften Währungsausschuß: a.a.O., S. 168.

945 Vgl. Europäische Gemeinschaften Währungsausschuß: a.a.O., S. 184; Mersch, Margrit: a.a.O., S. 80.

946 Vgl. Europäische Gemeinschaften Währungsausschuß: a.a.O., S. 177.

947 Vgl. Mersch, Margrit: a.a.O., S. 168; Wolff, Karl Friedrich: a.a.O., S. 144.

948 Vgl. Europäische Gemeinschaften Währungsausschuß: a.a.O., S. 177.

949 Vgl. Caesar, Rolf (1981): a.a.O., S. 321 F.33.

950 Vgl. Mersch, Margrit: a.a.O., S. 169.

951 Vgl. Mersch, Margrit: a.a.O., S. 169; Bouveret, Andreas Michael: a.a.O., S. 57.

952 Vgl. Bouveret, Andreas Michael: a.a.O., S. 42.

953 Vgl. Bouveret, Andreas Michael: a.a.O., S. 42. 
fen 954 . Der Devisenstabilisierungsfonds besitzt keine eigene Rechtspersönlichkeit, sondern ist ein Sonderkonto des Schatzamts bei der Notenbank ${ }^{955}$. Er wird bei seinen Operationen von der Banque de France unterstützt, indem diese von dem Fonds Devisen gegen andere ausländische Zahlungsmittel oder Franc ankauft ${ }^{956}$. Desweiteren gewährt sie dem Fonds zinslose Darlehen 957 . Die Bank war während der Geltungsdauer der europäischen Währungsschlange verpflichtet, über den Stabilisierungsfonds tätig zu werden, wenn der Kurs des Franc gegenüber anderen Währungen die jeweiligen Interventionspunkte erreichte958. Frankreich verließ im Januar 1974 erstmals und nach kurzer Rückkehr im März 1976 zum zweiten Mal die Schlange 959 . Während dieser Zeit war die Notenbank von einer Interventionspflicht im Rahmen der Schlange entbunden 960.1979 trat Frankreich dem neu gegründeten EWS bei 961 .

\subsubsection{Mindestreservepolitik}

In Frankreich wurde die Mindestreservepolitik im Januar 1967 eingeführt ${ }^{962}$. Sie löste den sogenannten Liquiditätskoeffizienten ab, der die Banken u. a. verpflichtete, einen Teil ihrer Mittel in Staatspapieren anzulegen 963 . Die reservepflichtigen Positionen werden vom Nationalen Kreditrat festlegt ${ }^{964}$. Bis 1971 unterlagen nur Passivpositionen der Mindestreserve 965 . Aufgrund einer Verordnung wurden 1971 zusätzlich auch Kredite einbezogen ${ }^{966}$. Mit der Aufhebung der quantitativen Kreditkontrollen im Jahre 1987 wurde die Mindestreservepflicht schließlich wieder auf die Passivseite beschränkt ${ }^{967}$. Die rechtliche Möglichkeit einer Aktivreserve besteht jedoch weiterhin ${ }^{968}$. Gemäß der Verordnung vom 9. Januar

\footnotetext{
954 Vgl. Mersch, Margrit: a.a.O., S. 23.

955 Vgl. Bouveret, Andreas Michael: a.a.O., S. 43.

956 Vgl. Bouveret, Andreas Michael: a.a.O., S. 45.

957 Vgl. Bouveret, Andreas Michael: a.a.O., S. 45.

958 Vgl. Bouveret, Andreas Michael: a.a.O., S. 43.

959 Vgl. Bouveret, Andreas Michael: a.a.O., S. 44.

960 Vgl. Bouveret, Andreas Michael: a.a.O., S. 44.

961 Vgl. Francke, Hans-Hermann: Der Deutsch-französische Weg zur Europäischen Zentralbank: Diskussionsbeiträge Institut für Finanzwissenschaft der Albert-Ludwigs-

Universität Freiburg i. Br. 8/91, S. 12.

962 Vgl. Europäische Gemeinschaften Währungsausschuß: a.a.O., S. 161.

963 Vgl. Stoffers, Erich: a.a.O., S. 126f, näheres zu den Liquiditätsrichtsätzen bei Wolff, Karl Friedrich: a.a.O., S. 70ff.

964 Vgl. Mersch, Margrit: a.a.O., S. 200.

965 Vgl. Europäische Gemeinschaften Währungsausschuß: a.a.O., S. 170.

966 Europäische Gemeinschaften Währungsausschuß: a.a.O., S. 170.

967 Vgl. Mader, Richard: a.a.O., S. 130.

968 Vgl. Obst, Georg; Hintner, Otto: a.a.O., S. 207.
} 
1967 sind französische und ausländische Banken mindestreservepflichtig, die der Aufsicht des Nationalen Kreditrates unterstehen, sowie alle Institute mit Sonderstatus, die Einlagen von Nichtbanken entgegennehmen und durch Kreditgewährungen am Geldschöpfungsproze $\beta$ beteiligt sind 969 . Die reservepflichtigen Institute sind verpflichtet, die erforderlichen Reserven als unverzinsliche Guthaben bei der Zentralbank zu halten 970 . Die Banque de France ist vom Nationalen Kreditrat ermächtigt, die Mindestreservesätze bis zu einem von ihm festgesetzten Höchstsatz autonom zu bestimmen ${ }^{971}$. Die Sätze werden nach Art und Höhe der reservepflichtigen Verbindlichkeiten gestaffelt 972 . Bei Nichteinhaltung der Mindestreservebestimmungen kann die Zentralbank Strafzinsen einfordern ${ }^{973}$.

\subsubsection{Zusammenfassende Beurteilung der funktionellen Unabhängigkeit der Banque de France}

Aufgrund der allgemeinen Weisungsbefugnis der Regierung gegenüber der Notenbank ist die Banque de France im Untersuchungszeitraum völlig abhängig und muß mit Bewertungsstufe L des Schemas in Abb. 5 beurteilt werden, auch wenn sie faktisch über einen großen Einfluß auf die geldpolitischen Entscheidungen verfügt.

\subsection{Japan}

Die Bank von Japan wurde im Oktober 1882 gegründet und im Februar 1942 unter dem Bank of Japan Law reorganisiert ${ }^{974}$. Ihr Sitz ist in Tokio ${ }^{975}$. Sie ist eine Aktiengesellschaft mit Sonderstatus, deren Aktionäre jedoch keinen Einfluß auf die Bankpolitik nehmen können $976.55 \%$ des Grundkapitals befinden sich in Staatsbesitz; die restlichen $45 \%$ werden von Privaten gehalten ${ }^{977}$. Zentrales

969 Vgl. Europäische Gemeinschaften Währungsausschuß: a.a.O., S. 170.

970 Vgl. Europäische Gemeinschaften Währungsausschuß: a.a.O., S. 171.

971 Vgl. Europäische Gemeinschaften Währungsausschuß: a.a.O., S. 172; Bouveret, Andreas, Michael: a.a.O., S. 66.

972 Vgl. Mersch, Margrit: a.a.O., S. 201; Europäische Gemeinschaften Währungsausschuß: a.a.O., S. 172.

973 Vgl. Stoffers, Erich: a.a.O., S. 127.

974 Vgl. Suzuki, Yoshio (Ed.): The Japanese Financial System, Oxford 1987, S. 305.

975 Vgl. The Bank of Japan Law, Art. 4.

976 Vgl. Schaede, Ulrike: Geldpolitik in Japan 1950-1985, Förderverein Marburger JapanReihe 1, Marburg 1989, S. 14.

977 Vgl. Wettlaufer, Hans-Dieter: a.a.O., S. 67. 
Exekutivorgan ist das Direktorium, das sich aus dem Gouverneur, dem Vizegouverneur und mindestens drei Direktoren zusammensetzt ${ }^{978}$.

\subsubsection{Personelle Unabhängigkeit}

\subsubsection{Ernennungsinstanzen (Ebene 1)}

Gouverneur und Vizegouverneur werden vom Premierminister ernannt, wobei sich eingebürgert hat, daß die Gouverneure abwechselnd aus den Reihen früherer Beamter des Finanzministeriums und der Notenbank selbst bestimmt werden 979 . Die Direktoren ernennt der Finanzminister auf Vorschlag des Gouverneurs 980 . Oberstes Entscheidungsgremium der Bank von Japan ist der Zentralbankrat, dem neben dem Gouverneur ein Vertreter des Finanzministeriums und des Planungsamtes, je ein Vertreter einer städtischen Großbank und einer Regionalbank sowie ein Vertreter der Industrie und der Landwirtschaft angehören ${ }^{981}$. Der Zentralbankrat bestimmt nicht nur die grundsätzliche Ausrichtung der Geldpolitik, sondern auch über Art und Umfang des einzusetzenden Instrumentariums982. Daher ist er das für die Beurteilung der personellen Unabhängigkeit der Bank von Japan entscheidende Notenbankgremium. Die beiden Regierungsvertreter haben kein Stimmrecht, so daß die geldpolitischen Entscheidungen mittels einfacher Mehrheit vom Gouverneur und den übrigen Mitgliedern getroffen werden 983 . Letztere werden von der Regierung mit Zustimmung beider Häuser des Parlaments ernannt ${ }^{984}$.

\section{Fazit:}

Die japanische Notenbank kann die Entscheidungsmehrheit ihrer Leitungsorgane nicht selbst ernennen.

978 Vgl. Schaede, Ulrike: a.a.O., S. 14.

979 Vgl. o. V.: Central Banks: Amerika versus Japan - The rewards of independence, in: The Economist 25.1.92, S. 22.

980 Vgl. Schaede, Ulrike: a.a.O., S. 14.

981 Vgl. Suzuki, Yoshio: a.a.O., S. 313.

982 Vgl. Suzuki, Yoshio: a.a.O., S. 313.

983 Vgl. Schiffer, Hubert F.: The modern Japanese banking system, New York 1962, S. 56.

984 Vgl. Kure, Bunji: Organisation und Aufgaben der Bank von Japan, in: Zeitschrift für das gesamte Kreditwesen H.19/70, S. 920. 


\subsubsection{Abberufungsinstanzen (Ebene 2)}

Der Finanzminister darf nach Rücksprache mit dem Kabinett Mitglieder der Notenbankleitung absetzen „whenever it is deemed particilarly necessary for the attainment of the object to the bank" $" 985$.

\section{Fazit:}

Die Notenbank ist weder die entscheidende Abberufungsinstanz noch kann sie drohende Abberufungen verhindern. Somit sind die näheren Abberufungsmodalitäten und Wiederernennungsvorschriften für die Beurteilung der personellen Unabhängigkeit der Bank von Japan unbedeutend.

\subsubsection{Kreis der Ernennungsfähigen (Ebene 6)}

Der Kreis der Ernennungsfähigen ist insofern eingeengt, als sich der Zentralbankrat in festgelegtem Verhältnis aus Regierungsvertretern sowie Repräsentanten der Geschäftsbanken, der Wirtschaft und Landwirtschaft zusammensetzen muß986. Ferner dürfen sich Mitglieder des Notenbankleitung während ihrer Amtszeit weder politisch noch in der Wirtschaft engagieren oder eine vergütete Tätigkeit ohne Zustimmung des Kabinetts annehmen ${ }^{987}$. Zur Vermeidung einer eventuellen Abwerbung von Notenbankmitgliedern, die vor Ablauf ihrer Amtszeit ihre Arbeit niederlegen, dürfen sie zwei Jahre lang keine Tätigkeit in einer Finanzinstitution aufnehmen, die von der Notenbank beaufsichtigt wird ${ }^{988}$. Die Notenbankleitung kann den Kreis der Ernennungsfähigen nicht beeinflussen.

\section{Fazit:}

Die Notenbank hat keinen Einfluß auf den Kreis der Ernennungsfähigen.

\subsubsection{Beurteilung der personellen Unabhängigkeit}

Die Bank of Japan ist mit Ziffer 26 des Entscheidungsbaums in Abb. 1 personell abhängig.

985 The Bank of Japan Law, Art. 47.

986 Vgl. Schiffer, Hubert F.: a.a.O., S. 55.

987 Vgl. Schiffer, Hubert F.: a.a.O., S. 57.

988 Vgl. Schiffer, Hubert F.: a.a.O., S. 57. 


\subsubsection{Funktionelle Unabhängigkeit}

\subsubsection{Instrumentenübergreifende Regelungen}

Die Bank von Japan gilt als vollständig untergeordnetes Instrument der Regierungspolitik ${ }^{989}$. Der Bank of Japan Act ermächtigt die Regierung nicht nur zu einer umfassenden Aufsicht über die Notenbank, sondern auch zur Erteilung von Weisungen bzgl. ihrer Geschäfte 990 . In der Praxis ist die Beziehung zwischen Notenbank und Regierung durch aktive wechselseitige Kontakte geprägt 991 . Die Geldpolitik wird soweit wie möglich im Entscheidungsbereich des Zentralbankrats belassen, doch ist die Regierung zweifelsfrei in der stärkeren Position. So kann der Finanzminister beispielsweise nach Rücksprache mit dem Kabinett den Gouverneur und seinen Stellvertreter absetzen und selbst die ihm notwendig erscheinenden Maßnahmen einleiten 992. Das Finanzministerium darf ferner nach Belieben die Notenausgabe der Bank und den Einsatz der geldpolitischen Mittel überwachen sowie den Status des Noteninstituts verändern 993 . Die Einzelpersonen, die $45 \%$ des Kapitals der Bank von Japan halten, haben weder Stimmrecht noch sonstige Möglichkeiten der Einflußnahme auf die geldpolitischen Entscheidungen ${ }^{994}$.

Aufgrund der weitreichenden Einflußmöglichkeiten des Finanzministeriums auf die geldpolitischen Entscheidungen der Notenbank, die weit über allgemeine Richtlinien hinausgehen, ist die Bank von Japan de jure völlig abhängig. Alle hier betrachteten geldpolitischen Instrumente müssen mit der höchsten Abhängigkeitsstufe $\mathrm{L}$ bewertet werden. Daher wird im folgenden nur ein kurzer Überblick über die Ausgestaltung des Instrumentariums gegeben.

\subsubsection{Ausgabe von Zentralbankgeld durch die Notenbank}

Die Bank von Japan kann Banknoten nur bis zu einem vom Finanzminister festgelegten Limit ausgeben 995 . Für eine Überschreitung des Limits benötigt die Bank wiederum die Zustimmung des Finanzministers.

989 Vgl. Schiffer, Hubert F.: a.a.O., S. 53f; o. V.: Central Banks: Amerika versus Japan The rewards of independence: a.a.O., S. 21.

$990 \mathrm{Vgl}$. The Bank of Japan - Economic Research Department: The Bank of Japan. It's organization and monetary policies, o.O. 1973, S. 7.

991 Vgl. The Bank of Japan - Economic Research Department: a.a.O., S. 7.

992 Vgl. Schaede, Ulrike: a.a.O., S. 15.

993 Vgl. Schaede, Ulrike: a.a.O., S. 15.

994 Vgl. Horke, Gertraude: Die Rolle der Banken in Japan, in: Österreichisches Bankarchiv 8/69, S. 305.

995 Vgl. Suzuki, Yoshio: a.a.O., S. 306. 
Die Notenbank ist ermächtigt, Staatspapiere zu zeichnen 996 . Es gibt weder für eine Buchkreditgewährung noch für den Erwerb von Staatstiteln gesetzliche Grenzen 997. Das Finance Law von 1947 verbietet ihr jedoch den direkten Erwerb langfristiger Papiere mit einer Fälligkeit von über einem Jahr sowie die Kreditgewährung mit einer Laufzeit über einem Jahr998. Die Bank von Japan ist verpflichtet, den größten Teil ihres Gewinns an das Finanzministerium abzuführen ${ }^{999}$. 1/20 des Gewinns wird an einen Reservefonds überwiesen. Weitere Rücklagenbildung bzw. die Zahlung einer Dividende von maximal $5 \%$ des eingezahlten Kapitals an die Anteilseigner bedarf der Zustimmung des Finanzministers 1000 .

Zum Zwecke der Refinanzierung darf die Notenbank eine Vielzahl von Papieren annehmen, die gesetzlich festgelegt sind ${ }^{1001}$. Es können sich nur die von ihr anerkannten Kreditinstitute bei ihr refinanzieren 1002. Mit Privatpersonen betreibt die Zentralbank keine Geschäfte ${ }^{1003}$. Das Gesetz verbietet dies aber nicht ${ }^{1004}$. 1962 legte die Bank von Japan erstmals Kreditlinien für die Banken fest, die nicht überschritten werden können 1005 . Der amtliche Diskontsatz wird traditionell vom Policy Board, dem kreditpolitischen Entscheidungsgremium der Bank von Japan, festgelegt ${ }^{1006}$. In der Praxis verkündet aber zuweilen auch das Finanzministerium ohne Einschaltung der Notenbank die Veränderung der Leitzinsen ${ }^{1007}$. Er ist nach ungeschriebenem Gesetz eng an die Zinsen für (kurzfristige) Bankkredite gekoppelt, so daß sich jede Zinsänderung sofort in den Geldbeschaffungskosten der Unternehmen niederschlägt ${ }^{1008}$.

996 Vgl. Schiffer, Hubert F.: a.a.O., S. 62.

997 Vgl. Hahn, Oswald (1968) Bd. II: a.a.O., S. 177.

998 Vgl. Suzuki, Yoshio: a.a.O., S. 311.

999 Vgl. Wettlaufer, Hans-Dieter: a.a.O., S. 67.

1000 Vgl. Wettlaufer, Hans-Dieter: a.a.O., S. 67.

1001 Vgl. Schiffer, Hubert F.: a.a.O., S. 62 f.

1002 Vgl. Pfisterer, Hans: Kredit und Währung in Japan, in: Sparkasse 1/74, S. 20.

1003 Vgl. The Bank of Japan - Economic Research Department: a.a.O., S. 12.

1004 The Bank of Japan - Economic Research Department: The Bank of Japan - It's function and organization, o. O. 1964, S. 24.

1005 Vgl. Kure, Bunji:a.a.O., S. 920.

1006 Vgl. o. V.: Central Banks: Amerika versus Japan - The rewards of independence: a.a.O., S. 21.

1007 Vgl. Sender, Henny: The Bank of Japan under siege, in: Institutional Investor 11/88, S. 59.

1008 Vgl. o. V.: Banken in Japan, in: Zeitschrift für das gesamte Kreditwesen H.23/81, S. 1032 . 


\subsubsection{Direkte Einflußnahme auf die Kreditvergabe der Banken}

Die japanische Notenbank verwendet quantitative Kreditrestriktionen, die für jedes Geldinstitut individuell festgelegt werden 1009 . Dieses Begrenzungsverfahren wird als window guidance bezeichnet 1010 . Es handelt sich dabei zwar nur um Appelle, jedoch müssen Banken, die sich nicht an die Plafonds halten, mit einer Einschränkung ihrer Refinanzierungsmöglichkeiten rechnen 1011. Auch auf die anderen Bereiche des Geschäftsgebarens der Banken nimmt die Notenbank mittels Empfehlungen starken Einfluß, da die Geldinstitute bei Nichteinhaltung mit Sanktionen rechnen müssen ${ }^{1012}$. Die Bank von Japan darf diesbezüglich jedoch keine gesetzlich bindenden Richtlinien aufstellen, so daß ihr nur das Druckmittel der Vorenthaltung von Refinanzierungsmöglichkeiten bleibt ${ }^{1013}$. Sinkende Einflußmöglichkeiten entstehen der Notenbank durch die zunehmende Internationalisierung des japanischen Bankensystems, da sich ausländische Banken nicht an diese Richtlinien halten 1014 .

Für Depositensätze gibt es Höchstgrenzen, die nur auf Vorschlag des Finanzministers geändert werden können. Die Änderungen werden von der Notenbank und dem Zinsanpassungsrat 1015 beraten, von der Notenbank beschlossen und vom Finanzminister bekanntgegeben ${ }^{1016}$. Ferner kann die Zentralbank Richtlinien für die Zinssätze verschiedener Einlagenkategorien festlegen 1017. Die Spareinlagenzinsen der Post, einem staatlich kontrollierten Sparinstitut, sind dem Zugriff der Notenbank entzogen. Sie werden vom Minister für Post und Telekommunikation festgesetzt ${ }^{1018}$.

1009 Vgl. Pfisterer, Hans (1974): a.a.O., S. 20.

1010 Vgl. Pfisterer, Hans (1974): a.a.O., S. 20.

1011 Vgl. Cargill, Thomas F.; Royama, Shoichi: The Transition of Fianance in Japan and the United States, Hoover Press Publication 372, Stanford 1988, 79.

1012 Vgl. o. V.: Discomfiture of Bank of Japan at loss of exalted power, in: The Oriental Economist 8,9/84 S. 15.

1013 Vgl. Bronte, Stephen: The Bank of Japan strikes back, in: Euromoney 11/80, S. 66.

1014 Vgl. Smith, Charles: Discounting theirs fears, in: Far Eastern Economic Review Vol. 138 Nr. 41, 8.11.87, S. 116.

1015 Dieses Gremium setzt sich aus Wissenschaftlern und gut unterrichteten Persönlichkeiten zusammen.

1016 Vgl. o. V.: Banken in Japan, a.a.O., S. 1031.

1017 Vgl. o. V.: Banken in Japan, a.a.O., S. 1031.

1018 Vgl. Bronte, Stephen: a.a.O., S. 66. 


\subsubsection{Offenmarktpolitik}

Die Bank von Japan ist ermächtigt neben gesetzlich festgeschriebenen Wertpapieren auch Gold und Silber zu handeln 1019. Für den Erwerb langfristiger Staatspapiere, deren direkter Ankauf durch die Notenbank nicht gestattet ist, gibt es im Rahmen der Offenmarktpolitik keine Grenze ${ }^{1020}$.

Zum Ausgleich der Devisenkurse führt die Notenbank Devisengeschäfte durch und kontrolliert die Devisenbestände sowie die kurzfristigen Devisentransaktionen der Außenhandelsbanken 1021 .

\subsubsection{Mindestreservepolitik}

Die Mindestreservepolitik wurde in Japan erst 1957 eingeführt 1022 . Die Notenbank benötigt für alle Entscheidungen zur Errichtung, Änderung und Abschaffung der Mindestreservepflicht die Genehmigung des Finanzministers ${ }^{1023}$. Die Mindestreservepflicht erstreckt sich auf eine vergleichsweise breite Palette von Bankpassiva, weil Finanzinnovationen zügig bei der Neubegrenzung der mindestreservepflichtigen Verbindlichkeiten berücksichtigt werden ${ }^{1024}$. Reservepflichtig sind Termineinlagen und sonstige Einlagen, ferner Wertpapieremissionen sowie Verbindlichkeiten gegen Off-Shore Zentren 1025 . Betroffen sind alle wichtigen Finanzinstitutsgruppen 1026. Für Mindestreservesätze gelten gesetzliche Höchstgrenzen 1027. Sie sind nach Art und Höhe der Einlagen sowie nach Bankengruppen gestaffelt ${ }^{1028}$. Im internationalen Vergleich weist das japanische Mindestreservesystem daher eine sehr differenzierte Struktur auf, die der starken Segmentierung des japanischen Finanzsystems Rechnung trägt, in dem sich die einzelnen Bankengruppen auf bestimmte Geschäftsarten konzentrieren und sich in unterschiedlicher Weise refinanzieren, ${ }^{1029}$.

$1019 \mathrm{Vgl}$. The Bank of Japan Law, Art. 20.

1020 Vgl. Swinburne, Mark; Castello-Branco, Marta: a.a.O., S. 34.

1021 Vgl. Kure, Bunji: a.a.O., S. 921.

1022 Vgl. Pfisterer, Hans (1974): a.a.O., S. 20.

$1023 \mathrm{Vgl}$. The Bank of Japan - Economic Research Department: a.a.O., S. 6.

1024 Vgl. o. V.: Mindestreserveregelungen im Ausland, in: Monatsberichte der Deutschen Bundesbank, 3/1990, S. 25.

1025 Vgl. Meyer-Horn: Mindestreserven nur noch Ultima ratio?, in: Sparkasse 4/1993, S. 157.

1026 Vgl. Mader, Richard: a.a.O., S. 129.

1027 Vgl. Kure, Bunji: a.a.O., S. 921.

1028 Vgl. Mader, Richard: a.a.O., S. 128.

1029 Vgl. Mader, Richard: a.a.O., S. 128. 


\subsubsection{Zusammenfassende Beurteilung der funktionellen Unabhängigkeit der Bank of Japan}

Aufgrund der allgemeinen Weisungsbefugnis der Regierung gegenüber der Notenbank ist die Bank von Japan mit Bewertungsstufe L des Schemas in Abb. 5 als abhängig einzustufen. Faktisch trifft sie ihre geldpolitischen Entscheidungen jedoch verhältnismäßig unabhängig 1030 .

\subsection{Niederlande}

Die Niederländische Bank mit ihrem Hauptsitz in Amsterdam wurde 1814 gegründet 1031 . Ihre Stellung und Tätigkeit beruht auf dem Bankgesetz von 1948 und dessen Ergänzungsgesetzen vom 18. Januar 1952 und 13. Juli 19551032. Die Nederlandsche Bank ist eine Aktiengesellschaft, deren Kapital ausschließlich vom Staat gehalten wird ${ }^{1033}$. Thre Organe sind das Direktorium, der Kommissarsrat, der Königliche Kommissar und der Bankrat ${ }^{1034}$. Das Direktorium, bestehend aus einem Präsidenten, einem Sekretär sowie mindestens drei und höchstens fünf Direktoren, ist das eigentliche entscheidungstreffende Organ.

\subsubsection{Personelle Unabhängigkeit}

\subsubsection{Ernennungsinstanzen (Ebene 1)}

Die Mitglieder des Direktoriums werden von der Krone ${ }^{1035}$ ernannt ${ }^{1036}$. Die Krone wählt die zu ernennende Persönlichkeit aus einer Dreierliste bzw. für die Ernennung des Präsidenten und des Sekretärs aus einer Zweinamensliste aus, die vom Kommissarsrat und Bankrat gemeinsam erstellt worden ist ${ }^{1037}$. Faktisch hat die Notenbank dadurch einen erheblichen Einfluß auf die Ernennungen. Das Ge-

1030 Vgl. o. V.: Central Banks: Amerika versus Japan - The rewards of independence: a.a.O., S. $22 f$.

1031 Vgl. Bank für Internationalen Zahlungsausgleich: a.a.O., S. 317.

$1032 \mathrm{Vgl}$. Bank für Internationalen Zahlungsausgleich: a.a.O., S. 317.

1033 Vgl. Stoffers, Erich: a.a.O., S. 138.

1034 Vgl. Schuster, Leo (1967): a.a.O., S. 91.

1035 Die Krone besteht aus dem Monarchen und den Ministern, Vgl. Woyke, Wichard: Die Niederlande: Raum, Bevölkerung, Struktur, Wirtschaft und Staat, in: Niedersächsische Landeszentrale für politische Bildung (Hrsg.): Die Niederlande und Deutschland. Nachbarn in Europa, Hannover 1992, S. 18.

1036 Vgl. Schuster, Leo (1967): a.a.O., S. 91.

1037 Vgl. Hahn, Oswald (1968) Bd. II: a.a.O., S. 99. 
setz geht davon aus, daß in der Regel einer der Kandidanten auf der Liste ernannt wird ${ }^{1038}$. Falls keiner der Bewerber genehm ist, kann erneut eine Liste vorgelegt werden. Erst, wenn wieder kein Kandidat berufen wird, ist die Ernennung ausschließliche Sache der Krone 1039.

Der Kommissarsrat besteht aus zwölf Mitgliedern, die vom Staat in seiner Funktion als alleiniger Aktionär bestellt werden ${ }^{1040}$. Die Auswahl der Persönlichkeiten erfolgt aus einer Dreinamensliste, die vom Kommissarsrat und dem Bankrat erstellt wird ${ }^{1041}$. Der Kommissarsrat überwacht die Führung der Bank und berät die Direktion in allen von Gesetz und Satzung vorgesehenen Fällen 1042. Treten Konflikte zwischen Direktorium und Kommissarsrat auf, entscheidet eine fünköpfige Expertenkommission ${ }^{1043}$. Durch den königlichen Kommissar, der von der Krone ernannt wird, überprüft die Regierung die Gesetzmäßigkeit von Bilanz und Gewinn- und Verlustrechnung der Bank ${ }^{1044}$. Er ist zudem Vorsitzender des siebzehnköpfigen Bankrats, der nur beratende Funktion hat ${ }^{1045}$. Diesem gehören neben dem Königlichen Kommissar vier Mitglieder des Kommissarsrats sowie 12 von der Krone ernannte Wirtschaftsvertreter an 1046.

Fazit:

Auch wenn die Direktoriumsmitglieder faktisch aufgrund der Vorschläge von Notenbankorganen ernannt werden, hat die Notenbank im Extremfall keinerlei Einfluß auf die Berufungen. Die Krone ist nicht an die Vorschläge der Notenbankorgane gebunden. Die Notenbank kann nicht die Entscheidungsmehrheit ernennen.

\subsubsection{Abberufungsinstanzen (Ebene 2)}

Die Krone als Emennungsinstanz kann Mitglieder der Notenbank abberufen 1047. Ein diesbezügliches Vetorecht hat die Notenbank nicht.

Fazit:

Die Notenbank ist nicht die maßgebliche Abberufungsinstanz.

1038 Vgl. Bank für Internationalen Zahlungsausgleich Basel: a.a.O., S. 321.

1039 Vgl. Bank für Internationalen Zahlungsausgleich Basel: a.a.O., S. 321.

1040 Vgl. Schuster, Leo (1967): a.a.O., S. 91.

1041 Vgl. Schuster, Leo (1967): a.a.O., S. 91.

1042 Vgl. Schuster, Leo (1967): a.a.O., S. 92.

1043 Vgl. Schuster, Leo (1967): a.a.O., S. 92.

1044 Vgl. Schuster, Leo (1967): a.a.O., S. 92.

1045 Vgl. Schuster, Leo (1967): a.a.O., S. 92.

1046 Vgl. Schuster, Leo (1967): a.a.O., S. 92.

1047 Vgl. Swinburne, Mark; Castello-Branco, Marta: a.a.O., S. 33. 


\subsubsection{Ernennungs- und Abberufungsmodalitäten}

Die Krone kann Amtsinhaber auf Empfehlung des Boards oder aus berechtigten Gründen abberufen ${ }^{1048}$. Des weiteren können Direktoriumsmitglieder von der Krone nach Anhörung des Staatsrates von ihren Ämtern entbunden werden, wenn sie Weisungen des Finanzministers trotz deren Billigung durch die Krone nicht oder nur nachlässig ausführen 1049. Diese Regelung ermöglicht Abberufungen aus politischen Gründen, weil die Weisungen einen direkten Eingriff in die geldpolitischen Entscheidungen der Bank darstellen.

Fazit:

Externe Instanzen können Abberufungen aus politischen Gründen vornehmen. Damit spielen nähere Abberufungsmodalitäten sowie Wiederemennungsregelungen keine Rolle für die Beurteilung der personellen Unabhängigkeit der niederländischen Notenbank.

\subsubsection{Kreis der Ernennungsfahigen (Ebene 6)}

Der Kommissarsrat setzt nach Billigung durch die Krone die Bezüge der Direktoriumsmitglieder fest ${ }^{1050}$. Das Zustimmungsrecht der Krone zu den Verträgen setzt der Entscheidungsfreiheit der Bank allerdings Grenzen, so daß das Institut über die Besoldungsregelungen nur bedingt Einfluß auf den Kreis der Ernennungsfähigen nehmen kann.

\section{Fazit:}

Die niederländische Notenbank kann auf den Kreis der Ernennungsfähigen durch ihren Einfluß auf die Besoldung der Notenbankmitglieder Einfluß nehmen.

\subsubsection{Beurteilung der personellen Unabhängigkeit}

Die niederländische Zentralbank erreicht mit der Bewertungsstufe 25 des Entscheidungsbaums in Abb. 1 den Unabhängigkeitsgrad abhängig.

1048 Vgl. Swinburne, Mark; Castello-Branco, Marta: a.a.O., S. 33.

1049 Vgl. Bernhuber, Max; Hauck, Hartwig: a.a.O., S. 25.

$1050 \mathrm{Vgl}$. Bank für Internationalen Zahlungsausgleich Basel: a.a.O., S. 322. 


\subsubsection{Funktionelle Unabhängigkeit}

\subsubsection{Instrumentenübergreifende Regelungen}

Die Niederländische Notenbank verfügt über ein umfassendes geldpolitisches Instrumentarium. Nach Anhörung des Bankrates kann sie zudem zu weiteren, über den gesetzlichen Rahmen hinausgehenden Geschäften ermächtigt werden, sofern diese im allgemeinen Interesse liegen 1051 . Grundsätzlich kann die Zentralbank über den Einsatz der geldpolitischen Mittel selbständig entscheiden 1052. Der Finanzminister kann ihr aber nach Anhörung des Bankrates alle Weisungen erteilen, die er für erforderlich hält, um die Politik der Regierung mit der der Notenbank zu koordinieren 1053. Die Bankdirektion kann gegen diese Weisungen binnen drei Tagen Einspruch erheben 1054 . In diesem Fall entscheidet die Krone, ob die Weisung zu befolgen ist oder nicht ${ }^{1055}$. Die Bank muß die Entscheidung der Krone akzeptieren. Befolgt sie die Weisungen nicht, darf die Krone die Mitglieder der Notenbankleitung ihres Amtes entheben 1056. Das Appellationsrecht der Bankdirektion bei der Krone wird zuweilen als Argument dafür vorgebracht, daß die Notenbank der Regierung nicht unterstellt, sondern ihr gleichgestellt ist ${ }^{1057}$. Dem ist insofern nicht zuzustimmen, als die Regierung die weisungsgebende Instanz ist, wenn auch im Falle eines Widerspruchs der Notenbank, nur mit Genehmigung der Krone. Die Bank hat dagegen keinerlei Entscheidungsrechte und ist somit de jure völlig abhängig. Aufgrund des umfassenden Weisungsrechts müssen sämtliche geldpolitischen Instrumente mit dem höchsten Abhängigkeitsgrad bewertet werden. Daher wird im folgenden nur ein kurzer Überblick über die Ausgestaltung des Instrumentariums gegeben.

\subsubsection{Ausgabe von Zentralbankgeld durch die Notenbank}

Trotz der dominierenden Stellung des Finanzministers setzen die Statuten der direkten Kreditvergabe der Zentralbank an die Regierung enge Grenzen ${ }^{1058}$. Die Notenbank ist verpflichtet, dem Staat jederzeit einen zinslosen Kredit bis zu ei-

1051 Vgl. Schuster, Leo (1967): a.a.O., S. 93.

1052 Vgl. Bank für Internationalen Zahlungsausgleich Basel: a.a.O., S. 359.

1053 Vgl. Veit, Otto (1961), a.a.O., S. 184f.

1054 Vgl. Bank für Internationalen Zahlungsausgleich Basel: a.a.O., S. 359f.

1055 Vgl. Bank für Internationalen Zahlungsausgleich Basel: a.a.O., S. 360.

$1056 \mathrm{Vgl}$. Eizenga, Wietze: The independence of the Federal Reserve System and of the Netherlands Bank - A comparative analysis; Société Universitaire Européenne de Recherches Financières, Tilburg 1983, S. 12.

1057 Vgl. Bank für Internationalen Zahlungsausgleich Basel: a.a.O., S. 361.

1058 Vgl. Castello-Branco, Marta; Swinburne, Mark: a.a.O., S. 21. 
nem festgelegten Höchstbetrag zur Verfügung zu stellen ${ }^{1059}$. Darüber hinaus ist ihr eine weitere Kreditgewährung freigestellt ${ }^{1060}$. Die Bank darf keinen Kredit ohne Sicherheiten gewähren ${ }^{1061}$. Das Bankgesetz ermächtigt sie zur Diskontierung von Tratten und Solawechseln, die bestimmte Bedingungen erfüllen, ferner von Schatzpapieren der niederländischen Regierung sowie bestimmten Schuldverschreibungen 1062. Desweiteren kann sie festgelegte Werte durch Gewährung eines Kredits oder im Kontokorrent lombardieren ${ }^{1063}$. Bei der Notenbank können sich Banken, Devisenhändler sowie sonstige natürliche und juristische Personen refinanzieren ${ }^{1064}$. Die Niederländische Notenbank legt keine Rediskontkontingente fest, aber sie kann jederzeit eingereichtes Material ablehnen, auch, wenn es den notwendigen Anforderungen entspricht ${ }^{1065}$. Ebenso kann sie die Gewährung von Krediten auch an zusätzliche Bedingungen knüpfen ${ }^{1066}$.

\subsubsection{Direkte Einflußnahme auf die Kreditvergabe der Banken}

Das Gesetz über die Nederlandsche Bank von 1948 enthält keinen Hinweis über das Instrument der Kreditplafondierung1067. Durch das Gesetz betreffend die Aufsicht über das Kreditwesen vom 21. Juni 1956 ist die Notenbank gehalten, quantitative Kreditbeschränkungen im Rahmen von freiwilligen Abkommen mit den betroffenen Banken zu erreichen ${ }^{1068}$. Nur, wenn keine Einigung erzielt wird, kann sie entsprechende Vorschriften erlassen, die vom Finanzminister genehmigt und innerhalb von drei Monaten durch das Parlament gebilligt werden müssen 1069 . Die Notenbank ist ermächtigt, diese Vorschriften einmal um die ursprüngliche Laufzeit von maximal einem Jahr zu verlängern ${ }^{1070}$. Jede weitere Verlängerung bedarf wiederum der Billigung von Finanzminister und Parlament ${ }^{1071}$. Die Kreditbeschränkungen können sich auf bestimmte Arten und For-

1059 Vgl. Bank für Internationalen Zahlungsausgleich Basel: a.a.O., S. 354.

1060 Vgl. Bernhuber, Max; Hauck, Hartwig: a.a.O., S. 16.

$1061 \mathrm{Vgl}$. Bank für Internationalen Zahlungsausgleich Basel: a.a.O., S. 336.

1062 Vgl. Bank für Internationalen Zahlungsausgleich Basel: a.a.O., S. 334f, näheres zu den rediskontierbaren Papieren bei Europäische Gemeinschaften Währungsausschuß: a.a.O., S. 307.

1063 Vgl. Bank für Internationalen Zahlungsausgleich Basel: a.a.O., S. 335.

1064 Vgl. Europäische Gemeinschaften Währungsausschuß: a.a.O., S. 306.

1065 Vgl. Veit, Otto (1961), a.a.O., S. 637.

1066 Vgl. Bank für Internationalen Zahlungsausgleich Basel: a.a.O., S. 354.

1067 Vgl. Bredemeier, Sonning: a.a. O., S. 104.

1068 Vgl. Bredemeier, Sonning: a.a.O., S. 104.

1069 Vgl. Europäische Gemeinschaften Währungsausschuß: a.a.O., S. 317.

1070 Vgl. Europäische Gemeinschaften Währungsausschuß: a.a.O., S. 317.

1071 Vgl. Europäische Gemeinschaften Währungsausschuß: a.a.O., S. 317. 
men von Krediten beziehen und können sowohl allgemein als auch für einzelne Banken ausgesprochen werden 1072 .

In ihrer Zinsgestaltung sind die Banken in den Niederlanden frei1073. Das Gesetz zur Überwachung des Kreditwesens läßt keine diesbezüglichen Weisungen zu1074.

\subsubsection{Offenmarktpolitik}

Das Gesetz befugt die Bank zum Kauf und Verkauf von börsennotierten staatlichen und staatsverbürgten Schuldtiteln ${ }^{1075}$. Die Nederlandsche Bank beschränkt sich bei der Offenmarktpolitik i. e. S. jedoch auf kurz- und mittelfristige Staatspapiere. Dafür steht ihr ein Operationsfonds zur Verfügung, der aus Forderungen an das Schatzamt aus dem Jahre 1952 stammt ${ }^{1076}$. Vorher war das Schatzamt selbst am Geldmarkt tätig1077. Neben Kreditinstituten und Wechselmaklern können auch Wirtschaftsunternehmen direkt als Marktpartner der Zentralbank auftreten ${ }^{1078}$. Die Notenbank ist auch zum Handel mit Edelmetallen berechtigt ${ }^{1079}$ und kann auf dem Devisenmarkt intervenieren 1080.

\subsubsection{Mindestreservepolitik}

Das Instrument der Mindestreserven wurde 1954 durch ein Gentlemen's Agreement zwischen der Notenbank und den niederländischen Geschäftsbanken eingeführt ${ }^{1081}$. Bis 1963 wurde die Mindestreservepflicht als Mittel zur Finanzierung der Devisenreserven der Zentralbank aufgefaßt und die Sätze daher an den Veränderungen der Devisenreserven orientiert ${ }^{1082}$. Berechnungsgrundlage sind die Guthaben und Einlagen von Kunden sowie von Kreditinstituten, die dem Abkommen nicht beigetreten sind und sonstige kurzfristige Verbindlichkeiten mit Einlagencharakter ${ }^{1083}$. Devisenverbindlichkeiten und Spareinlagen sind nicht

1072 Vgl. Europäische Wirtschaftsgemeinschaft: a.a.O., S. 253.

1073 Vgl. Bernhuber, Max; Hauck, Hartwig: a.a.O., S. 37.

$1074 \mathrm{Vgl}$. Europäische Gemeinschaften Währungsausschuß: a.a.O., S. 308.

1075 Vgl. Europäische Gemeinschaften Währungsausschuß: a.a.O., S. 313.

1076 Vgl. Bernhuber, Max; Hauck, Hartwig: a.a.O., S. 45.

1077 Vgl. Schuster, Leo (1967): a.a.O., S. 131.

1078 Vgl. Bernhuber, Max; Hauck, Hartwig: a.a.O., S. 45.

1079 Vgl. Bank für Internationalen Zahlungsausgleich Basel: a.a.O., S. 335.

1080 Vgl. Europäische Gemeinschaften Währungsausschuß: a.a.O., S. 316.

1081 Vgl. Veit, Otto (1961), a.a.O., S. 637.

1082 Vgl. Europäische Gemeinschaften Währungsausschuß: a.a.O., S. 310.

1083 Vgl. Europäische Gemeinschaften Währungsausschuß: a.a.O., S. 311. 
mindestreservepflichtig1084. Das Abkommen setzt eine Höchstgrenze für den Mindestreservesatz von $15 \%$, wobei die Notenbank einen Satz oberhalb von $10 \%$ nur unter bestimmten Bedingungen fordern darf 1085 . Der Satz wird einheitlich auf alle mindestreservepflichtigen Positionen angewandt ${ }^{1086}$. Die Mindestreserven werden unverzinslich auf laufendem Konto bei der Notenbank gehalten 1087. Die niederländische Zentralbank fordert nicht dauernd eine Mindestreserve ein 1088 .

Das Noteninstitut hat auch die Möglichkeit, die Kreditinstitute auf administrativem Wege zum Halten von Mindestreserven zu verpflichten. Rechtsgrundlage dafür ist das Gesetz zur Überwachung des Kreditwesens vom 18. Januar 19521089. In diesem Fall ist sie jedoch an die gesetzlichen Bestimmungen über die Anwendungsdauer von Mindestreservevorschriften und deren Genehmigung durch den Gesetzgeber gebunden 1090 .

Seit 1989 begründet eine Ausweitung der Bankkredite über eine bestimmte Richtgröße hinaus, die nicht durch langfristige Bankverbindlichkeiten refinanziert wird, zusätzlich eine fiktive Reservepflicht ${ }^{1091}$. Die Kreditinstitute müssen dabei keine unverzinslichen Reserven bei der Notenbank hinterlegen, sondern lediglich die aus der Reservepflicht entstehenden kalkulatorischen Zinskosten an die Zentralbank abführen 1092 .

\subsubsection{Zusammenfassende Beurteilung der funktionellen Unabhängigkeit der Nederlandschen Bank}

Die niederländische Notenbank muß aufgrund der umfassenden Weisungsmöglichkeit des Finanzministers bzw. der Krone gemäß des Schemas in Abb. 5 mit Bewertungsstufe $\mathrm{L}$ und als funktionell abhängig eingestuft werden. Faktisch besitzt das Institut jedoch eine erhebliche Unabhängigkeit, weil die Regierung von ihrem Weisungsrecht keinen Gebrauch macht ${ }^{1093}$. Die gesetzlichen Regelungen gewährleisten zudem, daß mögliche Konflikte zwischen Regierung und Notenbank, die eine Weisung des Finanzministers nach sich ziehen, an der Öffentlichkeit ausgetragen werden, sofern die Bank gegen die Weisungen Einspruch erhebt.

1084 Vgl. Europäische Gemeinschaften Währungsausschuß: a.a.O., S. 311.

1085 Vgl. Europäische Gemeinschaften Währungsausschuß: a.a.O., S. 311 f.

1086 Vgl. Tobler, Ewald: a.a.O., S. 52.

1087 Vgl. Tobler, Ewald: a.a.O., S. 52.

1088 Vgl. Mader, Richard: a.a.O., S. 131.

1089 Vgl. Europäische Gemeinschaften Währungsausschuß: a.a.O., S. 310.

1090 Vgl. Europäische Gemeinschaften Währungsausschuß: a.a.O., S. 310.

1091 Vgl. o. V.: Mindestreserveregelungen im Ausland: a.a.O., S. 26.

1092 Vgl. o. V.: Mindestreserveregelungen im Ausland: a.a.O., S. 26.

1093 Vgl. Eizenga, Wietze: a.a.O., S. 13. 
Die Veröffentlichung soll übereilte Beschlüsse verhindern und disziplinierend und kontrollierend auf die Regierung einwirken ${ }^{1094}$. In der Praxis kann die Niederländische Bank über Art, Umfang und Zeitpunkt des Einsatzes ihrer geldpolitischen Instrumente frei entscheiden.

\subsection{Vergleichende Gegenüberstellung des Unabhängigkeitsgrades ausgewählter Notenbanken}

Abb. 8 faßt die Untersuchungsergebnisse der betrachteten Notenbanken für die funktionelle und personelle Unabhängigkeit zusammen. Zur Visualisierung der Ergebnisse werden die ermittelten Werte im Anschluß daran in einer Matrix dargestellt (Abb. 9).

\begin{tabular}{|c|c|c|}
\hline Land & funktionelle Unabhängigkeit & personelle Unabhängigkeit \\
\hline D & F & 25 \\
CH & D & 25 \\
USA & D & 26 \\
I & bis 1981: zwischen G und H, da- & 8 \\
& nach: zwischen E und F & \\
GB & L & 25 \\
F & L & 26 \\
J & L & 26 \\
NL & L & 25 \\
\hline
\end{tabular}

Abb. 8: Funktionelle und personelle Unabhängigkeit ausgewählter Länder

Bis auf Italien, dessen Notenbank über einen erheblichen Einfluß auf die personelle Besetzung ihrer Organe verfügt, sind alle betrachteten Notenbanken personell abhängig. Bei der funktionellen Unabhängigkeit gibt es größere Unterschiede. Die größte funktionelle Unabhängigkeit ihres Noteninstituts weisen die Schweiz und die USA auf. Ebenfalls eher unabhängig ist die Deutsche Bundesbank, deren Bewertung jedoch aufgrund des aufschiebenden Vetorechts der Bundesregierung etwas schlechter als die der Schweiz und den USA ausfällt. Seit der Aufhebung der Verpflichtung zur Kreditgewährung der Notenbank an den Staat im Jahre 1981 liegt Italien hinsichtlich der Unabhängigkeit ihrer Notenbank sogar noch vor Deutschland. Bis 1981 war die Banca d'Italia aber eher abhängig.

1094 Vgl. Castello-Branco, Marta; Swinburne, Mark: a.a.O., S. 20; Bank für Internationalen Zahlungsausgleich Basel: a.a.O., S. 360f. 
Die restlichen vier der untersuchten Notenbanken, nämlich die der Länder Großbritannien, Frankreich, Niederlande und Japan, sind alle als abhängig einzustufen aufgrund umfassender Weisungsrechte notenbankfremder Instanzen.

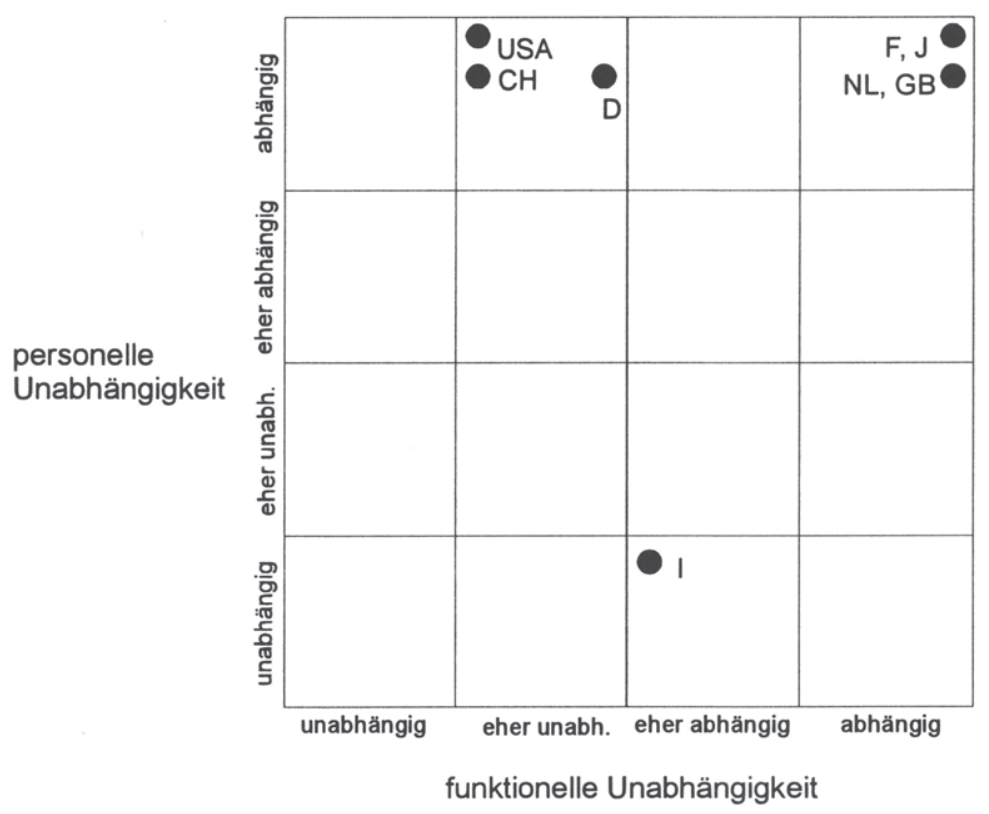

Abb. 9: Portfolio der funktionellen und personellen Unabhängigkeit ausgewählter Länder 
Sylvia Liebler - 978-3-631-75025-4

Downloaded from PubFactory at 01/11/2019 09:08:34AM

via free access 


\section{Einfluß der Unabhångigkeit von Notenbanken auf die Ent- wicklung des Geldwertes}

Um den Einfluß der Unabhängigkeit von Notenbanken auf die Entwicklung des Geldwertes $\mathrm{zu}$ analysieren, wird zunächst die Inflationsentwicklung der ausgewählten Länder für den Untersuchungszeitraum von 1975 bis 1990 betrachtet. Mit Hilfe des Rangkorrelationskoeffizienten von Spearman wird nachfolgend versucht, die Korrelation zwischen beiden Größen zu ermitteln. Im Anschluß daran wird untersucht, ob neben der Unabhängigkeit von Zentralbanken auch andere Faktoren auf die Geldwertstabilität einwirken.

\subsection{Inflationsentwicklungen in den untersuchten Ländern}

Abb. 10 und 11 zeigen die Inflationsentwicklungen der betrachteten Länder für den Untersuchungszeitraum von 1975 bis 1990, wobei Abb. 10 die absoluten und Abb. 11 die kumulierten Inflationsraten darstellt. Die Inflationsraten der 8 Länder zeigen für den betrachteten Zeitraum eine vergleichbare Entwicklung. Die durchschnittliche Inflationsrate der Gesamtheit der betrachteten Länder hat sich während dieser Zeitspanne um mehr als die Hälfte reduziert. Eine vorübergehende Steigerung des Inflationsniveaus während des zweiten Ölpreisschocks 1980/81 ist erkennbar. Das Niveau der Preissteigerungsraten zeigt jedoch deutliche Unterschiede. Die durchschnittliche Inflationsrate im Untersuchungszeitraum ist der Schweiz und in Deutschland mit 3,28 bzw. 3,31 Prozent am niedrigsten, dicht gefolgt von Japan und den Niederlanden mit 4,07 und 4,14 Prozent. V. a. in den 80er Jahren weisen die Niederlande und Japan teilsweise sogar bessere Ergebnisse auf als Deutschland und die Schweiz. USA und Frankreich verfügen über ein mittleres Inflationsniveau mit durchschnittlich 6,33 bzw. 7,99 Prozent. Die schlechtesten Inflationsergebnisse zeigen Großbritannien und Italien mit durchschnittlich 10,13 bzw. 12,35 Prozent im Untersuchungszeitraum. 


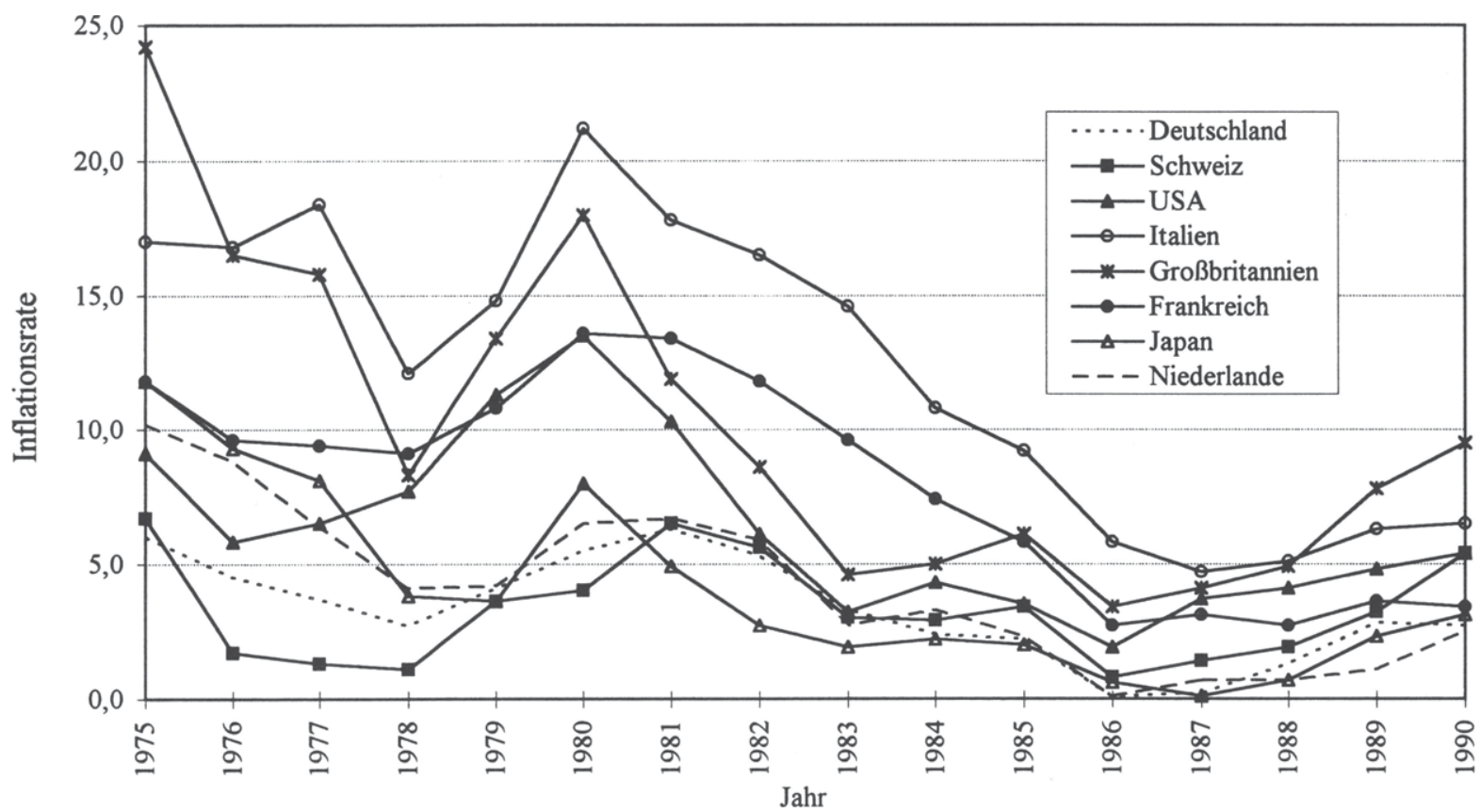

Abb. 10: Inflationsentwicklung der untersuchten Länder 1975 - 1990 Quelle: OECD: Historical Statistics. 


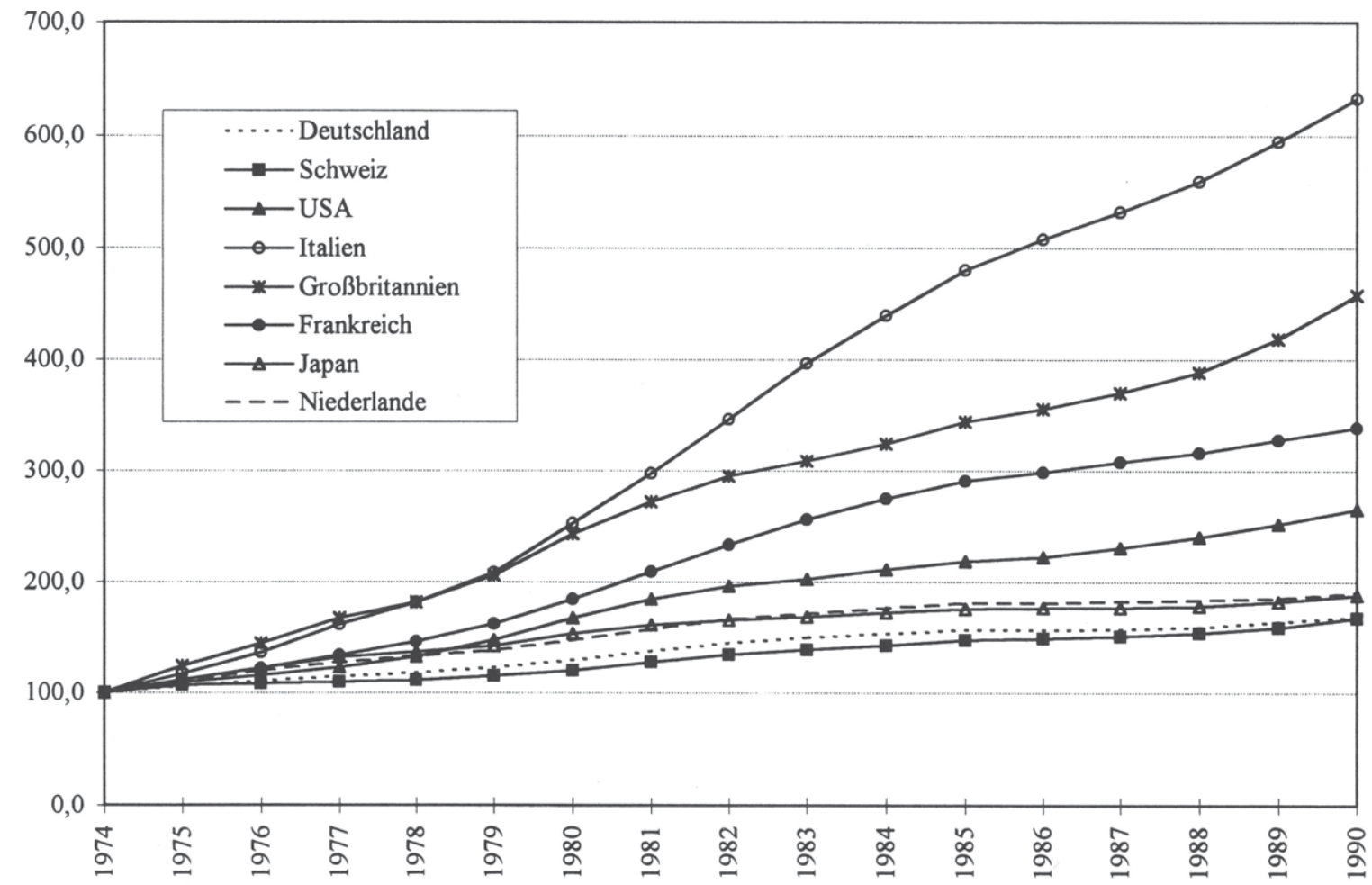

Abb. 11: Kumulierte Inflationsraten der untersuchten Länder 1975 - $1990(1974=100)$

Quelle: OECD: Historical Statistics. 


\subsection{Korrelationsanalyse zwischen dem Unabhängigkeitsgrad der untersuchten Notenbanken und der Inflationsentwicklung}

Wie oben gezeigt, wird der Rangkorrelationskoeffizient von Spearman zur Überprüfung des Zusammenhangs zwischen den Unabhängigkeitsgraden der untersuchten Notenbanken und der Inflationsentwicklung der jeweiligen Länder im Untersuchungszeitraum von 1975 bis 1990 herangezogen. Dieser ergibt sich, wie bereits erläutert, aus folgender Formel:

$$
r_{s}=1-\frac{6 \sum d_{i}^{2}}{n\left(n^{2}-1\right)} \text { mit } d_{i}=R\left(x_{i}\right)-R\left(y_{i}\right)
$$

$\mathrm{R}\left(\mathrm{x}_{\mathrm{i}}\right)$ kennzeichnet die Rangwerte der Unabhängigkeitgrade der untersuchten Notenbanken und $R\left(y_{i}\right)$ die Rangwerte der kumulierten Inflationsraten der betrachteten Länder im Untersuchungszeitraum. Für die untersuchten Länder ergeben sich damit die in Abb. 12 aufgeführten Rangwerte und Differenzen.

\begin{tabular}{|c|c|c|c|c|}
\hline Land & $\begin{array}{c}\text { Unabhängigkeit } \\
\mathbf{R}\left(\mathrm{X}_{\mathrm{i}}\right)\end{array}$ & $\begin{array}{c}\text { Inflation } \\
\mathbf{R}\left(\mathrm{Y}_{\mathrm{i}}\right)\end{array}$ & $\mathrm{d}_{\mathrm{i}}$ & $\mathrm{d}_{\mathrm{i}}{ }_{\mathrm{i}}$ \\
\hline $\mathrm{D}$ & 6 & 7 & -1 & 1 \\
CH & 8 & 8 & 0 & 0 \\
USA & 7 & 4 & 3 & 9 \\
$\mathrm{I}_{\text {(bis 1981) }}$ & 5 & 1 & 4 & 16 \\
GB & 3,5 & 2 & 1,5 & 2,25 \\
F & 1,5 & 3 & $-1,5$ & 2,25 \\
J & 1,5 & 6 & $-4,5$ & 20,25 \\
NL & 3,5 & 5 & $-1,5$ & 2,25 \\
\hline
\end{tabular}

Abb. 12: Daten und Berechnung des Rangkorrelationskoeffizienten $r_{s}$

Man erhält den Korrelationskoeffizienten $r_{s}=0,37$ und damit eine niedrige Korrelation. Legt man nun zugrunde, daß kein signifikanter Zusammenhang zwischen der Unabhängigkeit von Notenbanken und der Geldwertentwicklung besteht, so müßte dies anhand der oben eingeführten Hotelling-Pabst-Statistik bestätigt werden. Man erhält für die Prüfgröße D den Wert 53. Für das Testniveau $\alpha=0,1$ erhält man, wie oben beschrieben, die beiden kritischen Werte $h_{8: 0.05}=32$ und $h_{8: 0,95}=136$. Da nun gilt: $h_{8: 0,05}<D<h_{8: 0,95}$, bedeutet dies, daß die getroffene Hypothese wirklich zutrifft. Es kann also für die untersuchten Länder kein signifikanter 
Zusammenhang zwischen dem Grad der Unabghängigkeit und der Inflationsentwicklung festgestellt werden 1095 .

\subsection{Interpretation der Ergebnisse}

Die Untersuchungen haben gezeigt, daß der Grad der Unabhängigkeit einer Notenbank offensichtlich keinen signifikanten Einfluß auf die Inflationsentwicklung eines Landes hat. Wie ist das zu erklären? Drei prinzipielle Überlegungen lassen sich unterscheiden. Erstens können auch abhängige Notenbanken eine inflationsbekämpfende Geldpolitik betreiben. Ferner ist eine unabhängige Notenbank keine Gewähr für eine inflationssenkende Geldpolitik. Schließlich wirken auf die Inflationsentwicklung auch exogene Einflüsse ein, die die Zentralbanken mit ihren geldpolitischen Mitteln nicht oder nur unzureichend beeinflussen können.

\subsubsection{Abhängige Notenbanken und inflationsbekămpfende Geld- politik}

\subsubsection{Differenz zwischen juristischer und faktischer Unabhängigkeit}

Eine de jure abhängige Notenbank kann unter Umständen de facto eine unabhängige Geldpolitik betreiben. Dies ist beispielsweise der Fall, wenn externe Instanzen von ihren Einflußrechten keinen Gebrauch machen. So wurde beispielsweise das aufschiebende Vetorecht der Bundesregierung im Falle der Deutschen Bundesbank noch nie angewendet. Faktisch setzt die Bundesbank das ihr per Gesetz zur Verfügung stehende geldpolitische Instrumentarium frei nach ihrem Ermessen ein. Die guten Inflationsergebnisse in Deutschland könnten sich womöglich darauf zurückführen lassen. Sehr kraß ist die Diskrepanz zwischen Unabhängigkeitsgrad und Inflationsentwicklung in Japan, wo eine völlig abhängige Notenbank relativ guten Inflationsergebnissen gegenübersteht. Auch hier gilt die

1095 Die Veränderung der Vorschriften zur Staatsfinanzierung durch die Notenbank in Italien im Jahr 1981 bewirkt eine veränderte Reihenfolge der Notenbanken hinsichtlich ihrer Unabhängigkeit. Italien steht seitdem an Rang 6 und Deutschland an Rang 5. Dadurch ergibt ein Korrelationskoeffizient $r_{s}=0,226$. Dieser ist sogar noch kleiner und impliziert damit einen noch geringeren Zusammenhang. Auch bei einer getrennten Untersuchung beider Zeitabschnitte unter Verwendung der jeweiligen durchschnittlichen Inflationsrate für den Zeitraum 1975 bis 1980 und 1981 bis 1990 ist keine signifikante Korrelation zwischen dem Unabhängigkeitsgrad von Notenbanken und der Inflationsentwicklung festzustellen. Für den Zeitraum 1975 bis 1980 ergibt sich ein Korrelationskoeffizient von 0,27 und für 1981 bis 1990 ein Koeffizient von 0,23. 
Geldpolitik als unabhängiger als die Gesetzgebung vermuten läßt1096. In Frankreich hat der Gouverneur der Bank faktisch einen erheblichen Einfluß auf die Entscheidungen des Nationalen Kreditrates, in der die Grundzüge der Geldpolitik beschließt, weil er in der Regel den Finanzminister im Vorsitz des Rates vertritt1097.

Wie in einem früheren Kapitel bereits erörtert wurde, kann auch die Persönlichkeit des Notenbankgouverneurs oder der Mitglieder der Notenbankleitung die Position der Notenbank in positiver oder negativer Hinsicht verändern. Ein Notenbankleiter, der befähigt ist, die der Zentralbank anvertrauten Interessen entschlossen gegen alle zuwiderlaufenden Interessen zu verteidigen, kann auch einer de jure stark abhängigen Notenbank eine verhältnismäßig selbständige Stellung verleihen. Das Vertrauen in eine Währung beruht auch ,auf der Einschätzung der charakterlichen Qualitäten derjenigen Persönlichkeiten, die für die Stabilität der Währung zu kämpfen berufen sind“1098.

\subsubsection{Offentliche Präferenz für Geldwertstabilität}

Öffentlicher Rückhalt und das Verständnis der Öffentlichkeit für die Rolle der Zentralbank ist ein wichtige Faktor für die Stärke einer Zentralbank ${ }^{1099}$. Tief verwurzelte soziale Präferenzen für eine höhere Preisniveaustabilität bieten dem Noteninstitut eine gewisse moralische Unterstützung, geldpolitische Disziplin auch wider anderer Pressionen zu halten. So dürfte beispielsweise die starke Inflationsangst der deutschen Öffentlichkeit einen nicht unerheblichen Beitrag zu der starken Stellung der Bundesbank leisten 1100 . Auch in der Schweiz, das gute Inflationsergebnisse verzeichnet, genießt die Preisstabilität traditionell einen hohen Stellenwert ${ }^{1101}$. Zudem sind Bürger mit einer großen Inflationsangst eher bereit, zugunsten von Geldwertstabilität anderweitige Nachteile, wie z. B. den Verzicht auf Einkommenssteigerungen, in Kauf zu nehmen 1102.

1096 Vgl. Schaede, Ulrike: a.a.O., S. 15ff; Swinburne, Mark; Castello-Branco, Marta: a.a.O., S. 48; o. V.: Central Banks: Amerika versus Japan - The rewards of independence: a.a.O., S. 22f; Francke, Hans-Hermann: a.a.O., S. 13.

1097 Vgl. Veit, Otto (1961), a.a.O., S. 663.

1098 Hahn, L. Albert: Probleme staatlicher Konjunkturbeeinflussung, Frankfurt am Main 1956, S. 10.

1099 Vgl. Erb, Richard D.: Die Rolle der Zentralbanken, in: Finanzierung \& Entwicklung 12/89, S. 13.

1100 Vgl. Swinburne, Mark; Castello-Branco, Marta: a.a.O., S. 15.

1101 Vgl. Lusser, Markus (1990): a.a.O., S. 66; Caesar, Rolf: Notenbanken im Spannungsfeld der Politik, in: Wirtschaftsdienst 1982/XI, S. 573.

1102 Vgl. Noelle-Neumann, Elisabeth: Geldwert und öffentliche Meinung. Anmerkungen zur "Psychologie der Inflation", in: Andreae, C.A.; Hansmeyer, K. H.; Scherhorn, G. (Hrsg.): 


\subsubsection{Disziplinierungszwang durch internationale Abkommen}

Als externe Quelle von Disziplin für Notenbank und Regierung können auch internationale Vereinbarungen über Wechselkurssysteme u.ä. dienen. So müssen Interventionen zur Stützung von Währungen, die zu Abwertungen tendieren, nicht mit den eigenen, sondern mit fremder, starker Währung durchgeführt werden 1103 . Im Falle von Frankreich darf vermutet werden, daß nicht zuletzt der Disziplinierungszwang des EWS eine Ursache für die v. a. in der zweiten Hälfte der 80er Jahre niedrigen Inflationsraten darstellt 1104 .

\subsubsection{Technisch-institutionelle Einschränkungen}

Regelungen, die für die Unabhängigkeit von Zentralbanken technischinstitutionelle Beschränkungen bedeuten, können sich auf die Preisstabilität tendenziell positiv auswirken. Dies gilt beispielsweise für ein Verbot oder die Beschränkung von Staatsfinanzierung durch die Notenbank. Die Bank kann nicht gezwungen werden, Defizitfinanzierung zu betreiben. Ähnliches gilt auch für eine Begrenzung der Geldschöpfungskapazität der Notenbank beispielsweise durch eine Bindung an Edelmetalle. Dies bietet auch einer weisungsgebundenen Notenbank einen gewissen Schutz, nicht nur vor allzu großer Inanspruchnahme für die Staatsfinanzierung, sondern auch vor allem um die Behauptung und Verbesserung der Lebensansprüche kämpfenden Gruppen und Bevölkerungsschichten, die auf die Geldpolitik Einfluß zu nehmen suchen. Jedoch darf nicht vergessen werden, $\mathrm{da} B$ solche Bindungen gerade in Krisenzeiten häufig wieder aufgehoben wurden.

\subsubsection{Unabhăngige Notenbanken und inflationsfördernde Geld- politik}

\subsubsection{Fehlentscheidungen der Notenbankleitung}

Eine unabhängige Notenbank ist keine Garantie für Preisstabilität oder auch nur für autonomes Handeln der Bank. Dies hat die Geschichte mehrfach eindrucksvoll bewiesen. In den Weltkriegen haben unabhängige Notenbanken ebenso Inflation getrieben wie abhängige ${ }^{1105}$. Doch auch außerhalb von Extremsituationen ist eine unabhängige Notenbank keine Gewähr für eine erfolgreiche Geldpolitik. Sie ist nicht gefeit gegen Fehleinschätzungen, sei es aufgrund von mangelndem

Geldtheorie und Geldpolitik - Günter Schmölders zum 65. Geburtstag, Berlin 1968, S. 37.

1103 Vgl. Francke, Hans-Hermann: a.a.O., S. 13.

1104 Vgl. Swinburne, Mark; Castello-Branco, Marta: a.a.O., S. 48.

1105 Vgl. Eynern, Gert v. (1968): a.a.O., S. 224. 
Sachverstand, einer schwachen Persönlichkeit des Notenbankpräsidenten oder aufgrund der Kompliziertheit und Koordinationsabhängigkeit der Notenbankgeschäfte. Eine unabhängige Zentralbank kann lediglich nicht gezwungen werden, geldpolitische Entscheidungen wider besseres Wissen zu treffen.

\subsubsection{Zielsetzung der Geldpolitik}

Die Aufgabenstellung einer Notenbank ist kein Kriterium für Unabhängigkeit. Eine klare und alleinige Verpflichtung einer Notenbank auf das Ziel der Geldwertstabilität erhöht jedoch die Chancen einer erfolgreichen preisstabilitätsorientierten Geldpolitik. Eine Notenbank kann nur dann zielgerichtet handeln, wenn sie sich an Größen orientiert, die sie kontrollieren kann. Die Verpflichtung einer Zentralbank auf ein Bündel makroökonomischer Zielsetzungen ohne eine klare Priorität für die Preisstabilität kann bewirken, daß das Noteninstitut die Preisstabilität im Interesse von Wachstum, Beschäftigung oder tiefen Zinssätzen vernachlässigen muß. Ein klar begrenzter Aufgabenbereich einer Zentralbank auf Geldwertstabilität erleichtert zudem die Erfolgskontrolle der Notenbank ${ }^{1106}$. Dies gilt v. a., wenn die Geldpolitik an leicht zu beobachtenden Maßstäben, wie Geldmengen- oder Inflationszielen, ausgerichtet wird. Öffentlich bekanntgegebene Zwischenziele ermöglichen den Wirtschaftssubjekten zudem eine frühzeitige Anpassung an die künftigen wirtschaftlichen Gegebenheiten, so daß die Notenbank zur Zielerreichung weniger Maßnahmen ergreifen muß. Ferner helfen klare Zielvorgaben der Notenbank, andersgerichteten Pressionen seitens der Regierung oder Interessengruppen standzuhalten.

\subsubsection{Anreizstruktur}

Eine klar der Geldwertstabilität verpflichtete Notenbank ist nur dann erfolgreich, wenn die Notenbankleitung ausreichenden Anreiz hat, dieses Ziel zu verfolgen. Notenbankfunktionäre sind einer Vielzahl von Anreizen ausgesetzt, die ihr Verhalten beinflussen 1107. Die Anhänger der Theorie des Public Choice gehen dabei davon aus, daß die Notenbankleiter ihr Amt zur Verfolgung eigener Interessen nutzen, die im Zweifel auch gegen die Wohlfahrt der Gesellschaft stehen. Jedoch läuft eine unabhängige Notenbank, die eine Politik betreibt, die nicht von einer breiten Öffentlichkeit akzeptiert wird, Gefahr, daß ihr autonomer Status von Wählern, Parlament oder Regierung in Frage gestellt wird. Insofern hat die Notenbankleitung einen Anreiz, den ihr gestellten Auftrag zu erfüllen. Andererseits

1106 Vgl. Lusser, Markus (1988): a.a.O., S. 5; Schmitz, Wolfgang (1989): a.a.O., S. 19.

1107 Mit der Frage der Notenbank als nutzenmaximierenden Einheit, die eigene Ziele verfolgt haben sich u. a. beschäftigt: Frey, Bruno S.; Schneider, Friedrich: Central Bank Behavior - A positve empirical analysis, in: Journal of Monetary Economics 7 (1981), S. 291-315 und dort angebene Literatur. 
kann die Abschaffung des Unabhängigkeitsstatuses auch als Druckmittel seitens der Regierung eingesetzt werden, die die Notenbank dazu bewegen soll, unabhängig von ihrer Aufgabe eine mit den Regierungswünschen im Einklang stehende Geldpolitik zu betreiben. Ähnlich sind auch Repressalien wie eine vom Wohlverhalten der Notenbankfunktionäre abhängig gemachte Wiederernennung denkbar ${ }^{1108}$. Notenbankmitglieder könnten auch aufgrund früherer politischer Bindungen oder Abhängigkeiten nicht bereit sein, die Wahrung des Geldwertes als alleiniges politisches Leitmotiv zu akzeptieren. Ein Anreiz, eine Politik der Preisstabilität zu betreiben, besteht dann, wenn diese mit erfolgsabhängigen $\mathrm{Ge}-$ hältern, sozialem Prestige etc. belohnt bzw. mit Einkommens- bzw. Imageverlust oder gar, wie es Vaubel ${ }^{1109}$ vorschlägt, durch Entlassung bei andauernder Inflation sanktioniert wird.

\subsubsection{Exogene Einflüsse auf die Geldwertstabilität}

Sanktionen bei Mißerfolg der Geldpolitik sind jedoch nur dann sinnvoll, wenn die Notenbank für die Fehlentwicklungen auch tatsächlich verantwortlich zu machen ist. Zahlreiche exogene Einflüsse, die die Notenbank mit ihren Mitteln nicht oder nur bedingt beeinflussen kann, wirken ebenfalls auf den Geldwert ein.

\subsubsection{Lohnpolitik der Tarifpartner}

$\mathrm{Zu}$ nennen ist hier zunächst stabilitätswidriges Verhalten der Tarifparteien. Die Tarifpartner genießen in vielen Ländern eine beträchtliche Autonomie gegenüber Eingriffen von außen ${ }^{1110}$. Bei der Aushandlung der Löhne und Preise fühlen sie sich weitgehend unabhängig von Rücksichten auf die Währung111. Die Löhne sind zudem in der Regel nach oben weitaus flexibler als nach unten. Besonders problematisch sind indexierte Löhne. So wurde die Inflation in Italien über 30 Jahre lang durch den automatischen Anpassungsmechanismus der Löhne an die Inflation, die sog. Scala Mobile (Rolltreppe), angetrieben ${ }^{1112}$.

\subsubsection{Preisregulierungen}

Ein weiterer Faktor, den die Notenbank nicht oder nur bedingt beeinflussen kann, ist die Tatsache, daß vielfach über Preise und damit über Kaufkraftstabilität durch

1108 Wie in Kapitel 4.4.5.3 bereits dargelegt.

1109 Vgl. Vaubel, Roland: Überholte Glaubenssätze, in: Wirtschaftsdienst VI/1989, S. 278

$1110 \mathrm{Vgl}$. Arndt, Hans-Joachim (1973): a.a.O., S. 25.

1111 Vgl. Schmölders, Günter (1957): a.a.O., S. 28.

1112 Vgl. o. V.: Die Rolltreppe steht, in: FAZ vom 4.1.1992; o. V.: Lohnstopp in Italien statt automatischer Anpassung, in: FAZ vom 3.8.1992. 
staatlichen Hoheitsakt oder internationale Preisregulierungen entschieden wird1113. In Frankreich wurden die meisten industriellen Preise bis 1979 und zwischen 1981 und 1986 in Form von Preiskontrollen oder Preisstopps reguliert ${ }^{1114}$. Auch in der Schweiz gibt es viele staatlich administrierte Preise und Indexierungsvorschriften, wie etwa die Bindung der Mieten an die Zinskosten, so daß die Nationalbank mit ihrer Geldpolitik nur etwa die Hälfte der Preise beeinflussen kann 1115. Im Rahmen der EG und hier besonders in der Landwirtschaft bewirken garantierte Preise, daß ein wesentlicher Bestandteil der Lebenshaltungskosten aus dem marktwirtschaftlichen Zusammenhang gelöst ist.

\subsubsection{Ausrichtung der allgemeinen Wirtschaftspolitik des Staates}

Die allgemeine Wirtschaftspolitik des Staates, bestehend aus der Finanz-, Sozial-, Steuer-, Außenhandels-, Lohn-, Preis- und Subventionspolitik, ist ein wichtiger Einflußfaktor auf die Inflationsentwicklung eines Landes. Eine erfolgreiche Inflationsbekämpfung erfordert besonders eine flankierende, oder wenigstens nicht entgegengerichtete staatliche Finanzpolitik. Dies gilt besonders angesichts der immens hohen Staatsquoten in den westlichen Industrieländern. Ein bedeutender Teil der Einkommensströme und der Vermögensbildung wird nicht von rein wirtschaftlichen Überlegungen geleitet, sondern von sozialen und politischen Maßstäben bestimmt 1116 .

\subsubsection{Internationale Einflüsse}

Aufgrund der starken Integration der Güter- und Geldmärkte und der Währungskonvertierbarkeit wirken in beträchtlichem Maße Einflüsse aus dem Ausland auf die inländische Inflationsentwicklung ein. Die inländische Notenbank hat in der Regel keine Einwirkungsmöglicheiten auf den Grad der inflationistischen Strömungen in anderen Ländern, aus denen sich vielfältige Rückwirkungen für das Inland ergeben können. Der Umfang der Einflüsse hängt von Faktoren wie der relativen Größe und der Außenwirtschaftsabhängigkeit des jeweiligen Landes und seiner Stellung im Währungssystem ab1117.

1113 Vgl. Kerschagl, Richard: Zukunftsprobleme der Notenbanken: in: Schmollers Jahrbuch für Gesetzgebung, Verwaltung und Volkswirtschaft, hrsg. von Alfred Kruse, 87. Jg., I. Halbband, Berlin 1967, S. 270; Bernauer, Engelbert: a.a.O., S. 45.

1114 Vgl. Bourdet, Yves; Jonung, Lars: Economic performance and stabilization policies in Sweden and France 1970-1990, in: Skandinaviska Enskilda Banken Quarterly Review 12/1992, S. 28.

1115 Vgl. o. V.: Weitere Konzentration bei Schweizer Banken, in: FAZ vom 13.1.92

1116 Vgl. Muthesius, Volkmar (1958): a.a.O., S. 494.

1117 Vgl. Caesar, Rolf (1981): a.a.O., S. 103. 


\section{Zusammenfassung und Schlußbetrachtung}

Ziel der vorliegenden Arbeit war es, die Bedeutung der Unabhängigkeit von Zentralbanken für die Stabilität des Geldwertes zu untersuchen. Dazu wurde, was zugleich den Schwerpunkt der Arbeit darstellt, ein Bewertungsschema entwickelt, anhand dessen sich der Unabhängigkeitsgrad einer Zentralbank ermitteln läßt. Dazu mußte zunächst geklärt werden, was unter einer unabhängigen Notenbank zu verstehen ist. Nach der hier verwendeten Definition ist eine Zentralbank dann unabhängig, wenn sie ihre geldpolitischen Entscheidungen selbständig treffen kann. Es wurde dargelegt, daß Unabhängigkeit sowohl die Unabhängigkeit von staatlichen als auch die von nicht-staatlichen Akteuren umfaßt, wobei es für den Unabhängigkeitsgrad unerheblich ist, welche Partei eine Einschränkung der $\mathrm{Au}$ tonomie hervorruft. Faktisch kann die Unabhängigkeit einer Notenbank von der juristischen abweichen, sei es z. B., weil notenbankfremde Akteure die ihnen per Gesetz zustehenden Einflußrechte nicht wahrnehmen oder die Stärke der Persönlichkeiten in der Notenbankleitung oder die öffentliche Meinung die Machtverhältnisse verändern. Das Bewertungsschema beschränkt sich lediglich auf die Ermittlung der juristischen Unabhängigkeit, die sich aufgrund der die Zentralbank betreffenden Normen und Gesetze ergibt.

Unabhängigkeit läßt sich in einen institutionellen, vermögensrechtlichen, personellen und funktionellen Aspekt gliedern. Es wurde dargelegt, daß die Faktoren, die die institutionelle und vermögensrechtliche Unabhängigkeit bestimmen, nämlich im wesentlichen die Rechtsform, Eigentumsverhältnisse und haushaltsmäßige Selbständigkeit einer Zentralbank per se die Unabhängigkeit entsprechend der hier verwendeten Definition nicht berühren. Die Unabhängigkeit wird nur dann beeinträchtigt, wenn sich aufgrund dessen konkrete Einflußrechte notenbankfremder Instanzen ergeben, die die Entscheidungsfreiheit der Notenbank, das geldpolitische Instrumentarium nach ihrem Ermessen einzusetzen, mindern. Diese Freiheit der geldpolitischen Entscheidungen ist wiederum der Kern der funktionellen Unabhängigkeit. Daher gehen eventuelle aus institutionellen oder vermögensrechtlichen Regelungen herrührende Einschränkungen der Unabhängigkeit in die funktionelle Unabhängigkeit mit ein und werden daher im entwickelten Bewertungsschema nicht gesondert berücksichtigt.

Die personelle Unabhängigkeit, die dann gewährleistet ist, wenn die Notenbank über die Besetzung ihrer Leitungsorgane alleinige Entscheidungsgewalt hat, steht dagegen in keinem direkten Zusammenhang zu den geldpolitischen Entscheidungen. Die Besetzung der Notenbankspitze durch notenbankfremde Instanzen kann, muß aber nicht bedeuten, daß sich die Funktionäre deren geldpolitischen Wünschen beugen werden. Daher wurde für die Ermittlung der personellen Unabhängigkeit ein gesondertes Bewertungsschema in Form eines Entscheidungsbaumes entwickelt, das als Kriterien die Ernennungs- und Abberufungsinstanzen, Abberu- 
fungs- und Wiederernennungsvorschriften sowie den Kreis der Ernennungsfähigen verwendet.

Das Schema zur Bewertung der funktionellen Unabhängigkeit wurde auf Basis des geldpolitischen Instrumentariums aufgebaut. Eine Notenbank kann nur dann ihre geldpolitische Entscheidungen nach eigenem Ermessen treffen, wenn ihr zum einen sämtliche existierenden geldpolitischen Mittel prinzipiell zur Verfügung stehen und zum anderen, wenn die Anwendung dieser Mittel weder durch technisch-institutionelle Einschränkungen noch durch Einflußrechte externer Instanzen behindert werden kann. Um das existierende geldpolitische Instrumentarium möglichst vollständig zu erfassen, wurden, von dem klassischen geldpolitischen Instrumentarium losgelöst, vier Instrumentenkategorien gebildet. In den Kategorien Ausgabe von Zentralbankgeld durch die Notenbank, direkte Einflußnahme auf die Kreditvergabe der Banken, Offenmarktpolitik und Mindestreservepolitik wurden jeweils vier Variablen identifiziert, durch deren Veränderung geldpolitische Wirkungen erzeugt werden können. Diese wurden hier als geldpolitische Instrumente bezeichnet. Es wurde herausgearbeitet, daß nicht die Effizienz einzelner geldpolitischer Mittel die Unabhängigkeit einer Notenbank beeinflußt, sondern ausschließlich der Umfang, in dem die einzelnen Instrumente der Notenbank zum Einsatz zur Verfügung stehen. Daher konnte der Grad der funktionellen Unabhängigkeit einer Notenbank daran bemessen werden, mit welchen Einschränkungen eine Notenbank jedes der 16 geldpolitischen Mittel einsetzen darf. Dabei wurden die möglichen technisch-institionellen Einschränkungen und die verschiedenen Formen der Einflußnahme Externer auf die geldpolitischen Entscheidungen entsprechend der Intensität ihrer Beeinflussung berücksichtigt. Den Grad der funktionellen Unabhängigkeit einer Zentralbank konnte nun durch Bildung des Medians aus den 16 Einzelbewertungen ermittelt werden.

Die Ermittlung des Unabhängigkeitsgrades von 8 ausgewählten Notenbanken und die anschließende Gegenüberstellung der Werte mit den Inflationsentwicklungen über einen Rangkorrelationskoeffizienten ergab keinen signifikanten Zusammenhang zwischen dem Unabhängigkeitsgrad der Banken und der Inflationsentwicklung des betreffenden Landes für den Untersuchungszeitraum von 1975 bis 1990.

Die Gründe liegen zum einen bei der Notenbank selbst, zum anderen bei externen Faktoren. Mögliche Differenzen zwischen juristischer und faktischer Unabhängigkeit können bewirken, daß eine de jure unabhängige Notenbank schlechte Inflationsergebnisse aufweist und umgekehrt. Ferner wirken sich einige Faktoren, die die Unabhängigkeit einer Notenbank mindern, tendenziell positiv auf den Geldwert aus. Zu nennen sind hier v. a. das Verbot oder die Einschränkung einer Staatsfinanzierung durch die Notenbank oder eine Begrenzung der Geldschöpfungskapazität der Notenbank. Andere Faktoren, die eine erfolgreiche Geldpolitik begünstigen, wie beispielsweise eine ausschließliche Verpflichtung der Notenbank auf die Geldwertstabilität oder eine Sanktionierung der Notenbankleitung 
bei Mißerfolg sind dagegen kein Kriterium für Unabhängigkeit. Eine weitere Erklärung besteht darin, die Notenbankpolitik nur einer von vielen Faktoren ist, von denen die Stabilität der Währung abhängt. Die Notenbank kann mit den ihr gegebenen Mitteln und Möglichkeiten das Ziel der Geldwertstabilität nicht alleine erreichen. Sie kann nur die monetären Rahmenbedingungen für ein inflationsfreies Wirtschaftswachstum schaffen. Die Währungspolitik ist nur ein Teil der allgemeinen Wirtschaftspolitik. Zwischen Währungspolitik und den übrigen Bereichen des makroökonomischen Geschehens bestehen vielfältige Abhängigkeiten. Eine Konsens über die wirtschaftspolitischen Prioritäten und ständige Koordination und Kooperation zwischen der Notenbank und den sonstigen Trägern der Wirtschaftspolitik, sind für eine stabile Währung von entscheidender Bedeutung. Maßvolle Tarifabschlüsse, eine öffentliche Präferenz für Geldwertstabilität sowie stabilitätskonforme internationale Zusammenarbeit tun ihr übriges.

Die Unabhängigkeit der Notenbank ist keine hinreichende, nicht einmal eine notwendige Bedingung für eine stabile Währung. Insofern hat sich die anfangs aufgestellte Hypothese bestätigt. Auch unabhängige Notenbanken können oder wollen Inflation nicht immer verhindern. Aber die Unabhängigkeit ist zweifellos eine gute Basis für eine erfolgreiche Geldpolitik. Der Vorteil einer unabhängigen Notenbank liegt darin, daß sie sich eher für langfristige und eventuell unpopuläre Ziele einsetzen kann als die Regierung, weil sie nicht unmittelbar im politischen Rampenlicht steht und sich nicht in relativ kurzen Abständen der Wiederwahl stellen muß. Ferner kann sie nicht gezwungen werden, wider besseres Wissen falsche geldpolitische Entscheidungen zu treffen. V. a. aber bietet die Unabhängigkeit die Gewähr, daß stabilitätspolitische Bedenken nicht leichtfertig beiseite geschoben werden und senkt die Gefahr, daß die Geldpolitik zum Spielball politischer und wirtschaftlicher Kräfte wird. 
Sylvia Liebler - 978-3-631-75025-4

Downloaded from PubFactory at 01/11/2019 09:08:34AM

via free access 


\section{Literaturverzeichnis}

\section{Bücher}

Adebahr, H.: Währungstheorie und Währungspolitik, Außenwirtschaft Bd. I, Berlin 1978.

Alensia, Alberto; Summers, Lawrence: Central bank Independence and Macroeconomic Performance: Some Comparative Evidence, Discussion paper Number 1496 Harvard University, July 1990.

Andreae, W.: Geld- und Geldschöpfung, Stuttgart/Wien 1953.

Arndt, Hans-Joachim: Politik und Sachverstand im Kreditwährungswesen, Berlin 1963.

Aufricht, Hans: Comparative Survey of Central Bank Law, London 1965.

Bachmann, Gerhard: Die geldpolitische Rolle der Bundesbank, Bad Honnef 1981.

Bade, Robin; Parkin, Michael: Central Bank Laws and Monetary Policy; Dept. of Economics, University of Western Ontario, London, Ontario, Canada N6A 5C2, June 1987.

Bamberg, Günter: Statistik, 2. Aufl., München, Wien, Oldenbourg 1982.

Bär, Hans J.: The Banking System of Switzerland, 4. Aufl., Zürich 1973.

Bank für Internationalen Zahlungsausgleich Basel (Hrsg.): Acht europäische Zentralbanken, Frankfurt am Main 1963.

Batten, Dallas S.; Blackwell, Michael P.; Kim, In-Su; Nocera, Simon E.; Ozeki, Yuzuru: The Conduct of Monetary Policy in the Major Industrial Countries, International Monetary Fund, Washington D.C., July 1990, Occasional Paper No.70.

Beck, Heinz: Gesetz über die Deutsche Bundesbank. Kommentar, Mainz-Gonsenheim, Düsseldorf 1959.

Beckh, Susanne: Das Instrumentarium der Deutschen Bundesbank seit dem Übergang zur Geldmengensteuerung, Berlin 1990.

Becker, Wolfgang: Das währungspolitische Instrumentarium in der Bundesrepublik Deutschland und in Frankreich - Ein Vergleich, Diss. Hamburg 1985.

Bernauer, Engelbert: Staat und Notenbank - Autonomie und Koordination, Diss. Freiburg i. Br. 1960.

Bernhuber, Max; Hauck, Hartwig: Funktionen und Instrumente der Zentralbanken in den EWG und in Österreich. Wiener Studien zur Wirtschafts- und Sozialpolitik, Wien 1965.

Bing, Walter B.: Wirtschaft und Währung Frankreichs - Im Spiegel der Jahresberichte der Banque de France, Frankfurt am Main 1956. 
Bonin, Konrad v.: Zentralbanken zwischen funktioneller Unabhängigkeit und politischer Autonomie, Baden-Baden 1979.

Boreham, Gordon F.; Bodkin, Ronald G.: Money, Banking and Finance, The Canadian context, Toronto Ontario 1988.

Born, Erich: Die finanzielle Heranziehung der Zentralnotenbank durch den Staat in Europa, Leipzig 1907.

Bouveret, Andreas Michael: Die zentralen Lenkungsorgane der französischen Kreditwirtschaft. Struktur und Strukturwandel im Zentralbank- und Bankenaufsichtssystem Frankreichs, Würzburg 1979.

Braun, Karlpeter: Die Stellung der Notenbank als währungspolitische Instanz - Das Verhältnis zwischen Regierung und Notenbank in der Bundesrepublik Deutschland und in den Vereinigten Staaten von Amerika, Diss. Tübingen 1969.

Bredemeier, Sonning: Erfahrungen mit der Kreditplafondierung, Berlin 1972.

Buchanan, James M.; Wagner, Richard E.: Democracy in deficit, The political legacy of Lord Keynes, New York, San Francisco, London 1977.

Caesar, Rolf: Der Handlungsspielraum von Notenbanken, Baden-Baden 1981.

Cargill, Thomas F.: Solomon Brothers Center for the Study of Financial Institutions: Central Bank Independence and regulatory responsibilities: The Bank of Japan and the Federal Reserve, New York 1989.

Cargill, Thomas F.; Royama, Shoichi: The Transition of Fianance in Japan and the United States, Hoover Press Publication 372, Stanford 1988.

Clifford, Jerome A.: The Independence of the Federal Reserve System, Pennsylvania 1968.

Deutsche Bundesbank (Hrsg.): Sonderdruck der Deutschen Bundesbank Nr. 7: Die Deutsche Bundesbank, 1987.

Dickertmann, Dietrich; Siedenberg, Axel: Instrumentarium der Geldpolitik, Düsseldorf 1984.

Dohnanyi, Klaus von: Notenbankkredit an den Staat, Baden-Baden 1986.

Eizenga, Wietze: The independence of the Federal Reserve System and of the Netherlands Bank - A comparative analysis; Société Universitaire Européenne de Recherches Financières, Tilburg 1983.

Emminger: D-Mark, Dollar, Währungskrisen, Stuttgart 1986.

Englert, Michael: Der Handlungsspielraum der amerikanischen Bundesbank im Regierungssystem der Vereinigten Staaten, Rheinfelden 1988.

Europäische Gemeinschaften Währungsausschuß: Die Währungspolitik in den Ländern der Europäischen Wirtschaftsgemeinschaft, Institutionen und Instrumente, o. O. 1972. 
Europäische Wirtschaftsgemeinschaft: Die währungspolitischen Instrumentarien in den

Mitgliedsstaaten der Europäischen Wirtschaftsgemeinschaft, Brüssel 1962.

Eynern, Gert v.: Die Unabhängigkeit der Notenbank. Vortrag anläßlich der Jahresfeier der Deutschen Hochschule für Politik Berlin am 15. Januar 1957, Berlin 1957.

Eynern, Gert v.: Grundriß der politischen Wirtschaftslehre, Köln Opladen 1968.

Felder, Karl R.: Die Schweizerische Nationalbank. Auftrag und Instrumentarium, NZZ-Schriften zur Zeit, 35, Zürich 1976.

Fögen, Hermann: Geld- und Währungsrecht, München 1969.

Forsthoff, Ernst: Lehrbuch des Verwaltungsrechts, Band I, 9. Aufl., München, Berlin 1966.

Francke, Hans-Hermann: Der Deutsch-französische Weg zur Europäischen Zentralbank: Diskussionsbeiträge Institut für Finanzwissenschaft der Albert-LudwigsUniversität Freiburg i. Br. 8/91.

Gaugenrieder, C. A.: Die rechtliche Stellung der deutschen Zentralnotenbank in Geschichte und Gegenwart, Diss. Würzburg 1961.

Geisler, Rudolf Paul: Notenbankverfassung und Notenbankentwicklung in USA und Westdeutschland. Eine vergleichende Untersuchung über das Problem der Zentralisation und Dezentralisation und des Verhältnisses von Staat und Notenbank, Volkswirtschaftliche Schriften Heft 9, Berlin 1953.

Grimberg, Rainer: Rechtsprobleme der Swapsatzpolitik der Bundesbank. Legitimation und Rechtsnatur, Schriften des Instituts für internationales Recht des Spar-, Giro- und Kreditwesens an der Universität Mainz, Band 7, Berlin 1974.

Guba, Jürgen: Der Wandel der amerikanischen Notenbankpolitik, Frankfurt am Main 1989.

Haase, Heidrun: Die Lombardpolitik der Zentralnotenbanken, Berlin 1962.

Hahn, L. Albert: Probleme staatlicher Konjunkturbeeinflussung, Frankfurt am Main 1956.

Hahn, Oswald: Die Währungsbanken der Welt, Band I; Stuttgart 1968.

Hahn, Oswald: Die Währungsbanken der Welt, Band II; Stuttgart 1968.

Hartung, Joachim: Statistik: Lehr- und Handbuch der angewandten Statistik, 6. Aufl., München, Wien 1987.

Hauser, Siegfried: Statistische Verfahren zur Datenbeschaffung und Datenanalyse, Freiburg im Breisgau 1981.

Hütz, Gerhard: Die Bankenaufsicht in der Bundesrepublik Deutschland und in den USA: Ein Rechtsvergleich, Berlin 1990

Hultman, Ivar: Die Centralnotenbanken Europas, Berlin 1912.

Humm, Hubert: Bankenaufsicht und Währungssicherung, Berlin 1989. 
Issing, Otmar: Einführung in die Geldpolitik, München 1981.

Issing, Otmar: Einführung in die Geldpolitik, 4. Aufl. München 1992.

Issing, Otmar: Unabhängigkeit der Notenbank und Geldwertstabilität, Mainz, Stuttgart 1993.

Kaiser, Rolf H.: Bundesbankautonomie - Möglichkeiten und Grenzen einer unabhängigen Politik, Frankfurt/Main 1980.

Keller, Paul: Von den Aufgaben der Notenbank in der Gegenwart, Zürich-St. Gallen, 1950.

Kindermann, Elmar: Die Anfechtung von kreditpolitischen Beschlüssen der Bundesbank, Berlin 1974.

Kleinewefers, Henner: Inflation und Inflationsbekämpfung in der Schweiz, Frauenfeld 1976.

de Kock, M. H.: Central Banking, 4. Ed. London 1974.

Köhler, Claus: Geldwirtschaft, 1. Band Geldversorgung und Kreditpolitik, 2. Aufl., Berlin 1977.

Könke, Jörn: Die institutionelle Koordination von Geld- und Finanzpolitik in Großbritannien, Berlin 1971.

Könneker, Wilhelm: Die Deutsche Bundesbank, Frankfurt/Main 1973.

Lampe, Ortrun: Die Unabhängigkeit der Deutschen Bundesbank, München 1971.

Masera, Francesco: Struttura e funzioni della Banca d'Italia, in: Quaderni sardi di economia, 4/1987, S.295 - 316.

Maunz, Theodor; Dürig, Günter: Grundgesetz, Band II

Menzel, Ch.; Tanner, U., Bearb.: Schweizerische Nationalbank. Aufgaben, Instrumente, Organisation, o. O. 1979.

Mersch, Margrit: Die Banque de France: Organisation und Operationen, Berlin 1972.

Moreau, E.: Souvenirs d'un Gouverneur de la Banque de France. Histoire de la Stabilisation du Franc (1926-1928), Paris 1954.

Myers, Margaret G.: Paris as a Financial Centre, London 1936.

Obst, Georg; Hintner, Otto: Geld-, Bank- und Börsenwesen, Stuttgart 1980.

OECD: Monetary Policy in Italy, OECD Monetary Studies Series, Paris 1973.

OECD: Monetary Policy in the United States, OECD Monetary Studies Series, Paris 1974.

Pecchioli, Rinaldo M.: Bankenaufsicht in den OECD-Ländern: Entwicklungen und Probleme, Baden-Baden 1989.

Preuße, Heinz Gert: Zur Autonomie der Notenbank unter veränderten internationalen Rahmenbedingungen, Göttingen 1991.

Prost, Gerhard: Wandlungen im deutschen Notenbankwesen, München 1972. 
Puckler, Godehard: Das Bank- und Börsenwesen in den USA, 2. Aufl., Frankfurt/Main 1986.

Rittershausen, Heinrich: Die Zentralnotenbank, Frankfurt am Main 1962.

Ritzmann, Franz: Zum Instrumentarium der Schweizerischen Nationalbank. Kritische Betrachtungen, Bern, Stuttgart 1977.

Robert, Rüdiger: Die Unabhängigkeit der Bundesbank, Kronberg/Ts 1978.

Samm, Theodor: Die Stellung der Deutschen Bundesbank im Verfassungsgefüge, Schriften zum öffentlichen Recht, Band 63, Berlin 1967.

Schaal, Peter: Geldtheorie und Geldpolitik, 2. Aufl., München 1989.

Schacht, Hjalmar: Die Politik der Deutschen Bundesbank, München 1970.

Schaede, Ulrike: Geldpolitik in Japan 1950-1985, Förderverein Marburger Japan-Reihe 1, Marburg 1989.

Schiffer, Hubert F.: The modern Japanese banking system, New York 1962.

Schmid, Beat: Die Unabhängigkeit der Schweizerischen Notenbank, Diss. Bern 1979.

Schmölders, Günter: Geldpolitik, 2. Aufl., Tübingen Zürich 1968.

Schuppler, Edith: Die Unabhängigkeit der Notenbank, Schriftenreihe der österreichischen Bankwissenschaftlichen Gesellschaft, hrsg. v. H. Krasensky, H. XIX, Wien 1962.

Schuster, Leo: Zentralbankpolitik und Bankenaufsicht in den EWG-Staaten, Köln, Opladen 1967.

Siebelt, Johannes: Der juristische Verhaltensspielraum der Zentralbank, Baden-Baden 1988.

Spindler, Joachim v.; Becker, Willy; Starke, O.-Ernst: Die Deutsche Bundesbank, Stuttgart Berlin Köln Mainz 1973.

Spindler, Joachim v.; Becker, Willy; Starke, O.-Ernst: Die Deutsche Bundesbank, Stuttgart 1957.

Steeb, Guido: Time lags der Geldpolitik, Frankfurt am Main 1978.

Suzuki, Yoshio (Ed.): The Japanese Financial System, Oxford 1987.

Swinburne, Mark; Castello-Branco, Marta: Central Bank Independence: Issues and Experience, IMF Working Paper 91/58, June 1991.

Tamagna, Frank M.: Processes and instruments of monetary policy: A comparative analysis, in: Monetary Management, A series of research studies prepared for the Commission on Monetary credit, Englewood Cliffs, N. J. 1963.

The Bank of Japan - Economic Research Department: The Bank of Japan - It's function and organization, 0. O. 1964.

The Bank of Japan - Economic Research Department: The Bank of Japan. It's organization and monetary policies, 0.O. 1973. 
The New York Clearing House Association: The Federal Reserve Re-Examined, New York 1953.

Tobler, Ewald: Entwurf eines schweizerischen Mindestreservesystems auf der Grundlage ausländischer Methoden und Erfahrungen, Zürich 1967.

Uhlenbruck, Dirk: Die verfassungsmäßige Unabhängigkeit der Deutschen Bundesbank und ihre Grenzen, Diss. Köln 1967 a.

Veit, Otto: Der Wert unseres Geldes, Frankfurt am Main 1958.

Veit, Otto: Grundriß der Währungspolitik, Frankfurt/Main 1961.

Veit, Otto: Grundriß der Währungspolitik, Frankfurt/Main 1969.

Vocke, Wilhelm: Gesundes Geld, Band I, 2. Aufl., Frankfurt am Main 1956.

Waschmann, Wolf-Peter: Die Rechtsnatur der quantitativen und qualitativen Beschränkungen im Diskontgeschäft der Deutschen Bundesbank, Diss. Hamburg 1977.

Wettlaufer, Hans-Dieter: Der Gewinn der Notenbank in volkswirtschaftlicher Sicht, Idstein 1987.

Wolff, Karl Friedrich: Die Leitungsorgane der Bankwirtschaft in Frankreich, Diss. Tübingen 1962.

Young, Ralph A.: Instruments of Monetary Policy in the Unite States. The Role of the Federal Reserve System, ed. by IMF, Washington D.C. 1973.

Zimmermann, Theo: Strukturwandel und Entwicklungstendenzen im schweizerischen Bankensystem, Suttgart 1988.

\section{Literatur aus Zeitschriften, Zeitungen und Sammelwerken}

Achterberg, Erich: Coyne oder die unabhängige Notenbank, in: Zeitschrift für das gesamte Kreditwesen H.16 1961, S. 770 - 772.

Arndt, Hans-Joachim: Von der politischen zur plangebundenen Autonomie - Die Bundesbank in der parlamentarischen Demokratie, in: Duwendag, Dieter (Hrsg.): Macht und Ohnmacht der Bundesbank, Frankfurt/M. 1973, S. 15 - 35.

Arnim, Hans Herbert von: Die Deutsche Bundesbank - Pfeiler der Demokratie, in: Zeitschrift für Wirtschaftspolitik 37. Jg. 1988, S. 51 - 63.

Badura, Jürgen: Time lags der Geldpolitik, in: Badura, Jürgen; Issing, Otmar (Hrsg.): Geldpolitik, Stuttgart, New York 1980, S. 24 - 37.

Barro, Robert J.: Inflation and economic growth, in: Bank of England Quarterly Bulletin, May 1995, S. 166 - 175.

Blessing, Karl: Die Einflußmöglichkeiten der Notenbank, in: Junge Wirtschaft 6. Jg. 1958, S. 490 - 493. 
Bopp, K. R. 1941: The Government and the Bank of France, in: Public Policy. A Yearbook of the Graduate School of Public Administration, Havard University, ed. by C.F. Friedrich/E.S. Mason, Vol.II, Cambridge Mass., S. 1 - 35.

Bourdet, Yves; Jonung, Lars: Economic performance and stabilization policies in Sweden and France 1970-1990, in: Skandinaviska Enskilda Banken Quarterly Review 1-2/1992, S. 22 - 32.

Bronte, Stephen: The Bank of Japan strikes back, in: Euromoney 11/80, S. 65 - 75.

Brüggemann, Gerd: Präsidentenwahl und Fed., in: Bankinformation 4/88, S. 2.

Büschgen, H. E.: Offenmarktpolitische Interventionen der Deutschen Bundesbank am Rentenmarkt - und auch am Aktienmarkt?, in: Die Aktiengesellschaft, 17. Jg. 1972, S. 210-215, S.244 - 247.

Caesar, Rolf: Die Unabhängigkeit der Notenbank im demokratischen Staat. Argumente und Gegenargumente, in: Zeitschrift für Politik, H.1/80, S. 347 - 377.

Caesar, Rolf: Staatsfinanzierung durch die Notenbank - Pro und Contra, in: Socher, Karl; Smekal Christian (Hrsg.): Staatsfinanzierung und Notenbank. Referate und Diskussionszusammenfassungen des Symposiums am 4.15. April 1984 in Innsbruck/Igls; Österreichisches Forschungsinstitut für Sparkassenwesen Bd. 24, Wien 1984, S. $49-73$.

Caesar, Rolf: Bundesbank-Autonomie : Internationale Bedrohungen?, in: Wirtschaftsdienst 1988/1II, S. 124 - 129.

Caesar, Rolf: Central Banks in the Political Area, in: Intereconomics, Jan./Feb. 1983, S. 3 - 10.

Caesar, Rolf: Notenbanken im Spannungsfeld der Politik, in: Wirtschaftsdienst 1982/XI, S. 569 - 576.

Cairncross, Alec: The Bank of England: Relationsships with the Government, the Civil Service, and Parliament, in: Toniolo, Gianni: Central bank's independence in historical perspective, Berlin, New York 1988, S. 39 - 72.

Castello-Branco, Marta; Swinburne, Mark: Die Unabhängigkeit der Zentralbank, in: Finanzierung \& Entwicklung 3/92, S. 19 - 21.

Christians, F. W.: Deutsche Bundesbank: Autonomie für Sachverstand, in: Die Bank 5/77, S. 4 - 5.

Chrystal, Alec K.: Commentary: The Behavior of Foreign Central Banks: Comparisons and Contrasts with Fed Performance, in: Belongia, Michael T. (Hrsg.): Monetary Policy on the 75th Anniversary of the Federal Reserve System, Boston, Dordrecht, London 1991, S. 84 - 95. 
Cukierman, Alex; Webb, Steven B.; Neyapti, Bilin: Measuring the independence of central banks and ist effects on policy outcomes, in: The World Bank economic review, Vol. 6, No. 3, S. 353 - 398.

Dickertmann, Dietrich; Hansmeyer, Karl-Heinrich: Die Bundesbank im Streit der politischen Interessen, in: Wirtschaftsdienst 1973/XI, S. 579 - 584.

Dickertmann, Dietrich: Staatsfinanzierung und Notenbank aus finanzwirtschaftlicher Sicht, in: Socher, Karl; Smekal Christian (Hrsg.): Staatsfinanzierung und Notenbank. Referate und Diskussionszusammenfassungen des Symposiums am 4./5. April 1984 in Innsbruck/gls; Osterreichisches Forschungsinstitut für Sparkassenwesen Bd. 24, Wien 1984, S. 117 - 170.

Donner, O.: Mindestreservenpolitik in den USA, in: Zeitschrift für das gesamte Kreditwesen, 18/1952, S. 467 - 469.

Duwendag, Dieter: Einführung: Macht und Ohnmacht der Bundesbank?, in: Duwendag, Dieter (Hrsg.): Macht und Ohnmacht der Bundesbank, Frankfurt/M 1973, S. 3 - 11 .

Eckert, Lucia: Verfassungsrecht und Autonomie der Deutschen Bundesbank, in: BankArchiv Band 38, 6/1990, S. 415 - 427

Erb, Richard D.: Die Rolle der Zentralbanken, in: Finanzierung \& Entwicklung 12/89, S. $11-13$.

Fair, Don: The independence of central banks, in: The Banker 10/79, S. 31 - 41.

Frey, Bruno S.; Schneider, Friedrich: Central Bank Behavior - A positve empirical analysis, in: Journal of Monetary Economics 7 (1981), S. 291 - 315.

Furth, Herbert J.: International Regulations and the Federal Reserve System, in: Prochnow, Herbert V. (Ed.): The Federal Reserve System, New York 1960, S. 273 $-294$.

Gaddum, Johann Wilhelm: Die Geldverfassung in der Bundesrepublik Deutschland, in: Die Bank 7/86, S. 336 - 339.

Gal, M.: Erfahrungen der Schweiz mit der Kreditplafondierung, in: Kredit und Kapital, 4. Jg. 1971, S. 195 - 222.

Geiger, Helmut: Aspekte einer gemeinsamen Europäischen Notenbank, in: Sparkasse 5/89, S. 199 - 202.

Géronomus, René: Notenbank und Bankenkontrolle in Frankreich - Ein Vergleich mit der Bundespublik Deutschland -, in: Bank-Betrieb, 9. Jg. 1969, S. 382 - 384

Gemper, Bodo B.: Der Schweizerische Geldmarkt nach der Revision des Nationalbankgesetzes, in: Österreichisches Bank-Archiv, 28. Jg. 1979, S. 356 - 369. 
Gleske, Leonhard: German Central Banking and the Bundesbank's Structure, in: Banco Central De Chile (Hrsg.): Seminario "Experiencias sobre Autonomia e la Banca Central", Santiago 1989, S. 33 - 45.

Goodman, John B.: The Politics of Central Bank Independence, in: Comparative Politics, Vol. 23 3/1991, S. 329 - 349.

Grilli, V.; Masciandaro, D.; Tabellini, G.: Political and monetary institutions and public finance policies in the industrial countries, Economic Policy 1991, S.341 392.

Gronau, Klaus, D.: Bedenkliche Sonderstellung der Bundesbank, in: Wirtschaftsdienst 1970/V, S. 297 - 298.

Hahn, Hugo J.; Siebelt, Johannes: Zur Autonomie einer künftigen Europäischen Zentralbank, in: Die öffentliche Verwaltung 1989 H.6, S. 233 - 243.

Hahn, Oswald: Zentralbankrat. Praktiker.../...oder Politiker, in: Zeitschrift für das gesamte Kreditwesen 1976, S. 527f.

Hankel, Wilhelm: Brauchen wir eine unabhängige Notenbank?, in: Wirtschaftsdienst 1970/V, S. 289 - 291.

Hankel, Wilhelm: Mehr Stabilität durch eine Offenmarktpolitik mit Jedermann - Effizienzbedingungen der Geld- und Kreditpolitik in einer offenen Volkswirtschaft, in: Duwendag, Dieter (Hrsg.): Macht und Ohnmacht der Bundesbank, Frankfurt/M. 1973, S. 149 - 159.

Hansmeyer, Karl Heinrich: Wandlungen im Handlungsspielraum der Notenbank?, in: Andreae, C. A.; Hansmeyer, K. H.; Scherhorn, G. (Hrsg.): Geldtheorie und Geldpolitik, Günter Schmölders zum 65. Geburtstag, Berlin 1968, S. 155 - 166.

Heller, H. Robert: Notenbanksystem und Geldpolitik in den USA, in: Zeitschrift für Wirtschaftspolitik 37. Jahrg. 1988, S. 97-120.

Hettlage, K. M.: Über Sparsamkeit und Wirtschaftlichkeit in der Verwaltung, in: Wirtschaftliche öffentliche Verwaltung, hrsg. von Baden- hoop, Reinhard K., Stuttgart 1961, S.38 - 61 .

Horke, Gertraude: Die Rolle der Banken in Japan, in: Osterreichisches Bankarchiv 8/69, S. $303-313$.

Issing, Otmar: Die Unabhängigkeit der Bundesbank. Bemerkungen zur geplanten Novellierung des Bundesbankgesetzes, in: Klatt, Sigurd; Willms, Manfred (Hrsg.): Strukturwandel und makroökonomische Steuerung, Berlin 1975, S. 365 - 377.

Issing, Otmar: Die Unabhängigkeit der Bundesbank, in: Ehrlicher, Werner; Simmert, Diethart, B. (Hrsg.): Geld- und Währungspolitik in der Bundesrepublik Deutschland, Berlin 1982, S. 49 - 60. 
Ittensohn, Jacques: Schweizer Beispiel: "Wenig Staat", in: Zeitschrift für das gesamte Kreditwesen 1/1959, S. 30 - 33.

Johnson, Harry G.: Problems of Efficiency in Monetary Management, in: Journal of Political Economy, Vol. 76, S. 971 - 990.

Kamitz, Reinhard: Goldwährung und Finanzpolitik, in: Zeitschrift für das gesamte Kreditwesen 1/1955, S. 16f.

Kerschagl, Richard: Ungelöste Probleme der modernen Währungspolitik, Sonderdruck aus Schmollers Jahrbuch für Gesetzgebung, Verwaltung und Volkswirtschaft, 76. Jg. 4. Heft 1956, S. 81-98.

Kerschagl, Richard: Zukunftsprobleme der Notenbanken: in: Schmollers Jahrbuch für Gesetzgebung, Verwaltung und Volkswirtschaft, hrsg. von Alfred Kruse, 87. Jg., I. Halbband, Berlin 1967, S. 257-274.

Kilgus, Ernst: Das neue schweizerische Notenbankgesetz, in: Ósterreichisches BankArchiv, 28. Jg. 1980, S. 4 - 12.

Kleinhans, Joachim: Die Unabhängigkeit der Bundesbank muß Tabu bleiben, in: Raiffeisen-Rundschau 23. Jg. 1971, S. 191f.

Kloten, Norbert: Die Verantwortung des Zentralbankensystems für die deutsche Wirtschaft, in: Bankinformation 11/76, S. 1 - 9.

Knieper, Rolf: Korrekturen an der Autonomie der Deutschen Bundesbank, in: Gewerkschaftliche Monatshefte 1975, S. 791 - 796.

Koester, Hans-Georg von: Das Gesetz über die Deutsche Bundesbank, in: Sparkasse 18/1957, S. 279 - 283.

Könneker, Wilhelm: Vom Zentralbanksystem zur Deutschen Bundesbank, in: Zeitschrift für das gesamte Kreditwesen 20/1957, S. 796 - 798.

Kritz, M. A.: Central Banks and the State today, in: AER, Vol. XXXVIII, 1948, S. 565 $-580$.

Kure, Bunji: Organisation und Aufgaben der Bank von Japan, in: Zeitschrift für das gesamte Kreditwesen H.19/70, S. 920f.

Lusser, Markus: Die unabhängige Notenbank - vierte Gewalt im Staate?, Vortrag vor der Generalversammlung des Kantonalbernischen Handels- und Industrievereins, Sektion Biel-Seeland, Biel, am 25.4.88, abgedruckt in: Deutsche Bundesbank/ Auszüge aus Presseartikeln Nr. 30, 2.5.88, S. 3 - 6.

Lusser, Markus: Die volkswirtschaftliche Bedeutung der Schweizerischen Nationalbank, in: Quartalsheft SNB 1/92, S. 63 - 72.

Mader, Richard: Die Mindestreservepolitik im internationalen Vergleich, in: Die Bank 3/1989, S. 128 - 133. 
Mairose, Ralf: Soll die Bundesbank den Kurs bestimmen?, in: Wirtschaftsdienst 1970/V, S. 285 - 288.

Massey, Patrick: The changing role of New Zealand's Reserve Bank, in: The Irish Banking Review, Autumn 1990, S. 15 - 27.

Mast, Hans J.: Schweizerische Nationalbank, in: Regul, Rudolf; Wolf, Herbert (Hrsg.):

Das Bankwesen im größeren Europa, Schriftenreihe Europäische Wirtschaft, Bd. 67, Baden-Baden 1974, S. 149 - 155.

Merusi, Fabio: Die verfassungsrechtliche Stellung der Zentralbank in Italien, in: Instrumente der sozialen Sicherung und der Währungssicherung in der Bundesrepublik Deutschland und in Italien, Beiheft 5 zu "Der Staat", Berlin 1981, S. 81 108.

Meyer-Horn: Mindestreserven nur noch Ultima ratio?, in: Sparkasse 4/1993, S. 153 158.

Möller, Alex: Bundesbank - Hüterin der Währung, in: Versicherungswirtschaft 18/1956, S. 479 - 481.

Müller, Lothar: Die Problematik einer europäischen Zentralbank, in: Europa-Archiv, Folge 12/1990, S. 381 - 388.

Muthesius, Volkmar: Das wilde Tier, in: Zeitschrift für das gesamte Kreditwesen 16/1976, S. 755f.

Muthesius, Volkmar: Die Notenbank im Bundesstaat, in: Zeitschrift für das gesamte Kreditwesen 23/1949, S. 535 - 537.

Muthesius, Volkmar: Wer oder was bedroht den Geldwert, in: Junge Wirtschaft 6. Jg. 1958, S. 494 - 496.

Neumann, Manfred J.M.: Precommitment by Central Bank Independence, in: Open economies review 2/1991, S. 95 - 112.

Noelle-Neumann, Elisabeth: Geldwert und öffentliche Meinung. Anmerkungen zur "Psychologie der Inflation", in: Andreae, C.A.; Hansmeyer, K. H.; Scherhorn, G. (Hrsg.): Geldtheorie und Geldpolitik - Günter Schmölders zum 65. Geburtstag, Berlin 1968, S. 35 - 46.

OECD: Economic Outlook: Historical Statistics 1960-1980, Paris 1982.

OECD: Economic Outlook: Historical Statistics 1960-1990, Paris 1992.

o. V.: Auch Belgiens Zentralbank unabhängig, in: FAZ vom 22.4.1993.

o. V.: Banken in Japan, in: Zeitschrift für das gesamte Kreditwesen H. 23/81, S. 1025 1035.

o. V.: Vgl. Buba stands as most independent central bank. G7 Daily Briefing, Washington, September 1, 1995, abgedruckt in: Deutsche Bundesbank: Auszüge aus Presseartikeln Nr. 60 vom 6. September 1995, S. 7. 
o. V.: Bundesbank ohne Illusionen, in: Zeitschrift für das gesamte Kreditwesen 21/1952, S. 551 - 554.

o. V.: Bundesregierung und Bundesbank, in: Monatsberichte der Deutschen Bundesbank 24. Jg. Nr. 8/1972, S. 15 - 17.

o. V.: Central Banks: Amerika versus Japan - The rewards of independence, in: The Economist 25.1.92, S. 21 - 23.

o. V.: Die italienische Zentralbank wird von der Regierung unabhängig, in: FAZ vom 12.11.1993, S.15.

o. V.: Die Rolltreppe steht, in: FAZ vom 4.1.1992.

o. V.: Discomfiture of Bank of Japan at loss of exalted power, in: The Oriental Economist 8,9/84 S. 14 - 18.

o. V.: Festina Lente!, in: Zeitschrift für das gesamte Kreditwesen 19/1956, S. 723 725.

o. V.: Karriere-Knick, in: Der Spiegel vom 21.6.1976, S. 78.

o. V.: Lohnstopp in Italien statt automatischer Anpassung, in: FAZ vom 3.8.1992.

o. V.: Mindestreserveregelungen im Ausland, in: Monatsberichte der Deutschen Bundesbank, 3/1990, S. 22 - 29.

o. V.: Nicht zu viele Verwaltungsfachleute, in: Zeitschrift für das gesamte Kreditwesen 1976, S. 461.

o. V.: Paris bestellt unabhängigen Zentralbankrat, in: FAZ vom 6.1.1994.

o. V.: USA: Ermächtigung zu Kreditkontrollen, in: Neue Züricher Zeitung, Zürich, vom 23. Dezember 1969, abgedruckt in: Deutsche Bundesbank: Auszüge aus Presseartikeln, Nr. 101 vom 30.12.1969, S. 5.

o. V.: Vergleichende Studie zur Autonomie der Zentralbanken in der Bundesrepublik Deutschland, Frankreich und Großbritannien, in: Udvalgte forskningsdokumenter / Europa-Parlamentet, Gene-raldirektoratet for Forskning, 1989, S. 34-40

o. V.: Warum ausgerechnet die?, in: Der Spiegel vom 19.7.1976, S. 22 f.

o. V.: Weitere Konzentration bei Schweizer Banken, in: FAZ vom 13.1.92

o. V.: Wir heißen Euch hoffen, in: Zeitschrift für das gesamte Kreditwesen H.23 1967, S. $1055-1057$.

o. V.: Zuviel Macht für die Bundesbank, in: Wirtschaftswoche Nr.8/1973, S. 50 - 55.

Papier, Hans-Jürgen: Die Zentralbank im Verfassungsgefüge - Generalbericht, in: Instrumente der sozialen Sicherung und der Währungssicherung in der Bundesrepublik Deutschland und in Italien, Beiheft 5 zu "Der Staat", Berlin 1981, S. 109 $-121$.

Pfisterer, Hans: Kredit und Währung in Japan, in: Sparkasse 1/74, S. 20 - 22. 
Pfisterer, Hans: Zur Notenbankpolitik der EG-Partnerstaaten, in: Sparkasse 2/81, S. 49 $-53$.

Pfleiderer, Otto: Die Notenbank im System der wirtschaftspolitischen Steuerung, in: Planung III, hrsg. v. Joseph. H. Kaiser, Baden-Baden 1968, S. 409 - 427.

Poullain, Ludwig: Für eine „demokratische“ Autonomie - Der Entscheidungsspielraum der Bundesbank, in: Duwendag, Dieter (Hrsg.): Macht und Ohnmacht der Bundesbank, Frankfurt/M 1973, S. 36 - 52.

Tobias Piller: Banca d'Italia - Ein Hort der Kontinuităt im unruhigen Italien, in: FAZ 11.12.1993, S. 12.

Rich, Georg: Central Bank Autonomy: A Swiss Perspective, in: Banco Central De Chile (Hrsg.): Seminario "Experiencias sobre Autonomia e la Banca Central", Santiago 1989, S. 21 - 31.

Richebächer, Kurt: Die Bank von England als "Kreatur" des Schatzkanzlers, in: Zeitschrift für das gesamte Kreditwesen 12. Jg. 1959, S. 857 - 859.

Scharnberg: Schriftlicher Bericht des Ausschusses für Geld und Kredit (Scharnbergbericht), BT-Drucksache zu Drucksache Nr. 3603, 2. Wahlperiode 1953, abgedruckt in Beck, Heinz: Gesetz über die Deutsche Bundesbank. Kommentar, Mainz-Gonsenheim, Düsseldorf 1959, S. 597 - 610.

Schmidt, Reiner: Grundlagen und Grenzen der Unabhängigkeit der Deutschen Bundesbank, in: Caemmerer, E. von u. a. (Hrsg.): Xenion, Festschrift für Pan. J. Zepos,. II. Band, Athen, Freiburg/Br., Köln, Katrikalis 1973, S. 655 - 680.

Schmidt, Reiner: Die Zentralbank im Verfassungsgefüge der Bundesrepublik Deutschland, in: Instrumente der sozialen Sicherung und der Währungssicherung in der Bundesrepublik Deutschland und in Italien, Beiheft $5 \mathrm{zu}$ "Der Staat", Berlin 1981, S. 61 - 80.

Schmidt, Willi: Das Bundesnotenbankgesetz, in: Zeitschrift für das gesamte Kreditwesen 18/1956, S. 698f.

Schmitz, Wolfgang: Der Beitrag der Währungspolitik zum Binnenmarkt, in: Aus Politik und Zeitgeschichte 39. Jg. 1989, S. 15 - 24.

Schmitz, Wolfgang: Staatsfinanzierung durch die Notenbank aus der Sicht der Geldordnung, in: Socher, Karl; Smekal Christian (Hrsg.): Staatsfinanzierung und Notenbank. Referate und Diskussionszusammenfassungen des Symposiums am 4./5. April 1984 in Innsbruck/Igls; Österreichisches Forschungsinstitut für Sparkassenwesen Bd. 24, Wien 1984, S. 87 - 106.

Schmölders, Günter: Die Politiker und die Währung, in: Zeitschrift für das gesamte Kreditwesen 1/1957, S. $28 f$.

Schuster, Leo: Neues Nationalbankgesetz, in: Die Bank 7/79, S. 340 - 342. 
Sender, Henny: The Bank of Japan under siege, in: Institutional Investor 11/88, S. 59 64.

Smith, Charles: Discounting theirs fears, in: Far Eastern Economic Review Vol. 138 Nr. 41, 8.11.87, S. 116.

Starke, Otto-Ernst: Das Gesetz über die Deutsche Bundesbank und seine wichtigsten öffentlich-rechtlichen Probleme, in: Die öffentliche Verwaltung H.22 1957 a, S. $606-612$.

Starke, Otto-Ernst: Die Stellung der Notenbank im Staatsgefüge, in: WertpapierMitteilungen, 11. Jg., Teil IV B, Nr. 3 vom 19.1.1957 b, S. 75 - 94.

Stoffers, Erich: Die Notenbanken der Länder, in: Regul, Rudolf und Wolf, Herbert (Hrsg.): Das Bankwesen im größeren Europa, Baden-Baden 1974, S. 113 - 156.

Sylla, Richard: The Autonomy of Monetary Authorities: The Case of the U.S. Federal Reserve System, in: Toniolo, Gianni: Central bank's independence in historical perspective, Berlin, New York 1988, S. 17 - 38.

Szagunn, Volkhard: Notenbank und Staat, in: Versicherungswirtschaft 12. Jg. 1957, S. $19-21$.

Tuchtfeldt, Egon: Gentlemen's Agreements als Instrument der schweizerischen Geldpolitik, in: Andreae, C. A.; Hansmeyer, K. H.; Scherhorn, G. (Hrsg.): Geldtheorie und Geldpolitik, Günter Schmölders zum 65. Geburtstag, Berlin 1968, S. $135-154$.

Uhlenbruck, Dirk: Die Grenzen der währungspolitischen Gefolgschaftstreue der Deutschen Bundesbank gegenüber der Regierung, in: Der Betrieb 1/1967 b, S. 1 - 4.

Uhlig, J.: Bank von England: verstaatlicht und doch "unabhängig", in: Zeitschrift für das gesamte Kreditwesen 23. Jg. 1970, S. 602 - 604

Vaubel, Roland: Überholte Glaubenssätze, in: Wirtschaftsdienst VI/1989, S. 276 - 279.

Wilbert, Rudolf: Ein Vorschlag zum Bundesbankgesetz, in: Zeitschrift für das gesamte Kreditwesen 5/1955, S. 145 - 148.

Woll, Artur: Die Unabhängigkeit der Deutschen Bundesbank muß gesichert werden!, in: Wirtschaftsdienst 1988/III, S. 122-124.

Woll, Artur: Zur Unabhängigkeit der Deutschen Bundesbank - Unzeitgemäße Betrachtungen zu einem aktuellen Problem, in: Nienhaus, Volker; Suntum, Ulrich van (Hrsg.): Grundlagen und Erneuerung der Marktwirtschaft, Baden-Baden 1988, S. 185-197.

Woolley, John T.: Monetary Politics: The Federal Reserve and the Politics of Monetary Policy, Cambridge: Cambridge University Press 1984, S. 69 - 87. 
Woyke, Wichard: Die Niederlande: Raum, Bevölkerung, Struktur, Wirtschaft und Staat, in: Niedersächsische Landeszentrale für politische Bildung (Hrsg.): Die Niederlande und Deutschland. Nachbarn in Europa, Hannover 1992, S. $9-24$.

\section{Gesetze}

Außenwirtschaftsgesetz (AWG), Stand Mai 1990.

Bank of England Act, 1946, abgedruckt in: Aufricht, Hans: Central Bank Legislation:

A Collection of Central Bank, Monetary and Banking Laws, published by the IMF Washington, D.C. 1961/62, S. 185 - 191.

Bundesbankgesetz über die Schweizerische Nationalbank vom 23.12.53 (Nationalbankgesetz), auszugsweise abgedruckt in: Schmid, Beat: Die Unabhängigkeit der Schweizerischen Notenbank, Diss. Bern 1979, S. 125 - 128.

Bundesbeschluß über den Schutz der Währung vom 8.10.71/ 28.6.74, abgedruckt in:

Schmid, Beat: Die Unabhängigkeit der Schweizerischen Notenbank, Diss. Bern 1979, S. 130f.

Bundesbeschluß über Geld- und Kreditpolitik vom 19.12.1975, abgedruckt in: Schmid, Beat: Die Unabhängigkeit der Schweizerischen Notenbank, Diss. Bern 1979, S. $131-133$.

Bundesgesetz über die Banken und Sparkassen vom 8.11.34 / 11.3.1971 (Bankengesetz), auszugsweise abgedruckt in: Schmid, Beat: Die Unabhängigkeit der Schweizerischen Notenbank, Diss. Bern 1979, S. 128 - 130.

Gesetz über das Kreditwesen (KWG).

Gesetz über die Deutsche Bundesbank vom 26. Juli 1957.

Il Codice Bancario Fascista. Disposizioni per la difesa del risparmio e per la disciplina della funzione creditizia (Regio decreto-legge 12 marzo 1936-XIV, n. 375).

LOI n 73-7 du 3 janvier 1973: abgedruckt in: . Bonin, Konrad v.: a.a.O., S. 248.

Statute of Bank of Italy, 1936: abgedruckt in: Aufricht, Hans: Central Bank Legislation: A Collection of Central Bank, Monetary and Banking Laws, published by the IMF Washington, D.C. 1967, S. 421 - 440.

The Bank of Japan Law: abgedruckt in: Aufricht, Hans: Central Bank Legislation: A Collection of Central Bank, Monetary and Banking Laws, published by the IMF Washington, D.C. 1961/62, S. 425 - 441

The Federal Reserve Act. as amended to November 1, 1946.

The Law of December 2, 1945: abgedruckt in: Aufricht, Hans: Central Bank Legislation: A Collection of Central Bank, Monetary and Banking Laws, published by the IMF Washington, D.C. 1967, S. 199-209. 


\section{SOZIALÓKONOMISCHE SCHRIFTEN}

Herausgegeben von Professor Dr. Dr. h.c. Bert Rürup

Band 1 Marietta Jass: Erfolgskontrolle des Abwasserabgabengesetzes. Ein Konzept zur Erfassung der Gesetzeswirkungen verbunden mit einer empirischen Untersuchung in der Papierindustrie. 1990.

Band 2 Frank Schulz-Nieswandt: Stationäre Altenpflege und "Pflegenotstand" in der Bundesrepublik Deutschland. 1990.

Band 3 Helmut Böhme, Alois Peressin (Hrsg.): Sozialraum Europa. Die soziale Dimension des Europåischen Binnenmarktes. 1990.

Band 4 Stephan Ruß: Telekommunikation als Standortfaktor für Klein- und Mittelbetriebe. Telekommunikative Entwicklungstendenzen und regionale Wirtschaftspolitik am Beispiel Hessen. 1991.

Band 5 Reinhard Grünewald: Tertiärisierungsdefizite im Industrieland Bundesrepublik Deutschland. Nachweis und politische Konsequenzen. 1992.

Band 6 Bert Rürup, Uwe H. Schneider (Hrsg.): Umwelt und Technik in den Europăischen Gemeinschaften. Teil I: Die grenzüberschreitende Entsorgung von Abfällen. Bearbeitet von: Thomas Kemmler, Thomas Steinbacher. 1993.

Band 7 Mihai Nedelea: Erfordernisse und Möglichkeiten einer wachstumsorientierten Steuerpolitik in Rumänien. Dargestellt am Beispiel der Textil- und Bekleidungsindustrie. 1995.

Band 8 Andreas Schade: Ganzjăhrige Beschättigung in der Bauwirtschaft - Eine Wirkungsanalyse. Analyse und Ansătze für eine Reform der Winterbauförderung. 1995.

Band 9 Frank Schulz-Nieswandt: Ökonomik der Transformation als wirtschafts- und gesellschaftspolitisches Problem. Eine Einführung aus wirtschaftsanthropologischer Sicht. 1996.

Band 10 Werner Sesselmeier / Roland Klopfleisch / Martin Setzer: Mehr Beschăftigung durch eine Negative Einkommensteuer. Zur beschäftigungspolitischen Effektivităt und Effizienz eines integrierten Steuer- und Transfersystems. 1996.

Band 11 Sylvia Liebler: Der Einfluß der Unabhängigkeit von Notenbanken auf die Stabilität des Geldwertes. 1996. 
Sylvia Liebler - 978-3-631-75025-4

Downloaded from PubFactory at 01/11/2019 09:08:34AM

via free access 
Sylvia Liebler - 978-3-631-75025-4

Downloaded from PubFactory at 01/11/2019 09:08:34AM

via free access 